
so 








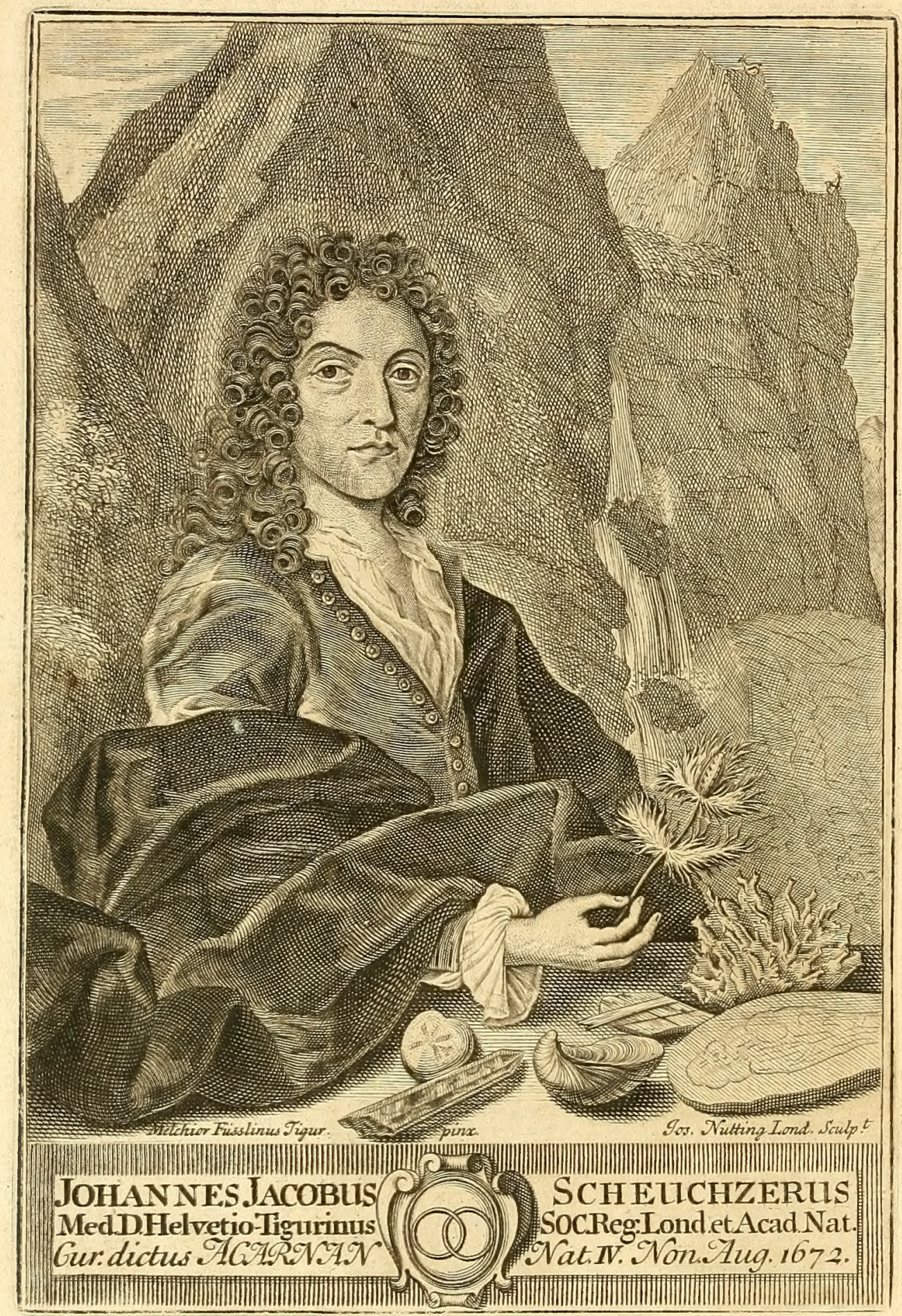




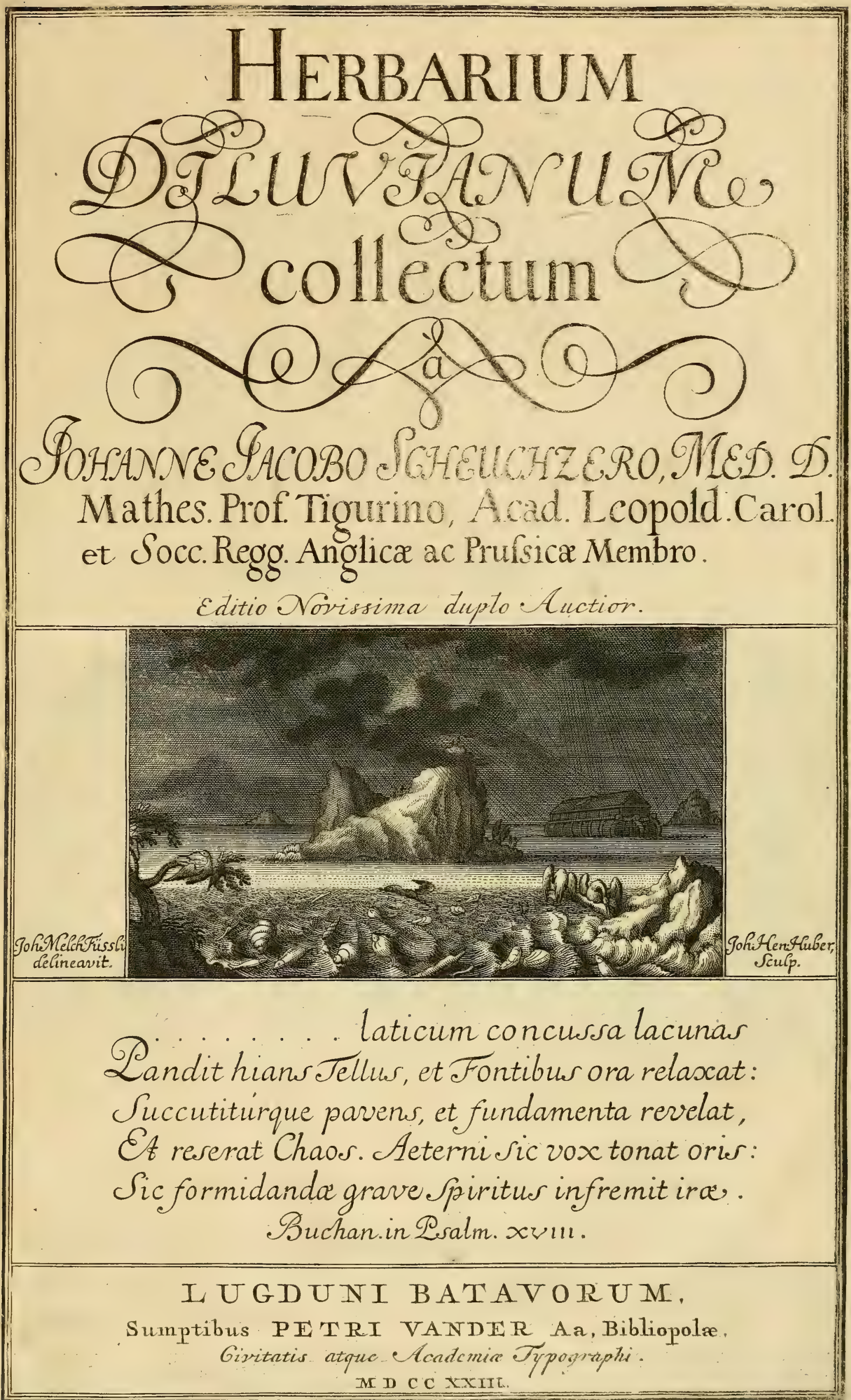





\section{JOHANNIS JACOBISCHEUCHZERI,}

Tigurini, Medicina Doctoris, Matbefeos Frofefforis, Academia Leopoldino-Caroline \& Societatum Regiarum, Anglica ac Pruffica, Membri,

\section{H E R B A R I U M \\ DILUVIANUM.}

Editio Noviffima, duplo Auctior.

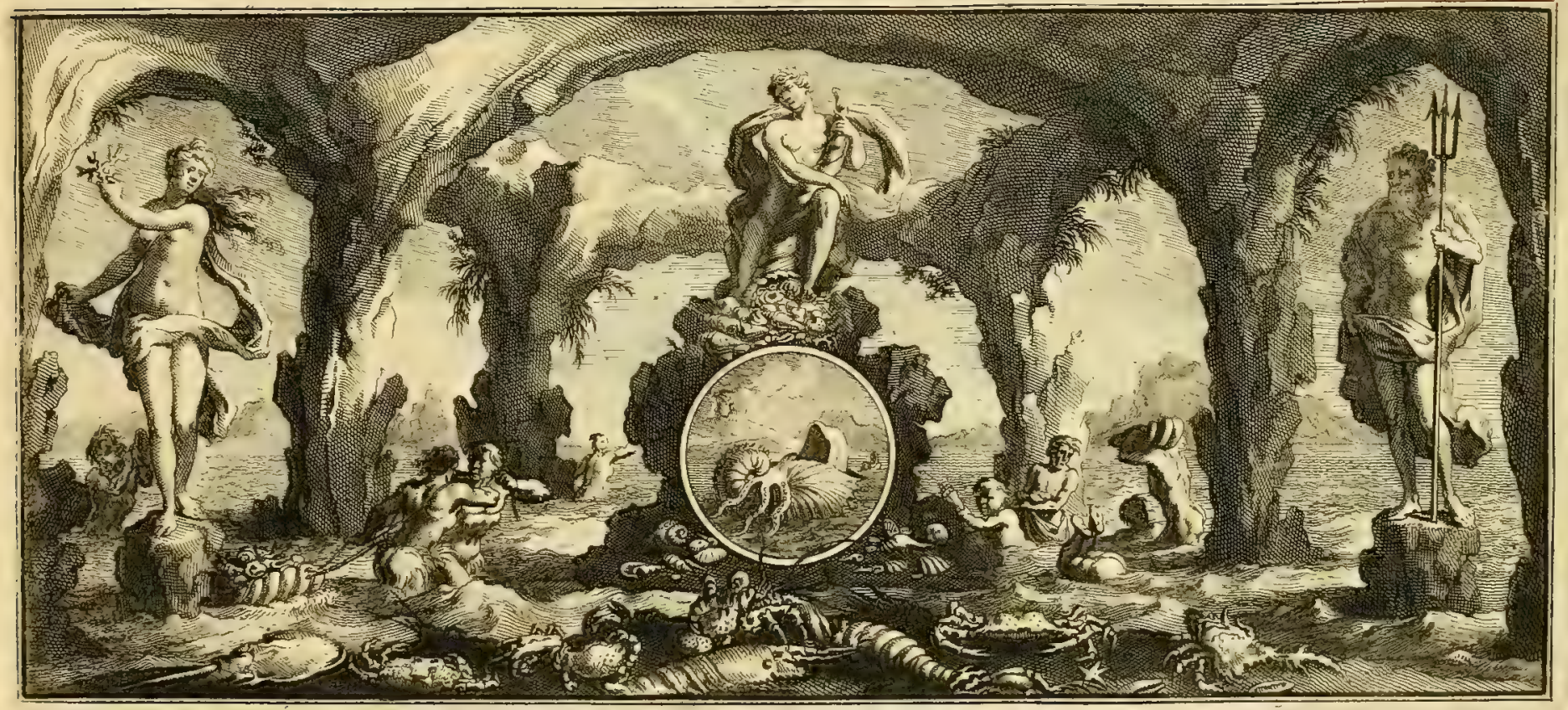

$L U G D U N I$ B ATAVORUM,

Sumptibus PETRI VANDER Aa, Bibliopolæ,

Civitatis atque Academice Typograpbi.

M D CC XXIII. 

CLARISSIMO ET ILLUSTRISSIMO VIRO,

\section{D. FRANCISCO XAVERIO BON,}

EQUITI, REGI A B O M I B US

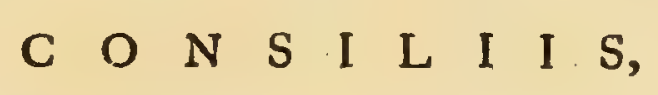

M A R C H I O N I S. H I L A R I I,

V I C E C O M I T I S. QU IN T I N I, BARONI DE FOURQUES, SOLEZ, E T L A T O U R,

DOMINO DE CELLA NOVA,TERRADE,

\&c. \&c.

PRINCIPI SENATUS MONSPELIENSI,

REGIE SCIENTIARUM ACA DEMIE

EJUSDEM URBIS PR \& I DI, DOMINO MEO GRATIOSISSIMO,

Laborem hunc fubmiffâ Devotione

Dico

A C A R N A N. 



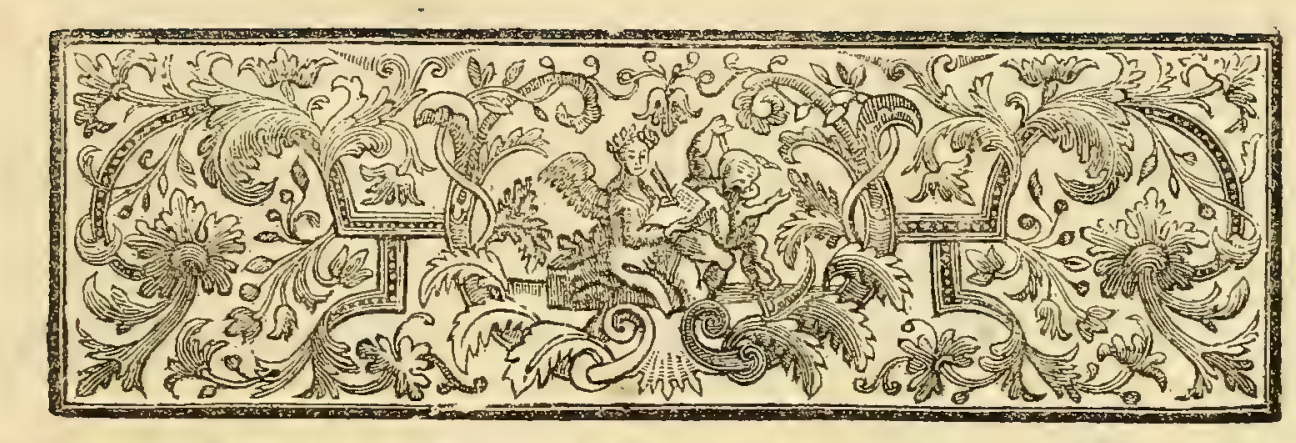

P R E F A I O A D

\section{E C TOREM,}

PRIORI EDITIONI

Præmiffa.

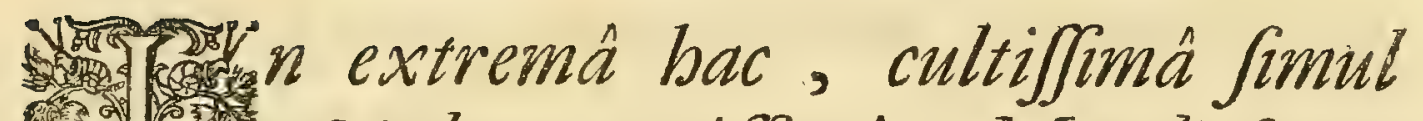
1 a cta ex equo fere furgunt, $E^{\circ}$ ad fummum ufque gradum, Scientice cum Probitate, E̋ Ignorantia cum Malitiâ. Singulari accidit Sapientiffima Providentice Conflito, ut eâ ctate, quâ Scholafticifmus, Atheifmus Eo Scepticifmus Diluvianæ Inundationis veritatem dubiam reddere, fi pote, evertere, vel abfurdis explicationibus obfcurare conantur, ea velut Aurum Igne depuratum reddatur tanto clarior Eण nitidior. Amicas invicem porrigunt manus Scriptura $\widehat{C}^{\circ}$ Natura. Con- 


\section{P R E F A T I O}

quiruntur bodie in omni Terre angulo, magnâ diligentià, borrende illius Cataftrophes, qua ante tot mille annos toti Ierre exitio fuit, Reliquiz: Integra inde for mant Musea non famà duntaxat, fed ftemmaie quoque E' dignitatibus Illugtres in omni Europâ, Ẽ ipfis Indiis, Viri. Adeò copiofa proftat fupellex, ut feligere poffint alii Cochleas $E^{\circ}$ Conchas, alii Pifces, eorumve Ea aliorum Animantium partes, alii Plantas, Ligna, Fructus, Semina, qua omnia ut durabilitate, curiofitate, ita quoque Antiquitate $\sigma^{\circ} u f u$ fuperant Numos, Sculpturas, Picturas, Regnorum trium, Animalis, Vegetabilis E Mineralis producta recentia, Eq quicquid in Pinacotbecis colligit Hominum curiofitas. Spem ciminis loco fit prefens Plantarum Diluvianarum, multis bactenus involuta dubiis, confideratio, quam taniò planiorem reddit Lufuum Naturæ, ut vocantur, jux ta pofitio, ut fimul veluti in Theatro $\sqrt{2}$ Aantur DEI juftiffimi Peccatorum Vindi-

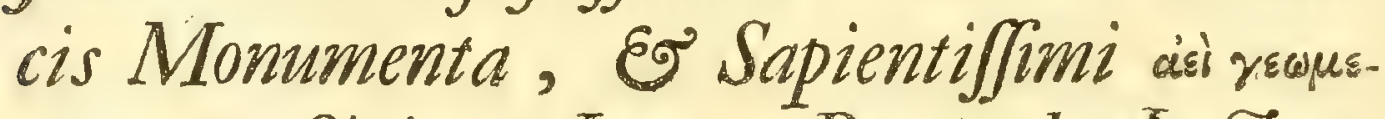
трё̈ros veftigia. Lege, Benerole Lector., 


\section{A D L E C T O R E M.}

animo, $\mathcal{A}$ placet, à prajudiciis libero, $E^{\circ}$ judica, ratiocinantem recte tolera, errantem corrige, fed cum ratione.

\section{ADDITA AB AUCTORE}

\section{A D}

P R Æ C E D E N T E M PR EFA TIONEM.

I bac, quam oculis legis $60^{\circ}$ manibus, Benevole Lector, al10. tera Herbarii Diluviani Editio, Iypis exquifitiffimis Officince D" Vander Aa jubjecta, gratior futura priore, quia auctiorem babet Textum, E Appendicem integram novam, maximâ curâ elaboratam, quò Plante Foffiles ad metbodum Tournefortianam funt reduct ce, E longa ferie ita ordinate, ut quivis abfque labore, vel parum in Re Botanicâ verfatus, Folfiles, quas vel babet, vel videt Plantas, vel quroúpфøs Lapides commodé difponere, Herbariumque fic omni are perennius, blattis tineifgue invictum conficere,

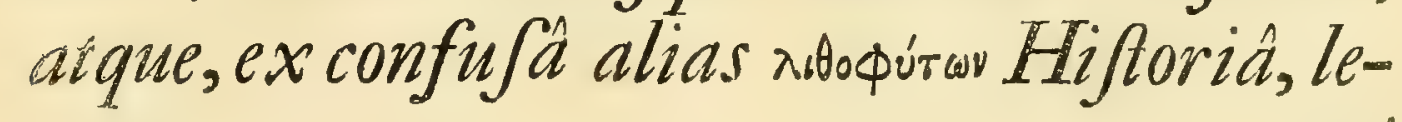




\section{PREFATIO AD LECTOREM.}

vi negotio fe extricare polfit, imo E novis vel animadverfionibus, vel additionibus, addo $\sigma^{\circ}$ correctionibus, angere. Adjecta Juni, prater Indices neceffarios, aliquot Tabulx Enex nove Plantarum, tum ex proprio Mufeo, tum aliunde conquifrtamum, pro faciliori fimul $\boldsymbol{\sigma}^{\circ}$ jucundiori Operis Lectione.

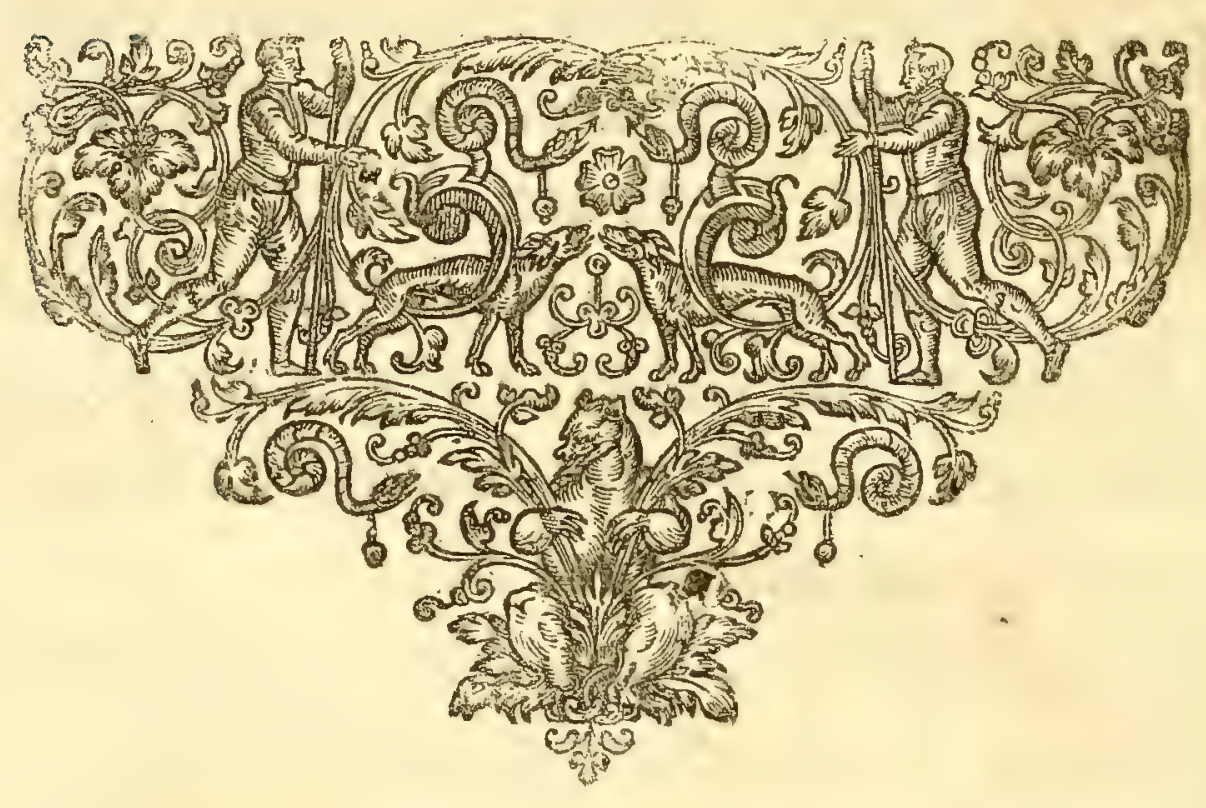


Pags.
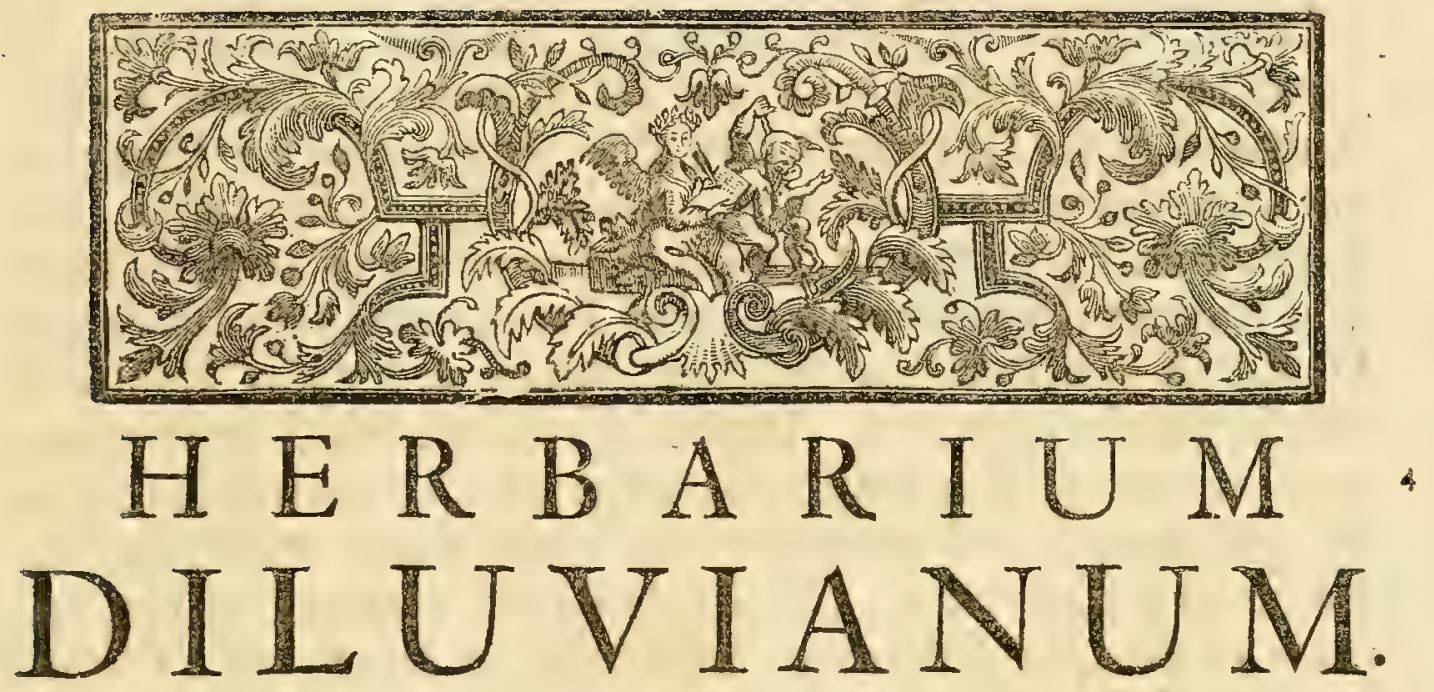

$\rightarrow$ rodierunt non ita pridem in fenam Pifces, non

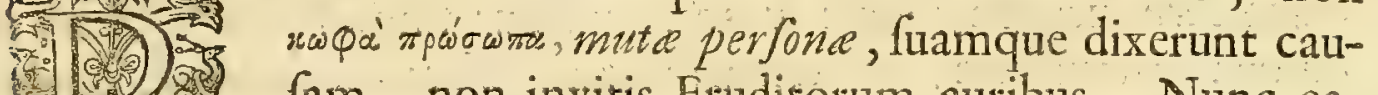
fam, non invitis Eruditorum auribus. Nunc eadem quidem agitur, non Fabula, fed Hiftoria, fed mutantur Perfonx. Tremenda illa, omniumque, quas Terra unquam tulit, mutationum maxima, Diluviana $\mathrm{Ca}$ taftrophe, Arcæ ipf Noachicx frmilis, quod aliam femper ex alio confpecta loco, oculis exhibeat Scenographiz Ideam. Aliam ejusdem rei exhibuêre faciem Pifcès, aliam nunc fiftent Plantre, inde $a b$ Inundatione fatali illa \& univerfali refidux. Muta $\mathrm{Pi}$ fcium Turba juftitia \& fimplicitate caufæe confifa, eam defendic fine alieno fubfidio, aft Vegetabilia Advocato indigent, qui caufam eorum fuficipiat, diftinctiones neceffarias anticipet, \& folvat, nodum non unâ difficultate-implicitum extricet. Plus hîc laboris, plus difficultatis, plus habemus quod defendamus, plus quod oppugnemus Vegetabilia, vel Vegetabilium rmulas imagines, offendemus antediluvianas, diluvianas, in Diluvianâ ftratorum Terræ fubfidentiâ genitas, \& poftiluviañas, quotidiè adhuc produci folitas. Sum cuique adminiftrandum jus, fuum adjudicandum tempus, fui fingulis Regnis ponendi limites, condendx regulx, juxta quas obvix quxvis in Lapidibus Plantx poffint cognofi, \& à falfis imaginibus dignofci. Adfruenda $\mathrm{Hy}$ pothefis, ut vulgo nunc appellitatur, Diluviana, fed nec extra fanx Philofophix limina pellendum illud Syftema, quod Naturam habet productricem, Leges puta DEI mechanicas extra Regnum Vegetabile operantes, \& miros in Minerali tractus delineantes. Sum tribuendum cuique. Parum autem, vel nihil, relinquetar Archro, parum Ideis Luidianis, in Atmofphærâ circumvolitantibus, qua adeò tenui nituntur pede, adeo decurtatis funt alis, \& deplumes, ut vix incedere, nedum in liber $\hat{A}$ Aurâ 
volitare, nedum in Terra poros fefe infinuare, rudimentula fua expandere, \& Pifcem integrum vel Plantam efformare poffint. Parum id genus Diis tutelaribus aliis, ignorantix, vel pervicacix in erroribus femel receptis, Afylis ; DEI eft hic Labor, non Atomorum Epicurearum, nullo ordine invicem occurfantium, non Idearum Platonicarum, non Facultatum Scholafticarum. Oculatum nimis eft hoc Seculum, quàm ut ineptiis hujufmodi fibi fucum fieri patiatur. Digna elt materia folidâ inquifitione, quæ omnium penè hominum agitat mentes, omnium filtitur oculis, quæ magnâ curâ conquiritur ex omni Terræ angulo, in $\mathrm{Mu}-$ fea integra congeritur, ipfa ftatim de fuo ortu quxftionem formans etiam apud illiteratos: providente ita DEO, qui in ultimâ hac Mundi fenectâ, quâ fcientia de DEO atque Atheifmus ex æquo ferè furgunt, vires fuas pro viribus finguli pro Veritate \& contra, intendunt, Diluvianæ Cataftrophes memoriam, multis nimiùm remotam, \& tantùm non abolitam renovari, \& $\mathrm{Hi}$ ftoriæ veritatem ab omni Fabulæ fuco alieniffimam etiam per argumenta è Naturâ petita probari, \& ab incredulorum infultibus, atque Philofophaftrorum finiftris interpretationibus liberari vult. 5 Iterum hæc moneo, ut videant Sacrarum Literarum \& Religionis Interpretes, quanti ipfis interfit, hæc ex Hiftoriâ Naturali fubfidia non fugitivo contemnere oculo, fed examine aftimare digna, \& pro Veritatum Divinarum defenfione applicare. Sint Herbx nottrx Diluvianæ, Cochlex, Conchx, Pifces, alixque reliquix frena, quibus Athei ad rationis normam cogi poffunt.

Conveniunt Hypotheles, quas quidem habemus de Lapidibus ita dictis Figuratis in eo, quòd ortum trahant ex corruptâ $\mathrm{Na}$ turâ. Aft differunt, quòd Id $x i f x$ \& Archxiftx incipiant à corruptâ fux Mentis Naturâ, à cerebri figmentis, quibus veluti columnis Naturæ xdificium fuperftruunt, quod tamen, uti illud Scholafticorum, vel propriâ mole corruit, vel à Vento Veritatis fubvertitur: nos verò inchoemus à corruptâ Naturâ Terræ, quæ ut nos, quotquot vivimus, portat, \& nutrit, ita bafeos loco infervit omni Scientiæ Naturali, tanquam res facti. Eft hæc fanè una ex graviffimis retardati in Philofophia Naturali progreffus caufis, quòd de ædificio erigendo, \& compaginando omnes hactenus fuerint folliciti, dico, de Syftematibus condendis, antequam Trabes fuere præftò, antequam fatis habuimus Obfervationum, fatis materiæ de qua; imò una ex præcipuis caufis tot diverfarum Sectarum, tot litium, rixarum, inutilium contentionum. Et Laudabile admodùm Societatum Regiarum Euro- 

Pag.7

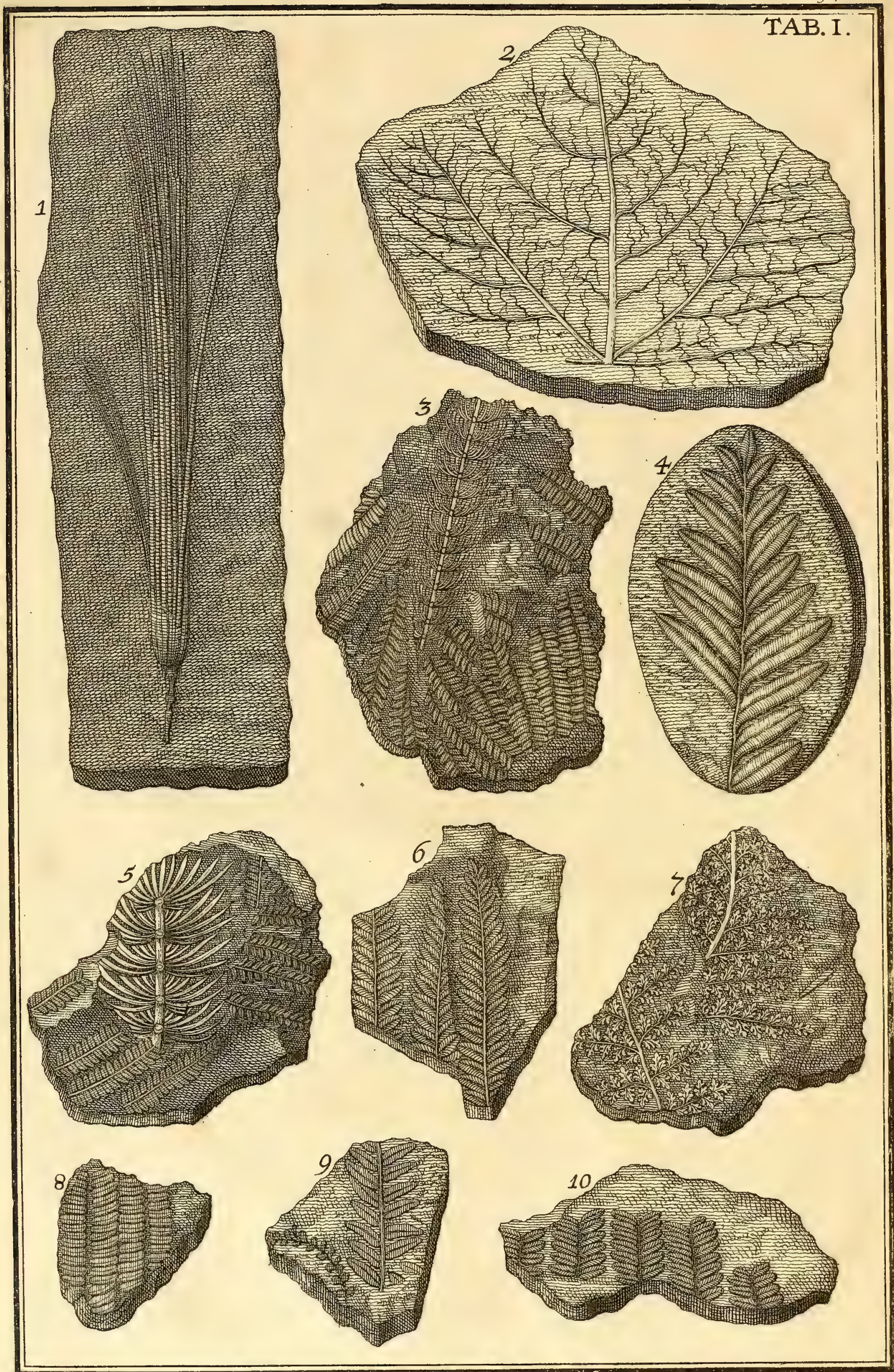

Reverendissimo in CFCR S STO Datri J homa, Prov. Divina Archiepisc.

Cantuariensi, totiue Anglia Primati et Metropolitano.

gohren Lruber, deletfculo: 


\section{I I U U V I A $\mathrm{N}$ U}

pxarum, Scientix Naturalis confultarum, inftitutum, quo innumeras ante, de quavis materia, colligunt Obfervationes, quàm de Syftemate condendo cógitant. Conferant ad hoc ædificium Lapides, Arenam, Ligna, Metalla, operas Angli, Galli, Itali, Germani, Populi Septentrionales, conferant non Cartefii foli, aut Gaffendi, Boylei, aliique magni nominis viri, fed inferioris quoque fortis, minoris famx homines, minorum quoque Gentium Dii. Ego, in angulo Europx haud incuriofo degens, Pifees foffiles haud ita pridem fux reftitui Familix, Plantis nunc reddere conabor fua jura, quibus ab ufurpatoribus Mineralibus fuere defraudata ; illuftraturus fimul integram de Dendritis, figuris Lapidibus impreffis plantarum æmulis Hiftoriam, cocptam jam ante bina Annorum luftra, \& fub formâ Differtationis E $E$ iRolice de Dendritis, alizsque Lapidibus, qui in Juperficie fui Plantarum, Foliorum, Florum figuras exprimunt, Ad Celeb. D. D. Micbaelern Fridericum Locbnerum, Medicum Norimbergenfem peritiffimum \& eruditiffimum, Acad. Nat. Curioforum Periandrum, ex qua nunc, quæ ad rhombum faciunt, denuò excerpo.

\section{T A B. I.}

Hx celeberrima fi non Europx, Helvetix faltem, Lapicidina 1- Tabularum nigri coloris fiffilium, qux fupra pagum Matt, Glaronenfis Ditionis centenis aliquot pedibus extat, Pifces protuli Diluvianos aliquot in Vindiciis eorum \& Quevelis. Nunc ex

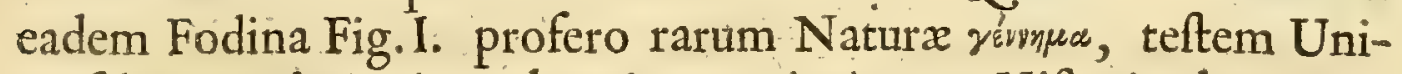
verfalis Inundationis authenticum, imò non Hiftorix duntaxat, fed Temporis quoque Indicem genuinum, Spicam Frumenti $H_{i-}$ froricam fimul \& Cbronologicam, Ingenii cibum valde nutritium, quem Cereri, frugum inventrici, dicâffet Pagana Antiquitas, ut Monumentum ære, quod per aliquot Seculorum decurfum in Terra corrodi incipit, perennius. Frumenti generali termino utor, ne Lectori, vel mihi ipf, ex prima denominatione aliquod nafcatur prejudicium. Frumenti fpicam hanc effe, certum. Sed incertum, cujufnam. Sunt hujus generis Herborifationes pro Rei Herbariæ Ignaris, Tyronibus, \& frmul pro Botanicis expertis. Illi generali quodam Titulo ignorantiam fuam velare, hi ex paucis indiciis non genus duntaxat, fed fpeciem ipfam de- 6 : terminare poffunt, licèt id fxpe fit expertiffimis vel difficillimum, vel inpoffibile. Poffet huc trahi Triticum affivum C. B. Theatr. 358. Trimeftre alias dictum, quia Martio menfe fatum, terno hinc Menfe maturum demetitur. Differt enim boc 
à Tritico hyberno $\sigma^{\circ}$ Siligine non folo fationis tempore, fed $\int p i-$ $i \hat{\imath}$ longiore, crafiore, $\mathcal{G}^{\circ}$ longioribus ariftis ad Hordei fimilitudinem, quales etiam in noftra confpiciuntur fpica. Potius tamen huc traxerim Secale bybernum vel majus. C. B. Theatr. 425. Secale ]. B. II. 4r6. Rogga vulgò, Roggen, Rocken; Roggen-Korn dictum, quod autumno feritur, EO nono plerumque à fatione mense in borrea convebitur. Imò potiùs adhuc huc pertinet Hordeum. An verò Diftichon fit, vel Polyftichon, determinare non audeo. In fpicâ noftrâ Hordeaceâ attendi merentur, I. corpulentia, nam in unâ Tabula eft concava, in altera convexa, ut grana in eo ftatu, quo fuerunt, fatis foliditatis habuerint ad exprimendam in materia Lapidis lutofa figuram. z. Maturitas fermè dimidia, qualis in Hordeo confpicitur medio ferè Majo, quo Diluvium contigit, \& qualem prx fe ferunt Avellane Nuces, de quibus infrà, folfiles, utpote frpiùs, ob cortices non fatis induratos, corrugatx, fxpe in ambitu fiffuram paffa. 3. Culmi fummitas, cui fpica infidet. 4. Spica ipfa dodrantalis ferè, ariftis, quæ Grana obtegunt, armata. 5. Lineo12 in arifis transverfæ, conferendæ cum bamilis illis ferratis, in Secali \& Hordeo præ aliis frugibus confpicuis. 6. Prominentiæ nodofx infra fpicam in fummo culmo confpicuæ, in Hordeo cumprimis obviæ. 7. Arifte laterales ex ima fpica furgentes, fpicæ fecundariæ, vel faltem ferțilis admodùm indicium, inter Hordeaceas fpicas fæpiùs quoque, quàm inter frumentaceas alias, obvium.

Specialem confiderationem meretur Locus fpicæ hujus natalis; vel potiùs depofitionis, Lapidum ipforum fiffilium fodina, quæ ejus elt altitudinis, in Monte Blattenberg, qui Liberi, des Freybergs, pars eft, quali per univerfam Helvetiam, multò minùs extra eam, Frumentum nec feritur, nec metitur : quo ipfo clarè evincitur, elevatam fuiffe hanc fpican fupra Locum natalem, elevari non potuiffe aliâ, quàm Inundationis, occafione, Inundationem hanc non aliam effe, quàm Univerfalem illam toti Terræ fatalem, quæ ipfa Montium altiffimorum cacumina fuperavit, quod alibi preffù̀s ex Naturæ Phænomenis demontratum ibo: in ftratis quoque Ardefrarum noftrarum deponi non potuiffe, nifi eo tempore, quo fuere formata, id elt, in $\mathrm{Di}$ luvio.

In eadem hac Lapicidina quotquot hactenus reperti fuere cum . fpicâ noftrâ Pifces, Helveticæ funt indolis. Quidfi igitur ex præfentiâ Spicæ hujus hordeaceæ arguerem, Helvetiæ fuos quoque fuiffe incolas ante Diluvium, qui frumenta feverint, eosque Terrico- 


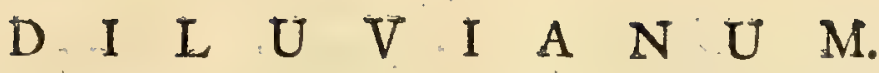

ricolis aliis laboriofiores, \& pientiores (fi pietas aliqua tribui poteft Terre implete violentiâ, in qua omnis caro corrupit viam fuam. Gen. VI. I 2.) quandoquidem Terra noftra Helvetica antediluviana, utut modernâ longè fuerit focundior, eâ tamen proportione culturam admifit difficiliorem, intuitu aliarum Terrx partium, quâ nunc poltdiluviana cedit aliis etiam vicinioribus Gallicis, Italicis, \& Germanicis ; proindeque incolas tulit labori magis addictos, vitiis minùs deditos, fi, quod pulchrè oftendit Cl. Woodwardus Geograph. Phyf. p. 85. \&c. Terre antediluvianæ fertilitas nimia fuit caufa occafionalis fceleratæ vitx. Qui hanc Helvetix primævæx conditionem, Helvetiorumvè primorum ftatum, negat, eum rogo, ut præter Mappam Helvetix antediluvianx proferat Hiftorica genuina de Helvetis antediluvianis, vel non antediluvianis, monumenta.

Animadverti meretur circa ftructuram Corticis exterioris Terræ, in Diluvio natam \& fractam, quòd Plantx, \& Pifces in iis duntaxat ftratis reperiantur, qux tenuia funt à dimidia linea ad digitum ufque, non in craffioribus pedalibus, perticalibus, \& multiperticalibus. Exempli loco fiftam Glaronenfia noftra Lapidum fiffilium Atrata, qux fola ex Helveticis, quantum quidem hactenus conftat, Plantas \& Pifces fepultos continent, Oningenfia, Ilmenavienfia, Eislebienfia, Anglica, Veronenfia. De hoc Phænomeno ita ratiocinor : In refolutione corticis terrei (de interiori nucleo nobis non noto nulla nunc eft quxftio) diftinguendx probè funt, quas in diverfis Atratis offendimus, particulx, cretacex, arenofx, faxex, lutofx, bituminofis aliquando junctx, terrex, qux diverfum habent, non duntaxat gravitatis fpecificx, fed quoque cohæfionis, tenacitatis gradum. Minimè omnium cohæfere arenofx, qux compofuere ftrata tum arenofa, tum faxea; $\mathrm{Hx}$ ubi in magna extiterunt copia, ut in Regionibus pofteà montofis, qualis eft Helvetica noftra, fubfedere fine impedimento, remanentibus, qux natârunt in fuperficie Vegetabilibus, \& Animantibus variis, fubfidentibus tamen, fimul cum particulis terreftribus faxofis, conchyliis \& cruftaceis, qux ejufdem fuêre gravitatis fpecificx. Hinc eft, quòd faxa Helveticorum Montium nec Pifces contineant, nec Plantas, aliquando quidem, fed rarò, Ligna carbonum foffilium fpecie fre mediis faxis inclufa, fed quidem Teftacea \& Cruftacea, nec ubique tamen. Lubet hîc

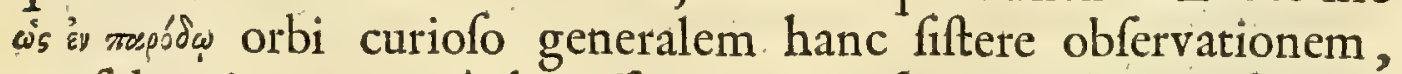
confideratione attentâ digniffimam. Proftant quidem in fummis montium Cacuminibus rupes è Conchis, cochleisque marinis conftantes, in perpetuum Veritatis monumentum, quòd Aquis 
operti fuerint onnes montes excelfi, qui fuertint Jub universo coclo; \& furrexerint Aque ad quindecim cubitos fupra altifimonim montium vertices. Gen. VII. 19, 20. Pleraque tamen, eaque copiofiffima, Teftacea Diluviana proftant in toto Montis furce tractu à Scaphafiano ágro in Burgundiam ufque per Territorium Tigurinim, Conitatum Badenfem, Ditionem Solodorenfem, BernenSem, Bafileenfem, \& Comitatum Neocafrenfem protenfo. Hujus réi oportet aliqua fit caufa Phyfica. Ego hanc ex fitu conjecto. Crufta Terre exteriori fractix fummitas eft in fummis Alpibus Helvéticis, Gotbardo, Adula, ẻarumque brachiis. Hinc defcendituir gradatim, five deprimuntur ftrata ad Littora, \& ipfum fundum Maris, non tamen per Planum inclinatum continuum, quin hîc ibi furgant alix inæqualitates montofx, ortæe ex fpeciali ftratorum interjacentium fractura, \& fubfidentia horum, elevatione illorum; Hinc protenfio vallium, \& Montium, Fluminumque fluxus, verfùs omnès quidem plagas, pracipuè verò verfìs meridiem \& feptentrionem, atque verfüs ortum \& occafum. Ultimi hujus generis prominentia funt Furce, limitaneus primut Lapis, quô Teltaceorum, Cruftaceorum, \& Vegetabilitum Aquíis innatantium inter fummás Alpes, \& Juræ Juga fuere devolutæe, ut adhuc ibi tum in interaneis, tum in Agris fuperficiè, \& Montís íplús dorfo paffim \& magnâ copiâ inveniantur; provolutis últeriùs, quæ Jugum transfluxêre, undis cum fuis primi orbis Animalis \& Vegetabilis reliquiis, in Alsatia, Palatinatu, Lotharingia, Belgio Inferiori obviis. Eadem ratio eft, cùr verfùs Meridiem non ftatim Diluvianas reliquias fiftant $L e$ pontiorim, \& Rbetorim Juga, fed Veronenfia cum Apenninis. Non impedit generalis hæc regula, quò minùs hîc ibi in locis intermediis fuerint depofita tum Animantia, tum Plantæ, quæ fcil. vel motum colluviei integræ affequi non potuerunt, ut vegetabilia leviora, (unde tot in Helvetia Turffifodinæ, feu Cefpitum bituminoforum ingens apparatus, qui nunc demùm in ufum trahi incipit) vel aliis gravioribus adhæerunt, uti fpica noftra frumentacea, vel in cœno lutofo fefe fepeliverunt Animantia, ut Pifcés Glàronenfes faxei. Nimirum adhæfere paffim Plantæ, sprefertim Capillares, materix Atratorum vifcidiori, quacum fuê re hîc ibi, convenienter Legibus Gravitatis, fepultx, \& fic ab ínteritu confervatæe, ut fi non vita, figura faltem, reftet. Pifcium alia páulò eft rátio. Natârunt hì in Aquầ Diluviali hinc inde, prorfum, retrorfum, emerfuræ ex cœno, \& Liquidum vitæ fuæ conveniens quæfituræ, paffim tamen evitantes Charybdim, incidêre in Scyllam, demerfi vel in faxa craffiora, unde, veluti ex Infer- 


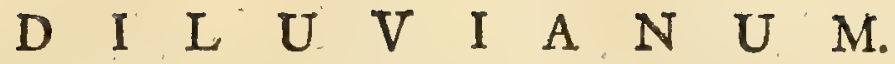

no, nulla redemtio, vel inter Itrata tenuiora, unde in hifce poltremis temporibus, eruditis fimul \& curiofis, eruuntur, \& veluti ex carcere quater mille annorum liberantur, ut Teftes fint Innocentix propriæ, \& criminis alieni.

Nondum hic contemplationum, quas Spica noltra Hordeacea fuggerit, finis. Supereft ufus Chronologicus. Difputant inter fe Chronologi, quo Menfe acciderit Diluvium? In Anno fexcentefimo vite Noab Mense fecundo, decimo Septimo die Menfis-rupti funt omnes fontes Aby/fi magne, EO feneftre coli aperte funt. Ita Sacer Codex Gen. VII. I I. Difputant filicet, an hic locum habeat ordo Menfium Civilium, an Sacrorum? Hinc aliqui ad Autumnum ufque, vel Hyemem, relegant Diluvii initium, alii ad vernum tempus, vel Principium Eftatis. Meum non eft, tricas, quas varia Calculi ratio fuggerit, vel examinare, vel folvere, fed intra Cancellos Hiftorix Naturalis manere, \& qux contemplatio Antiquitatum Diluvialium fuggerit momenta ponderare, nec in ullius præjudicium novâ hac argumentandi ratione uti. Tenuit alios generale hoc dubium, vix tempore byberno DEUM Noacho exitum imperâffe ex Arcâ, fed verno, ut ex fqualore carceris liberatus exbilararetur amonitate Veris, Eo Animalia pafum invenirent. Alfted. Cbronol.p. 9. Et quî, quxfo, Noachi ipfus familia inveniffet, vergente Anno, quo fe nutrire potuiffet? Quî Animantia Bruta féfe difpergere per Terrarum orbem, fingula ad id Clima, quod Temperamento fuo convenit ? Quî Plantx ipfer radices fuas agere, germinare, \& ad fructificandum fe difponere? Nonne repreffffet omnia frigus, enecâffet Animantia calidiori Climati affueta, Plantas in primâ germinatione fuffocâffet Algor, Pruinx, Nives? Trinis fanè ad fubfequens ufque Ver fuiffet Naturx, non renafcentis, fed emorientis, facies. Opus habebat Terra fuperior limofa, cœnofa, non algore, fed calore, qui humiditatem nimiam expelleret, fibras Vegetabilium nimio humore relaxatas firmaret, femina foveret, germina protruderet, fuccis nutritiis motum daret, circulationem promoveret, viventia omnia fqualore femimortua refufcitaret.

Negativa potiùs hæc eft argumentandi ratio, videamus, quid pofitivi produci queat tum pro initio fatalis illius Cataltrophes, tum pro fine. Januam aperit Woodwardus meus Geogr. Pby/. pag. 228. \& 229. Idem tempus, inquit, vernum intelligens, quo profluxerint Aquæ Diluviales, defignat ipja quoque Natura, adeò quidem exactè, ut nemo non pofjt ip is palpare digitis convenientiam Relationis Mofaice, Eo borum Nature lineamentorum, utriusque etiam indicii ab eadem origine dependentiam. Ita 
confentiunt invicem Pbanomena, ut ex Reliquiarum uniformi col latione detegere potuerim ipfum tempus Anni, quo Diluviana Inundatio contigit, Eo Jpeciatim determinare ipfum menfem Majum; non mibi obviam venit in tanta renu, quas oculis meis ufurpavi, multitudine unica Planta, vel alud corpus, quod referri polfit ad ullam aliam confitutionem Anni: nibil, quod maturius eft, vel ferius; nibil, quod provectiorem babuerit, vel molliorem cetatem, quàm nunc communiter babent in memorato menfe. Non defunt alia Animalis, quod ante Diluvin vixit, Regni Pbonomena, que plura alia nec minis demonfrativa, fuppeditant in eundem ofinem Argumenta. Aft enimverò in generali hac demonltratione fubfiftit celeberrimus Vir, fpecialiorem Reliquiarum recenfionem, \& Calculi ipfus evolutionem, refervans pro ampliori Opere, ad cujus elaborationem vires \& vitam mecum apprecabuntur ex animo omnes boni. Ego veluti anticipando nunc fifto Spicam Frumenti femimaturam, qux certè non ad Autumnale, vel Hyemale tempus, fed ad Vernum referri debet, fed paffim in hoc opufculo vegetabilia alia, \& Animalia, qux huc collimant.

Gloriæ mihi duco fingulari, inferere heic judicium ut fubactiflimum ita faventiffimum, 1ll. Actorum Societatis Regiæ Gallicæ Collectoris. Voila des nowvelles efpeces des Medailles, dont les dates font $\mathcal{E}^{\circ}$ fans comparaifon plus anciennes, $\sigma^{\circ}$ plus importantes, $0^{\circ}$ plus fures, que celles des toutes les Medailles Grecques 60 Romaines. Hift. de l'Acad. Roy. I710. p. 28. Edit. Belgic.

In gratiam corum, qui calculi ipfus funt curiofi, w's घy $\varepsilon \pi n \pi \mu n$ integram fiftam Diluvianx Inundationis feriem Chronologicam, viam monftrantibus ipfis Sacræ Scripturæ Textibus.

Gen. VII. ro. Et factum eft, poft feptem dies, venerunt Aque Diluvii fuper Terram. Septem fcilicet dies ante ingreffus eft Noachus Arcam cum fua Familia, \& Animantibus, quàm Diluvium copit: ita ut feptem hi dies etiam ingrediantur calculum de mora Noachi in Arca.

Gen. VII. I I. In Anno fexcentefmo vita Noab, menfe fecundo, decimo feptimo die Menfis, eodem fiilicet die, rupti funt omnes Fontes aby/fi magne, छo fenefure coeli aperte funt. Hic in fententiarum divortia abeunt Chronologi Commentatores. Intelligunt quidam Menfem fecundum Civilem, qui octavus eft Sacer, Marchefuan dictus, Jofepho Maporáw, \& Octobri noftro, præcipuè verò Novembri refpondet. Diem r.3. Odobris Anno ab. Orbe condito r 657. numerat Scaliger; Spanbemin ad $N_{0}$ yembrim tranfit: Ufferius diem 7 . Decembris determinat. Juxta 
hos Inundatio copit Autumno, vel ingruente Hyeme. Aft funt alii, quibus \& nos calculum adjicimus, qui Menfern fecundum Sacrum intelligendum volunt. Eft hic octavus Civilis, Iiar dictus, refpondens Aprili, præcipue Majo. Diem 7. Funii pro initiali ponit Langius. Nos intra Maji confinia manemus, eligentes potiùs diem 4. vel 5. Maji ex Kalendario Hebraico Seb. Miinfteri, qui nunc foret dies I 5 . vel 16 . ejufdem menfis.

Gen. VII. I 2. Et fuit plavia fuper Terram quadraginta dies, E quadraginta noctes. Vo/fo interprete definunt hi 40 . dies 28 . die tertii menfis, Sivan, qui relpondet Majo, præcipuè verò Funio. Ut adeò finis Pluviæ hujus quadragefimalis incidat in finem circiter Junii.

Gen. VII. 24. Aucte fint itaque Aque fuper Terram centum E. quinquaginta diebus. Sub his I 50 . comprehendunt Commentatores illos 40. atque fic finis horum I 50 . dierum incidit ad finem Octobris. Aucte funt, ut verfro noltra Tigurina habet, Aque, continuatâ per vices pluviâ, \& eruptione ip $\hat{\mathrm{a}}$ Aquarum Abyfl, donec incefferit Arca fuper Aquas, Eo operti fuerint omnes montes excelfi, qui fuerunt fubuniverfo coclo. Gen. VII : I8, 19.

Gen.VIII 3. Et reverfe Junt Aque de Terra, magis, magifaue decrefcentes, imminuteque funt Aque poft centum quinquaginta dies. Quia nimirum DEUS adduxit ventum fuper Terram, Go obfructi funt fontes Aby/fi, atque feneftre cocli, cobibita eft pluwia de calo. Verf. I. 2 .

Gen. VIII. 4. Sepimo verò Mene, decima feptima Men/ss, reSedit Arcafuper Montes Ararat. Eft hic Septimus Menjis Sacer Thifri, ex Civilibus primus, refpondens Septembri, majori ex parte verò Octobri, ut adeò lefederit Arca ftatim poft finitos I 50. dies, ad finem Oetobrís.

Gen. VIII. 5: Et Aque quidem magis magifque decrefcebant 10 ufque ad decimum Menfem, decimo enim Menfe, prima die Menfis, vifa fant cacumina Montum. Menfis hic Thebet Sacrorum decimus, Civilium quartus, refpondet præcipuè Fanuario, circa cujus initium datum fuit confpicere Montium Juga.

Gen. VIII. 6,7. Factum eft antem, poft quadraginta dies, 14 Noach aperta feneltra Arce, gatam fecerat, corvum emitteret. Incidit corvi emiffio verfus medium Februarii.

Gen. VIII. 8, 9. Emifit quoque columbam à fe, wit videret, $f$ imminuce effent Aque à fuperficie bumi, at columba now inveniens, quò pedem reponeret, reverfa eft ad eum in Arcam, erant enim Aque in fuperficie iniverfe Terre. 'Ille vero exerta mani recepit eam, introduxitgue eam ad se in arcam. Septiduim ex-

$$
\text { B } 3 \text { pecta- }
$$


pectavit poft corvi emiffionem, ut adeò columbæ primæ cvolatio incidat polt medium Februarium.

GEN. VIII. ro- I 4. Porrò quum expectâfet alios feptem dies, rurfus emifit Columbam ex Arca, que veniens ad eum fub vefperam folum olece decerptum in ore fuo geftabat. Cognovit ergo Noab, quid Aque imminute effent Juper terram. Expectatis autem adbuc feptem diebus aliis rurfus emifit Columbam, quee ultra non eft reverfa ad eum. Factumque eft fexcentefimo primo Anno, Menfe primo, ejusdemque primo die, exiccaice Junt Aque de Terra, amovitque Noab operculum Arca, E profpexit, $\sigma 0$ ecce Juperficies Terre erat ficcata. Bis feptem, vel quatuordecim hi dies, quibus emiffæ fuerunt binæ, una polt alteram, Columbæ, protrahunt tempus ad principium Martï; Refpondet enim primus Menfis Nifan, Civilium feptimus, Martio, \& initio Aprilis. Eft Olea ex iis arboribus, quæ longi ævi, \& facillimè regerminat, ut etiam ftipitem Oleæ aridum \& levem Terræ implantatum germinare, \& radices agere Fortunius Licetus expertus fuerit, \& hoc ipfo confirmetur illud Virgilii:

Truditur è fucco radix oleagina Ligno.

Quantò magis regerminare potuit, imò verò folia confervare, aliavè nova protrudere, Olea, qux unà cum radicibus, Trunco, \& ramis Aqux innatavit. Certum boc eft, verba funt Woodwardi pag. 2 19. quod ultimo fublederint Vegetabilia, utpote Terreftri materiâ leviora: $ఠ$ per confequens jacuerint plura ex illis in fuperficie Terre, illa autem, que notabilis fuere molis, uti e. $g$. Arbores craffiores, G latè fua pandentes bracbia, furrexerint cum ramis fuis ad infignem Aque altitudinem, imò comas fuas elevârint in ipfum Aërem, ficque ductum $\sigma^{\circ}$ fluxum Aqux recedentis facile potuerint Sequi, iis prefertim in locis, ubi ob declivitatem contigit precipites volvi fluctus. Tanto facilior fuit Arborum omnis generis, fpeciatim Olex, confervatio, quòd Aqua Diluvialis fuerit non fimplex, pura, limpida, fed cœnofa, limofa, partibus terreis copiofè imprxgnata: Accedit, quòd prima Terræ nondum plenè exiccatæ crufta etiam fuerit limofa, ut nec Noachus, nec Animantia incedere potuerint ante diem 27. menfis fecundi. Ita enim Sacer Codex:

Gen. VIII. I 4. Porrò in Menfe fecundo, vigefimo feptimo die menfis, arefacta eft Terra; ita fcil. ut greffum ferret, \& fatis fuccreverit Herbarum pro nutrimento Hominum, \& Beftiarum. Egreffus igitur Noachus ex Arca fub initium Maji, vel verfus medium hujus Menfis, nam refpondet fecundus Sacer, Fiar dictus, Civilis octarus, Aprili, pracipuè verò Majo; diem I s. vel I6. 


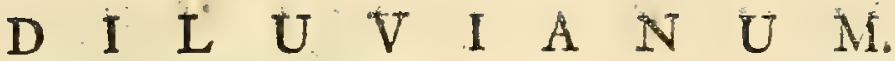

Maji refpondere vult in Kalendario Hebraico Sebaft. Mimblerus. Confat hine, Noachum ab uno Majo ad alterum, per Annum plus minusve, moratum fuiffe in Arca.

Hæc quidem occafione Spicx noltræx Hordeacex, cui affociari $x$ potelt Spica Secalina Liid. Lith. Britt. pag. 1o8. culmus integer frimentaceis 24. pedum profunditate, in puteis Mutinenfibus repertus. Ramazzin. 1.c. Spica Tritici in fiffli Mansfeld. Bitttner. Rud. Dil. Tejt. p. 203.

Fig. 2. exhibet Vitis Folintiz flavefcentis coloris in Lapide fiffili candido cretaceo Oeningenfi, in Dicecefr Conftantienfis; ad Diluviana quoque referendum, uti omnia illius Lapicidinx figurata foffilia, feu Animale referant Regnum, feu Vegetabile. Illius plura Specimina, extant in Querelis \& Vindicios Pifcium; hujus plura quoque exhibebimus in praferiti Tractatu. Ex confpectu Lapidum fiffilium Glaronenfoum \& Oeningenfaum evanefcit dubium Luidii pag. 132. Cur extra Ferri Fodinas \&O Puteos carbonarios nusquain ferè appareanit Folia mineralia?

Hig. 3. Dutum generum Plantas fittit in eodem Lapide fiffli nigro, ex Carbonariis Anglicis, unde tranfmifit $W_{o o d w d r d t s .}$ Una videtur Equifetum paluftre brevioribus foliis polyspermon. C. B. Theatr. 242. Equifetum minimum feis cauda Equina minima. Myl. Sax. Subt. pag. 30. fig. I2. ad p. I9. Altera ad Epiphy1lofpermas pertinet, difficillima determinatu. Haud mulcùm abludit Fig. 2. Tab. ı०4. Plukenet. Amalth. Botan. nifi quòd faxea noftra acutioribus fit foliis, illa rotundioribus.

Fig. 4. Donum eft $W$ oodwardi, Planta alia Diluviana Epiphyllofperma, ut videtur, in dimidiato faxo oviformi, five extùs convexo, ex Fodinis Novocaftrenfíbus Anglix. Eft omninò animadverfione dignum, quòd maxima Plantarum Dilavianarum pars fit ex Familia Epiphyllospermarum, feu Dorfferarum, qux Capillares vulgò vocantur, \& hâc precipuè Notâ ab aliis diftinguuntur, quờ habeant femen minutifimum pulvereum folizs $\xi^{\circ}$ plenumque averfis innafcens. Sunt autem hujus generis Plantex ftructuræ tenacioris, vivacioris, fibrarum rigidiorum, qux fxpe per integram Hyemem virent, nec, ut alia aliarum Plantarum folia, fefe marcefcendo contrahunt, quæ proin expanfa potuere Aquis Diluvialibus innatare, \& margæ faxofæ paffim adhærefcere.

Fig. 5. Conferenda cum Fig. 3. Equifetum conferri poteft cum Equijeto majori Myl. Sax. Subt. p. 30. Fig. 3. ad p. 16. Ut \& Fig. 5 .

Fig. 6. In Lapide fiffili nigro Ilmenavien/2, exhibet Plantam epiphyllofpermam Tricbomani fimilem: quacum conferri debet 
Filix mineralis mari non ramofo finilis, pinmulis obtufius mucrow natis. Luid. Lith. Britt. n. 184 . Minera Ferri exprimens. Filicem marem. Wolfart. vale Hanov. S. Io.

Fig. 7. ERt Filicula, \& quidem Filicula fontana major five Adiantbum album Filicis Folio. C. B. Pin. 358. Adiantum album -Filicis folio. J. B. III. 733 cui jungo Filicem Saxatilem caule tenui fragili Raji Hiftor. Plant. is 2, vel potiùs Filicula montana folio vario Tour. Intt. 542. Adiantuin album tenuifolium Rute murarice accedens. J. B. III. 735 . Adrantum foliz minution in oblongum Jcifis pediculo viridi. C. B. Pin. 355 . Color Lapidis, qui induratx paulò Margx fpeciem præbet, eft cinereus, aft Plantæ ipfius ater; Locus natalis funt Fodinæ Lithantracum ad pagum Altwaffer ducbus à Suidnicio milliaribus in Silefia. Idem hoc videtur, quod cum Maro, Majorana, vel Dictamno Cretico comparat Myl. Sax. Subt. p. 39. Fig. 5. ad p. 26. Ab eodem eandem Plantam marg $x$ cinerex fubinde colore Martiali tinctx impreffam obtinui vom Scburtzwald ex Silesia. Habet \& Luidius Lith. p ro8. Adiantbum album five Rutam murariam Schifto Carbonario impreffam.

12 Fig. 8. Siftit quoque Plantulam Fig. 2. fimilem nigrofufci coloris in Lapide grifeo, ex Fodinis Manebachenfibus, \& ex Silefra. Poteft hic, fi quis alius hujus generis Lapis, referri inter dubios, vel fi mavis, amphibios, \& vel ad Diluvianas Plantarum reliquias referri, vel ad Terrigenos. Nulli proptereà dicam fcribam, five prius elegerit, five pofterius, ufque dum certiùs fimus informati. Priori tamen opinioni ego accedere interim malo.

Fig. 9. In eodem Lapide cinereo Silefiaco duplicem monftrat Plantulam: 'una ad Filices referenda videtur, altera ad Filicislas. Illi accedit Trichomanes minerale longifolium five Lithotrichomanes longioribus foliis integris donatum. Luid. num. I97.

Fig. 10. Videtur etiam Filicis Species in Lapide Manebachenfi.

\section{T A B. II.}

F ig. I. Lapidem fiftit fiffilem cinereo fufcum ex Mufeo Civico Tugurino, cui impreffum cernitur Equifetum, \& quidem, fi conjecturæ locus. Paluftre brevioribus folits polyspermon. C. B. Specialem attentionem heic merentur I. Rami, vel furculi ex eodem caule, vel radice, fi mavis, prodeuntes, \& ad angulos quidem acutos, qui dubiam reddere poffent Equifeti denominationem, quandoquidem ex radice reptante perpendiculariter furgere folent ftolones. 2. Rami geniculati. 3. Folia è fingulis ge- 


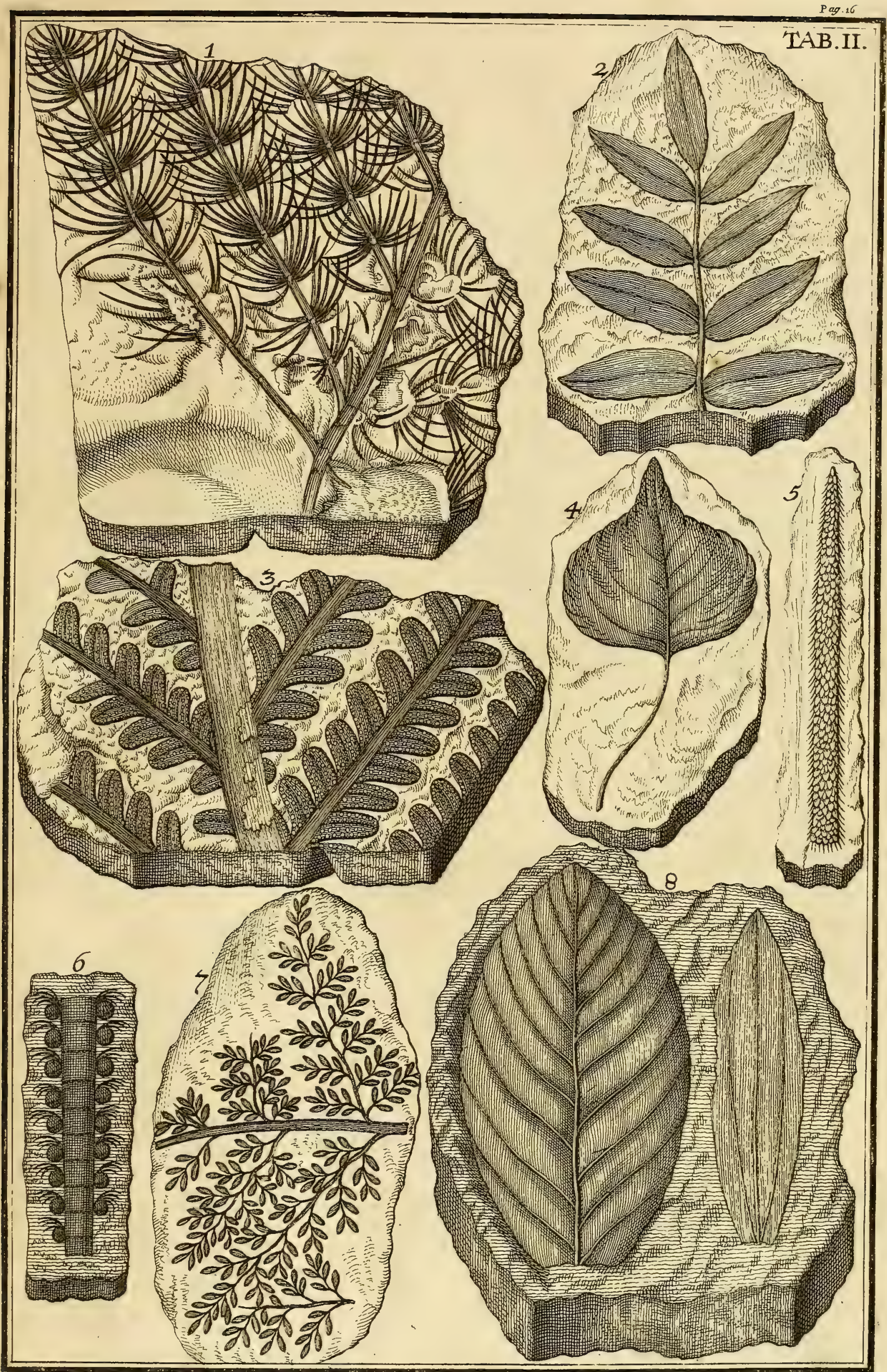

Gllustrissimo JSaaco Jesvton, Equiti Aurato, Societatis Regia Anglica Prasidi_. 



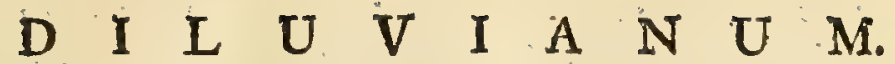

niculis in orbem prodeuntia $6-8$. ad $\mathbf{1 2}$ 2. \& plura. Qualis qualis fit hæc Planta, inde hoc elici poteft, quòd fit Diluviana, \& quidem ejus magnitudinis, qualem exhibet Majus. Sunt Equifeti caules tenuiores, quàm ut conveniant Plantæ adultx, xftivæ; vel autumnali: Hippuritam hunc Lapidem vocavi aliquando.

Fig. 2. In Fiffili Lapide Oeningenfí cretaceo fiftit, pallido flavefcenti colore, coftam foliofam Plantx alicujus leguminofx, vel Filicinæx, quam fpeciatim determinare arduum duco. Per medium fingulorum foliorum nervus trajicitur, ut de origine $\mathrm{Di}$ luviali nullus dubitare poffim. Haud abfimilis videtur Filix florida five Lithofmunda Luid. n. I 88.

Fig. 3. In Nigro Lapide atram monftrat Filicem, \&, quantum videtur, marem folio dentato. C. B. Modò dentate foliorum margines paulò forent diftinctiores, quas non dentatas delineavit Sculptor. Fragmentum caulis adeft cum foliis ex eo alternatim prodeuntibus. Singulari tamen confideratione digna funt puncta aterrimi coloris in foliis confpicua, qux irrefragabile prxbent Plantx epiphyllofpermx, nec nifi rariflimè in Lapidibus obvium; indicium. Sunt hæc Puncta, feminum rudimenta, in foliis, non Lapide ipfo, nec caule confpicua, ejus efficaciæ, ut veluti enfe acutiffimo, pungant. Adverfarios quosvis Diluvianæ Hypothefeos. Miror hîc, adhuc cxcutire Luidium qui tamen p. 107. teftatur, nonmunquam ipfîfima folia materiâ flexilì membranaceâ conflata inveniri: \& vel hinc reliqua ab ipfis folizs jam. dudum abfumptis aliquando impreffa fuiffe fufpicit; \& p. 108. a foffore fide digno, 'Thoma Kirkmanno Filicem integram mineralem repertan tradit : imò p. I I8. Filicis pinnulam obfcurè viridefcentem (adeòque in colore haud multùm variatam) in mediâr Scbitto Carbonariâ ad altitudinem 30. pedum inventam memorat.

Fig. 4. In Lapide cretaceo Oeningenfi folium Popili nigre C. B. que Populus nigra fen Ab́rap (G) I. B. Flavefcenti colore à Lapide ipfo diftincum, figurâ fubrotundâ, circa marginem ferratâ, in acúmen abeunte, \& longo infuper pediculo, tanquam. totidem notis characterifticis fefe fatis ab aliarum Arborum foliis diftinguens. Examinet curiofus Lector atque Spectator, num, quod tradit Luidius p. I33. nondum compertum fic folionum mineralum ulla Arborum \& Friticum folizs reppondere? \& conferat, rogo, Fig. 8. hujus, Fig. 6. \& 8. Tab. III. Fig. 7.8.9 10. Tab.IV. \& fimul judicet, an verum fit, quod fcribit idem, folia mineralia muliò pleruinque minora effe iis, que referre videantur?

Fig. 5: Ex Tabulis Nob. D. Friderici Heyn, Fodinarum SaxoGothanarum primi Infpectoris, qui de Plantis Lapidibus im

$$
\text { C pref }
$$


preffrs Librum edere frbi confituit, fpicam fiftit Graminis cujusdam panicei, vel potiùs fulum pradicta Populi nigra. C. B. Qui ipfus lanuginis reliquias oftendere videtur. Comparent autem hi juli amentacei Aprili, \& Majo, ut inde rurfum argumentum peti poffit pro Inundatione Majali. Conferri poteft Graminis Paniceifpica Luid. pag. Ió8.

Fig. 6. Proftat in Nob. D. Gotbofredi Mylii Saxonia fubterianea, p. 30. \& refert, ipfo Interprete, frucum Arboris Abovai Indicum: Lapis fifflis, in quo confpicitur, eft Manebachen/is, productis hujus generis figuratis dives.

Fig. 7. Ex codem Opere Myliano 1. c. mutuò petitur, eftque, ipfo ita fentiente, Fumaria in Lapide fffli Manelacbenfy. Ef hre Eitbopteris femina Tricbonanis pinmulis longionibus. Luid. Lith. Britt. num. I 86. ipfa quoque, ut videtur filix ramofe Myl. 1. c. Fig. 8.

Fig. 8. Saxum arenarium flavefcens ac cinereum durius, ex Abbaiz cellanorum Territorio mihi allatum, folia ofentans varii generis. Unum ex his, qua depingere jufli, eft Sorbi alpine 1. B. Fen Alni effigie lanato folio majoris. C. B. que Crategi characterem \& nomen fert apud Tournefortium. Alterum anguftus trinervium videtur. Plantagineum, determinatu non ita facile, ut prius. Circa hunc Lapidem obfervare eft, non mihi conftare certo , an Diluvianis fint adnumerandx figurxe impreffx, an Poft-Diluvianis. Fieri enim potelt, ut arena per montium parietes devoluta fecum ferat deflua ex Arboribus folia, qux molli adbuc materix vefigia fua imprimunt, vel, ut folia ftrato alicui jam impreffa fuperinducantur alio frato arenario, omniaque tandem coalefcant in faxum, quemadmodum videmus, quotidie folia Arborum nafci in Tofo.

\section{TA B III.}

Tig. I. Elegantiflmum en fatalis Inundationis productum. In 1- eodem Lapide nigro è Fodinis Faringdonenfibus Anglix eruto, \& a Woodwardo dono dato, confpicui funt Stipites varii feu caules Plantarum, fpeciatim Arundinis, folium item Plantre conI4 ferendx cum Fig. 6. Tab. IV. fed cumprimis oculos ad fe rapiunt furculi Trichomanis five Polytricbi officinarum C. B. Tricbomanis, five Polytricbi, J. B. adeò affabrè elaborati, \& atrâ frâ Tincurâ à reliquo Lapide difcernendi, ut nemo non Plantam primo intuitu diftinguere, ac nominare poffit. Non ignorant, quibus Plantahre eft cognita, ex eadem radice plures erigi furculos, nec proin mirabitur, fi \& hîc in eodem Lapide videat fex feptemve firculos foliofos ad eandem fere plagam directos.

Fig. 


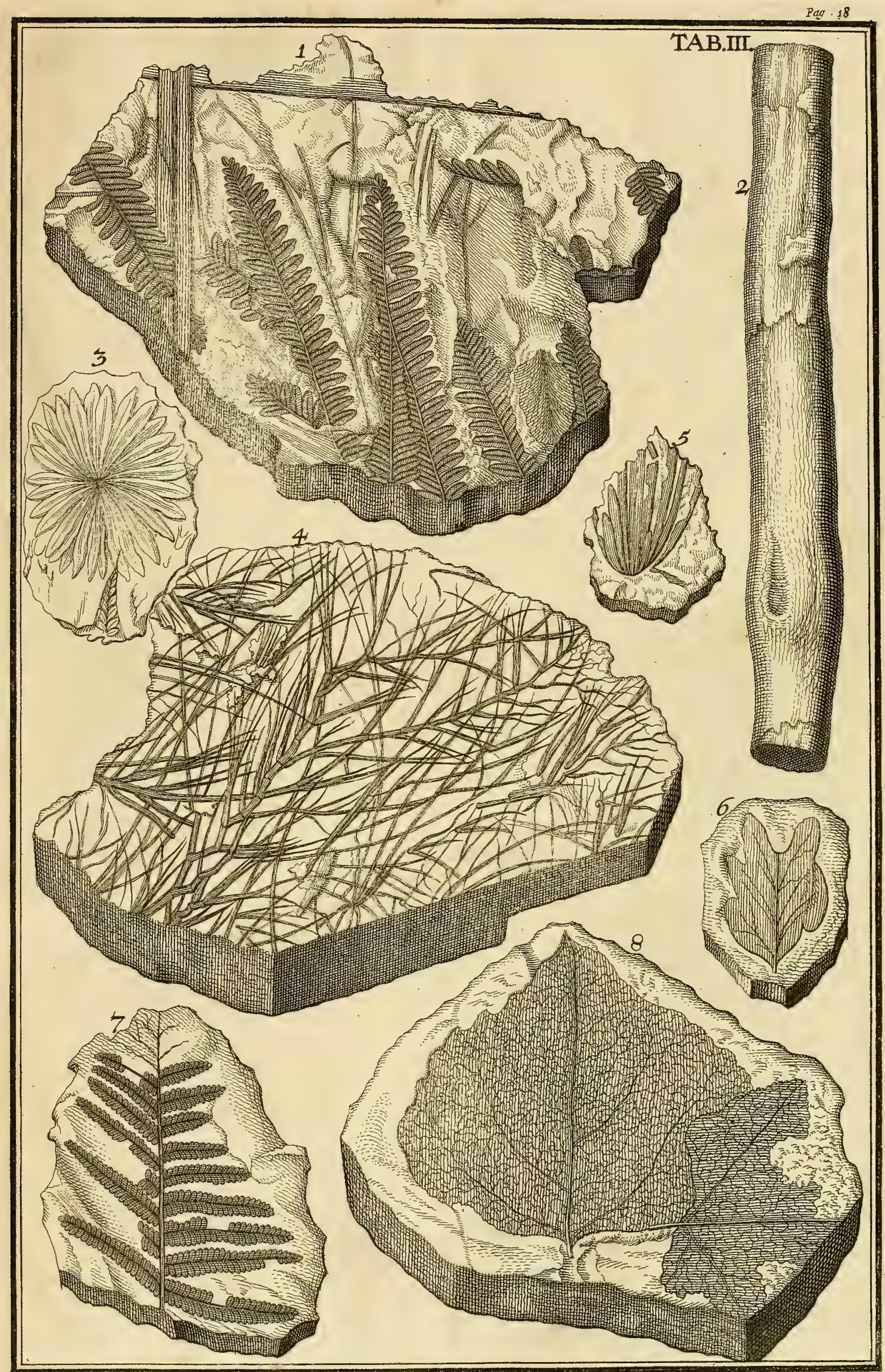

Gll. ac Reverend. Sohanni $\mathcal{L} a u l o . B$ ignonio Larisiensi Abbati es. 2 uintini, Consiliario status ordinario. 




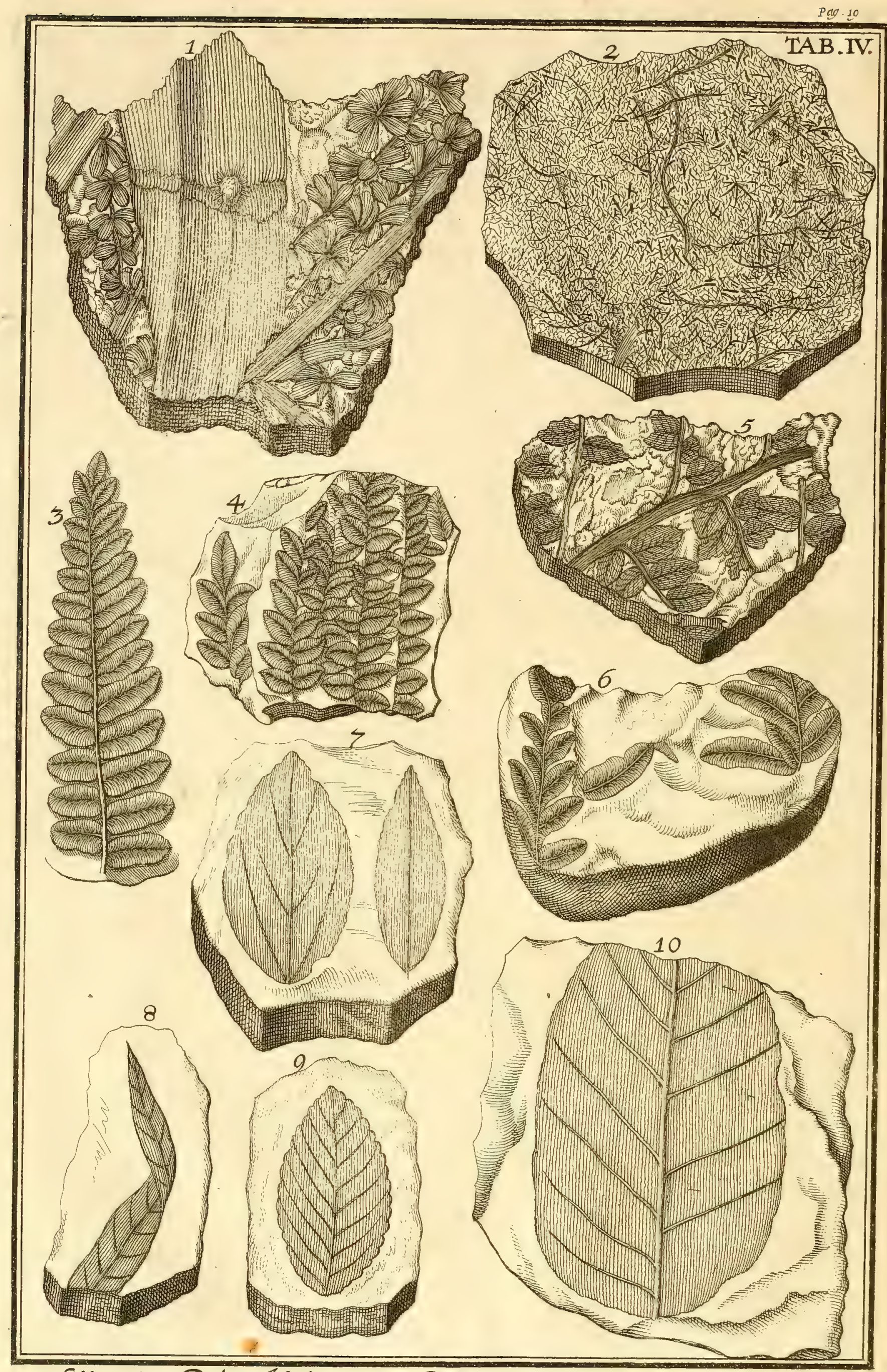

Gel. et Exc. Petro Walkenier Lotentivs. Reip. Belgica ad Sac. Cas Maj.

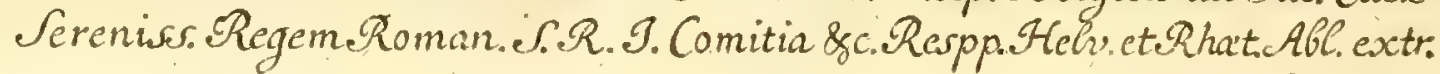




\section{I L U V I A N U M.}

Fig. 2. Non duntaxat impreffum Plantx alicujus veltigium fiftit, fed, quod rarum, furculum, vel caulem folidum, in Lapidem, vel Metalliforme corpus, ferruginei coloris, tranfmutatum. Digiti craffitie eft hoc caulis fragmentum, in quo notabile geniculi veftigium, \& caulis ipfus tumidior ibi craffities. Planta ipfa videtur Arundo quædam. Locus natalis eft meéxwi().

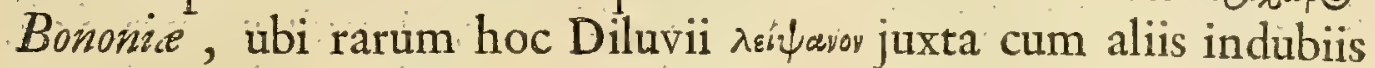
Inundationis univerfalis Monumentis Teftaceis, Cruftaceisve eruit Jobannes Scheuchzerus Frater.

Fig. 3. Mutuo fumta eft ex Clariff. D. Eduardi Lirdii Lithopbyl. Britt. Ichnogr. num. 20I. ubi hoc Titulo extat. Aparine denfivis foliate cmulum Lithopbyton radiofum. E Fodinis Glamorgenfibus. Videtur haud quoque abludere bafis foliofa $A l y / f_{i} \mathrm{cu}=$ jusdam, vel Myagri, \& huc quoque pertinere Rubeola mineralis Luid. num. 202.

Fig. 4. In Lapide Oeningenfs fiftit Gramen quoddam, frequenter geniculatum, foliis è geniculis prodeuntibus in extremo bifurcatis, ac trifurcatis. Perrarum Naturæ genimen. Graminis autem quænam fit hæc fpecies, determinare perdifficile judico. No-

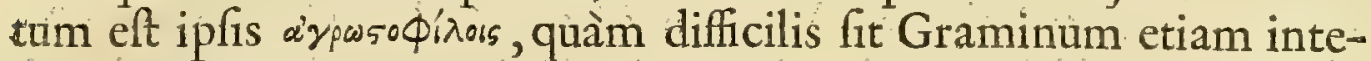
grorum, Hiftoria, àSpicis, glumisve potiùs quàm foliis definienda. Hîc autem defunt fpicx floriferæ, fructiferæ, defunt paniculx, glumi. Nec exigum movent fcrupulum ipfe foliorum in extremis bifurcationes, quoniam nullibi hactenus inter Gramina talem frueturam offendi, ut fufpicari liceat, adeffe folia non reverà bifida, trifidave, fed ex uno geniculo prodeuntia, nondum plenè è vaginis evoluta, fuas tamen extremitates jam porrigentia.

Fig. 5. Ex Sile ia Lapis folia plura exhibens ex uno puncto prodeuntia, qualia funt Plantarum ftellatarum, conferenda cum Fig. 3.

Fig. 6. Folium Mespili Apii folio fylveftris, Jpinofe Jive Oxyacanthe. C. B. qux elt Oxyacantba vulgaris Seu Spinus albus. J. B. in Lapide fiffili Oeningenf.

Fig. 7. Fibicis quxdam fpecies pinnulis denfo ordine coftx adnatis in Lapide nigro Silefaco. Filix Myl. Sax. Subt. pag. 30. Fig. 6. ad pag. 19. Haud abludit Filix non ramofa major, pinnulis longis anguftis, profundè dentatis, Jupremâ pinnâ longius mucronata. Pluk. Amalth. Botan. p. 93. Tab. 403.

Fig. 8. Tilice folium in Lapide fifili candido Oeningenf.

$$
\text { T. A B. I V. }
$$

Tig. I. Ex Fiffilibus Anglicis nigri coloris, impreffa fervat 1 veftigia Plantx cujusdam Atellatæ : \& quidem videre me puto caules Galliz albi vilgaris. Tourn. feu Molliginis montance 
angulitifolic, vel Gallii albi latifolii. C. B. Pin. 334. atque infüper caulem, geniculo inftructum, Arundinis cujusdam, ut mihi videtur; Frequens fatis eft hæc Planta in Fodinis tum Anglicis, tum Germanicis; Laidii eft Ignota Planta mineralis Neurophyllon Carbonarium dicta num. 184 . Lithophyl. Brittannic. \& fortè Lithophyllon finuatum facie arundineâ, five friatula Carbonaria: Item caulis cujusdam Plante mineralis. Ejusdem num. 199. 200. pag. I 2. Mylinus in Sax. Subt. comparationem inftituit cum Ligno Aloes \& Arundine pag. 30 . imò, quod fingulari attentione dignum judico, eandem hanc Plantam, in foliis integris, eodem modo, ut hoc Lithophyllon, geniculatis, mollibus, craf$f_{1 s}$, offendi in cefpitibus bituminofis, qui propè Conobium Rüti effodiuntur, de quibus infrà amplior dicendi locus erit. Videtur huc pertinere Arundo Sativa C. B. Ex Anglia integra poffideo Caulium fragmenta, utrinque ftrata, compreffa valde, quibufcum conferri poffunt Trunci hi \& Atipites Lignofi in Atratis faxeis prope Thunum reperiundi, quos offendi in Itinere Anni $17 \mathrm{I} I$.

Fig. 2. Lapis fiffilis cinereus melanoftictos \& melanogrammos Deningenfis, cineribus quafi ttipulisve combuftis confperfus.

Fig. 3. Mutuò fumta eft ex Luidii Lithoph. Brittann. n. I89. ubi vocatur Lithofmunda minor, five Ofmunda mineralis pinnulis brevioribus denfiùs dispoftitis. E Carbonariis Denenfabus apud Glow ceftrenfes. Refert fanè nervorum è medio fcapo folii prodeuntium parallelifmo, atque figura ipforum foliorum Ofmundam regalem an Filicem floridam Park. Tour. qux Filix eft ramofa non dentata florida; C. B. Feu Filix floribus infignis. J. B. Conferri etiam poffunt Icones Filicum, qux extant in Plukenet. Almag. Tab.402. Fig. 2. 4 .

Fig. 4. Ex eodem Luidii Libro, ubi num. I9r. audit Trichomanes minerale foliis integris mucronatis. E Carbonariis juxta Leeswood, in Agro Flintenfi.

Fig. 5. Fillix eft quxdam ramofa, foliis denticulatis, vel leguminofa quxdam Planta, quam dono accepi à Nob. Dn. Maximiliano Spenero Medico Potentiffimi Pruffix Regis Aulico, Amico honorando.

Fig. 6. Ofmunda, vel Filix alia ex Northbierly, Lancaftrenfis Agri: \& ex Fodinis Flintenfibus in Cambro-Brittannia: conferenda cum Fig. 3. hujus Tabulx; item Fig. 2. \& 4. Plukenet. Alma. Tab.402. ex fol. 82, \& 83. Pl. 2. \& 6. Mantiff.

Fig. 7. Pyri aliusve Arboris folium in Lapide fiffili Oeningenfi。

Fig. 8. Salicis anguftifolix folium in Lapide fiffili Oeningenfi.

Fig. 9. Folium Carpini Dod. Pempt. 84I. feu Oftrye Ulmo $\int_{i-}$ milis 



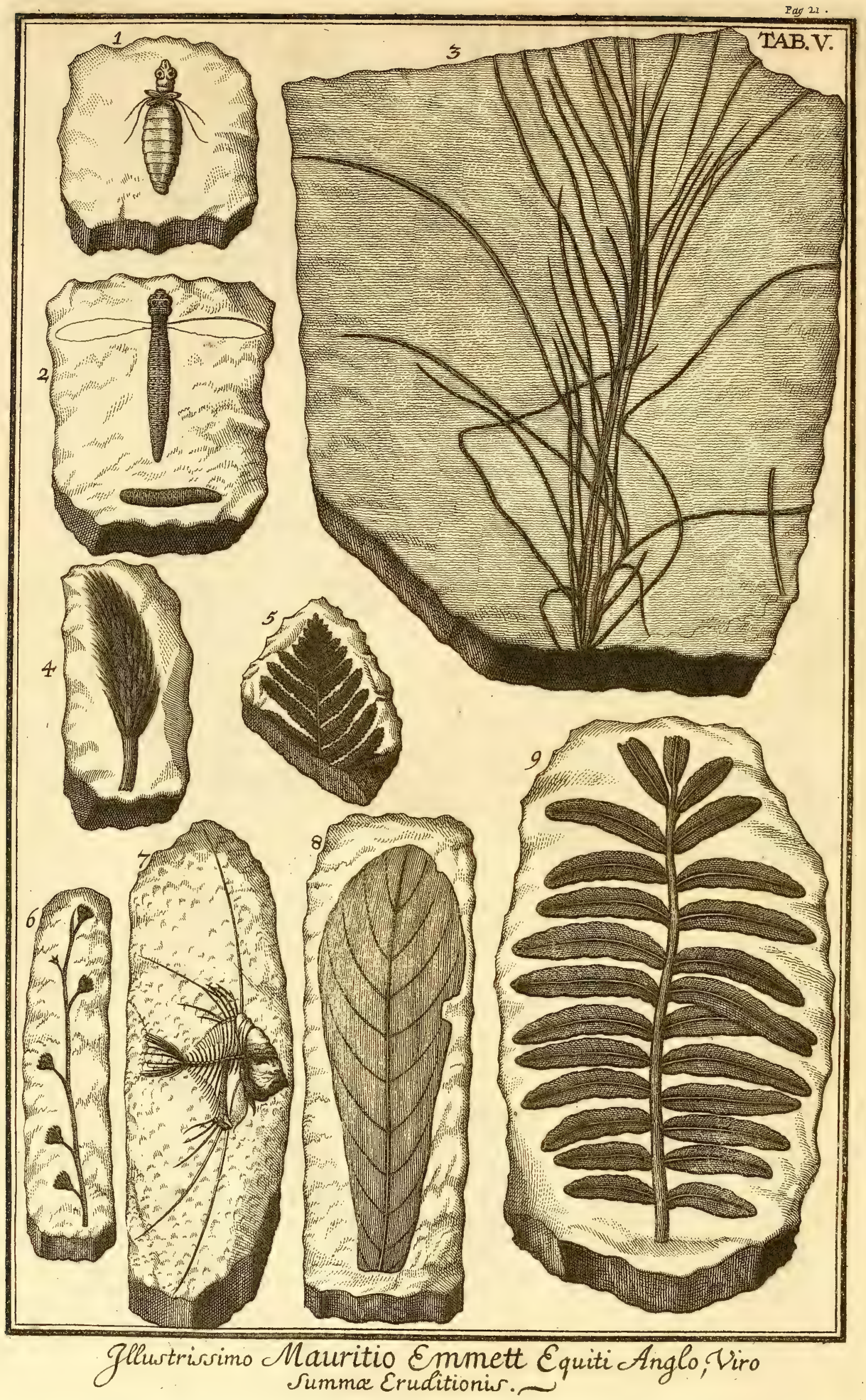


milis fructu in umbilicis foliaceis C. B. Pin. 422. Teu Fagisepium, viulgò Oftrys Theophrafti. J. B. I. I 46.

Fig. 10. Folium Nucis Juglandis five Regice vulgaris. C. B. Pin. 417 . feu Nucis Fuglandis J. B. I. 241 .

\section{T A B. V.}

$\mathrm{F}$ ig. I. Libellam fitit, vel Perlam, Cevettone dictam Florentinis, Venetis Coroculo, aliis Monacbella, Spofo, Saetta, Liburnenfibus Cavalocchio, Gallis Demoifelle, Germanis Scbneidermätze, Augenfchieffer, Belgis Fufferken fatx xtatis, plenè jam elaboratam, \& ejus quidem generis, qua maxima dicuntur. Figurâ prorfus convenit Libella Sexta apud fonfton. Hift. Nat. Infect. pag. 42. Tab.IV. capite, pectore, ac dorfo viridis, alvo tota corulea, per quam linea fertur à dorfo ad extremum ufque aterrma, alis cinereis, pedibus nigris. Putaret quis primo intuitu, reprafentari in hac Figura Vermiculum Libelle, co quidem metamorpholeos ftatu, quo Tubercula quatuor è dor $\varsigma_{0}$, ubi Thorax ventri connectitur, nitidè protuberant, que Tubercula Alarum Sunt receptacula, conferretque cum Fig. IV. Tab. VIII. Swammerdam Hif. Infect. p. 175. Sed obftat non parallela deorfum, fed cruciformis velut Tuberculorum horum expanfio, qua non nafcentes, fed natas jam alas, licet in Lapide non expreffas, indicat, mereturque conferri Fig. Fonfoni fupra jam citata. ME-

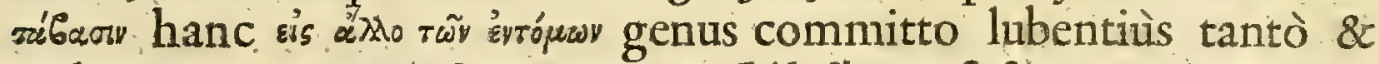
audentiùs, quod obfervatio hxc Libelle in fiffli Lapide Oeningenfi, Dioecefeos Conftantien/is (quam in Mufeo fuo fervat Exc.

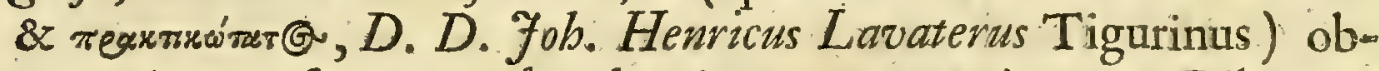
viæ, lucem foeneretur haud exiguam tempori, quo Diluvium contigit, quodve fupra retuli ad Majum menfem, quo ipfum hoc Animal fuam acquirit perfectionem, \& vergente Æitare maturè fefe in fuos folliculos convolvit.' Eodem, fi non majori, xtimio haberi merentur hujus generis Producta naturalia, quoEpoch $x$ frgnatx in Nummis Afraticarum \& Ægyptiacarum $T_{r}$ rbium.

Confirmat ratiocinium hocce aliud Libellie genus in Lapide fiffili candido Fig. 2. quod ex Agri Veronenfis valle montana Bolga dicta obtinuit, meoque Mufeo donavit, vir Hiftorix Naturalis, fpeciatim Infectorum, peritiffimus $D$. D. Antonins de $V$ allifnerius de Nobilibus Vallifneriis, Medicinæ Profeff. in Illuftri Lyceo Patavino Clariflimus. : Comparet in eodem Lapide Libella alis expanfis, quarum tractus non obfcurè quidem, fed nec ita clarè, ut fculptor expreffit, vifuntur, $\&$ ad bafin vermiculus $V$ allifnerio $A c$ quajuolo nuncupatus. Libella eft ex Maximarum Familia. 
Fig. 3. Alge tenuifolix, feu, fr mavis, Graminis fpecies in faxo fiffili candido, ejusdem cum pracedente loci natalis. For taffis non longè à Veritatis femita aberro, fi huc traxero Pbyciten Plinii Hift. Nat. L. 37. c. Io. ita dictum ab Alge Figura: vel etiam Dendritas latiores, qualem delineari curavi in Mifc. Nat. Cur. Dec. III. Ann. V. \& VI. App. p. 59. Imò verò communiffimos noftros Dendritas Pbycitarum nomine infigniet, qui Icones eorum conferet cum Fuco maritimo Rorismarini foliis dentatis. Boccon. Museo Fific. p. 268. Ad prefentem Figuram pertinent forfan Alge tenuifolice Luid. p. Io8.

Fig. 4. Hordei Spica immatura coloris fufci feu nigricantis in Lapide fiffili grifeo, ex Fodina S. Andrex Sylva Hercynix, aus St. Andreas Stollen am Hartz, memorata \& depicta à Clariff. atque Confultiff. Dn. Gotbofredo Mylio Saxon. Subterr. pag. 15. Coincidit Spicx hujus conditio immatura tempori verno ad xitatem vergenti, quod hactenus indicârunt Spica Frumenti Tab. I. \& Libelle Tab. hujus V.

Fig. 5. Filicis fpecies in faxo Farringdunenf Anglix, commu-

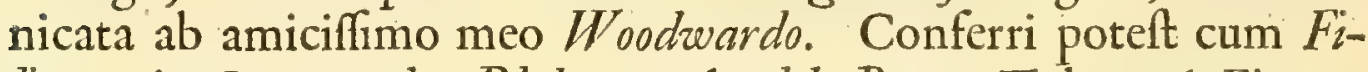
lice, cujus Iconem dat Plukenet. Amalth. Botan. Tab. 406. Fig. 3.

17. Fig. 6. Atrofufci coloris Planta in faxo fiffili candido ex Bolga valle Agri Veronenfis communicata ab Amico certiflimo, fimul atque defideratiffimo, $V$ allifnerio. Refpondet ferè, imò, dicat quis, examuffim, Icon Scorpioidis montani. J. B. II. 899. rare Plante, montiumque folitudinibus inacce/fis tantim familiaris;

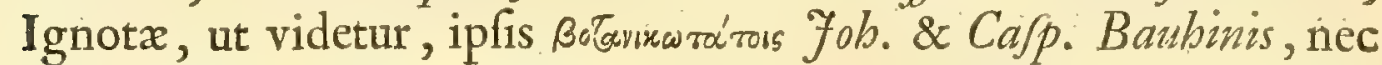
nifi ex Hift. Lugd. cognitæ. Tantò proin rarius erit noftrum hoc Lapidi impreffum Diluvianæ Inundationis monumentum, fi nec mihi, nec ullis fortè Botanicis modernis, notum eft Vegetabile áváìorov.

Fig. 7. Non minùs rarum eft fatalis illius Cataftrophes $\mu$ innóouvov, Pifcis foffilis elegans ex eodem loco natali, ejusdem Amici donarium, quod figurâ integrâ, pinnis, caudâ, bracbio utrinque extenfo in medio ferè corpore, magis tamen verfùs anteriora, adeò exactè convenit cum Guaperva Braflienfibus Marggravii, The American Toad-Fifch, defcripta in ferie Pifcium cartilagineorum oviparorum ab Ill. Francifco Willougby Hiftor. Pifc. Lib. III. cap. 3. p. 90. Ut Iconem ipfam, qux extat Tab. O. 1. n. 4. Lapidi nottro impreffam dixeris. Quomodo autem rara hæc Ranæ Species ex America in oras Italiæ fuerit delata, vel an alii quoque Pifci Maris Mediterranei, vel Adriatici incolæ congruat, meum nunc non eft determinare. Habeant alii etiam, quod indagent. 



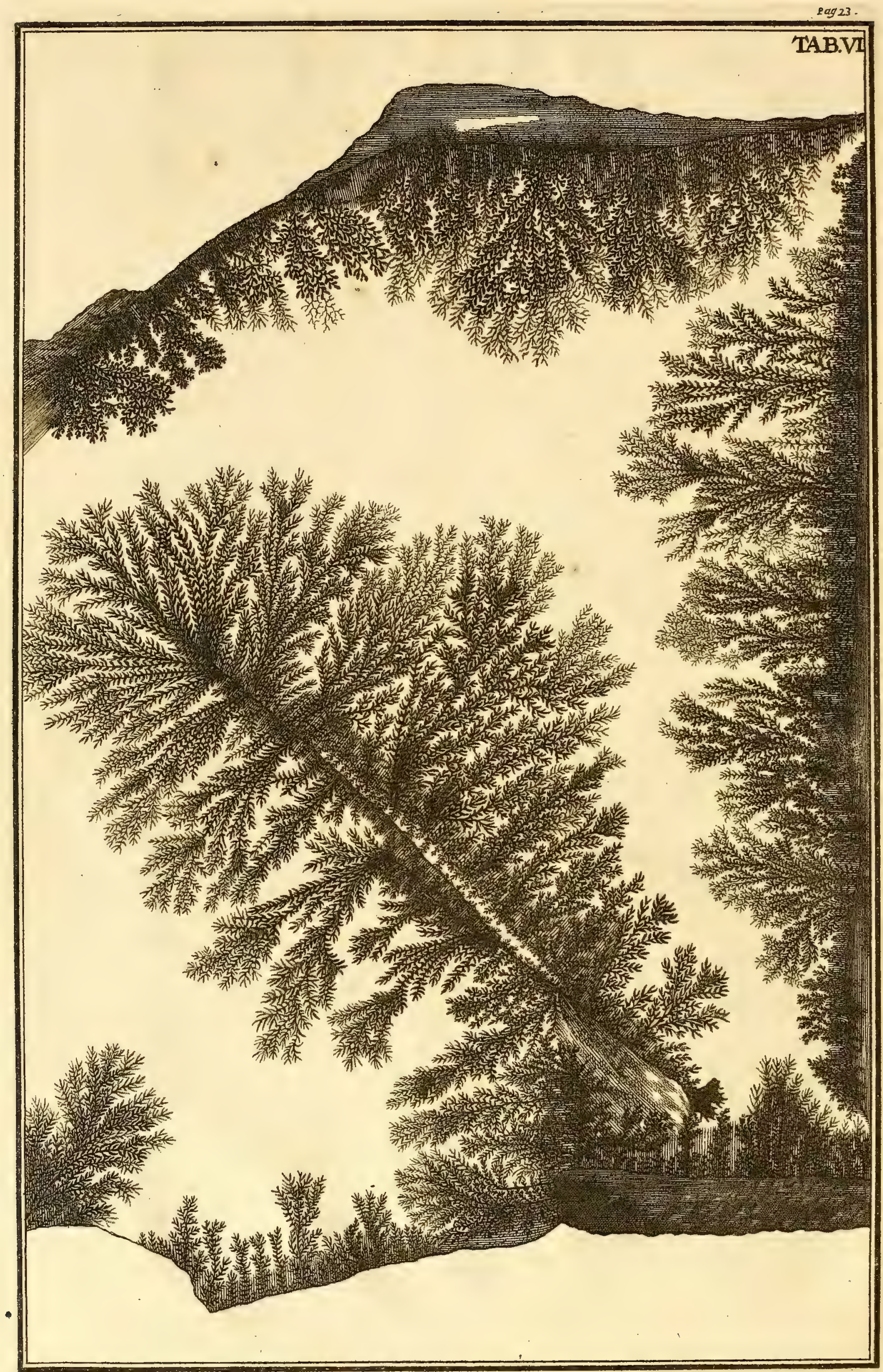

Celeb. 'Johanni TPoodswardo Med.D. Thys in Colleg. Grasham. Prof. Colleg. Medicor. et Societativ Reg. Anglica Membro. 
Fig. 8. Folium Plantæ in oblongâ figurâ rotundatum ex eodem Loco natali.

Fig. 9. Filicis videtur fpecies foliis longis duodecies pinnatis feu conjugatis, impari claudente extremum fcapum; Iconem tranfmifit Vallifnerius, qui Lapidem ipfum poffidet, eodem cum præcedentibus loco depromptum.

\section{T A B. VI.}

T Meic, in Tabule VI. profpectu, aperit fe campus Naturæ II in Philofophorum opprobrium ludentis jucundiffinats, campus difficultatum contra Hypothefin noftram patentiffimus. Hîc habent, quod Natura pictrici, formatrici exprobrent $\mathrm{Ve}$ getabilia Poëtæ illud

\section{Fal/is ludis imaginibus.}

$$
\text { crudelis, Tu quaque }
$$

Inveniunt hîc \& clypeos, \& arma, quibus fefe defendant, \& adverfarios oppugnent, quotquot Plantas Lapidibus impreffas pro Naturx lufibus afpiciunt: Habent heic Afyla Archriftx, Ideiftr, Scholaftici, alii, qui fplendidos Titulos reali Philofophix prxferunt, ac præfigunt. Cur enim, quæfo, non proferat Natura Plantas, Folia, Flores, Pifces, Infeeta, quæ Arbufta, Dumeta integra, in Marmoribus Florentinis infuper Saxa, Flumina, \&des tam affabrè pingit, ut omnem Topiariorum Pictorum artem eludat? Si opus integrum, cur nọn \& partes? Si omnia, cur non fingula? Si majus, cur non minus? Digna omninò eft hæc materia, quæ penitiùs excutiatur, vel ut difcrimen patefcat inter Plantas Diluvianas, \& generaliori alio Naturæ ludentis mechanifmo productas falfas Herbarum imagines, atque per has æque ac illas Potentiffimi Crearoris ubique præfens Sapientia mentibus Hominum fiftatur celebranda. Lapis, quem curioforum contemplationi fubjicio, defumtus eft ex curiofo, non minùs quàm docto, Saxonice fubterranee Specimine, cujus elaborationem felicibus aufpicis, licet infelicibus temporibus, in fe fufcepit D. Gotbofredus Mylizus, Li-

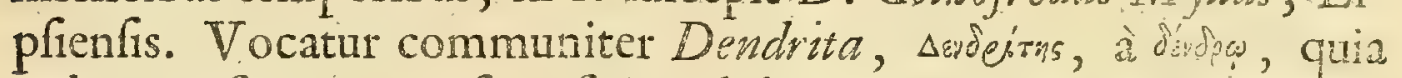
Arborum figuram in fuperficie exhibet. Germ. Baumfein in Spe-ner. Muf. pag.9r. Metallifoforibus Sublenfibus, in quorum Fodinis \& hoc fpecimen fanè pulcherrimum, non figurâ duncaxat, arbufcularum magnitudine, fed \& colore flavefcente, Locum is natalem accepit, Blumen, Flores dixeris metallorum fibjacentium, quorum hæ arbufculæ topiariæ fint veluti vafa capillaria, explicante ita Fofforum mentem laudato Mylio p. 58. Apud Ferr.

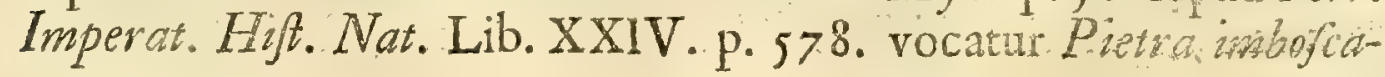




\section{H E R B A R I U $\mathrm{M}$}

ta, Pietra naturalmente delineata in figure de bofchi: item $P$ ietra di Sinai, quòd ex monte Sinai alportari vulgò credatur, quamvis non inficias eam, poffe in monte Sinai extare id Lapidis genus, adeòque appellari Dendritas Sinaiticos: teftatur fane celebris ille Itinerator Monconifus Voyag. T. I. pag. 238. fe in defcenfu ex monte Sinai Dendritas reperiffe. An hac pertineat Dendrites Plinii Hif. Nat. L. 37. c. I r. ubi Dendritide alba defolfa fub Arbore, que cedatur, fecuris aciem non bebetari foribit, determinare non audeo, quandoquidem nullam figurx defcriptionem addit Hiftoriographus. Certiùs afferimus, referendam huc effe Dendracbaten Plin. L. 37. c. ro. qui velut arbufcula infignis, licet materia Achatx fit nobilior vulgari faxo, vel Marmore, in quibus communiter confpiciuntur Dendritx. Attendimus hic ad figuram, non ad materiam. Orpheus non unâ fed pluribus arbufculis eum infigniri canit, adeò ut viridarii fpeciem vel nemoris prx fe ferat: Verfus hi funt, quibus Lapidem defcribit.

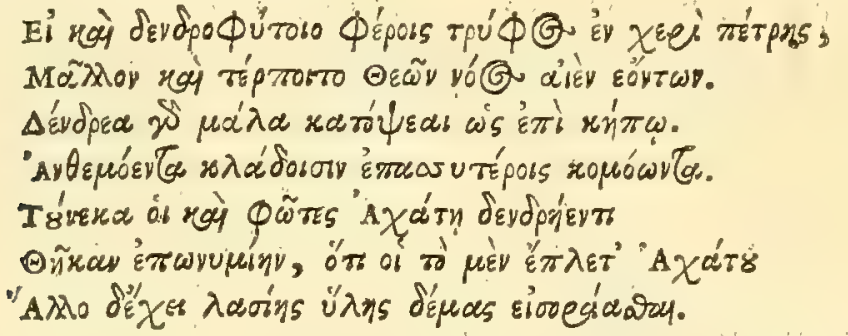

$S_{i}$ in manu geftaveris fragmentum Lapidis Dendrachatis,

Deorum immortalium valde animus delectabitur.

In quo arbores multas confpicies, velut in borto

Florente frequentibus ramis frondente.

Idcirco ei bomines Achatis arborefcent is

Cognomen impofuerunt, quoniam partim fimilis eft Achati,

Partim vierò Speciem prebet birta filua.

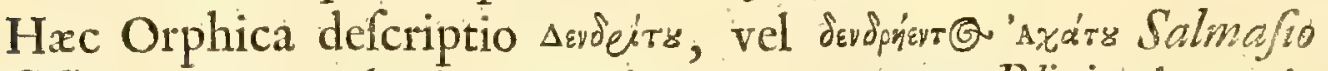
in Solin. pag. 94. planè convenit cum eo, quem Plinizis 1. c. ait in India repertum nemoris fpeciem reddere. Et in India invente contra eadem pollent $\sigma$ aliis magnis miraculis. Reddunt enim pecies fluminum, nemorum $\sigma^{\circ}$ jumentorum. Hxc qux nemoris pe-

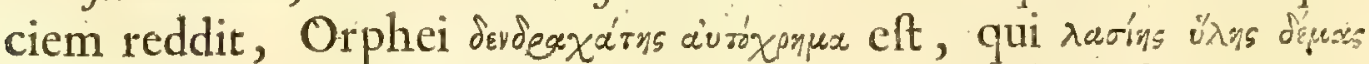

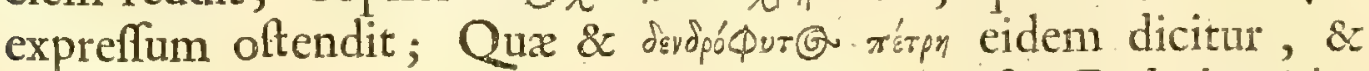
¿sydpy'ss 'Axátus. Camillus etiam Pifaurenfis, tefte Dalechampio, Achaten fe teftatur vidiffe, in cuius planitie feptem Arbores delineate confpiciebantur. Hodie hæc Achatum genera non funt rara nimis, quin in Indoftanenfibus montibus circa Suratam Indie 


\section{I I L U U}

Orientalis fatis familiaria, Belgifque fub Titulo Boomfteenties, Boomties Acbates fatis nota. Pulcherrimam feriem exhibet $T a b$. LV. \& LVI. ad Rumph. Amboinfch. Rarit. Kamer. pag. 287. Aft ex prefenti Dendritarum Familia non fejungi duntaxat me-

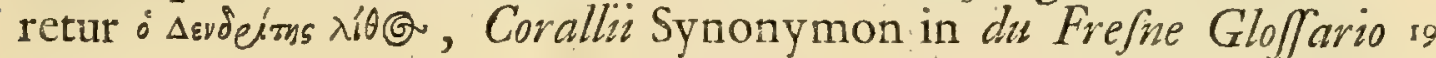
Grecitat. Sed quoque Dendritis Calapparia, \& Dendritis Arborea, Meftica Caju dicta, Lapides in Arborum Indicarum Truncis, reperiundi, quorum ille defcribitur in Rumph. p. 32 r. hic p. 323 .

E contrà ad Synonyma Lapidis noftri Dendritx reduci debent, qui Ericeta reprefentant ap. B. de Boot. Gemm. Eo Lapid. L. II. c. 285 . Incolis pagi Somberg prope Wuraburgum Wafferfteine, quia fub aquis nafcantur, vocaci. Lapis artificiofâ celaturâ in figuram Abrotani plante effictus : item Lapis Naturce vi affabrè efformatus in figuram E Typum nemoris. Calceolar. Mus. Sect. III. pag. 419.420. forte etiam Lapis fiffilis, per quem difcurrentes vence ex argilla cinerea delicativis lapidefcente arborem coralli inftar patulam in ramos bine inde diffifos reprefentant, pro quibus tamen fculptor perperàm figuras hominum pinxit. Baub. Hif. Font. Boll. de Liapid. pag. 4 .

Non de nihilo eft Synonymorum hxc ex variis locis congeftio, conjungendorum conjunctio, fejungendorum divifio. Non exiguam creat Mineralogix ftudiofis nominum in eadem re multiplex confufro, \& optandum omninò eft, ut, quod in Botanica immortali fuâ laude præltitit ó xacisar (G) Cafp. Baubinus, in Mineralogia fufciperet alius, cui quidem R egnum hocce cum fuis Incolis, Provinciis, Urbibus, Pagis, Sylvis, Montibus, Vallibus, Fluminibus eft perfpectum.

Verùm enimverò non fubfiftimus in Cortice hoc Onomatologico, nucleum intus quxrimus, xtiologiam ipfam, modum generationis hujufmodi figurarum, idque per viam variarum obfervationum, tum in Dendritis, tum alibi, obviarum.

Obfervat Imperatus 1. c. quòd fi igni imponatur Dendrites, brevi evanefcat pictura, relicto Lapide fimplice \& nudo, picturâ fuâ orbato, qui adeò fit tenax, \& igni invictus, ut diutiffime vim ignis fuftineat, abfque quod calcinetur, imo continuata ignis actione in vitrum abeat. Nec omittenda funt, qux 1ll. D. D. Lac.e Scbröckio Acad. Imperial. Nat. Curiof. Præfidi perfcripfit ' xaptésar(a) Scbulzius Breslavienfis Medicus, quòd nigredo a Lapide recenti

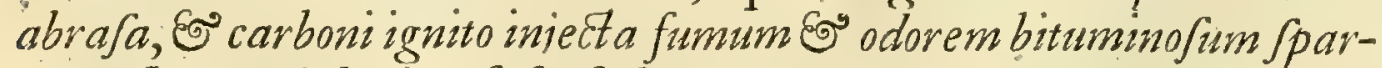
gat: Ip le verò lapis, I frufulum ejus purum, छo nigredinis bujus omnino expers igniatur, nec fumet, nec odorem ullum Spiret. Patet hinc omninò, Tincturx illius nigræx, quâ Lapides cxterà albidi vel 
cinerei, pinguntur, materiam aliam effe à materia Lapidis ipfius, \& quidem illam hac effe fubtiliorem, mobiliorem, fluidiorem, quia poris folidi corporis ab igne referatis illa, frve particulæ magis volatiles, fpirituofx, fulphurex avolant, relictâ maffâ Tinctura experte. Et effe quidem Tincturam hanc fulphurex, bituminofie naturx, patet tam ex odore bituminofo \& fumo, quem igni injectus Lapis de fe fpargit, tum ex loco natali. Memorabile quippe, quod Scbulzio retulêre foffores, $\sqrt{e}$ dum puteos in profindum agunt, frata plura Lapidis fifilis reperive, in nullo vero earum figurarum bujusmodi quidpiam conjpici, nifi in ultimo, cui vena Lithantbracum immedratè fubjacet. Salinx vitriolicx imo \& Martialis naturx effe tincturam perhibet Buttn. Rud. Diluv. p. I 25. \& infuper obfervat corrofam paffim lapidis materiam, ubi Tinctura confluit copiofa. Confirmat hæc obfervatio conjecturam Cl. D. Liebknecht, Literis d. 8. Ann. 7 I 5. ad me datis, exhalationibus metallicis picturas adfcribentis, cui equidem non effragor, fi effluvia hre intra Lapidum ftrata fluido alii commifceri addat: nam ex arbufcularum \& ramorum haud confufa regularitate fluido alicui, non ficcis exhalationibus figuras arceffendas effe autumo. Ita quoque fiffilia varia, exprimentia figuras plantarum, deprehendi in Carbonariis Anglicis tegulx cuidam nigrx impreffas, qux ad fuperficiem Carbonis proximè adjacet, fcribit Cambden. Brittan. Edit. Londin. 1695. pag. 692. Ubi verò per hanc Ignis torturam non evanefcunt picturx, quod mihi Dendritam Pappenheimenfem igni per bihorium ferè committenti accidit, cogitandum eft, effe Particulas Tincturæ volatiles ita cum terreftribus alcalicis fixatas, ut ab earum compedibus vix liberari queant. Quod Imperatus memorat de evanefente per ignitionem Tincturâ, id quoque mihi accidit Adianzotum foffile Silefiacum prunis exponenti, ut evanuerit nigredo, aft remanferint figuræ ipfius impreffæ veftigia. Quòd verò Dendritæ adeò tenacis fint \& compactæ fubftantiæ, ut igni maneant invicti, inde concludere licet, effe eorum fubltantiam valde homogeneam, in minimis partium conftituentium fuperficieculis applicabilem, quam homogeneitatem, vel ipfe fiffilium faxorum parallelifmus, frpe ad axxibsas Mathematicam.exquifitus, homogenearum partium fimul fubfidentium Index certiffimus, comprobat. Ubi varii generis particulæ in eadem maffa mifcentur, ibi facilitatur calcinatio, quia ignis illarum maffularum vicinitatem turbat, minima fua fpicula in eas frequentiùs ac impetuofiùs impellendo, \& has eoufque fuccutiendo, donec contiguitatem ac cohæfionem mutuam derelinquant, hincque quod hacte- 
nus compactum \& tenax, porolum; \& friabile evadat corpus, vel in pulverem collabafcat, ficuti Calcinationis actum optime explicat Celeb. Bubnius Diff. Pby. Chym. XII. \$. 4.

Solent Dendrite femper folas Arborum \& Fruticum ramificationes, prout ex longinquo fpectantur, à Pictoribus miniato vel punctulato opere (en miniature) exprimuntur, reprefentare, nunquam flores, vel femina, vel fructus, nec etiam folia, prout vifui propiùs admota fefe offerunt. Ex hujus Phænómeni confideratione ftatim patet, non effe has arbufcularum imagines ipfas arbufculas, qux extiterint aliquando, petrefactas, nec etiam Fruticum impreffiones in molliori adhuc Lapidis fuperficie factas, nam fic exprimerentur non nudi ramuli, fed ipfa florum, foliorum, fructuumque adeffent veftigia, imò confpicerentur folia non opere miniato, prout è longinquo afpectantur frondes, fed, uti fuprà in Diluvianis Plantis vidimus, in naturali fua extenfione, cum pediculis \& fibris, atque fic diftinguerentur facilè Plantæ vel Arbores unæ ab aliis. Vel inde conftat, non eodem modo produci has Plantas in Lapidibus depictas, quo progerminant è Terræ gremio Vegetabilia. Qui Ideas fui pictrices in fcenam proferunt, ii fateantur neceffe eft, transvolâffe potiùs ex Pictoris alicujus Topiarii cerebro in faxa fiffilia, quàm ex ipfa Natura. Eadem cujusvis alius Principii Plaftici, quod tanquam operativum produci poffet, ratio \& imitatio eft.

Qui Dendritarum figuras potiùs conferret cum Ericx, Abrotani, Mufci Iconibus, atque fic hos ipfos fuffrutices, ac Plantulas à fubverfionibus Terrarum, Inundationibus Aquarum \&c. delatas diceret inter Lapidum fiffilium Atrata, atque his utrinque impreffas, vel ab Ideis Mufciformibus ibi delineatas; hunc Tyro quivis Botanicx facile confutabit. Qui enim vel primis attigit digitis fcientix hujus limina, enuntiare poterit, quanti laboris, indultrix, dexteritatis opus fit, Herbarium vivum, ut vocant, conficere, foliola fingula, quæ, fi recentia \& fucculenta fuerint, facilè confunduntur, fi ficciora, corrugantur, evolvere, explicare, ut diftinctè confpici, \& in figura expanfioneque naturali confiderari queant, \& ad primum Dendritæ alicujus obtutum ftatim, \& verè quidem, judicabit, aut adfuiffe fummam Artis induftriam, Plantam ipfam inter binas laminas fiffiles collocantem, digitorum apices valde acuminatos, foliola explicantes, \& cuncta ita difponentes, ut ne minima quidem facta fuerit ramufculorum vel intricatio, vel confufio, vel interfectio, aut, quod potius mihi videtur, productas effe has figuras ex motu fuidi alicnjus inter duo folida inclufi, compreffi \& fefe inter illa

$$
\mathrm{D}=\text { diffun- }
$$


eliffundentis. Kircherus Mund. Subterr. Lib.VIII. pag. 37. quadruplici modo figuras Lapidibus imprimi polfe fcribit. I. Cafue Eo fortuitò, ut nubes, naves, montes, urbes, Caftella, Cruces, Literas Alphabetbicas, figuras Matbematicas. Exemplo poffunt 2r effe Marmora Florentina. 2. Ex difpofitione terrence fubftantice, intra quam tanquam intra formam receptus bumor tinctus tandém fpiriu lapidifico in eam figuram, quam terrene fubfantice matrix refert, induratur, ut Pifes in'Icbtyite. Clarius potuiffet eloqui modum hunc per impreffionem corporis alicujus folidi in materiam mollem, qux moduli vice fubjicitur. 3. Ew aliquo fingulari accidente, quo figure in Lapidibus nunc in banc, nunc in illam figuram emergunt. Quomodo hoc accidens à cafu fortuito differat, fcire defidero; vel, an accidentia dentur fingularia; alia univerfalia? 4. Coclitum prefertim figuras ex difpofitione Divina. Quadrat hic non nobis, fed is, qui colitibus corumque miraculis ad fuperfitionem ufque nimium tribuunt. Pro arbufcularum noftrarum Iconibus explicandis eligit Kircherus tertium modum ex recenfitis, hancque fovet opinionem, quam propriis ipfus verbis p. 40. reperiundis exponam. Cium in terra, inquit, lapidescenten variarm ftirpium Plantarumque pulveres infint, in quibus unà cum exiguo calore neficio quid spermaticum adbuc ineft, quod in Lapide adbuc molli materiem nactum utcunque ad id aptam, cium Plantarum fubftantiam ex ea conftituere non poffit, id quod poteft, id eft, folas in materia Herbarm imagines, plafica facultate, que feminali virtuti aliquo modo inexiftit, depingit. Perbella Philofophia, qure pari paffu ambulat cum Facultatibus Scholafticorum formatricibus, cum Vi Plaftica quorundam Recentiorum, cum Eduardi Luidii Ideis, quas hoc nobili Titulo donare nondum audet pag. I 34. Lithoph. Brittan. Icbnograph. Dico, inquit, fuppicari me, qui ex mari feruntur vapores, Eo formâ pluvie aut nebularim fuperiona Terre ftrata ad requifitam altitudinem pervadunt, teflaceorum $0^{\circ}$ multorum feminio fapius impragnari: atque exinde pro data feminit poritone, छ2 pro matricis congruentia, formari alicis $P$ ifces integros, aliàs eomum tanium lineamenta: aliàs dentes, mandibulas, vertebras, aut alia officula, atque inter cruftacea nunc integra animalia, quandoque eorum arisculos; inter Teftacea nonnunquam univalvia, \& repius bivalvia. Idem quoque imaginabar de origine foliorim mineralium, notandum enim, ea ut plurimum folia effe dorfiferarum, Mulcorum, aliarumque Plantarum, quas minis perfectas vocare folemus:- quarum femina cum adè Jint minuta, ut nifi Microfcopio utamur, vifum fugiant: tanto facilius aquâ abforpta 
in Terre penetralia devebunur.' En quim pancis Lineis abfolvi, filicet! queat integra Lapidum omnis generis figuratorum genefis! En oraculum, quod omnem fcrupulum eximit! infignem Kircheri, qui spermaticum quid refiduum agnofcit , Commentarium ! Democriti Puteum, ubi arcana Generationis delituerant, apertum! Ecce volant, animarum infar illarum ex Purgatorio redimitarum, Idex onnis generis Animalium \& Vegetabilium, Ideæ vel rudimenta non integrorum duntaxat corporum Animatorum, Pifcium, Avium, Infectorum, Mufci, Polypodii, fed fingularum quoque partium, Foliorum, Florum, Spinarum, Idex Idearum, cur non addiderimus fibrarum, Sanguinis, Lymphæ! Quis non audito tam egregio Syftemate admiratione percellitur, ftupore corripitur ? Quis non volare fibi videtur Atomos illas Epicureorum, qui fortuito fuo occurfu Mundum primitùs efformârunt! Quis mirabitur, fi hîc ex gremio Terræ benigno Fungorum ad inftar propullulent capita, brachia, crura, oculi, caudx, fructus, flores, folia fine Truncis ? Quis, qurfo, non videt innumeras circa hoc Syftema difficultates, circa Idearum harum exiftentiam, qux nuilibi nifi in Cerebro Authorum fuum inveniunt fundamentum; circa horum rudimentorum perfectionem \& imperfectionem; divifionem in alia rudimentula (fit venia verbo) minutiora; circa corum volatum fine alis: circa infinuationem in Terrx, Lapidumve poros, circa eorum expanfionem in integra folia, integras Plantas, integros Pifces, cum fuis ariftis, pinnis, carnibus? Longum nimis foret hxc omnia difcutere, imò vix operx pretium, longum nimis, figmenta hujufmodi, qur nec ingenium fapiunt, nec Phrnome- 22 nis Naturx experimentisvè refpondent, recenfere; perfpectầ veritate noltrx Hypothefeos patebit quoque aliarum falfitas, Penes Lectores ftet judicium.

Notabilis eft, \& una ex precipuis Dendritarum circumftantiis, quòd ita juxta invicem exurgant arbufculx, ut nulla aliam impediat, una alteri cedat, nullus ramus, vel ramufculus, alium permeet, vel interfecet. Putaret quilibet, materiam fluidam inter lapidum fiffuras compreffam, atque fuper corum plana effufam, non poffe tam ordinatè \& difincte moveri, quin vel totam inundet fuperficiem, eamque fic uno codemque colore tingat, vel faltem confufas fine ordine pingat maculas, non difinctas fruticum icones: difficultatem auget, quod ne duo quidem rivuli, utut prope juxta invicem effluentes, cuífus fuos commifceant, ne duæ quidem arbufculæ, ne ramuli duo quidem invicem confundantur, licet interfitia tam exigux fint latitudinis, 
ut vix oculis difcerni poffint. Hoc fcrupulo menti-mex jam olim oblato ftatuebam fuxum perennem materix fubtilis per fingulos corporis porulos, qux jugi fuo per corpus etiam folidiffimum tranfitu non folùm confluxum atque mifcelam fluviorum prohibeat, fed \& ipfam fluidi tingentis ramificationem determinet, \& latitudini æquè ac longitudini fingulorum rivulorum leges qua$f_{1}$ \& terminos figat, quos transgredi non poffit. Magnam vim effe fluidi permeantis exemplo longitudinis filorum evincit Stenon Prodr. Diff. de Solid. intra Solid. pag. 65. qux circa Magnetis poros è Ferri limatura exurgunt, non folùm, quando eadem limatura Magnetem proximè contingit, fed etiam, quando intercedens charta à Magnete illam dividit: cui obfervationi nixus idem Author pag. 66. \& 100. Cryftalli incrementum per appofitionem materix certis folùm cryftalli faciebus, figurationem \& erectionem Salium volatilium, alembici collo adhxrentium, aliàque id genus Phænomena permeanti fluido fubtili adfcribit. Verùm infufficientiam hujus ratiocinii declarat fimul atque viam ad veritatem pandit Experimentum facile, vel pueris notum, quo bina marmora polita, vel Lapides fiffiles laves, fuper invicem, oleo vel Aqua interfluente, triti, easdem prorfus, quas in Dendritis videmus, arbufcularum figuras exprimunt, \& cum hac quidem notabili circumftantia, quòd \& hîc nulli ramuli alios interfecent, ne vel minimi quidem oculis vix ampliùs vifibiles, quos artificio obtinebis, fi trituram, qux initio, copiofiori exiftente fluido, craffiores fiftit arbufculas, continues, donec fluidum fit quantitate minus, \& pluribus terreis particulis intermixtum: Hic; utrobique, idem prorfus adelt effectus, quid impedit, quò minùs eandem ftatuamus caufam. In Marmorum lævigatorum experimento quamdiu Tabulx cohærent, fluidum xqualiter preffum fefe æqualiter fuper Tabulas expandit, nullaque certa prodit figura: Verùm diductis ab invicem Tabulis fluidum inter eas medium, præfertim fi oleofum fit; atque tenacius, elevatur fimul, formanturque ex cohxfione partium extremi primùm ramuli, hinc ex pluribus confluentibus Trunci coralloidis inftar ramofi, quorfum fcil. fluidi hîc ibi elevati portio fefe concentrat. Obfervari \& hoc meretur, quòd ramificatio femper incipiat ex ea parte, ex qua fit Tabularum abinvicem diductio. Si hrc fit fupernè, Truncus ab imo ramos fuos expandit furfum: fi Tabulas diducam inferiori, quâ cohxrent, parte, Truncus fefe ramificat deorfum. Et fic vel dextrorfum, vel finiftrorfum, arbufculas formare poteris pro lubitu. In Terræ vifceribus, cruftâve fuperiori poftquam fubfedit refo- 
luta in pulverem maffa, formavit ex Strata parallela, mollia primùm five lutofa, pofteà indurata, qux ipfa nunc funt Marmora, faxavè fiffilia híc ibi arbufcularum figuris pulchrè exornata, Dendritarum nomine venientia. Dubium nemini ampliùs fupereffe poteft, Dendritas eodem prorfus modo ab interfluente in ftratis fluido figuratos fuiffe, quo arbufcularum in Tabuli; lævi-23 gatis icones: Atque ex fitu Arbufcularum, quoniam Trunci femper in Lapidis marginibus, vel fiffuris Lapidum, funt confpicui, ramis hinc ad Tabulx medium, ut in Tabulx prefentis Dendrita, directis, inferri fimul potelt, faxorum fiffilium invicem incumbentium medium vel denfrus effe, frve compactius, $\&$ proin in altitudine contractius, marginibus, vel faltem priùs, condenfatum. Imò verò hinc formari potẹt univerfalis Regula. Ubicunque in fifili quodam faxo arbufcule confpiciuntur miniato veluti pictorum opere picte, quarum ramuli omnes abivicicen funt diffinti, neque ulli alios intersecant, ibi generatio debetur interjecto fluido. Juxtaponenda huic eft fequens, ex Tabulis pracedentibus efformata. Plante integre, earumve Partes, folia cum fius venis, flores, Fructus in Lapidibus expreffe, tales quoque extiteriunt dim, Vegetabili fic Regno accensendie. Quxfio duntaxat eft de modo, \& tempore, quo hæc Vegetabilia fuerint in hæc, ubi inveniuntur nunc, aliena loca delata. Conformis eft huic effato Prop. II. Stenon. lib. cit. pag. 25. Si corpus folidum alii corpori folido non modò quà Juperficiè conditiones, fed etiam quà intrinfecam partium, particularuinque ordinationem, per omina fimile fuerit, etiam quà modum Eo locum productionis illi fimile evit, quâ acutiffimus Author Teftacea, Cruftaceavè foffilia, $\mathrm{Pi}$ fees, horumque Dentes Animali Regno vindicat, Mineralique demit.

Contingit aliquando, \& quidem in ipfo præfentis Tabulæ Lapide, ut fuper arbufculas origine priores, \& emarcidas quafi, proindeque flavefcentes, alix exurgant recentes nigricantes, ut hîc pulchro certè fpectaculo ipfa Natura Naturam imitari videatur. Pro hujus phænomeni ratione ftatuenda eft temporis ratione prioris \& pofterioris diverfitas, \& adfcribenda illi genefis foliorum flavefcentium \& quafi marcefcentium, quia fitu funt inferiora, huic productio foliorum recentium illis fuperinductorum. Ut autem hæc diftinctiùs intelligantur, fupponendum, fluidum arborificum inextitiffe ipfis Lapidum poris, atque exudare; vel potiùs exprimi à confrictione pororum, quæ confolidationem Lapidis neceffariò comitatur, ex ipfo Lapidis fiffilis corpore; vel aliunde in Strata hæc, Dendrite jam formato, affuere. Quando 
ita poft aliqualem \& primam pororum conftrictionem, $a b$ expreffone prima fluidi, fuit prodncta prior feu inferior arbufcularum feries (ita ut etiam hæc pictura exiccata fuerit) nova fit $\grave{a}$ frigore vehementiori, vel alia caufa, ejusdem Lapidis nondum plenè compacti feu confolidati conftrictio, tunc materia tingens fluida, in poris refidua, de novo exprimitur, atque pro ratione fitus vel prifinarum arbufcularum faciem denuò inundat, vel fuper nudam quampiam, nec dum tinctam faciem fefe effundit: Idem potelt accidere ex fluido affuente, nec poris Lapidis expreffo: quod autem Tinctura prior coloris fit flavefcentis, non atri \& vividi, ficut pofterior, ejus ratio defumi poteft ab illius majori tenuitate, fluxilitate, faciliori ab halitibus fulphureis aliisque furgentibus mutatione, hujus verò ftatu fixiori, craffiori, durabiliori.

Sunt radices, vel imi trunci, arbufcularum in ipfis Lapidum commiffuris, five, quod idem eft, incipiunt fefe expandere Fruticuli hi à Naturâ depicti ibi, ubi fiffles Lapides alios contiguos in fua craffitie tangunt. Conclufimus hinc jam fuprà, denfari priùs mediam Lapidis partem, \& nunc inferimus, fieri Dendritas per expreffionem fluidi cujusdam ex ipfius Lapidis fubftantia, quod polteà fuper externam ejus fuperficiem fefe diffundat, \& quidem fieri exudationem illam fluidx Tincturæ per craffiorem \& breviorem Lapidis fiffilis diametrum, non per longiorem feu 24. fuperficiem ampliorem, qua in fiffuris fe invicem tangunt, five in planitiebus fuis ftratorum ad inftar fuperimponuntur : atque hinc infuper colligere facile eft, fieri expreffionem illam fluidi tingentis ex poris Lapidis per conftrictionem pororum in duabus maximis, invicem parallelis, fuperiore una, inferiore altera, à frigore, pondere fuperincumbentium fratorum, inductam. Arguit hoc ipfum Corticis Terrx genefis, ex ftratis fuper ftratis compofitio, vis gravitans in perpendiculari linea fe exerens, effectum ad latera, ubi minor eft refittentia, exercens. Poteft idem Phxnomenon concipi, ex hypothefi fluidi aliunde in ftratorum interftitia affuentis.

In fingulis lapidum fiffuris novx obfervantur picturx, novx

- confpiciuntur fruticum \& arborum icones, \& quidem eodem in duabus fibi contiguis fuperficiebus. Phænomeni hujus confideratio anfam dat cogitandi, quòd $\mathrm{r}$. à caufa conftrictoria pluribus vicinis ftratis inducta è fingulis exudet fluidum tingens. 2. Fluida duo ex duobus contiguis ftratis expreffa, \& ad idem interftitium effufa, fefe conjungant, \& eandem fimul viam ineant. 3. Si vel ex unico contiguorum ftratorum feu vicinorum Lapidum fiffilium exudaret fluidum, hoc inter binarum fuperficierum anguftias 


\section{I I $\quad$ U V I I A $\mathrm{N} \cdot \mathrm{U}$ M.}

compreffum utrique ex dictis fuperficiebus contiguis Tincturam eandem impertiet : Sicuti videmus poft difruptionem duarum Tabularum, è Lapide fiffli nigro politarum, oleo vel Aquâ priùs illitarum, \& fuper invicem tritarum, easdem arbufcularum effigies in utriusque Tabulx fuperficie exprimi.

Sunt Dendritạe, quorum Tinctura arborifica totam Lapidis craffitiem penetrat, ita tamen, ut in fola fuperficie prima diftinctas arborum icones reprxfentet, quales funt Pappenheimenfes: hi enim fi poliuntur, fenfim fenfimque obfcuriores evadunt, atque fic eam, quâ fuperbiebant anteà , pulchram picturam, in maculofum nefcio quid transmutant, vel prorfus amittunt. Alii è contrà, ut Dendritz Hetrurix, \& Dendrachatæ, quò plùs poliuntur, eò prodeunt in figuris arbufcularum diftinctiores, atque proptereà politi capfulis vel ciftulis ornandis egregiè inferviunt. Alii tandem Lapides in fuperficie duntaxat figuras oftentant, quibus abrafis ne veltigium quidem ullum effigiei arborex comparet. Horum Phænomenorum attenta confideratio anfam dat cogitandi de æqualitate vel inæqualitate materix, quâ Dendritarum Lapides conftant, uti \& de tempore ac gradibus confolidationis : notum quippe eft ex Mineralogia generali, Lapides etiam folidiffimos fi fecundùm Naturæ Leges producti fint, è fluido productos effe, vel quafi fluido, ut etiam hanc Prop.III. fuis de folido intra folidum meditationibus in Prodr. Diff. premittat Stenon. Et fane, nifi hoc effatum verum foret, nemo unquam fibi poffet concipere Dendritarum figuras folidum Marmoris vel Achatx corpus penetrantes \& permeantes, ut vel ex hoc folo Dendritarum afpectu veritas Propofitionis Stenonianx abundè pateat. Prout materia folida Lapidis, five arenulx, funt craffiores \& rudiores, uti pro folutione primi ex recenfitis modò Phænomenis fupponendum erit, non poterit Tinctura arborifica eodem totam maffam lapideam permeare ordine, quin à jugi arenarum craffiorum objectu à recta pororum via deflectat, ficque inordinatam \& maculofam quamvis figuram inordinato fuo motu defcribat; imò frepe fefe perdat, antequam ad mediam ufque Lapidis materiam penetret, ut non mirum, in hoc Dendritarum genere, fi poliantur, non folùm diftinctas arbufcularum Icones, fed ipfam quoque Tincturam evanefcere. In Dendrachatis verò adeft materia magis æqualis, fubtilis, arenulæ pulvifculorum in alcohol redactorum inftar tenues, ut ita propter æqualitatem materiæ fluidum tingens, poftquam fefe per fuperficiem ftrati exteriorem diffudit, fefe etiam infinuando in potos fluidx adhuc Lapidis mallix, perpendiculari femper \& recto 
rramite incedat, abfque quòd à particularum crafforum objectu avia quxrere cogathr, \& hinc fit, ut confolidata hæc mafía, quò plìs politur, eo nitidiores, \& expreffiores reddat arbufcularum imagines, licet in Dendritis Marmorum Florentinorum aliqua $f_{x-}$ pe confufio oriatur. Pro illis tandem Dendritis, qui in extima duntaxat fuperficie pinguntur, ftatuendum eft, fuiffe productas arbufcularum in fuperficie exteriori imagines vel ex fluido tingente juftò craffiori, ad ulteriorem infinuationem inepto, vel confructầ jam, \& nimiùm confolidatâ Lapidis fubftantiâ : dum enim fluidum tingens à poris lateralibus fuit expreffum, ut fuper externam effunderetur fuperficiem; potuit eodem tempore ita à caufâ externâ conftricuus fuiffe lapis, ut ulteriori Tincturx, quam dinifit, reforptioni factus fuerit ineptus.

Prabet tandem Dendritarum noftrorum confideratio argumentum novum pro amicifimi $W$ uodwardi Hypothefi, qua Terra, faltem exterior, fúerit diffoluta; ex fubfidentia materix gravioris in Strata difpolita, qux poltmodùm rupturâ fuâ eam, quam prac octlis videmus, Terra inæqualitatem pepererunt. Quis; quæfo, Archeus, quæ Natura, quænam Ideæ, quæ rudimenta, que Facultates, qui halitus, potis funt duriffimam Achatæ alicujus, vel Marmoris fubftantiam, in ftatu quo funt, penetrare, non duntaxat fuperficiem, fed ipfius quoque interna vifcera pingere, \& veluti arterias aut venas efformare ? Superant hæc Rationis captum.

\section{T A B. VII.}

$\mathrm{D}$ ecet hominem Philalethen, Veritatis in omni Hiforia amantem, non ea duntaxat, qux omnium oculis fub veri fpecie irradiant, proferre, fed \& dubia, falfa, Evartroథavéa in fcenam producere, ut ex collatione diligenti, ab omni partium ftudio remota, tandem in lucem protrahatur id, quod adeò follicitè quærimus, Veritatis pretiofum depofitum. Exemplo talis Inquirtionis fit Tabula præfens VII: in qua varia fifto Experimenta, Hypothefi mex, apparenter faltem, adverfa, quæ reticere facilè potuifem, utpote a me ipfo facta, ingenuè tamen propalo, ut

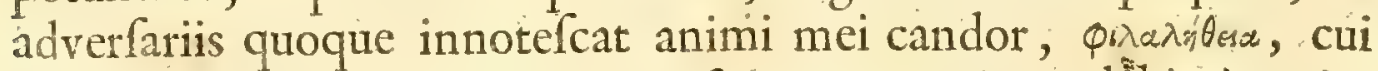
ftudeo, Laboresque meos unicè foveo, tum etiam dửbia à veris, fucata à certis diftinguantur, atque alii ad inquifitionem ulteriorem ejus, quod ego in incerto linquo, inftigentur.

Fig. I. 2. 3. Lufus Naturæ in Glacke exhibent: I. quidem foliorum æmulas figuras, quas in congelata Aqua Borraginis deAtillata confpexi d. 23. Januar. 1704. Figunt crucem Philofophis 


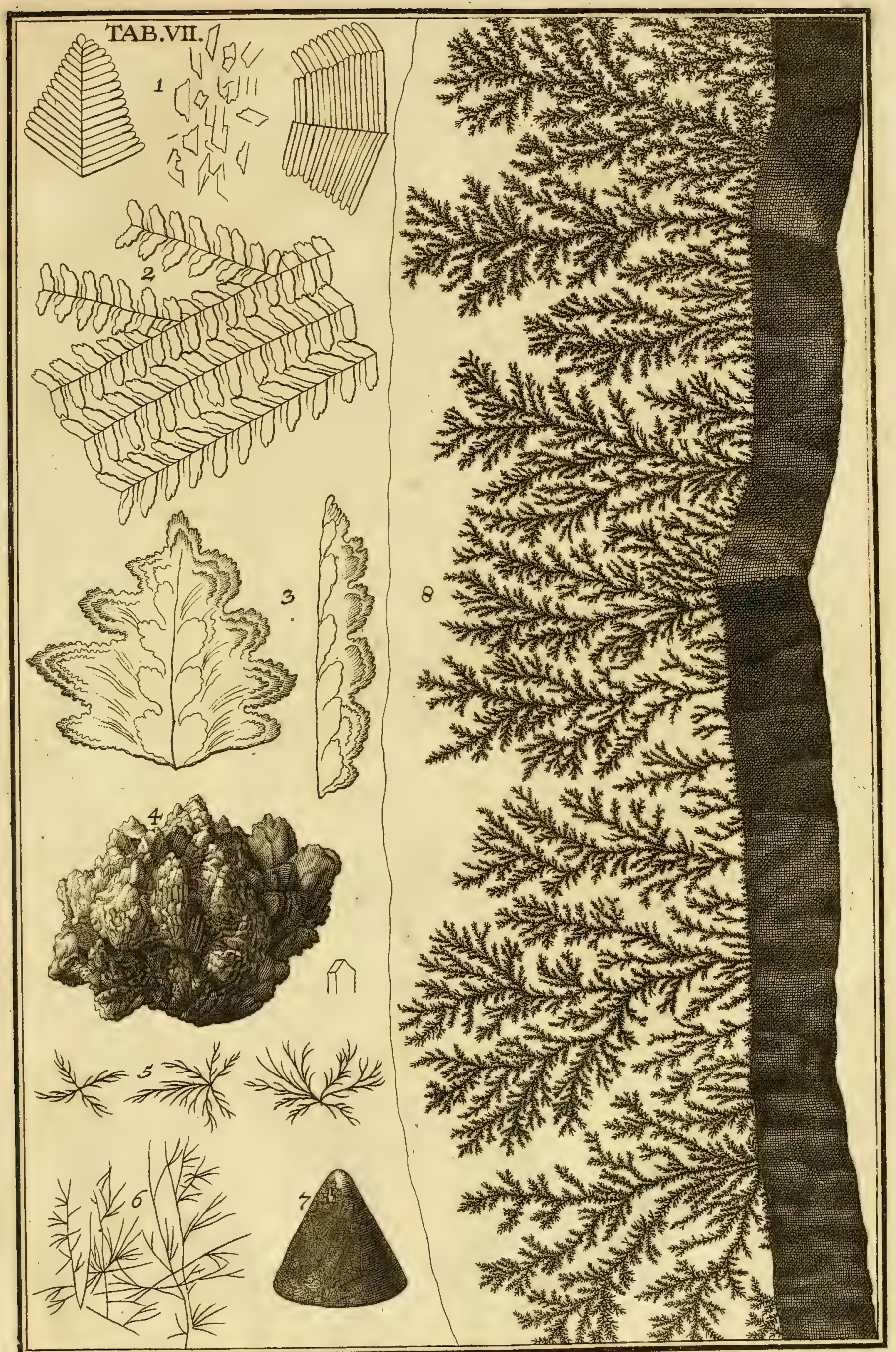

Gle. Guilielmo Scherardo I. U.D. Nationis Anglica Consuli o Smirnensi, Botanicorum $\mathcal{D}_{\text {rincipi. }}$ 



\section{I L U V I A N U M.}

admirandæ fanè in Glaciebus figuræ, nec fuit hactenus, qui genuinum, Philofophiæ modernæ Mechanico-Mathematicæ conformem de illis protulerit conceptum. Confugiunt omnes ad principium aliquod univerfale, fpirituofum in Natura operans, DEO fubordinatum, ad Archeum, Salia, eorumque vim acinobolicam, Salia Plantarum fpecifica, quorum vires es ufque exaltant Chymici, ut in lixivio ex combufte alicrijus Plantre cinere, vel Sale fixo parcto, atque conglaciato, peciem fuve Ideam ejusdem Plante in Glacie apparituram perhibeant, memorante ex aliis Scriptoribus Ill. Boyleo Tentam. Pbyflolog. pag. m. 43. qui tamen rem nullo fucceffu multoties tentâfe candide, prout in more habuit, teftatur. Nos in præfenti figura folia videmus, non 26 certè Borraginis, cujus fuit Aqua deltillata, fed, nefcio ipfe, cujusnam alius Plantæ, folia, alius, quàm Vegetabilis Regni, altioris, quale Meteoricum eft, producta. Fibras videre putamus, \& venas è fcapo folii medio lateraliter prodeuntes parallelas, in quarum Philofophica explicatione hæfit hactenus mens, obfcura caligine involuta. Hanc non quidem difcutere, forfan tamen ad difpulfionem preparare poteft confideratio Aeris comprefli, ex Aqua glaciali profilituri, à crufta impediti, hinc paflim fecundùm fuperficiei congelafcentis longitudinem viam affectantis rectam, (quæ fcapum medium folii efficit, \& in omnibus hujusmodi conglaciationibus eft confpicua) porrò etiam è medio fcapo ad angulos acutos evadentis; ficque venas laterales efformantis. Multùm fanè valere exiftimo vim Aeris frigore confricti in Aqua ad congelationem difpofita, exitum hîc ibi per mediam frep glaciei maflam quærentis, \& acuformeś ftricturas effigiantis ; Hîc forte lux accendi poteft genefi obfcuriffimæ canalium illorum, nunc cylindricorum, nunc quadrangulorum, qui in cryftallis pellucidiflemis aliquando confpiciuntur, imo \& varii generis \& coloris acuum, pilorum, graminum, in rectas lineas protenforúm, non quidem ratione materiæ, fed ratione directionis, ut Aeris compreff, frigore confricti vehiculo materia fluida heterogenea fuerit per congelafcentem, five in procinctu cryfallifationis exiftentem cryftallum veluti projeca. Non vacat nunc, hujusmodi Cryftallorum enumerare fpecies ; Lectorem dimitto ad Defcriptionem Itineris Alpini Anni 1705 . quo integra Cryftallorum continetur Hiftoria: Unum hoc animadvertere heic volui, quod fingularem inter Glaciem \& Cryftallos ratione genefeos affinitatem notent Ptrix utrobique obvix, in longum maffe folid $x$ protenfr: unde tamen nemo proliciet quidquam in favorem exoletrillius, \& dudum confutate Hypothefeos de Cryjtallorum ex 
Glacie indirata alpina ortu. Cum prima hac figura conferri poteft figura Urine glaciate apud Luid. p. 1 Ig.

Fig. 2. Exhibet Icones, in Aquâ Nitri Antimoniali conglaciati confpectas die 4. April. r701. Quis non ex Chymicorum ordine falis vegetabilis fpecifici dominium plenis decantaffet buccis, fi in Lixivio Cinerum Trichomanis, vel Filicis comparuiffet foliofum hoc, imò \& egregiè ramofum fpectaculum? Adeò oculos fafcinat fimilitudo! Adeò fimile non eft idem! Sufpicor fimilitudinem pro identitate fumfiffe Dn. Fridericum Hayn, Fodinarum metallicarum Infpectorem, qui Lapidem fiffilem Manebacenfem per aliquot dies fucceflive Igni ad uftulandum expofuit, pofteà pulverifatum per cribrum trajecit, Acetum deftillatum in vafe vitreo ampliori fuperfudit, ad quietem repofuit, \& in fuperficie figuras Plantarum, qux anteà Lapidi inerant, confpexiffe teftatus. Quod idem Experimentum multoties infelici fucceffu tentâffe fe fcribit Myl. Saxon. Subt. pag. 22.

Fig. 3. Novas reprafentat figuras, foliis Herbarum fimiles, quas d. 6. April. r7or. confpexi in Aquâ Nitri Antimoniati con-

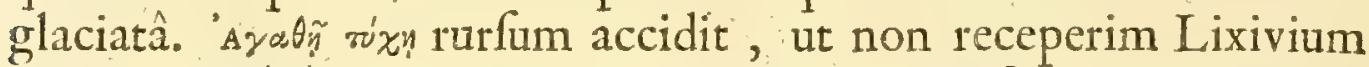
Urtice: Aliâs, \& per accidens quidem prodiiffer, quod Digbeo contigit, quodve inferuit Libro fuo de.Plantarum vegetatione. Verba ejus hrc funt: Infignem Urticarum quantitatem, radices fcilicet, caules, folia, Go flores, uno verbo, totam Plantam priis calcinabam. Ex bifce cineribus cum Aqua pura conficiebam Lixivium, quod filtrando ab omni terreftri materia depurgabam. Hoc Lixivium debito Anni tempore, ut à frigore conftringi poffet, à me expofitum erat. Et certo certius eft, quòd poftquam Aqua frigore indurata fuerat, ibi Urticarum in Glacie congelatarum magna abundantia appareret. Non babebant quidem colorem Urticarum, ${ }^{27}$ nec viriditas eas comitabatur, fed erant alba. Nibilominus nulla ratione ullus pictor fafciculum Urticarum exactius delineare potel, quàm ille in Aqua defignate erant. Obfervavit jam ante illum Quercetanus in Pefte Alexicac: in Lixivio Urticarum congelato mille Urticarum figuras cum radicibus, foliis \& Truncis, adeò perfectè defriptas, ut qui melius illas ad unguem expreffifet, figurafetque, vix pictor ullus reperiretur. Accidit perfape Chymicxe Gentis hominibus, ut Nubem pro Junone amplectantur. Nolim tamen negare, vidiffe hos viros Urticxformia folia, licet dubius hrream, an viderint folia Urticx à fale hujus Plantæ refufcitata. Ita mecum fortuitas maximam partem reputat Celeb. Dn. Fob. Mauritius Hoffmannus Med. in Acad. Altorffina Prof. figuras, quas vidit in Lixivio falis Meliffx à frigore cruftam gla- 
cialem folia cum contextu fibrofo reprefentantem adepto, quasvè delineari curavit in Mifcell. Nat. Cur. Dec.II. Ann. VII. pag. 39. Huc trahendas puto Arbusculas pulcherrimas Juniperi emulas, quas in Tartaro Vitriolato confpexit Hannibal Barletus Chemicus Parifnus: Uvam Ferrii Regis Anglix chymici, quam monfravit in fublimatione Salis Tartari Lixivi per Aceti primim deinde So $^{\circ}$ purgatiffmum vini Spiritum preparati, 16. EO ultra menJum patientiấ; porrò Chamxcyparifli figuram ex cineribus $\mathrm{Cu}$ prefli evectam à Borricbio in Act. Hafn. Ann. 1671. Obferv. 42. Secretum Medici illius Poloni, qui adeò eleganter cineres cujusvis Plante appurare norat, earumque fpiritus exactiffimè confervare, ut $f$ quis rogaret fibi Rofam a a Calendulam demonftrari, tunc cinerem illius cum vafulo, cujus Jpeciem effet editurus, vafis fundum lucerne admovit, ut aliquantilum intepefceret: tum tenuifjmus ac impalpabilis ille cinis ex fe apertam Rofe Speciem emittebat, quam Jenfim crefcere, vegetari, ac formam penitis totius Rofe floride Umbram ac figuram exprimere videbat; telte Tachen. Hipp. Cbym. p. I I r. Secretum, inquam, hoc, ut शuercetano infigni illi Chymico, qui id fummo Studio perquisivit, nunquam tamen affequi potuit, fuit ignotum, \& hodie forfan omnibus Chymiatris, fub prafentem confiderationem non venit.

Fig. 4. Fluor eft cryftallinus perrarus, qui fermè vegetabilis inftar fuccrevit, potiùs dixerim, concrevit, Ericæformis. Ex Plumbifodinis Arkendalenfibus Comitatus York Anglix habuit, mihique benevolè transmifit Amiciflimus Woodwardus. Non fatis benè expreffit fculptor biachia Fluoris ramofa, prouti ex radice ima, veluti centro furgunt. Eum Tabulx huic inferere volui, ut ex Cryftallorum quoque profapia proferrem, quod Vegetabile mentitur. Attentione digna funt in hoc Fluore Pyramides horum Fluorum bihedricx tecti adinftar difpluviati in angulum acutum coëuntes, quales nunquam hactenus alibi confpexi, \& propterea delineari curavi.

Fig. 5. Arbufculas monftrat Dendritarum æmulas in vitri parictibus confpicuas, cui infufum fuit Errhinum ex Manna foluta in Aqua Rofarum \& Liliorum convallium, menfe Februario I704. Dixiffes, partes ramolas refinofas, ex compedibus partium aquearum folutas, \& fui juris factas, figuras fibi nativas explicâffe. Talifmodi ferè figuræ, \& cum Fig. I. Tabulæ hujus conferend $x$ vifuntur in Effentia Campbore benè faturata cum Spiritu vini, inprimis tempore hyberno. Refricant hxc memoriam Experimenti circa Magifterium Gummi Guttce ante plures retrò annos facti: hoc dum ex mente Scbröderi cum Spiritu vini conficerem, \&

$$
\text { E } 3 \text { polt }
$$


poft folutionem dimidiamque menftrui abftractionem refiduo Aquam fimplicem copiofam affunderem, præcipitatione autem nulla fubfequente curiofitatis ergò Spiritum vitrioli infunderem, fecretio quidem facta eft copiofifima, fed materix vifcidioris, qux cum liquore integro in mucilaginofum quid concrevit. Mucilaginem hanc fluidam in Concham vitream effudi, \& die uno elapfo 28 rurfus decantavi, fic quod adhæefit vitro refiduum refinofum vi falina imbutum \& actuatum in exiccatione fui innumeras formavit ftrias, \& plures quidem $a b$ uno puncto latè verfùs unam pla$\mathrm{gam}$, vel undiquaque diffufas. Depingi figuras curavi in Mifc. Cur. Dec.lll. Ann.V. App. pag. 67.

Fig. 6. Qux dilineat Salvolatile Jerici, prouti fefe in deftillatione per Retortam Recipienti affigit, commodam filtit occafronem differendi de Salibus volatilibus, eorumque arboriformibus concretionibus, quas oftentant omnia ferè falia volatitia, Conu Cervi, Rupicaprx, Turfix feu Cefpitum bituminoforum, quorum falia volatilia etiam vidi in Recipiente, minori licet, quàm in deftillatione Serici, vel Cornuum, copia. Horum Generationem ita ego concipio. Particula falinx minimæ ignis vi vinculis partium terrearum, oleofarum, \& firituofo-aquearum folu$\mathfrak{t} \mathfrak{x}$, eâdem ignis violentiâ jaculorum adinftar, vel fagittarum, feruntur per Aerem, protrufe in ipfum vas recipiens, quoniam ultra provehi non datur, fefe hic ibi affigunt, parietibusque affixa manent, quoniam plana horum falium, dum in ftatu liquefactionis funt; fuperficiei vitri fefe accommodant. Affixa ubi fuerint, aliquandiu motum particularum internarum, ut alia quarvis corpora ignita, fervant, eum tamen fenfim amittunt. Sed cur advolantia nova fpicula non confufim fefe, ubicunque allidunt, affigunt, fed potiùs falibus jam parieti adhrrentibus, \& ad angulos plerumque acutos, ut arbufcularum in ramos fuos expanfarum figura prodeat? Hîc cardo difficultatis non contemnendæ vertitur. Num vocemus in auxilium Particularum ejusdem generis Sympathiam, imò verò amorem mutuum? Juxta motuum Leges Spicula noviter adventantia, ex collo Retortæ projecta, vel jaculorum inftar excuffa, hinc inde in Recipienti volantia, affigent fefe, ubi major eft refirtentia, major quies. Hanc ubique fere invenit æqualem, in omnibus fuperficiei internæ vitri punctis, potiùs fere, quam in falibus jam affixis, ut hinc elongare potiùs fefe deberent, quàm approximare ad fui generis particulas: Sed confiderandum, quòd falia volatilia vitro jam adhærentia fint quoque in plana fuperficie extantia, unde fit, ut qux f́picula aliunde à parietibus vitri reflectuntur, ad obices hofce falinos extantes allifi motum fuum 


\section{I I $U$ U V I A}

perdant, atque fic numerum ramorum augeant. Eadem prorfus mihi videtur ratio arbufcularum, que rigidâ Hyeme fefe orbibus feneftrarum vitreis affigunt, \& jucundo fpectaculo fepe Abietes, integra nemora, Dendritarum æmula, reprefentant. Verùm enimverò ex hujus figuræx confpectu ftatim patet differentia figurarum arboriformium in falibus volatilibus, \& dendritis. Non fervant fpicula falina hanc femper regulam, ut nulli ramí alios interfecent, omnes ab invicem fint ad minimos ufque ramufculos feparati ; Sed paffim junguntur rami arborefque vicina per alios oblique projectos, fylv $x$ ad inftar, in qua arbores, vel rami decifi in proximas arbores decumbunt. Effentialis hæc nota diftinguit facilề, ut figuras ipfas $a b$ invicem, ita quoque earum genefin. In generatione falium volatilium animadverti porrò, ineffe iis tenacitatem quandam, projicique ea per Aerem in formâ nunc perbrevium jaculorum, nunc longiorum : Obfervavi quippe in deftillatione ferici fila 4--6--8. digitorum longa ex pariete recipientis vafis filorum ad inftar, quas aranex conficiunt, pendula, qux aliter explicari nequeunt, nifi per coagulationem feu fixationem fili longi tenacis falini. Circa fitum falium volatilium porrò adnoto, protendi ea à collo ferè Recipientis verfùs ejus medium, truncis arbufcularum non verfùs fundum, fed verfüs collum fitis: Confideratio hec fitûs novas fuggeffit meditationes. Dubitare mecum coepi, num projectio falium, eorumque adhæefio, fiat juxta directionem à collo ad fundum, vel contra à fundo verfùs collum? Prius fuafit proximitas arbufcularum ver- 29 fùs collum ; motus manifeftus nebularum juxta fuperficiem vitri concavam circulantium: pofterius, quod mihi magis arridet, formatio ramorum, \& attentior confideratio fitus ipfius. Utut nebulx, falibus volatilibus prxgnantes, circulent juxta fuperficiem ipfius vitri concavam, certum tamen eft, motum fortiorem dirigi in linea recta à Retorta ad fundum, unde porrò fit reflexio juxta ipfius vitii latera, \& adhæefio eo in loco, ubi major eft in toto Recipiente quies, fcilicet in parte anteriore verfùs collum. Ita refluere autumo falia eâdem viâ, quâ nebulx fuẹrunt provolutx, vel fupra eas, Ventorum ad inftar, qui nebulas Atmofphrre fxpe in contrarias partes, infra fupraque invicem agitant. Huc pertinet Obfervatio, quam cafus fingularis \& fortuitus fuggerit. Serenifimæ Venetæ Reipublicx nomine ad Batavos \& Helvetios miffus Illuftris Vincenti, ex Belgio ad Tigurinos Redux fortè inter res fuas fociavit Sal Anglicum dictum, feu fores Salis Armoniaci, \& cochlearia minoris moduli argentea, qualibus Theam bibentes itimur. Frangitur, quod Sal continebat 
vitrum, $\&$ in Itinere variis concuffionibis Sal extravafatum cochleari argenteo adhærens omnem ejus fuperficiem ramufculis pulcherrimis corulei coloris (qui poft in viridantem fe convertit) ornat, flores Caryophyllorum \& alios, fr velis reprefentantibus. Quo cochleari Mufeum meum ditavit Illuftriffimus Refidens, Fautor meus fingularis, Ann. I7 I5.

Fig. 7. Regulum fiftit Antimonii Stellatum, in cujus conica fuperficie vifuntur figurx Trichomani vel Filici cuidam fimiles; fimiles, inquam, non exdem, conferendx cum nonnullis Diluvianis, quas Tabulæ priores exhibent, pracipuè verò cum figuris glacialibus, in Fig. $\mathbf{r}$. obviis.

Fig. 8. Et ultima, elegantiffimum exhibet Dendritam in Lapide finfli marmoreo candido, ex Lapicidina Pagi Solnhof Comitatus Pappenbeimenfis, quem in Mufeo proprio affervo.

\section{T A B. VIII.}

C onfpectui fefe fiftunt in hac quoque Tabula VIII. Naturæ ludibundr, calentis, frigentifque effecta.

Prxterita Hyems Anni r 708. per totam Europan ultia Hominum memoriam duriffima fingulares rigoris fummi produxit effectus, Lacuum Fluminumque incruftationes glaciales, Hominum Brutorumque mortes, vaporum conglaciationem in omnibus xdium angulis \& parietibus, Aqux in ipfis Hypocaultis, Febres multas, præfertim Catarrhales; Pulcherrima paffim nemora, \& Arboreta in orbibus vitreis, de quorum genefi jam fuprà aliquid tetigi, quorumve delineatione fuperfedeo. Singulare tamen Phxnomenon, Fig. I. depictum præterire non potui, quin à Sculptoris ipfius manu chartx, \& proin memoriæ, traderetur, æri nunc incifum. Orbis eft vitreus in occidentaliori Mufei mei parte, qui curiofiffimam hanc exhibuit figuram d. 8. Jan. I 709. Mufci Terreftris clavati C. B. æmulam, ramofam, clavis ramorum craffufculis erectis, in genicula innumera diftinctam, foliolis pilofis pulcherrimo ordine, \& alternatim veluti ex fcapi medio prodeuntibus infignitam, rariffimi cujufdam in Aere rigentiffimo motus indicem, de quo aliorum judicia audire malo, quàm immaturum quid è proprio proferre Cerebro. Dignum utique eft hoc Problema, quod fubtiliffimorum Philofophorum exerceat ingenia. Non unus duntaxat fuit orbis Iconibus his Mufciformibus exornatus, fed in eâdem Feneftrâ plures, non tamen alibi in aliis ædibus abs me vif. Num alii alibi fimile quid obfervaverint, fcire defidero, magis tamen, audire folutiones, quæ Rationi Phyfico-Mathematicis Principiis imbutæ fatisfaciant.

Fig. 


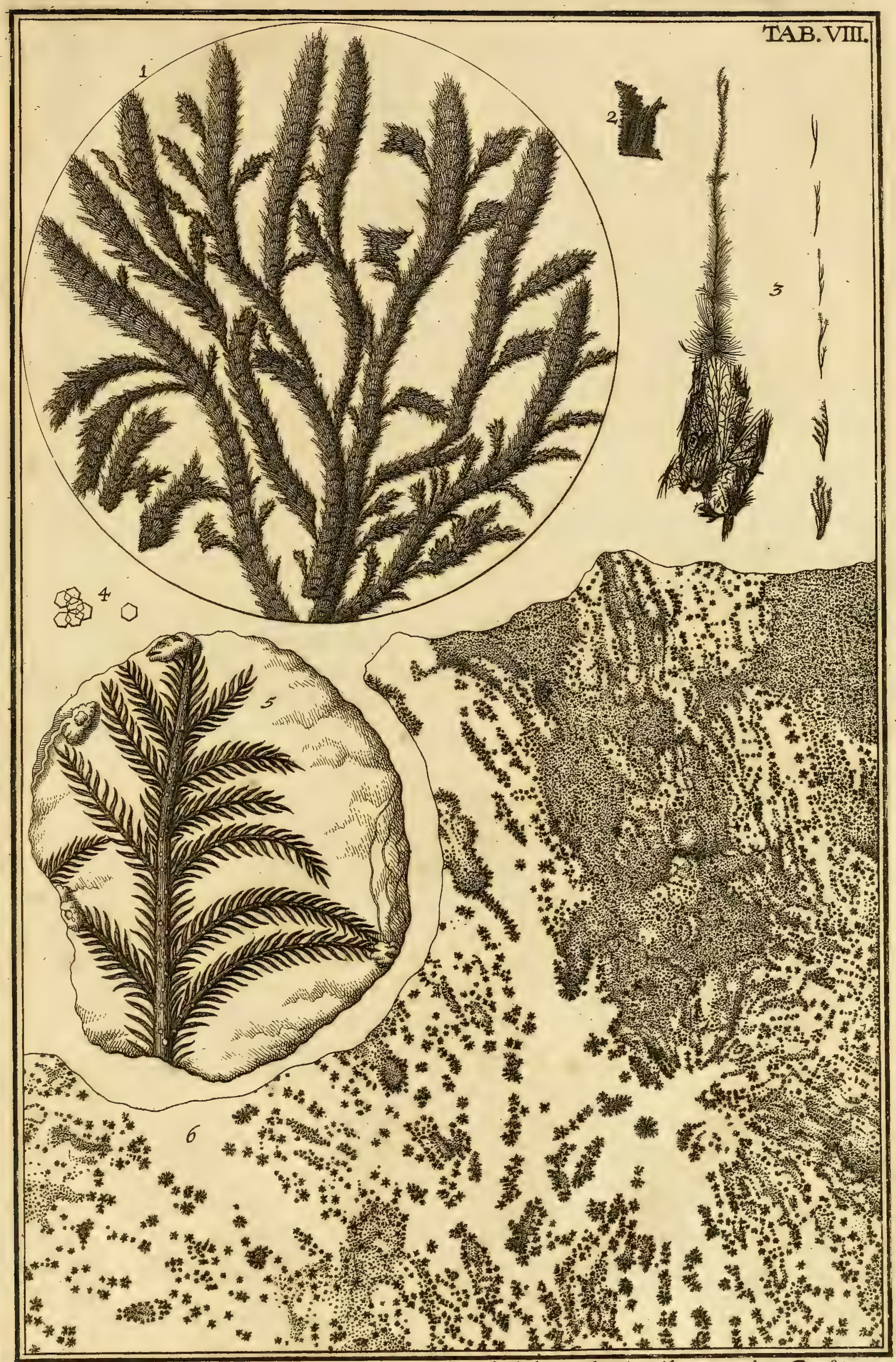

gle. Antonio Vallisnerio de Jobilibus de Vallisneria $\mathcal{P}_{u b t}$. Med. Dract. Prof. in inclyto fyceo $\mathcal{L a t a v}$. Acad. Reg. Angl. rocio. 



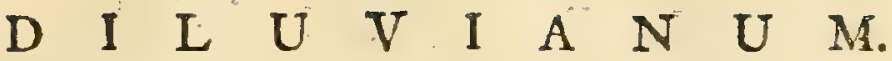

Fig. 2. Portiunculam fiftit Argenti puri, fui coloris, communicatam à Nob. Lin. Mylio Lipfienfi, qui in inftuetiffima fua Pinacotheca majus marcæ pondere poffidet fruftum, ex $\mathrm{Fo}_{-}{ }^{30}$ dinis Georgiopolitanis Saxonice, Argenti ditiffimis. Huic Argento fequentia jungo Synonyma apud Hiftorix Naturalis Scriptores paffim obria. Argentum crippatum Abrotani fruticem fermè cemulans, denfê flipatis ramufculis. Worm. Muf. pag. i i6. Aigentum purum frutice cens egregium undiquaque ramunculis abie-

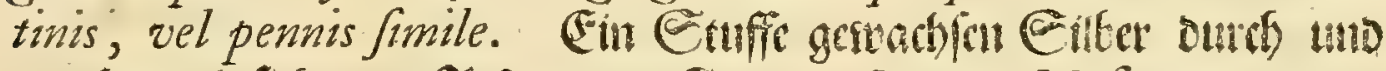

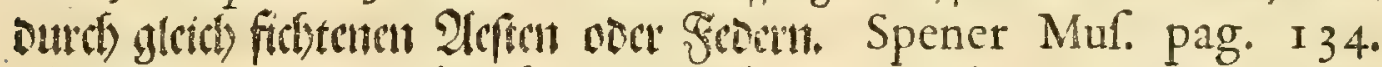
Argentum purum virgularum fpecies pre fe ferens, noic Bttoiglin

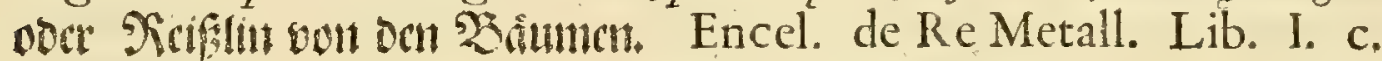
5. Argentum quod Natura format in figuras virgularum. A gric, Nat. Folfil. Lib. VIII. pag. 334. Argentum purum fruticefcens,

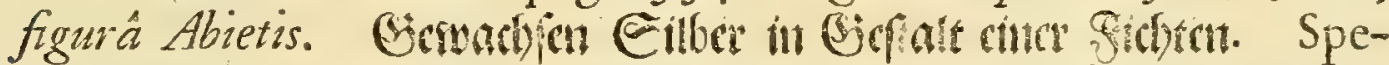
ner. Muf. 1. c. Argentum purum arborefcens undiquaque quafi

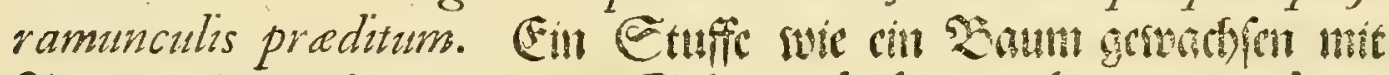

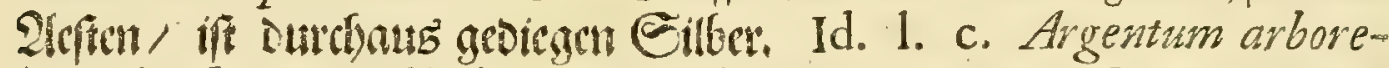
fens in figuram Abietis elatum album. Gesurdifn Eilber in (Sifralt cince Fidten, fort weis. Id. pag. I 37. Argentum fatim fum in figuram Arbufti concretum. Ein Enflut girstgen Eiber

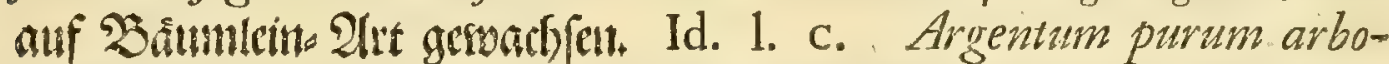

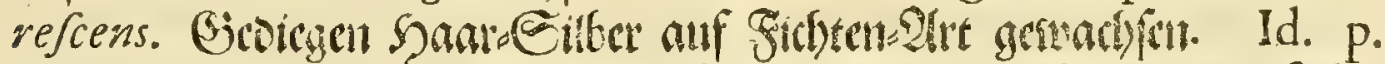
I 3 . De hujufmodi productionibus metallicis judico, transfudare ab xtu Terrx, vel igne in Fodinis accenfo, Argentum per poros Saxorum, \& hinc affumere figuras capillorum, uti Angentum fui coloris, purum putum, capillare, Sali:Eilfer nuncupatum, vel cryftallifationes quafdam fubire, uti præfens fragmentum, conferendum cum Regulo Antimonï Stellato fuprà exhibito in Fig. 7. Tab. VII. Longum nimis foret, \&c äzpordióverov, varias hîc enumerare figuras, quibus Argentum, aliave Metalla pura ludunt. Refervabitur hic Labor pro $P$ inace Mineralogico, quem ad imitationem Pinacis Botanici Baubiniani elaborare in animo

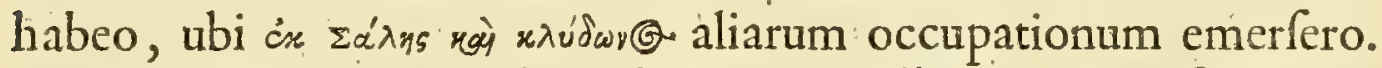

Fig. 3. Exhibet aliud productum metallicum. Forťifimo Igni Arenx in Retorta commifi menfe. Julio hujus Anni 1709. uncias 54. Venre Antimonii ex Valle Sexannina, Schams, Rhetice, qux præbuêre Spiritus acidi fulphurei drachmas 3. Grana 23. Antimonii verò in flores nigerrimos fublimati Unciam unam, cum drachma una femis. In fundo remanfit Antimonium ejufdem rurfus cum cruda minera ponderis. Horum Florum delineavi quofdam, qui quidem fcopo prafenti infervire vi- 
debantur, \&c egregiè confirmant id, quod fuprà de generatione falium volatilum expofui, \& in integra quidem ferie à fimpliciffima fibra ad mage compofitas ramofiores, fpiculis minimis lateralibus, veluti foliolis; ftipatas.

Fig. 4. Aliud fubminiftrat Problema mihi, quod ingenuè fateor, hactenus infolutum, rigentiffimx Hyemis productum. In orbibus vitreis Hypocaufti vifitationi xgrorum pauperum deftinati, Dic Seffratt Stube vocant, die 25. Jan. I >09. Sed \& alibi quoque, aliis diebus, innumeras vidi figuras hexagonas regulares, ex nive denfo agmine concreta \& conglaciata ortas, diaphanas, ejus magnitudinis, quam figura exhibet, unas aliis fuperitratas, qux memorix mex fiftunt rigidiffimam primam Hyemem, Inundationis Diluvianæ̌ fubfequam, quâ Cryßalli hexagon $x$ in vifceribus Terrx, Montiumve fuerunt, me conjectante, productx. Non quippe novam, fed antiquiflimam effe Cryftallorum, Fluorumve figuratorum productionem, alibi jam oltendi.

Fig. 5. Arbufculam filtit vel Plantam in Lapide fiffili ex Mylii Saxon. Subt. pag, 28. quam huic loco inferere volui, ut conferrem cum Fig. I. Dubius autem hxreo, an referri debeat ad Diluvianas Reliquias Plantarum, vel Naturx ludibria.

3I Fig. 6. Lapis eft fiffilis ex Lapicidina Oeningenfi Diœcefeos Conftantienfis, innumeris Stellulis per totam fuperficiem infignis, Dendritis affinis. Depicta habet nigricantia puncta minutiffima, ftellulas majores minorefque, arbufculas minimas, cuncta fubtiliffimo quafi penicillo expreffa, nec à commiffuris Lapidum, uti in Dendritis videmus, furgentia, fed medix Lapidis Planitiei fparfim impreffa; Qux circumftantia notam dat diftinctivam, fimulque occafionem cogitandi de alio modo, quo hx figurx generatx fuerint: fcilicet per exhalationes falinas, vel vapores aqueos falibus imprægnatos, qui humido abfumto coierint in ftellulas: vel falium ad inftar volatilium, co ferè modo, quo fimiles figuras generari videmus à frigore hyberno in orbibus vitreis. Qui Dendritarum Genefin pro conformi agnofcit, is $\mathrm{Ata}$ tuere neceflum habet non fluidum per totam Lapidis fuperficiem effufum, fed paffim minutarum guttularum formâ ei adhærens, diductis Tabulis in ftellulas fingulares concretum. llluftrandæ hujus Lapidis genefi apprime facit Experimentum, quod habui menfe Augulto Anni præfentis. Vitrum, in quo quartâ vice fublimavi Mercurium dulcem, calens extraxi ex Arena fervidâ, \& mox fundo parietibufque infra Mercurium adnatas vidi ftellu- 



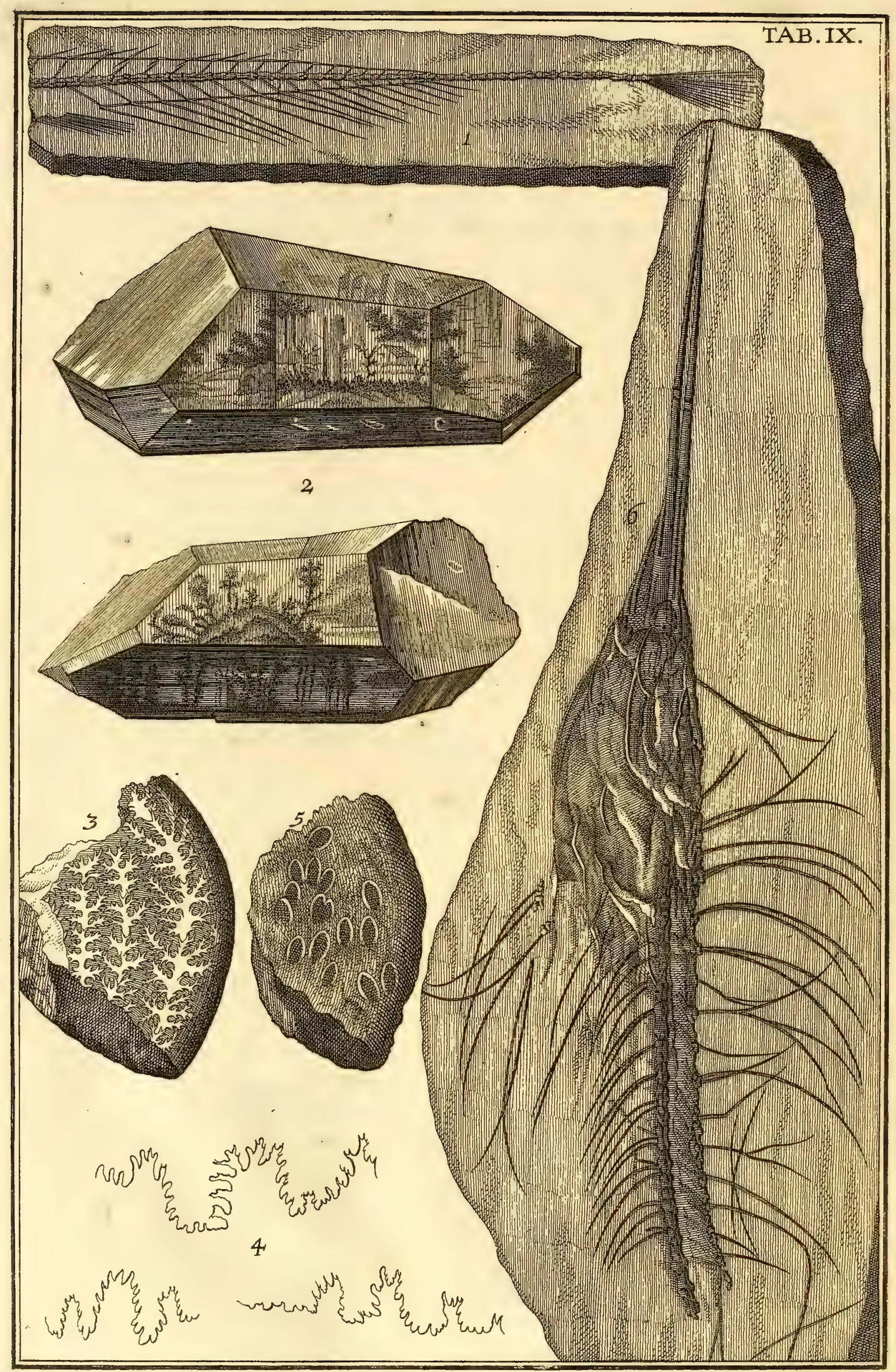

Dob ${ }^{m o}$ et $\mathcal{P}_{r u d} \mathfrak{d}^{\mathrm{mo}}$ (asparo Eschero, Reip. Tigurina Ducentumviro, Tener. (Clleg. Examinatorum Assessori, Amico optimo. 
las plures ab invicem diftinctas, fimiles prorfus figuris ftellaformibus in Lapide noftro confpicuis, rurfumque difparentes admoto igne; ut ita oculis ipfis intueri fuerit datum concretionem particularum volatilium Mercurialium, earundemque difperfionem. Ad hunc Lapidem referendum puto Rhoditem, non quidem illum Plinii Hift. Nat. Lib. 37, cap. I r. à Rofx fimilitudine in colore ita dictum, fed alium, quem multis infignem Rofis non equidem vidit ipfe, fed ex aliorum relatione defcripfit Gefner. de Fig. Lap. pag. I23. Rboditam verum, qui Rofas Stellarum loco (nam inter Aftroitas eum recenfet) exhibet $V$ elfch. Hecat. I. Obf. 44. Hunc, quem ante expofui, generationis modum participant figurx Dendritarum fimiles, obviæ paffim in fuperficie offrum folfilium, Unicornu folfilis, Marmorum, Acbatum, Cornutm Ammonis, alibique ftellarum formâ.

\section{T A B. IX.}

Caput \& caudam Tabulæ IX. conftituunt Pifces, caput quidem Fig. 1. delineat cauda Anguille Diluvianx in Lapide fiffili nigro Glaronen $/ 2$, jungenda $\&$ conferenda tum cum Anguillæ vivo originali, cui examuffim congruit, tum verò cum corpore Anguillæ Diluvianæ medio, reperiundo in Tab. II. ad pag. Io. Pijc. Querel. छo Vindic.

Fig. 2. Dendrites eft Cryftallinus, Lapis diaphanus hexagonus, in cujus finu confpicitur, præter maculas inordinatas, arbufcularum flavefcentium \& nigrovirefcentium feries. Rariffmum Naturæ in Alpibus Helveticis fummis ludentis productum: quod vel proptereâ fifto, ut novus pateat generationis Dendritarum, feu figurarum arboriformium modus. Cryftallorum materiam olim fuiffe fluidam aliunde certum eft : certum quoque, immiftam perfepe fluidæ huic in folidam cryftallum concrefcenti materix varias particulas heterogeneas, fluida alia viridia, nigra, rubra, flava, alitervè colorata, quæ nunc Graminis, Mufci, Straminis, Acuum, figuras mentiuntur: Alibi teftatum hoc reddo ex variis Obfervationibus, fpeciatim verò in $D$ ptione Itineris Alpini 1705. Idiomate vernaculo edito Tiguri in Tomo In. Scbweizerifch. Natur-Gefchicbt. Linguâ vero Latinâ ad Illuftrem Societatem Regiam Anglicam miffo. Huic ż Cryftallo, qux duplici facie fefe nobis fiftit, accidit, ut dum fefe difponeret precipitata \& formata in Lapidem, ex fuperiori Tabulato cavi fornicati defluxerit materia fluida heterogenea, quæ fefe in poros cryftalli infinuavit, \& inter plures nullius or-

$$
\mathrm{F}_{2} \text { dinis }
$$


dinis maculas efformaverit fpeciem hanc Dendritx, ita nempe ut materia gravior primò deflua dederic Truncos, levior polt fecuta ramos, eo ferè modo, quo Lacrymæ vitrex Belgicæ ex gutta vitri fluida in frigidam conjecta longam caudam poft caput trahunt, imò eo modo, quo argilla Aqux, mixta in Liquamen, polt obliquè ad decantationem locata circumcirca vafis internos parietes arbufculas format, ob partes aqueas per medias terras, qux parietibus adhæérunt, defluas.

Fig. 3. Exhibet foliaceas Carduo fimiles impreffiones, quibus exornantur perplura, omnis magnitudinis, Ammonis Cornua, quorum in his noftris Regionibus largus eft proventus. Ita hæc ornamenta illudunt imperitorum oculis, ut pro foliis Cardui revera fpiris Cornuum impreffis facile afpectent, \& in comparationem adducere poffint Ova Pafchalia, quibus circumducta folia Graminis, Petrofelini, aliusvè Plantre figuras perbellè imprimunt. Aft enim verò probè attendenti, \& ftructuram horum Lapidum figuratorum examinanti patebit, effe nihil aliud, quàm lineamenta extrema articulorum, quibus Cornua Ammonis per totam fuam circumvolutionem diftinguuntur, ut occafronem inde fumferit Wormins Mus. p. 86. articulationes hafce conferendi cum vertebris fpince ferpentis aut Anguillx, \& hoc genus Cornuum Ammonis nuncupandi Lapidem feleton ferpentis referentem: ipfa autem hxc lineamenta foliacea eleganter ita defcribit: Juperficies Lapidis exterior à Natura crebris depicta eft ramufculis quafi Eo linearum ductibus folia Arborum quodanmodo. referentibus, qui ex articulationum anfractibus ortum trabunt. Et $L i$ fterus de Cocblit. Angl. fub Tit. 2. \& 5. harum figurarum meminit quoque his verbis. Maxime in frattis (Cornubus Ammonis) articulos quofdam oblervare licet: Go in nonnullis iidem ipfi etiam exirinsecus apparent: Scil. quodam opere foliaceo (foliacề piiturâ) fingulos articulos difinguente. En rurfus novam, quâ figurx Plantis fimiles in Lapidibus formari queant, rationem!

Fig. 4. Eadem exhibet foliacea ornamenta ex Liflero.

Fig. 5. Aliud fiftit Cornu Ammonis fragmentum, \& in eo sonamenta foliacea ita impreffa, ut exprimant ferè folia trina fuperna Gguram Lilii Gallici.

Fig, 6. Alium reprefentat Pifcem in Lapide fiffili Glaronen$f i:$ in quo memorabiles cumprimis funt antenne feu cirri prelongi ex capitis anteriore parte protenfi.. Dubium tamen adhuc $\mathrm{eft}$, ad quamnam $\mathrm{Pif}$ is hic fofflis pertineat viventium Familiam; Talismodi enim cirros habent, ex Anguilli-formium Profapia, I. Silurus Rondeletii, Gefneri, qui \& Glanis Salviani, 



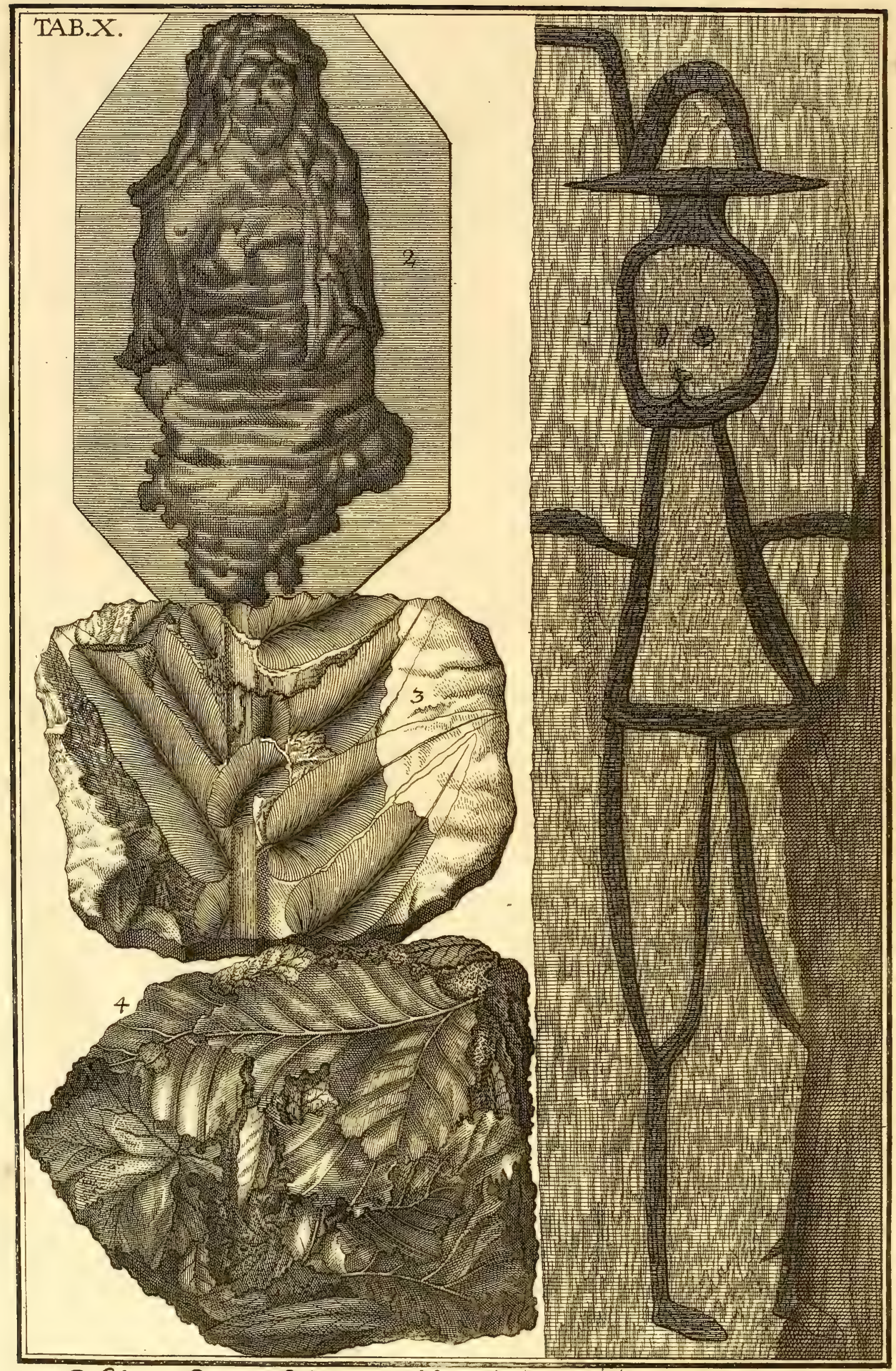

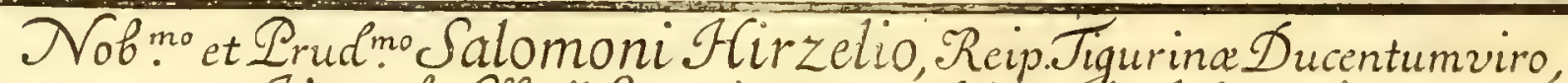
Tenerab. Cllegii Examinatorum Assessori, Amico optimo - Fuber del et fulp. 
\& Aldrovandi Lib. V cap. 5. Willougbii Pifc p. I 28 . II. Bagre Pifcis Brafilienfis barbati \& aculeati varice Species, quas ex Marggravio defcribit Willougbii pag. I 39. Ex Pifium corpore contractiore, vel faltem non admodùm lubrico, qui Pinnis ventralibus carent, Genere poffet huc quoque trahi cum roftro fuo Guébucu Brafilienfibus Marggrav. Xipbice affinis, Willougb. p. 163 . Proximè tamen \& quoad figuram, \& locum natalem accedit Silurus, qui Lacuum quoque Helveticorum, \& Bodamici, Moratenfis, eft incola, in profundo corum degens, ut proin, f1 Silumus hic foffilis ante Diluvium Lacus proximioris Bodamici fuit hofpes, centenos aliquot pedes in altum fublatus, \&z ad Glaronenfem Lapicidinam delatus infigne fit horrendæ $\mathrm{re}^{2}{ }_{35}$ volutionis argumentum fanè rariffmum, quoniam \& ipfi hi Pifces funt perrari. In cirris hifce memoranda inprimis elt decuffatio verfus extremitates, qux illorum flexibilitatem arguit, \& roftra aliorum Pifcium licet acuum inftar protenfa, fed rigida, ab analogia excludit.

\section{T A B $\mathrm{X}$.}

$I^{1}$ n. Tabula hac X. \& ultimâ, wis èv oxyvorga థía fiftitur quadruplex figurationis naturalis facies. Ad hanc in modo, ordine, Tempore, \& Efficiente varietatem qui attendit, de obviis rerum formis judicare difcet.

Fig. Monftrum fiftit ex Natura \& Arte formatum, virunculum pedalem cum omnibus fuis membris rudi Rulticano penicillo depictum in Ligno Fagino, quem ex dono Rev. Dn. Hannbardi, Vitodurani, V. D. M. Kurzdorffenfis in Turgo$j a$, procurante Cl. D. D. Huildrico Hegnero, Vitodurano Medico, poffideo. Qux mea de hoc Pygmæo mens, patebir ex

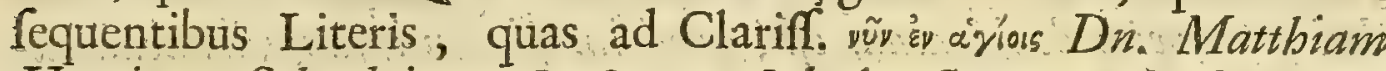
Henricum Scbachtium, Rectorem Scholx Cartemiindenfis in Fio nia die I 6. Nov. 1699. perfcripfi, occafione Tractatus à laudato Viro promiff de Figuris Hominum in Vegetabilibus. Eft prope Fravienfeldam, Turgoje oppidum, fylva, è qua ad ufus domefticos deductà \& diffecta Fagus in centro ferè Trunci, duos vix à medulla media digitos, exhibet hunc virunculum. Hoc an Naturx genimen fit, an Artis productum, mecum penfitabunt omnes, quibus Nature vis \& lufus ex tot Animantium monftroforum, Lapidum Figuratorum, atque Plantarum prodigiofarum productionibus eft perfpecta, quibusve Artificum nihil non defraudantium technæe non minus funt fufpectx. Indaganti mihi caufam mirandi hujus effectus hæ fubnatx funt cogi- 
tationes, qux Rufticis facilius in mentem venirent, quàm iis ; qui diu noctuque fedent inter Libraria organa. Confuetum eft agrefti proli, nominis fui famam, \& decus, cum figuris variis infcribere Corticibus Arborum, lævioribus præfertim, ut funt Fagorum. Ponamus nunc virunculi hujus, non metallici, fed lignei, imaginem cortici hujus Fagi incifam fuiffe, id quod fxpe fit, dum annum ageret quartum vel quintum, \& incifuras quidem ultra corticem ad peripheriam Ligni ipfius penetrâffe, inde autem, quantum ex craffitie Arboris conjectare licet, effluxiffe fex vel plura Annorum Luftra; quid, quxfo, facilius eft, quàm ftatuere, quod in hac quinti Anni circumferentia remanferint incifurx fatis latx atque profund $\mathfrak{x}$, qux novâ fucci nutritii acceffione obliterari non potuerit, véltigia, ambientibus interim hanc pictam fuperficiem tot ligni novis circulis, quot vixit polteà Annos ipfa Arbor, ficque imaginem hanc longè poft fe relinquentibus, veluti Utero claufum abortum? Plaufibilius reddit ratiocinium, quòd incifura fuerit haud dubiè tam profunda, ut plurimi ductus fucciferi fuerint difciff, ac nutrimentum, quod in interftitium illud effluxit, non ita potuerit affimilari, ut fibræ fuccreviffent lignex tales, quales videmus in reliquis $\mathrm{Ar}$ boris haud vulneratx partibus, ficuti videmus nunquam ita offa fracta coalefcere, quin callus per totum circumferatur xtatem ejufque veftigia fefe confpectui dent, non dicam periti Anatomici, fed vel è vulgo rudis. Addit rationibus allatis pondus, quod ex relatione Donatoris in eodem Fagi Trunco diffecto hinc inde vife fuerint characterum etiam inciforum relicta veftigia. ${ }_{36}$ Imò verò extra omnem dubitationem ponunt ratiocinium bocce preffarim extrorfum, à fucco sutritio extravafato, fibrarum, que fuccreverunt, veftigia in ip/is Ligni folidi (cariofum enim Eo veluti gangrana denigratum eft, quod imaginem ipfain vinunculi exprimit) fibris incifure respondentibus conspicua. Judicet Lector benevolus, an hæc, qux ad Clariff. Schacbtium feripfi, non potiora fint cogitatis Clar. Dn. Foh. Chriftophori Gottwald, qua crucifixum in medio pariter Fagi Arboris Trunco depictum attribuunt Natura fimplici impetui pro diversa materie palfive locique conftitutione operanti, vel Morbo cuipiam Arboris tabifico, quo defpumate fuccorum fermentantium feces per fubfantiam fe diffundant, $\Xi^{0}$ diverfos occupent angulos, variafque adè caufentur picturas. Mifcell. Nat. Cur. Dec. III. Ann. IX. \& X. Obf. I 58. Ita opinor nemini polthac figent crucem Crix in medio Ligno Auguftx Vindelicorum reperta, cujus meminit Erafm. Francif. Sine.. Luftgart. pag. I55. Crux cum initiali Litera

H. in 


\section{I L U V I A N U M.}

H. in Fago Mifc. Cur Dec. III. Ann. V. Obferv. 29. Crux in Ligno Fagino è Prxfecturâ Schenckenbergenfi illata Bibliothecx Bernenfi. Verba Danica Literis Latinis expreffa in Fagino Ligno reperta. Mifc. Cur. Dec. I. Ann. Vi. \& VII. Obf 4. Fur è Patibulo pendens in Fago depictus Mifc. Cur. Dec. II. Anno VII. Obf. 239.

Fig. 2. Exhibetưr infignìs Naturx, ut vulgò vocare folent caufarum merè naturalium, ex certo Mechanifmi principio aliud quid, quod aliam originem agnofcit, effigiantium productum: Virunculus in Ligno nodofo ac tortuofo confpicuus, cui obfcurior macularum color faciei, capillitii naturalis vel artificialis, pectoris, Mammæ dextræ, \& totius fere Trunci medii fuperioris formam quandam conceflit, quam nec artifex quifpiam ut in pracedente figura, dedit, nec Natura ipfa, fr cum Scholafticis eam introducere licet, intendit, nec feminale quidpiam ab Homine deciduum effigiavit, fed imaginatio potius noftra, ut in Dendritis Arbores, in Achatibus novem cum A polline Mufas, \& mille variantes picturas, frbi præfentat. Nil quider hic confpicitur, quod non Legibus Motus fir congruum, nîl tamen, quod humanam fapiat, vel etiam Satyrorum fylveftrium, indolem, nîl, quod tam nobilis progeniei originem; verbo, productum eft foecundæ admodùm noftræ Phantafiæ, nos ipfos jucundo quodam errore nobis ipfis fiftentis. Ita vidit perverfa mea Imaginatio in Lignis Juglandium \& Pyrorum Capita, Moniales, Monachos, \& quid non? quibus Conclaviun parietes, \& Capfarum valvæ fuperbiunt. In eadem cum his Lignorum maculofis figuris Claffe locari merentur Stalactite feu Stiriळ lapidex in Crÿptis fubterraneis paffim obvix, quae referunt $\mathrm{Ho}$ mines, crura, brachia, organi Pneumatici fiftulas, \& quicquid foecunda Phantafia noftra parere apta nata eft.

Quodque fidem fuperat, Stillantes Marmora guttas Efficere, Eo veris reddere Imaginibus.

Jurares Sipylo Nioben spectator ademtam Uxoris ftatuamque bíc fupereffe Lotbo!

Pbinea quis dubitet, Cepbalique in Marmore Cervi, Ulterius fiquis progrediare, Canem?

Perfea Gorgonios nempe bic pofuiffe Colubros Credibile eft, imifque occubuiffe locis.

Inde rigor Steropum, ferri qui pondera mulcent, Infuicantque tuas, Buda, frequenter Aquas.

Uti Antri Baumanniani miranda defcribit Foh. Ludoricus Füre-3i 
rus in Fob. Georg. Bebrens Hercyn. Curiof. cap. I. Non fanè fanctiori loco ponenda autumo à Sanctis Helvetix Proto-Martyribus, Felice $\mathfrak{E}^{\circ}$ Regula, à Legione Thebra profugis, impreffa digitorum, qux Glaronæ vifuntur in Petra eminenti, Burg dicta, cava, qux reverà aliud nihil funt, quàm ftalactitarum, nubem pro Junone Sancticolis offerentium, ludibria. Et quis enumeraret hujus farinæ figuras alias, qux fuperftitioni Gentilium

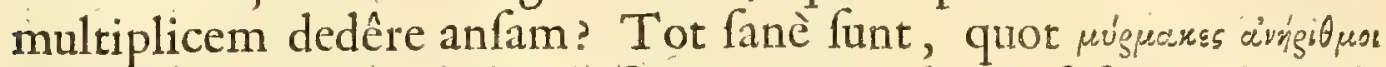

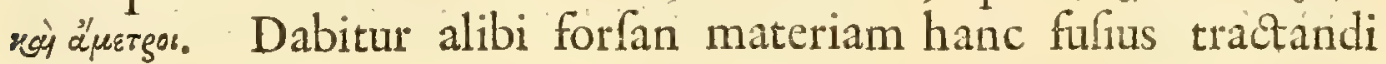
occafio.

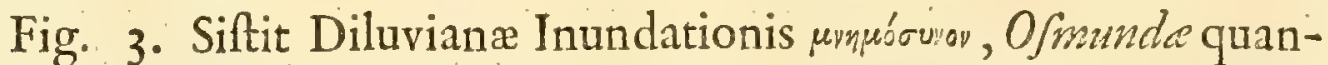
dam fpeciem, haud ita pridem ex Angliæ Carbonariis Mufeo meo illatam munificentia amiciffimi mei Woodwardi. Folium unicum hujus Plantæ fiftit Pbyllitidis mineralis nomine Lauidius Litoph. Britt. n. 190. Tab. 5. Adnumerandam autem effe Figuram hanc Vegetabilium Regno indicat non fuperficialis quiedam frmilitudo, fed integra in caulibus, foliis, fibris etiam minimis convenientia, ipfa frpe, qux in hoc faxo fefe obtulit, foliorum fuperftes, \& rafilis, textura.

Figura tandem 4. Plantarum polt Diluvium impreffarum fpecimen fiftit in Tofo foliis Arborum, Fruticum, \& Herbarum, fape etiam Cocbleis terreftribus pregnante, paffim in Helvetia, \& alibi extra eam obvio, productis Poltdiluvianis, imò etian recentiffimis accenfendo. Ecquem enim latet, Tofos èx Aquâ Tofaceâ, petrificante, id eft, partibus terreis imprægnatâ pronafci, \& ad ipfum fenfum accrefcere? Tofis vel Tartaro Thermali imprimi rerum futio injectarum figuras? Accedit notabilis hæc Circumftantia, quòd ea femper folia Quercus, Fagi, Alni, Salicis, Aceris, Oftryx, Vitis Tofis impreffa reperiantur, quarum Arbores fuperftantes, vel proximæ fuere parentes; imò, quod adhuc magis pro novitate, \& Vegetabili Regno pugnat, in mediis Tofis fepe reperiri folia ipfa, tanquam Archetypum Ectypo, five veftigio ipfi, adhuc immanentia, una cum pediculis, licet plerumque teneriora multò, \& vel in totum, vel ex parte corrofa, in pulverem mox collapfura. Qui Synonymorum eft amator, huc referre poterit Tofum candidum Miferim, in quo folia Quercus . 0 Alni fint impreffa: Kentm. Foll. 38. Tofum, cui figura frosdium Arborum à Natura impreffa. Wagner Hift. Nat. Helvet. 323. Pietra Tartara Figurata di foglie e Rami di Rovo. Imper. Hilt. Nat. 58.5 .

Nunc Tabularum quidem finis, nondum verò Tractationis ipfius, nondum Herbatio abfoluta ; fuperfunt Plantx, harum- 


\section{I $\quad L \quad U \quad V \quad I \quad A \quad N \quad U$.}

que umbrx, pictrve imagines, integrx arbores, Trunci, rami, fructus, Ligna, folia, femina, inde à Diluvio relicta: Plantx aliis quoque Scriptoribus memoratx, in Lapidibus obviæ, quas nullo quidem memorabo ordine, quemadmodum in Herborifatione nunc Arborem offendis, nunc Fruticem, hîc Gramen, ibi Hieracium. Sic demùm fatisfeciffe puto Titulo, quem Libro præfixi, Herbarii Diluviani, cui infunt, ut hactenus vidimus, Herbx verx, qux ante Diluvium extitere, Antedilivisne jure dicendx; porrò Diluviance in ipfo Diluvio, vel occafione ejus, eo tempore, quo Strata fueie formata, \& confolidata, effigiatæ, quò veniunt Dendrites, eifque affines: tandem Poftdiluviane, poft Inundationem illam fatalem Lapidibus impreffæ; inque iis. fepultæ, quò referenda funt folia Tofis impreffa.

Cifites poterit vocari, a xwòs hedera, Dendrites ille Musei 38 Wormiani, pag. 45. Per cujus Truncum bedera ferpit, diftinguendus tamen à Ciffite vel potiùs $C y$ /ite $\mathrm{Plinii} H$ Hif. Nat. L. 37. c. Io. qui Aetite Lapidi propiùs accedit. Ita enim Sonat Textus: Ciffites circa Copton nafcitur, candida, Ð0 videtur intus babere partum, qui fentiatur etiam frepitu, conferendus potiùs cum $C_{2}$ fite, quem eodem Capite ita defcribit Plinius. Cifjites in candido collucet Edere foliis, que totam tenent: Narcißjtes venis etiam Edere diftincta: Ubi Narcifiten cum Ciffite confundere videtur Hiftoricus, id quod etiam obfervavit Gefnerus Fig. Lapid. pag. 12 I. I22. Ciffites obtentu haud difficilis ei, qui prope Aquas petrificantes habitat, \& commodo loco, ubi Aqua incruftationes fuas applicare potelt, Hederam plantat. Talismodi Cifliten, Hederam in Tofo Rorbacenfi confpicuam habuit quondam profundæ \& copiofæ Literaturæ vir Dn. Gottbardus Heideggerus, ex Paftore Rorbacenfi vocatus Infpector Alumnorum Tigurinorum. Nondum tamen Ciffitæ Pliniani Titulum hic meretur, hic enim videtur Achates, aliavè Gemma, vel Marmor Hederæ foliis diftinctum, non rudis Tofus.

Memorantur Plinio 1. c. Achates fimiles limitum (leg. al. palmitum ) floribus, quos in Thracia, Eo circa Oetam, Go in Par nafo, $\sigma^{\circ}$ in Lesbo ac Mefene, G Rbodo reperire fcribit. Pertinent hi ad Naturæ lufus, uti quoque $N$ arciffi, Hyacintbi, Tulipe, Paronice, Gelfamince flores in Jaspidum generibus mira arte effigiati, quos memorat Kircher. Mund. Subt. Lib, 8, pag. 28.

Salicis folium in Lapide fiffili Oeningenfi confpicuum, Diluvianum delineari juffi in Tab. IV. \& in Pifc. Querel. छ V indic. Salicis folia Poltdiluviana, his nottris temporibus, vel ante 
pauca Secula fepulta in Tofo vidi non femel Stallikona, qui Ditionis Tigurinx eft Pagus, ad Albii montis radices fitus, ubi integer tractus montofus elt Tofis foliojis prxgnans; Merentur hi Lapides Iteitarum vel Salicitarum Titulum, non verò Saxa illa in Helvetia paffim reperiunda, quæ in externa fuperficie \& ubicunque franguntur, Salicis folia, imò \& Leguminum, Seminums figuras affabrè exprimunt, vel potiùs mentiuntur. Hiftoriam Lapidis hujus integram heîc inferere incongruum judico. Ampla fatis defcriptio extat in Specim. Lithograph. Helvet. pag. 30. fub Titulo: Lentes lapidec friatc, utrinque convexa, vitreis figurâ fimiles, in maffa lapide $\hat{a}$ vario fub Schemate conpicuse, nec non in Mifc. Cur. cit. pag. 63. item in 'Ouesw. Helv. feu Itin. Alpin. Ann. 1702. pag. 4. Edit. Londin. (pag. 7. Edit. noviff. Lugd. Batav.)

Qux porrò enumerand $x$ veniunt Plantx Lapidibus impreff $x$, quas Litbopbyta vocat Luidius, vocabulum hoc in alium torquens fenfum, quàm quo vulgò apud Botanicos accipitur; Tourneforinus, unus ex precipuis feculi hujus Botanicis Litbopbyton vocat Plante genus fubftantice veluti cornee, Eo Lapidem inter ac Lignum medice, cui plerumque adbarefcit cortex vel fibris contextus, vel Tartari emulus. Inflit. Rei Herbar. pag. 573. differentiffimo fanè fenfu, ut ex fpecierum enumeratione patet) ex funt vel malè denominatx, fcilicet non cum analogis Plantis bene collatx, qux collatio Botanicorum eft, in Hiftoria Plantarum benè verfatorum; vel denominatx duntaxat, non verò Seulptori ad delineandum traditæ: vel malè fculptæ: vel aliis defectibus laborantes, ut ad fupra recenfitas certò reduci nequeant; dignæ nihilominus recenfione, vel ut ab aliis ad fua Synonyma referantur:

Epiphyllosperma mineralis Scutellata, Pbyllitidis folio quatuor ad minimum nervis infignito. Luid. Lithoph. Britt. n. I \&o.

39 Filix femina mineralis. Luid. n. I 8 r. cui affocio Lapidis fcif fili ferè fimilis 5. frufta filicem (lege Filicem) exbibentia. Günf

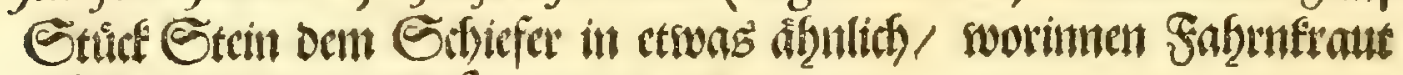
sulchent. Spener. Muf. pag. 92.

Polypodum minusminerale, pinnulis denfins dispofitis. Luid. n.I82. Polypodium minerale Lonchitidi majori accedens. Luid. n. I83. Foliorum quorundam mineralium pediculi compreffi. Luid. n. I 85. Litbopteris leptopbyllos, fue Filix mineralis longioribus $\sigma^{\circ}$ angiflis foliis. Luid. num. I93.

Lithosmunda minor Buxifolia. Luid. n. I96.

Lithotrichomanes vilgari fimile, pinnularum ordine alio furm firm, 


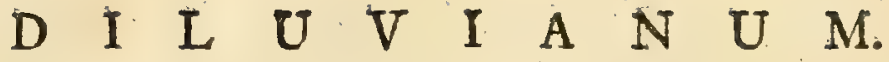

fim, alio deorfim jpectantibus. Luid. n. I98.

Litopbyton finuatum facie arundinế, five Striatula Carbona. ria. Id. n. 199. Lithopbyton atronitenti facie politifimum Corufcatula dictum. Id. n 203.

An Caulis cujusdam Plante mineralis? Id. n. 200.

Lithopbyllon gelafiris quibusdam falebrofum, Malleatula dis Etum. Id. n. 204. Malleatula minor five fquamofa. Id.n.205. Quinquefolii, Trifolii \& Fragarice folia Lapidibus impreffa. Raj. de Mund. Orb. Mutat. \& Interit. Edit. German. pag. I 43. Planta incognita in Minera Ferri. Wolfart Val. Hanov. S. ro. Fig. 6. videtur Misci Species, vel referenda ad Fig. 5. Tab. VIII.

Cnobryctis minor Vicie folios. C. B. Luid. p. Io8.

Folia Afragalina, Fraxinea. Id. 1. c.

lacece cujufdam aut Centaurei majoris capitulum. Id. 1. c.

Conferva Plinii. Id. 1. c.

Saxifraga graminea puiflla parvo flore tetrapetalo. Raji Synopf.

Meth. Id. 1. c.

Chrysantbemi nefcio cujus flos petalis bifidis. Id. pag. Io9.

Abietis cujufdain ramuli cortex. Id. 1. c.

Arundinis vallatorice Radix. Id. 1. c.

Lapis fifflis cinereus cupro dives, in quo fpicæ Frumenti. Myl.

Saxon. Subt. pag. I6. Fig. 4. ad pag. 8.

Capilli Veneris in fiffli Lapide Manebacenfi. Id. p. 3o. Fig.

2. ad p. 19.

Buxus Id. Fig. Io. 1. c.

Securidaca major. Id. Fig. Ir. conferenda cum Filice mare

Ejufd. pag. 39. Fig. 2. ad. pag. 26.

Filix femina minor. Id. Fig. 3. 1. c.

Ab/intbio Romano fimilis. Id. Fig. 4.

Sopbia Chirurgorum. Id. Fig. 6. pag. 40.

Serpillum. Id. Fig. 7. 1. c.

Thymus feu Serpillum bortenfe. Id. 1. c.

Herbario noftro Diluviano inferi merentur Ligna quoque Sub. terranea, fo/filia, quo nomine non intelligo Arborum radices, Truncosvè imos ex refectione in Terra fuperftites, non Mineralia Ligni formam mentientia, ut funt Marmora Salisburgenfia, aliavè venarum \& colore \& figura Ligna æmulantia, Venas quafdam Ferri pariter quoad externam fpeciem Ligniformes, quales in Monte Pinifero Germanix aliquando offendi, non Carbones Foffiles, qui ex Bitumine funt concreti: non Saxa Ligni formam aliqualem oftentantia, qux paffim in Curioforum Mufeis pro $L$; $\mathrm{G} 2$ gnis 
gnis petrefactis, five Litboxylis reponuntur; fed vera Ligna, licet non femper inflammabilia, \& pro varietate locorum Pyrite particulis, vel arenulis, vel crèa, aliâva materiâ in poris fuis repleta. Ligna veros Ligni characteres fecum ferentia, ut componantur I. Ex fibris ligneis fifulo/is, in fafciculos coagmentatis, Eo in retiformes plexus contextis. 2. Ex Utriculis earundem macu-

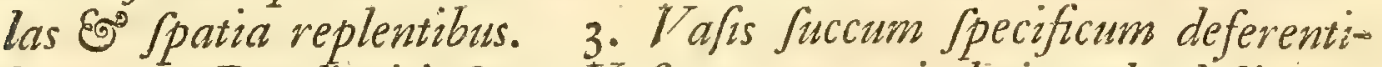
bus. 4. Peculiari infuper Vafis genere aeri derivando definato, 60 Animalium Trachee ac Pulmonibus refpondenti: tecto infuper fuo Cortice, qui rurfum iifdem ferè, quibus Lignum, partibus conftat, de quibus Raj. Hift. Plant. L. r. cap.4. p. 6. \& fufius Anatomici illi infignes Lyncei, Marcellus Malpigbius \& Nebemias Grew. Adde jacentes fub Terra Truncos, ramos, folia, fint Etus, licet rariffimè omnia fimul in eodem loce adfint. De hoc Ligno foffili, quod paffim in Europa univerfa, prefertim in Terra uliginofa, paluftri, jacet fepultum, aliis fuas linquo Hypothefes, qux Lignorum hanc genefin ac depofitionem adfcribunt vel Idolo illi tavroxgárwgs, fi Dii velint, quem Archai nomine vulgò infigniunt, vel Hominibus ipfis illa fepelientibus, vel Inindationibus Poftdiluvianis, vel Ventis, vel Terramotibus, quibus refutandis pretiofum nimis mihi videretur Tempus, quàm ut impendi debeat. Jacebunt errores, ubi firmo ftabit talo erecta Veritas, Diluvii fundata ruinis. Ego quippe impræfentiarum oftendere allaborabo, non aliunde derivandam effe Lignorum horum fubterraneorum originem, quàm à fatili illâ Diluviali ftrage, preunte Clariff. Dn. Woodwardo, qui Commentarii loco, quod fpero, habebit hafce Meditationes in aureolum fuum Geograpbice Pbyfice Latio à me donatum Tractatum, fpeciatim verò in pag. 97. Ubi ex obfervationibus factis in ipfis locis Arborum fubterranearum natalibus, circa earum Ligna, fitum, quem obtincnt inTerra, aliifque circumftantiis demonfraturum fe promittit, quod ibi depolita fuerint in ipso Diluvio, E inde ab illo tempore bic jacuerint. Ligna hrc fubterranea vera Ligna fuiffe ex Inundationibus, imprimis Diluviana, in Terra relicta, demonftrat Büttner. p. 189. Ex Lignorum à Lapidibus ambientibus difincta fubftantia, gravitate fpecifica, Circulis annorum, Cortice rugofo, colore inter corticem \& truncum medio, ligni porofitate, fragmentis fxpe à vermibus corrofis, putredine, medulla, ramis, nodis ad ramorum exortum, fifflitate \& frangibilitare, Ligno propriâ, differentiâ Arborum fpecificâ, variantibus coloribus. Ligna qux, non dicam inflammabilitatem, colorem, figuram externam, accidentia aliis quoque corporibus 


\section{I I U U V I A N U M.}

Naturalibus communia, fed feructuram internam Ligni habent pro Vegetabilibus omninò habenda; uti corpora, qua quoad partium internarum ftructuram Animalia referunt, pro Anizmalibus; Nemini videbitur dubia hæc Regula generalis, qui Anatomiam Vegetabilium \& Animalium juxta mentem \& obfervationes $\mathrm{Mo}_{-4}$ dernorum intelligit, non fortuiti cafus, fed Divinæ originis ftructuram attento adfpicit oculo, \& fpeciatim quidem in feminibus, Fructibus, ovulis ipfis delineatas jam, licet nondum evolutas partes nobifcum miratur. Ubicunque igitur Folia, Ligna, Fructus, Semina, Pisces, Infecta, Offa, Conchas, Cocbleas, Crufacea vera realia offendis, ibi originem ftatim ex ovo Regni Vegetabilis vel Animalis fimul agnoíces; imò nec originem duntaxat, fed quoque paulatinum incrementum ad eum ufque ftatum, in quo reperiuntur. Qui aliter fentit, Regna nefario modo commifcet, \& ordinem ipfum Naturx vel fubvertit, vel non intelligit, certiffimum licet in tanta obfervationum luce. Ut tandem quxetio reftringatur ad modum, tempusvè, quo Arbores fubterranex in hrc, ubi reperiuntur, loca, fuerint delatx? De fitu Arborum fubterranearum Belgicarum fpeciali obfervat $S c b o o-$ kius de Turfis pag. 90. Omnes Arbores plerumque unam plagam refpicere mundi, namque Radices inter meridiem Er occafum, Truncos verò inter ortum atque feptentrionem porrigi. Cui Phxnomeno non fanè frivola hrc quadrat ratio, quam fubjungit, quid Natura ibi, ubi tum radices, tum Trunci pofiti videntur, aptior Sit; quàm alibi ad vim progenerandi prodendam. Inundationis alicujus fatalis directio hæc Lignorum \& parallelismus eft indicium: fitum, quem memorat Schoockins fpecialem obfervamus nos quoque in Helvetia, licet hæc Regula non fit fine exceptione, frepeque fine ordine jaceant depofita Ligna. In Fluctibus Diluvianis certam fuiffe directionem, fpeciatim poft ftratorum fracturam, \& demerfionem, ex multifariis Experimentis undecumque collatis tandem eruendam, colligere licet ex variis Helveticæ Naturalis Hiftoriæ Phænomenis. Unicum nunc memorâffe fufficiat. Lacus Helvetix præcipui Bodamicus, Grypheuss, Papiconenfis, Tigurinus, IV. Civitatum Sylveftrium, Thunenfis, Genevenfis portio, Brientianus paralleli invicem funt in directione à SO. ad NO. circiter, \& fic quoque Valles, per quas fluunt, montofaque Juga, ripas claudentia, vallesque formantia. Porrò in fitu adnotanda venit profunditas. In Turfifodinis noftratibus reperiuntur Ligna a 10. I2. I6. pedum profunditatem. In fundis nonnullis prope Urbers Brugenfem, dum ad 10. vel 20. uinas foditur, integrie fylie reperiuntur, arborum-

$$
\mathrm{G} 3 \text { quse }
$$


que folia $\sigma_{0}$ Trunci tam exactè adbuc comparent, ut Species Arborum dignofic, E foliorum etiam feries, fingulis Annis delapfa, diflingui optimè pafirt. Boet. de Boot. de Gemm. Lib. II. cap. 158. In profunditate pedum 39. Fontium Mutinenfium Stratum paluftre duorum circiter pedum apparet I. ex Funcis, Plantarum foliis ac ramis congefum: \& huic fimile aliud infra 52. pedum profunditatem memorat Celeberr. Bernhard. Ramazzinus de Font. Mutinen/. admir. fcaturig. pag. 20. Binas en obfervationes, unam ad Helvetice occafum, alteram ad ortum factas, qux profundiori quidem fitu; quàm Helvetia ipfa, Ligna depofita oftendunt; nec mirum, devolutos utrinque ex fummis Alpium Helveticarum ftratis fractis Arborum Truncos, aliaque Vegetabilia à majori Terræ mole fuiffe obruta, quàm verò in noftris Regionibus Alpinis, ubi fæpè vix unius, duorumvè pedum profunditatem habent cefpites bituminofi Turffa dicti. Neque in Vallibus Helveticis duntaxat reperias materiam hanc Vegetabilium fermentatione putredinosâ corruptorum, pluriumvè confervatorum, qux Turffe nomine vulgò venit, fed quoque in $\mathrm{Pa}$ fcuis Alpinis, in fummis Alpium, ubi nullx amplius Arbores crefcunt, cacuminibus, ut alibi pluribus teftatum reddam. Pergo cum chariflimo Woodwardo, quid ingens effodiatur borum Lignorum (fubterraneorum) छo in magnis quidem fragminibus, nimerus è. Terra quarundam Infularum, ubi nille Arbores crefcunt, nec plantari polfunt, propter ferociam Ventorum, ac tantam Tempeftatum aifteritatem, que non patitur, ut ulla Vegetabilia ultra Fruticum altiudinem affurgant, nifi vallis aut aliis id genus munimentis ab injuriis externis deferidantur, uti in Hortis Infulanis paf42. Im videre licet. Speciatim adnotari meretur Lignum piceum छo abiegnum in Anglia fubterraneum, non fupraterraneum. TeAtem habemus graviffimum Fulum Cefarem Comment. de Bell. Gallic. Lib. V. fub init. UbiBrittannis proftare dicitur materia cujufque generis, it in Gallia, prater Abietem $\sigma^{\circ}$ Fagum. Idem obfervatur in Hollandia \& Zelandia, ubi Ligna foffilia vocantur. vulgo Keenen, Kienboomen, Kienhout, quòd vulgò perfuafum fit, ex Pinorum Sobole bac effe, nam nomen $\mathrm{Keen}$, aut $\mathrm{Kien}$ $P$ inus inter Belgas ferre folet $\therefore$ ficut apud nos quoque Helvetos notum eft idem nomen, Kien, Kienbolz: Hoc autem Arboris genus non apud imos Belgas crefcit, telte Scbookio Turff. pag. 74. 79. At ne quis exiftimet, Ligna fubterranea feu Anglica, feu Belgica non effe ex Pinorum genere, habemus non Truncos duntaxat, \& ramos, fed ipfos quoque Conos, ex Brittannico folo erutos, fpeciatim ex 'Agro Ceftrienfi; tales quoque effodimus 


\section{I L $\quad$ U $\quad V \quad I \quad A \quad N \quad U$.}

in Turffifodinis nofratibus $\mathbf{I} 2$. \& plurium pedum profunditate, juxta cum Avellanis, quales ex Anglice Infulx $V e c t i$ quoque recepi. In profunditate pedum 26. Coryletum cum fuis Nucibus adbuc incormptis inventum memorat Ramazzin. 1. c. Unde verò in Angliam Belgiumvè devenere Pini cum fuis Conis? Nulla fanè apparentia, quòd ibi creverint, \& feu ventis proftrata, feu Aquis obrutx fuerint fepultx. Devolutxe haud dubiè ex Regionibus harum Arborum feracibus, \& quidem fatali illa illuvie, occafione rupture ftratorum Alpinorum, ut nullam Rationi vim illatum iri putem, fi dixerim, translatas fuiffe has Arbores in maritimas illas Provincias \& Regna ex Helvetia, Sabaudia \& Tirolenfí Comitatu. Hinc Sanè eft, inquit Woodwardus pag. 220. fido me interprete, quid etiam nunc inveniantur be Arbores in Infulis, 8 frigidioribus aliis Terre Partibus, ubi nufquam amplins crefcere falexit, $E^{\circ}$ fortè germinärunt nunquam. Prebent. autem talium locorum Incolis utilitates non contemnendas, quatemis Ligna Suppeditant non folum in ufus Oeconomicos culinarios, in Regionibus bis frigidioribus apprimè neceffarios, Jed quoque Arcbitectonicos, Go diverfos alios: Cum è contrà iis in locis, unde advenerunt, carriffent omni ufü, imò verò impedimento fuiffent femimibus relictis, in nativo aptoque loco commodè tutoque depofitis, $\mathfrak{F}^{\circ}$ de nowo vegetandis pro Arboreto recenti, quandoquidem ex veteri Arborum antediluvionarum materia non multum evafit. At enimverò magno funt ufui Regionibus illis, ad quas ductu Aquarum fuerunt deportate. Eft certè notatu digniffmum, \& Providentice Divine fingulare argumentum, quòd vix occurrant Regiones ligno Arboribusque deftitute, que non largum babeant Arborum barum fubterranearum proventum. Non autem folis Anglis Belgisque in ufum cedir devoluta ex Alpibus Europxis ad oras ufque maritimas Vegetabilis, inflammabilis, materia , qux Cefpites ita dictos bituminofos, iisque intermixta Ligna conftituit. Etiam nobis refervata eft locuples talis materix Penus, deficiente fenfim Lignorum proventu in ufus trahendus. Non mehercle fruftrà apud nos depofita eft in Diluvio vegetabilis hrc materies, non periit hoc fedimentum, fed ad nobiles reftitit ufus. Sylvam hanc fubterraneam in Territorio Tigurino paffim obviam ad ufus trahere hoc ipfo Anno copit \& felicibus quidem, ut auguror, aufpiciis, Ampliffimus nofter Magiftratus, velificante Senatore Graviffimo atque Confultiffimo, Nobiliff. Dn. Fobanne Jacobo Efchero, quo Prafide alii Ducentum Viri vigilanti diligentique Prudentiâ confpicui mecum omnes intentabunt vires, ut negotium hoc Turffarum feu Cefpitum bituminoforum, fe- 
motis difficultatibus obviis, cedere poffit in Civitatis Agrique Tigurini fatisfactionem, totiusque adeò Reipublicx honorem atque commodum. - Effe autem Vegetabilis Profapiæ, nec Mineralis, Cefpites bituminofos cum Lignis foffilibus intermixtis nullâ probatione, fed folâ infpectione, experimentoque combuftionis indiget. Componitur hoc nobile fedimentum, neutiquam $o b$ fui putrefactionem reformidandum, multò minùs ob antiquitatem contemnendum, ex ftratis Mufcorum, Foliorum, feminum, ramorum, Truncorum, radicum inflammabilibus, at${ }_{43}$ que in cineres refolubilibus, Turffx adinftar Belgicx. Pergo cum Woodwardo meo: quid memorate Arbores Jubterranece paf fim reperiantur Petris ipfis $\mathcal{G}$ Saxis $v . g$. in Lapicidinis inchufa: in Marga item, aliifque Terre fpeciebus tumulata non minis, ac in nominata Terra fingofa palufteri. pag. 98. Obfervationes undequaque congerere opus non eft. In Lapicidina Hungarica prope Bruck ad Leitham Fluvium offendit Frater Chariffimus fobannes Scbeucbzerus infra ftratum primum Terre communis nigrx, toti orbi fuperextenfx: Secundum Terrx flavx: Tertium Terrx cœrulex variis Lapidibus intermixtx: Quartum Lignorum varii generis petrificatorum: infra id Offa petrificata Linguas \& oculos Serpentum, \& Sabulum, qux omnia fubfidentiam ordinatam indicant: Infit porrò Woodwardus, quod primitìs fuerint indifferenter depofite Arbores in omnem Terram, aliamvè materiam, que Terrei Globi fuperficiem conflituit: ex accidenti verò bodienum nullibi amplius, vel admodìm rarò, occurrant, nifi in Terra uliginofa Paluftri, quoniam bee ob bituminofam fuam Eo balfamicam naturam Ligna contumulata condire quafi valuit, atque fic ad noftra ufque tempora à corruptione prefervare: Arboribus aliis, que in alia Terra, laxiori magis, $\oint^{\circ}$ porofiori, fuere locata, traItu temporis diffolutis, \&o à putredine prorfus confuntis, ut nunc nil amplius de illis in confpectum veniat, utcunque fodiendo inquiratur: vel, fi quid de illis compareat, exiguarum Reliquiarum nomen mereatur: invenias quippe rarifime in porofiorum Terrarum vifceribus Truncos Arborum integros, \&o à Corruptione adbuc. İberos. Appofitè \& obfervationibus Hiftorico-Naturalibus congruenter! Solutam effe Vegetabilium ita invicem fuperftratorum fubftantiam per diutinam aliquot mille Annorum moram patet ex ipfa Analyfi Chymica. Deftillabam per Retortam Turffam noftram Tigurinam, qux partim prope Lacum Felinum, Kazenfee, partim prope Coenobium Rüitenfe effoditur, \& protraxi levi operâ non folum Spiritum, fed \& oleum xthereum, \& Salia volatilia, \& craffamentum bituminofum, quod in Spi- 


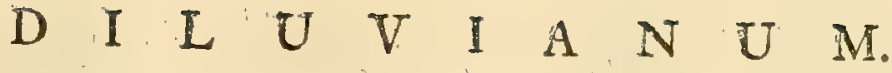

ritu vini folutum Tincturam largitur fanguinei coloris, hand dubiè prafantis in Medicina efficacix.

In Mufeo Wormiano Lib. II. cap. i6. defcribitur Lignum fofile, quod laminatim eruitur, colore nigerrimo, quandogue fubfufco, ponderofum, fragilc, exiccatum ubi fuerit, af, chim primùm è Terra eruitur, adeò lentum Eे flexile, ut viminis infar in quanvis partem trabi polfit, ac flecti. Fibris conftat obliquis, Eo nodis bini inde, plane inftar radicis majoris cujusdam Arboris. Faber quidam lignarius, in Lignis dijudicandis peritus, Juglandis Arboris radicem longâ Annorum ferie nigredine tantâ infectam effe putabat. Sed ins locis nunquam be Arbores confpecte funt. Polituram non facile admittit, nec operi fcriniario ob fragilitatem adbiberi potef. Iis in locis Islandice, ubi magnâ copiấ eruitur Terrâ ad duas ulnas effoffâ, nulle planè funt Arbores, aut fuiffe unquarm animadverti potefl. Hoc Lignum vulgo Sorturbrandur vocant, Eo latere ajunt in monte adeo preripto, Eo alto, it è nullus nifi audaciffimus penetrare valeat, qui à juventute precipitiis fuit affuetus, effodienda quoque Terra eft aliquot ulnis, antequam fe prodat boc Lignum. Wormii hunc Textum eum in finem allego, ut pro roboranda Hypothefi noftrâ conferre poffim cum obfervationibus quibufdam Helveticis. In altiflimo montis Beiftenberg, Uranice Ditionis, Cacumine, Lignum jacere dicitur exafciatum, quod ad Diluvium referunt accolx. De hoc autem Ligno non mihi certi quidpiam conftat. Aft certior, notatuque digniffima elt fequens obfervatio. Inter altifimas $R b_{a}$ tice, imò totius Helvetice, Alpes furgit velut inter Viburna $\mathrm{Cu}-$ preffus, vel ftellas inter Luna minores, mons Stella $P_{i z} d a$ Stail, accolis Sexcmnince vallis, Scbams dictus, in cujus editiffimo cacumine, nec nifi venatoribus Rupicaprarum audaciflmis, \& fcandendi peritifimis, jacet Truncus Ligneus, unam cum dimidiâ circiter orgyjam longus, fefquipidem circiter craffus, fupernâ fui parte, quấ Tempeftatum injuriis eft expofitus, aliquatenus corruptus, infernâ parte fermê integer. Ramorum 44 principia ad uncias aliquot extra Ligni fuperficiem porriguntur: Truncum Pini montanx, quem Cembro Alpicol $x$ nuncupant, putant fideles venatores a'viótral, qui hoc iplo Anno Fratrem meum veritatis hujus rei \& circumftantiarum cupidum, eodemque mecum in inquifitione Hiftorix Naturalis defiderio tractum, ad facras hafce Reliquias ducere, Julio menfe, volebant, fed irrito prorfus, ob Nivem copiofam nimis, fucceffu, ut re infectâ Tigurum redire, \& alterâ quidem vice, quâ idem tentare volebat, coactus fuerit. Ut interim Lectori curiofo conftet altitudo, ad quam pervenit, \& quam oculis duntaxat, non pedibus; 
fcandere fuit datum, infero heic Obfervationes fuas Barometricas, unà cum Calculi fumma.

Pro altitudine Andere, qui Pagus eft Sexamninx vallis precipuus, Die ro. Jul. Mercurii altitudo hor. 3. p. m, 24. dig. 9. Lin. Parifin. quibus refpondent in Tabulis Mariotti 435 . hexempedx, toifes, 5. Ped. Parif. in Tabulis Caffinianis veró 520. o. Pro altitudine lóci fupra Horizontem Maris. Die I I. Jul.

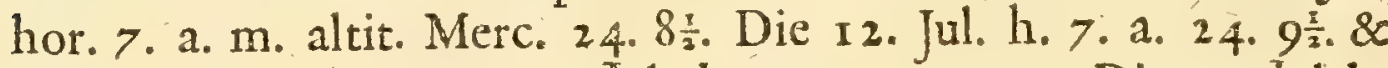
h. I. p. 24. ro. Die 13. Jul. h. 7. a. 24. Io. Die r4. Jul.h. Ir. a. 24. I $1 \frac{2}{2}$. Die I5. Jul. h. 4. a. 24. I I. fummæ altitudini refpondent juxta Mariottum 406. I. juxta Caffinum 479. o. Ut proin altitudo media æquata foret juxta Mariottum 42I. o. five 2526. pedd. Parifin. \&e juxta Caffinum 499. 3. five 2997. pedd. pro altitudine V allis Sexamnina fupra Mare.

Die I 3. Jul. In Montis T/chiere eo loco, ubi nullæ ampliùs

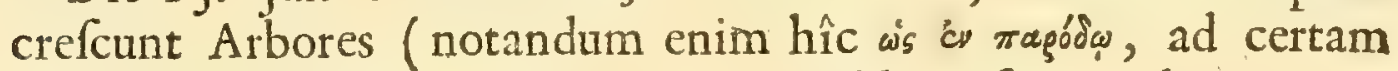
duntaxat altitudinem circiter 5442. pedd. crefcere Arbores, nec ultrà ob caufas alibi expofitas furgere poffe) horâ II. obfervata Barometri altitudo 2 I. 7. quibus refpondent juxta Mariottum 919. 4. feu 55 1 8. pedd. \& juxta Caffimum I 270. 3. feu 7623 . pedd.

Eodem die horâ meridianâ I 2. eò ufque fcanfum fuit, ut Mercurius delapfus fuerit ad 2I. I. è contrà atmosphæra furrexerit fuprà Maris Horizontem juxta Mariottum I002. 4. feu 6016. pedd. juxta Calfinum i 4 I I. o. feu 8466. pedd. Parifin.

Nondum verò hîc fumma, quam quidem Frater attigit, altitudo. Die r.5. Jul. In Monte Surfees dicto altitudinem habuit 20. 7. cui refpondent juxta Mariotti Tabulas, non quidem huc ufque productas, 6439. Pedd. Parif. juxta Cafinianas 9 196. fecundum Fratris computum verò 6585 .

Stelle montis cacumen, quantum ex afpectu conjectare potuit Frater, altitudinem hanc montis Surfees fuperat circiter 3000. pedd. foretque adeò 4000. circiter pedibus altior Truncus nofter, eo loco, ubi crefcere definunt Arbores. Quis autem, obfecro, Truncum arboris, centenarios aliquot, gravem \& informem, nullis ufibus aptum, huc detulit? Quxe curiofitas homines impulit? Imò, qux Machinæ eum fublevârunt? Eft enim loci tam præceps fitus, ut nullis penè humanis viribus, nullis Regum maximorum fumtibus, nullis Potentiis Mechanicis hîc, ubi nunc jacet, deponi potuerit, nihilque proin maneat, quàm fatale illud, \& univerfale quidem, quo altiffimi Montes Aquis fuere cooperti, Diluvium, nifi in fubfidium vocare malis ex leviffimæ armaturæ Hypothefi Luidiana, foliis quibusvis \& plumis leviores Ideas arborificas, quarum aliqua tantæ fue- 
rit efficacix, ut ex minutiffima atomo fefe expandere potuerit in formam Arboris ingentis detruncatx. Quis autem non sidet, in levi habendam Hypothefin? Dabitur aliquando occafio illuftrandi obfervationem hanc de Trunco extra omne dubium Diluviano rariffimam per circumftantias alias. Non quippe, fi DEUS vitam concefferit \& vires, defiftam aliis invigilare occafionibus, quibus culmen hoc editiffimum à Fratre, me ipfo, vel curiofis aliis confcendi poffit.

$$
\text { F I N I ' S. }
$$

I

\section{HERBARIUM DILUVIANUM.}

A.

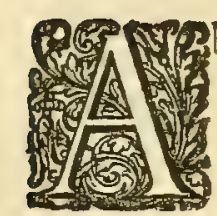

Alga. 22

Anderæ Altitudo. 58.

Anguillæ Diluviance cauda. 43

Antimonii flores nigri igne producti. $4 \mathrm{I}$

Aparinæ. 19.

Arca quando refederit. 12

Argentum purum arbufculi formá concretum. $4 \mathrm{I}$.

Ârundinis Caulis. I9

Vallatoric Radix. 51.

Aftragali folia., $5 \mathrm{I}$

Avellanæ ex Terra erute. 55

Augenfchiefer. 2 I

Autumnale tempus juxta nonmullos initiale Diluvii, fed faljo. I2

B.

Baumfein. 23

Boomftenties, Bomties Achates. 25

Borragines Aqua congelata, in qua Foliorim amule figureconfpiciebantur. 35
| Bruck, Lapicidina Hungarica, ejufs que frata. 56.

Buxus. 51

C.

Tapilli Veneris. $5 \mathrm{I}$

$\checkmark$ Carduo fimiles imprefjiones in Cormubus Ammonis. 44

Cavaloccbio Liburn. 2 I

Cefpites Bituminofi. vide Turifa

Cevettone Flor. 2I

Chryfanthemi. Flos. 51

Ciffites: 49.

Columbarum emífjio. I3. I4

Conferva Plinii. 5 I

Cornua Ammonis ornamentis folia. ceis notata. 44

Corocculo Venet. 2 I.

Cruces in Ligno confpicue. 46

Cryftallinus Flaor Ericaformis. 37

Cryftallus bexagona, in qua arbufoule conpiciuntur. 43

D.

7 anica verba in Ligno conspicua.

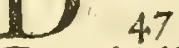

Demoifelle. 2 I

Dendrachates Plimii. 24

$\Delta \varepsilon v$ éress 'Axárys. 24

Dendrita. 23. \& c. Hypotbefi Diluviana contrariari videtur. 23

$\mathrm{H}_{2}$

Den. 


\section{N $\quad \mathrm{D} \quad \mathrm{E} \quad \mathrm{X}$}

Dendrita Arborea \&ु Calapparia ejus Equifetum, I5. I6. non funt fpecies. 25 Tinctura, qua pingitur, differt à Natura Lapidis. 25.26 que fit. 26 igni non cedit, fed plerumque picturas perdit. 26

Arborum faltem Ef fruticum ramificationes, munguam folia nec femina, nec fructus representat.27

Dendritapicturacum Ericiss, muscis, Ëc.affinibusPlantisnon convenit.27 Dendritarum productio juxta Kircherim Eु Luidium. 28 arbufcula fe invicem munquam interfecant. 29

lis adfcribi nequeunt. 29. 30 fluxui materice fubti- comparantur cum Arbufculis ex attritione Marmorum politorum vel Lapidum fifilium intercurrente aliquo fruido oriandis. 30 . exin Origo deducitur. $3 \mathrm{I}$ in uno fepe diverforum colorum ramificationes fibi fuperincumbentes comparent. 3I

- Arbufcularum radices funt ad commifuras Lapidum. 32'.

- Nove comparent pieture in fingulis fiffuris. 32

_- Diverfitas, ejufue Ratio. 33 confideratio monftrat totam Juperioris Terrachorticis in Diluvio deftructionem. 34 cmule arbufcule ad parietes vitri, cui Erkbinum ex Manna foluta infiufum. 37

Camploria. 37

_- genefis comparatur cum Genefi falium volatilium. 42.43

Dendrites Cryftallinus. 43

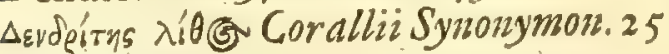

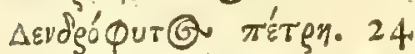

Diluvii Initium tempore verno. I I - Series Chronologica. 12.\&c. E.

Gpiphyllofperma mineralis Scutel -1. lata Luid. 50

Liphyllofpermæ Plante. 15. Ep pafsim.

tialem Menfem Diluvì inttialem monftrat. I7

\section{F。}

Telicis E Regule digiti, que Gla-

$H$ ronce Lapidi imprefie vifinutur. faladtite funt ludibriusm. 40

Filicula. I 6

Filix. 16. I9. 20. 22. 23: 50. 51.

Flores Narcifs, Hyacintbi E̋c. in Faspidibus \& Achat is occurrentes, quo referendi. 49

Fragaria. 5I

Fraxini folia. $5 \mathrm{I}$

Frumenti $\int p i c a .7 \cdot 51$

Fumaria. I 8

Fur e patibulo fispenfus in Fago ps: c7us. 47.

G.

allium album vulgare. is

Gramen. 18 . 19.

Graminis Jpica. I 8

Guaperva Brafilienfis. 22

H.

T Texagonæ figur e reguilares in vi-

11 treis orbibus objervata. 42

Hippurita. I7

Hordei fpica. 8. 22 Defriptio. 8

Origo à Diluvio. 8 offert conjecture locum cir. ca Helvetos Antedilurianos. 8 Diluvii initiumponit in Tems. pus vernum. II. \& ieqq.

\section{I.}

Tacex capitulum. $5 \mathrm{x}$

Imbofcata (Pietra.) 23

Fufferken. Belg. 21

Juglandis folium. 2 I

Juniperi amule Arbufcule in Tartaro vitriolato conppecta. 37

Jura Mons precipinum Teftaceorum

Diluvianorum bebitaculum. Io

K.

eenen. 54

Kienboomen. Kienbout. 54 


\section{IN HERBARIUM DILUVIANUM。}

Kircheri circa Dendritarum aliorumve Figuratorium productionem fententia affertur E eliuditur. 28

L.

T entes Lapidece. 50

Libella Diluviana Diluvii $1 n$ itium ponit in Majum. 2 I

Ligna fubterranea. 5 I

Note characterifica. 52

Origo à Diluvio. 52. 53

Situs. 53.

Profunditas, 53

reperiuntur in Cepitibus bi-

tumino/is E़ Terra uliginofa. 53. $54 \cdot 56$.

- - Infulis, ubi Arbores ipse non proveniunt. 55

- - - Regionibus, quibus minus largus fupraterraneorum proventus. 55

ก. 56

Petris E़ Jaxis inclu-

Lignum in Gacumine Montis Stella. 57.58.

Lilii Gallici foliorum amula orna. menta in Corrubus Ammonis conspicua. 44

Lithophyta. 50. 5 i

Lithopteris. I 8. 50

Lithofmunda. 20.50

Litho Trichomanes. 50

Luidii circa Figuratos Lapides Sententia affertur \& eluditur. 28

\section{$\mathrm{M}$.}

Majus Menfis juxta WoodwarII dum initialis Diluvii, Ef fonalis. II. I4

Monachella. 2I

Mufci terreftris clavati effigies in vitreo Orbe. 40

\section{N.}

Jeurophyllon. zo

1 Nitri Antimoniati aqua congelata figuras confpiciendas dat. 36

$\mathrm{O}$.

lea. $i_{4}$

Onobrychis. 51
Ofmunda. 20. 48

Oxyacantha. 19

P.

Derla. 2i

Phycites Plinii. 22

Phyllitis mineralis Luid. 48

Pini ES Abietis Lignum in Auglie fubterraneum non fuprater anieuth. 54. 55

Pifces. vide Plantæ.

Pifcis antennis prolongis in Lapide fifili. 44

Pifcium fata in Diluvio ro

Plantæ E્ pifces Diluviani cur in tenuibus duntaxat fratis reperiantur. 9

Plantarum Lapidibus imprefsarum $O$. rigo à Diluvio af eritiur. 5.7.

Pluviæ quadragefimalis initium $c$ de dit in Majum. I 3

Polypodium frnis in Finium. I3

Polypodium. 50

Pyri folium. 20

Q.

Quinquefolium. 5 I

R.

$\mathrm{D}$ and Pifcis. 22

R Regulus Antimonii fellatus To chomani vel Filici fimiles figuras Juperficie exhibens. 40

Rhodites Gefueri. 43

Rubeola mineralis Luid. is

\section{$S$.}

Salis Armoniacifores argentum ari. buculis ornant. 39

Salium volatilium, eorumque arboriformium concretionum generatio. 39 - Jitus. 39

Salix. 20. 42

Saxifraga. $5 \mathrm{I}$

Schaeidermätz. 2 I

Scorpioides montanum IBB. an? 22

Secalis Jpica. If

Securidaca major. 5 I

Serici fal volatile ejufque figura. 38 Serpillum. 5 I

$\mathrm{H}_{3}$ Sexas




\section{INDEX IN HERBARIUM DILUVIANEM.}

Sexamninæ $V$ allis Rhatorum Alti- $\mid$ Turfa Agri Tigurini. 54. 55 tudo. 8

Siluri Sceleton. 45

Pietra di Sinai. 24

Sophia Cbirurgorum. $5 \mathrm{I}$

Sorbus Alpina. i 8

Sorturbrandur. 57 Sorturbrandur. 57
Stalactitæ res varias reprafentan-
tes. 47.

Stella mons. $57 \cdot 58$.

- in eoTruncus ligneus. 57.58 ejus altitudo. 58

Stellulæ in fffili Lapide Dendritis affini conppicus. 42

Surfee Montis altitudo, 58

\section{T.}

The American Toadffch. 22 Thymus. 5I

Tiliæ folium. I9

Tofis impreffe Figure Diluviana. rum numero eximenda. 48

Trichomanes. 15.18 .20

Trifolium. 5

Tritici spica. I 5.

Tfchieræ Montis altitudo: 58.

Turffa. 54

deftillata. 56

- non in vallibus folum offenditur, fea E⿱乛龰 in fummis Alpious. 54

V.

Ternum Tempus Diluvii fuife initiale probant Argumenta ex Natura delumpta. II

Noacbi exitzi deftinatum. II

Veronenfium E̊ Apennina FugaReliquiarum Diluvianarum magis furat feracia, quam verò Lepontiorum ES Rhetorum. 9. I0.

Virunculus in Lizno Fagino. 45.46 ejus Origo. 45

Vitis Folium. I 5

Urticarum figure in Lixivio Cinerum bujus plantre congelato conPpicue. 36

Uvæ reprafentatio in Lixivio Cinerum clavellatoram. 37

W.

W aferfteine. 25

\section{F I N I S.}

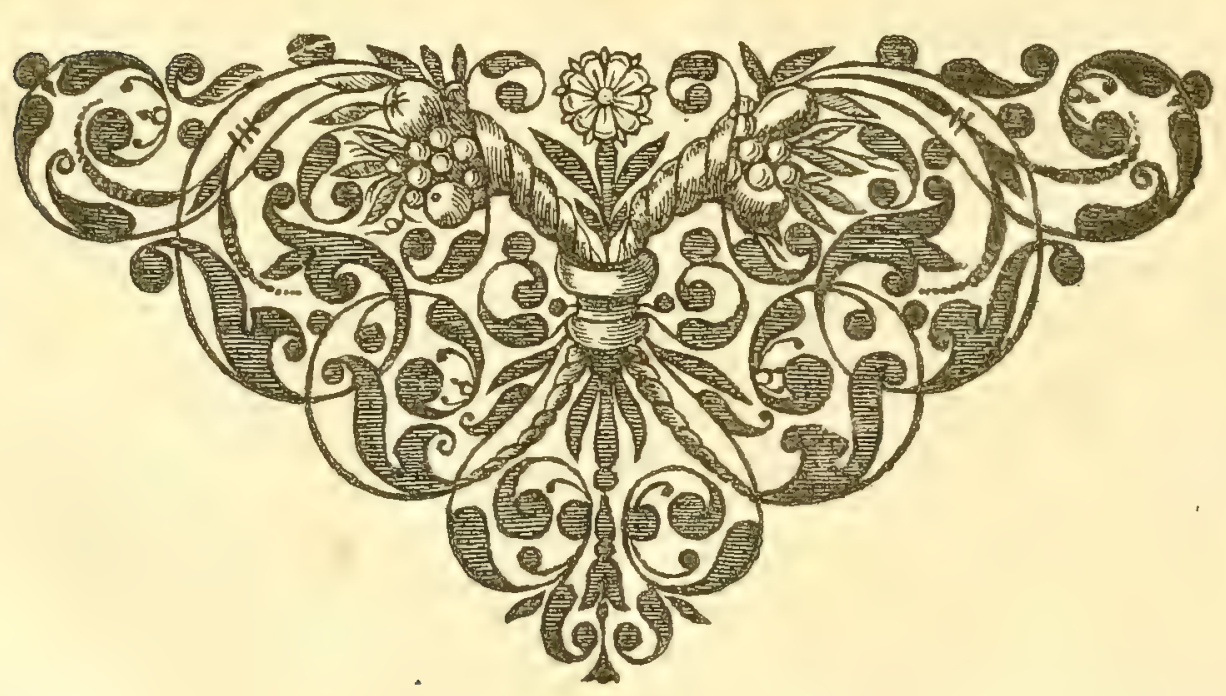

HERBARII 


\section{HERBARII DILUVIANI}

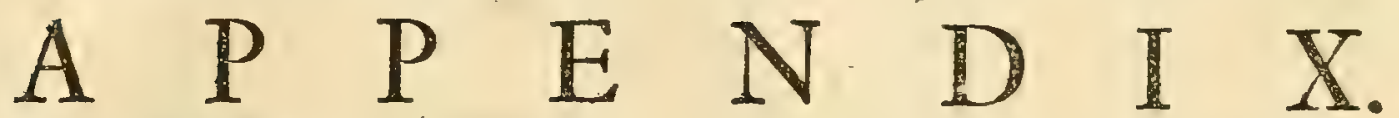

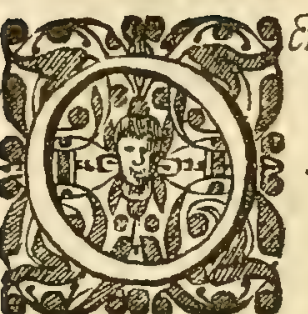

Etennium eft, ex quo Plantas Diluvicinas inde ab Exundatione bac fatali fimul $\sigma_{0}$ universali veluti Sepultas, novâ Eo inauditâ forfan palingenefice Specie refufcitavi, Eo Nature Curioforum applanfium, de quo mibi gratulor, reportavi. In Editione bac alterâ ut major Syftemati meo accenderetur lux, conftitui mecum Plantas five veras, five fpurias, foffles redigere ad Metbodum. Tournefortianam, ut quid ex quavis claffe baEtenus quidem repertum fuerit Orbi curiofo fimul $\Theta_{0}^{\circ}$ erudito innotefceret; indigitaturus finul, quid, meo quidem judicio, pertineat ad Diluviana, quid ad Poftdiluviana, quid ad dubia, quid ad Nature hufus? Sit itaque

\section{L A S S I S. I.}

Herba \& Suffrutices flore monopetalo, campaniformi.

I APARINE denfius foliatæ æmulum ex Silefia. Herb. Diluv.

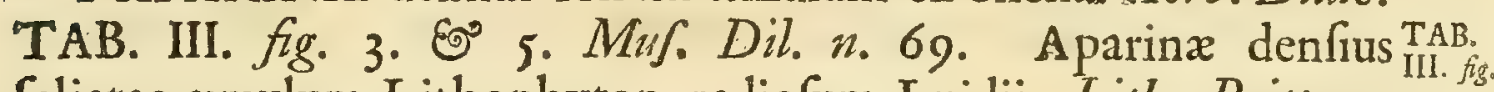
foliatae æmulum Lithophyton radiofum Luidii. Lith. Britt. n. 3.0.5. 201. an Rubeola mineralis Luidii. n. 202. Diluv.

2 Gallium album vulgare Tour. Mollugo montana angufti fo- TAB. lia vel Gallium album latifolium. CB. TAB. IV. fig. I. IV. fig.t Volkm. Siles. T. XV. f. 3. Diluv.

Donicbte Erde oder Lett mit einem Z zueiglein von dem TiI. malo Cypariffia foliolis angultis. CB. Cypreffen kleine Wolfsmilch. volkmann. Siles. 108. T. XII. f. 3. i. e. Terra argillacea cum Ramo Tithymali Cypariffix \&c.

4 Gallium luteum. CB. Convenit quoque Rubix anguftifolix fpicatz. CB. bey Volkmann. Sil.III.T. XIII. $f .8$.

\section{LA S S IS II.}

Herbe \& Suffrutices flore monopetalo infundibuliformi

$$
\text { \& rotato. }
$$

s Folium quoddam trinervium an PLANTAGINIS TAB. II. fig. 8. Dub. 
6 Folium rotundum CYCLAMINIS videtur in Lapide Öningenfi. Dilive.

$$
\text { C L A S S I S. I V. }
$$

Herba \& Suffrutices flore monopetalo labiato.

7 SERPILLUM \& THYMUS. Myl. Saxon. Sult. p. 40. fig. 7. Dubium nomen。

$$
\text { C L A S S I S. V. }
$$

Herba \& Suffrutices floribus polypetalis cruciformibus.

8 RAPA in Lignum mutata. Lang. Hijt. Lapid.p.73. Eximenda munero \& Diluvianorum \& Foffilium.

$$
\text { C L A S S I S V I. }
$$

Herba \& Suffrutices foribus polypetalis rofaceis. Orb. p. 143 .

9 TRIFOLY \& FRAGARIÆ folia. Raj. de mutat. छo interitu

Io Lithophyllon, fo mit einem grofen blatt der Opuntix majoris, oder groffen Indianifchen feigen faft ïberein kommet, feu Lithophyllon Opuntix majoris xmulum. Volkmann. Sil. Io6. $T_{\text {: }}$ XI. $f$. I.

i Nigella Arvenfis cornuta, CB. Id. r i o. T. XIII. f. 5: I 2 Flofculus Stellatus. Sternblimlein auf grauem Scbiefer, kommet dern blimlein einer Alfine bey. Convenit Alfines flofculo. Id. II $3 . T$ TV . f. 7 .

13 Alfines fpergulæ flore feu Arenariæ. I. B. obfcura veftigia in Lapide à Sole ferè calcinato, in circuitum expanfa. Helwing Lath. P. II. p. 94 .

\section{L A S S I S V I I.}

Herba floribus polypetalis umbellifera.

${ }_{14}$ Myrrbis Sylv. Camer. Cerefolium Sylv. perenne Mor. Myr when Körffel, an dem die flängel und Blätter pechfchwarz und glat find, foliis \& caule nigris lavibufque, Volkmann. Sil. 108. T. XII. f. x.

I5 Apium montanum ampliori folio. CB auf granem Scbiefer natiurlich und Scbwarz marquirt. Id. T. XII. 'f. 4. p. I09.

I6 Foniculum vulgare. CB. feu Mille folium Aquaticum folio Fœniculi. Id. I I 2. T. $X I V$. fig. 6. 



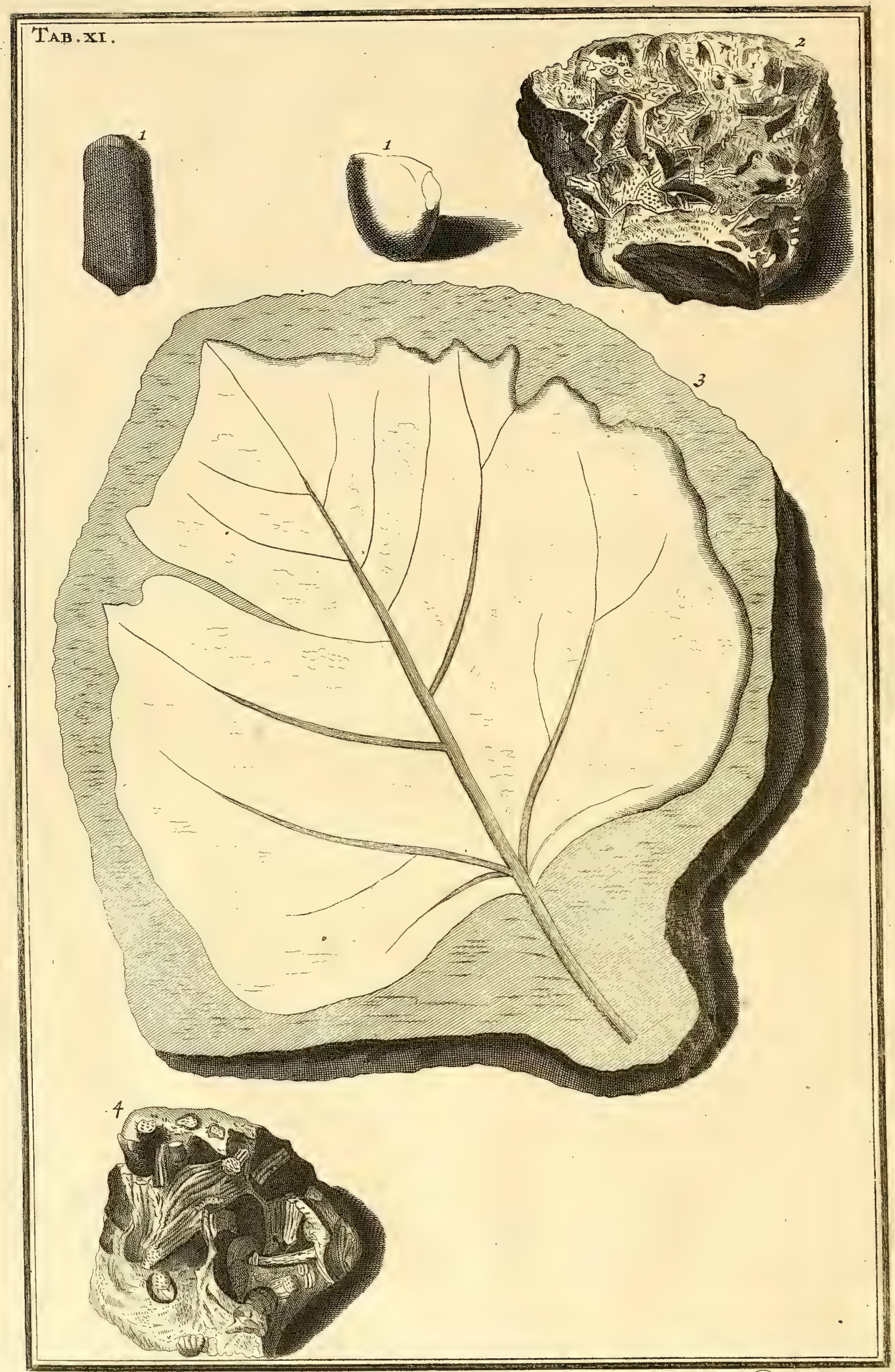

Gclcbmo Dn Helmanno Boerhave Botan. Ghem. \& Goll. Dract. in Tllustri Ecrademiá-Luaduno-Batava Professori. 


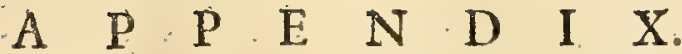

C L A S S I S. X.

Herba o Suffutices foribus polypetalis popilionaceis.

I7 ONOBRYCHIS minor Vicix foliis. CB. Luid. p. Io8.

Diluv. Kozia mit ka wamieniu Pol. Helwing. Ind. Foff. Pol.

I8 PISA coloris viridis in faxo fufco, Wickenfrem. Muf. Dil.

n. 1 20. Dub. Ein Siein darim Bobnen und Feldwicken. Myl. Sax.

P. I. p. 37. f. 2. 3. Braunrothes Geftein darinn Frïchte wie Bobnen, Erbjen, undWicken, i. e. Pifeolithus, die äuferlicbe Scbato ift Grasgriin, die Membranäuber dem Kern weifs, diefer aber ein weiffer Kiels. Volkm. Siles. I 29. T. XXII. f. 5. Brauner leberfarbener Stein, in welchem Zimmetfarbene Steinlein, fo theils länglicht in Groffe und Gefalt der Pinolen, theils rund in $G e$ falt kleiner Wicken liegen. Pífolithus, Pifis partim oblongis, partim rotundis. An ftatt des Kernes ift ein beller Cryftall Flufs. Volkm. 13i. T. XXIII. f. 6. 7. 8. Leberfarbene, und rebr barte Handfteine, in welchem Saamen fecken den Türkifchen oder gemeinen Bobnen gleich. lit. a. andere den kleinen weifjen mullichten und ovalen. bb. Griine Erbjen den naturlicben ganz gleich. c c. Andere denen Feldwicken und Linfen nicbt unäbnlich. dd. nebft einem Eindruck einer Mandel. e e. Id. T.XXIII. f 9. IO. Pifa majora Matth \& Fuchs. rufa, grofe rothe Erbfen. Id. I 34. T.XXIV: f: I 3 .

I9 SCORPIOIDES montanum IB. 'TAB. V. fig. 6. "Muf. TAB.V. Dil. n. 8. Diluv.

20 Phafcolithus, in einem gelben verfteinten Lett, if dern Phafeolo Peregrino magno coloris Caftanei levi, cum magno hilo Chabr: in allem ganz gleich, auch der Hilus tieff eingekäblet, und mit dem Cortice einerley Couleur; i. e. Phafeolus peregrinus magnus \&c. in marga lutea. Der innwendige Kern bat feine natirlich weiffe farb, Nucleus interior albus eft. Volkmann. Siles. i 30 . T. XXIII.f. 2.

21 Eine Fracbt dem Phafeolo Egyptiaco colore rufefcente änblich a a; nebft einer unbekanien Plätfchicbten Frucht b b. welche gleichfals eine fpecies Phafeoli cheinet in Brann rothem Geftein. Id, I 33. T.XXIII f. I2.

22 Siehet wie der Phafeolus Peregrinus hortenfi affinis fructu tumidiore minore niveo. CB. Id. I $34 . T$. $X X I V$. f. I I.

23 Phafole, die dem Phafeolo Brafiliano rubro gleichet. Id. 134. T. XXIV: f. I7.

24 Siliquaftrum Phafeolatum, feu ad PHASEOLI valvulum TAB. quodammodo accedens. Mort. Northampton. Tab. $X$. fig. 28. XI. fg. to p. 245. Luid. n. 1440. ACt. Pbilof. n. 200. fig. i. Di- 
luv. Sed an Phafeoli fit filiqua, vel etiam vegetabilis Profapix, de eo adhuc dubito. Idem judicium efto de fequentibus. In Lexico Diluviano reperias inter pifcium partes.

is Siliquaftrum latiufculum, feu LUPINI valvulo æmulum. Luid. n. 1448. A Bone of the Shape of a Lupine Shell. Mort. 1. c. Act. Phil.n. 200. fig. 2.

26 Siliquattrum minimum vibratum. Luid. n. I466. The Simalleft of all the ftrait Siliginaftra-Kind. Mort. 1.c.

27 Siliquaftro congener Ricinus, feu Siliquaftrum minus inftar feminis Phafeoli. ACt. Pbilos. n. 200. fig. 5. Luid. $n$. I 499. A jpecies of the fize and Shape, of a Kidney-Bean. Mort. p. 246.

28 Siliquattrum minus gibbofum. Luid. n. 1467. Mort.1.c. 29 Siliquaftrum tortile gibbofum minutis punctulis confperfum, feu Siliquaftrum marmoreum, Puntularia tortilis dictum. Act. Londin. n. 200. fig. 4. Luid. n. 1482. Morton. l. c.

30 Siliquaftrum minus triangulum. Luid. $n$ i 48 8. Mort. l.c.

3 I Siliquaftrum phafeolatum angufiffimum. Luid. $n$. I 443.

32 Siliqualtrum tenue longiufculum in dorfo ad cylindrum vergens. Luid. n. 1444.

33. Siliquaftrum Pifi filiquam referens fubviride, vibrato margine infignitum. Act. Pbil. n. 200. Luid. n. I 445. Idem coloris anthracini. $n_{1}$ i 446 .

34. Siliquaftrum omnium quotquot vidimus maximum, duas uncias, fi quadrantem excipias, longitudine, latitudine unam complectens, coloris nigri radice fpoliatum. Luid. n. I 449. fig.

35 Siliquaftra marmorea, vel lrviffimè expolita, coloris alias fufci aut hepatici, alias è luteolo fubviridis, variæ magnitudinis. Luid. n. 145 I.

36 Siliquaftra radice fulculis transverfis leviter exarata. Luid. n. $\times 452$.

37 Lupinati fpecimen minus coloris e cinereo fubfufci, perpendiculari margine, argutè admodum rugofâ. Luid. $n_{1456}$. $3_{8}$ Saamen von dem Lupino fylveftri flore luteo CB. Volkmann. Siles. I.35.T. XXIV.f. $2 \mathrm{I}$.

39 Siliquatrum minus gibbofum, fubtenue, feu vulgari fimile, arcuatum angultius. Luid. n. 1467.

40. Siliquaftrum gibbofum ex albido rufefcens fabuletorum radice infigni donatum. Luid. $n$. 1473 .

4 I Siliquaftrum Silo condictum, feu recurviroftrum gibbofum, ftrigâ quadam à dorfo ad mucronem procurrente. Luid. n. 1476. 


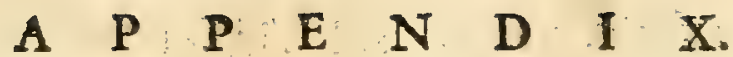

42 Siliquaftrum gibbofum tortile. Luid. n. 1480.

43 Siliquaftrum Portellaria dictum, five gibbofum marmoreum. Att. Pbilos. n. 200 fig. 4. Luid. n. 148r.

44 Siliquaftri tortilis gibbofi varietas, ad triangulare minus accedens, ob extremum alterum quafi obliquè refectum Limularia dicta. Luid. $n$. 1487 .

45 Siliqualtrum minus triangulum feu minus Conchx ad inftar roftellatum. Att.Pbil. n. 200. fig. 3. Luid. n. 4488.

46 Ricino accedens Siliquaftrum umbonatum feu fcutulatum minimis adnumerandum. Luid. $n$. 1 497. fig.

47 Siliquaftrum umbonatum longiufculum. Luid. n. 1498. fig.

48 Siliquaftrum afellarium feu minimum, Afello infecto nonnihil fimile. Luid. n.1499.

49 Siliquaftrum minimum punctulatum, Árquatula dictum. Luid. n. 1500. fig.

so Siliquaftrum Bufonitam orbiculatum minorem referens. Luid. $n$. I $50 \mathrm{I}$.

51 Siliquaftrum minimum orbiculatum marmoreum, minutiffimis punctulis confperfum. Luid. $n .1502$.

52 Siliquaftrum litorale venofum, (venulis nimirum à litore dorfali undequaque infculptum) feu Limaculum corrugofum. Luid. n. 1503. fig.

53 Siliquaftrum venofum radiolare, nodulorum ferie in dorfo infignitum, feu filiquaftrum à radioli textorii fimilitudine, $\mathrm{Ka}$ dins nodofus dictum. Luid. n. 1505 .

54 SECURIDACA major. Myl. Saxon. Subt. Fig. xr.

55 Lapis niger lævis, Fabe parvæ perfimilis. Helwing. Lith. Ang. 38. Forfan ad Silices.

56 Fabx Siliqua minimè vefca, veræx tamen formâ perfimilis, turgentibus intus granulis prægnans. Calc. Muf. 4 I I Pol. Strac bobowy Kamienny. Helw. Ind. Foff. Pol.

57 Siebet einer zufammen geplet/cbten grofen Feige, oder Fabx Indic $x$ Arborefcenti, ex Guinea latiffimæ fere quadratæ Cluf. gleich, oder der Fabæ arborefcenti feu phafeolo plano longo nigro. Volkm. Silef. 137. T. XXIV. f. 23 .

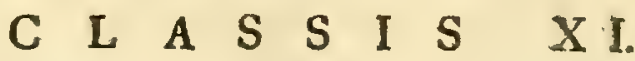

\section{Herba or Suffrutices floribus polypetalis anomalis.}

58 FUMARIA. Myl. Sax. p. 30. potius Lithopteris famina Trichomanis pinnulis longioribus. Luid. Lith. n. 186. vel Filix ramofa. Myl. fig. 8. v. TAB. II. fig. 7. Diluv. Scbiefer mit fis. \%.

$$
\text { I } 2 \quad \text { der }
$$


der Fumaria officinarum. Volkmann. Silef. x r . T. XIV. $f_{0}$. 59 Siebet wie femen Momordicx feu Balfaminx faminx, wann er nocb in der rotben Scbalen oder bäutlein ftekt, dum adhuc membrana rufefcente veftitur. Id. 134. T.XXIV. f. I 2.

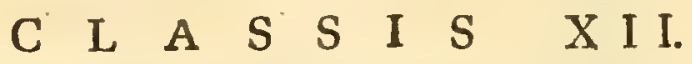

Herba or Suffrutices floribus flofculogis.

60 JACE E cujufdam aut Centaurii majoris capitulum. Luid. Lith. p. 108 .

6 I Eine Blum von der Jacea nigra Pratenfi latifolia. CB. kommet auch der Jacex montan $x$ candidiffim $x$ CB. oder Jacex montanæ hirfuto capite bey. Cluf. Pan. Volkman. Sil. x $3 . T . X V \cdot f .6$.

\section{L $\quad A \quad S \quad S$ I $S$ X I V.}

\section{Herba \& Suffrutices floribus radiatis.}

TAB. 62 TUSSILA GINIS folium in Lapide Fiffili Oeningenfi. Muf. fi. 3. Dil. n. 248. b. Diluv.

63 CHRYSANTHEMI nefcio cujus flos petalis bifidis. Luid. Lith. p. rog.

64 Radiatula, an flos cujufdam Chryfanthemi. Luid. in Transact. Pbil. n. 337. p. 95. Tab. I. fig. 4 .

${ }_{5}$ Eine Blum auf einem dunkelgrauen Scbiefer, fo dem Buboni luteo feu Afteri montano luteo folio falicis glabro CB. am atleväbnlicblten ift. Flos Afteri montano \&c. fimilis in Fiffili fufco. Volkmann Sil. x I 3. T. XIII. f. 9.

66 Auf einem Pomeranzenfarben Scbiefer. After anguftifolius, After Pyrenaicus præcox flore cœruleo fortè. $H$. R. P ar. Tour. id. p. I 13. T. $X V \cdot f \cdot 5$.

$$
\text { C L A S S I S X V. }
$$

\section{Herba \& Suffrutices floribus apetalis jeu ftamineis.}

67 HORDEI fpica Diluviana Lapidi fiffili Glaronenfi imTAB. I. preffa. Mus. Dil. n. I s v. TAB. I. fig. I. Diluv.

Tia.v. 68 Eine unreiffe Gerftenäbre. Myl. Sax. p. Is. v. TAB. V. fig. 4. Diluv.

69 Spica SECALINA. Luid. Lith. p. 108. Pol. Klos zytny w Kamieniu. Helw. Ind. Foffil. Polon.

70 Culmus integer frumentaceus 24 . pedum profunditate in puteis Mutinenfibus repertus. Ramazzini, Font. Mutin.orig. 
7 I Sica TRITICI in fiffili Mansfeldico. Buttn. Rud. Diluv. p. 203. Diluv. Spicæ Frumenti in Schwarzem Kupferchiefer von Franckenberg. Myl. Muf. n. 887. Scbiefer, mit einer und dreyfachen Kornäbren Id. n. 905. 906. Spicæ Frumenti Metallares ex Fodinis Franckenbergenfibus Haffix. M. D. n. 248. b. ${ }^{3}$ Metallifche Frucht Aebren von Franckenberg. Wolfart. Hif. Nat. Haff. 35. T. 5. n. $\frac{3}{5} \cdot 6$.

72 GRAMEN quoddam frequenter geniculatum folìs è geniculis prodeuntibus in extremo bifurcatis ac trifurcatis in Lapide fiffili Oeningenfi. TAB. III. fgg. 4. Muf. Dil. n. 40. De-TAB. fcriptione adde, quod exactius intuenti hanc Plantam, mihi vi-fil. ${ }^{4}$ deatur hoc qualecunque Gramen immaturum, ut folia nondum vaginis plene evoluta bifurcatorum fpeciem mentiantur.

73 ALGE vel GRAMINIS folia in lapide Fiffili Oeningenfi. Muf. Dil. n. 42. Diluv. Brauner Lett von der Alaun Gruben bey Foachims thal in Bobmen mit Gras. i. e. Gramen in Argilla fufea ex Fodinis Aluminis vallis Joachimicx in Bohemia. Myl. Muf. n. 762 .

74 Alga marinaLapidi impreffa ad Littora Maris Balthici, ubi Alga marina Lob. vel Fucus marinus alter. Dod. alias Alga anguftifolia vitriariorum $\mathrm{CB}$. copiofiffimè fluctuans ejicitur. $M . D$. n. 248. D ${ }^{3}$.In Lapide duro ductibus inordinatis albo colore confpicua. Helw. Lith. P. II. p. 94. T. II. f. I.

75 Graminis Panicei fpica. Luid. Lith. p. I08. qua cum contuli fpicam, fi non Julus \& populi nigræ. CB. v. TAB. II. TAB.It. fig. 5. Diluvi. Trawne lifcie w Kamienacb Wyrafone. Pol. Helw. fig. 5. Ind. Foff. Polon.

76 Graminis videtur, \& Avenacei quidem, fpecies, Lapis fifflis impreffionibus frugum elegantiffime notatus. Schieferftein mit Frucbt Aebren aus dem Kleinen Scbmalkalder Thal oder Grund. Wolfart. H.N.HafJ. $35 \cdot T \cdot V . f .3$.

77 Grauer Schiefer cum Spica Graminis Alopecurini, II. Tab. vel potius Graminis Canini, III. Tab. Aus einer Koblgruben zu Breitenhau. Volkm. Sil. T.IV. f. 8 .

78 Silex duriffimus corulafcens, in cujus utroque fuperficie Gramen tenuiffimum ex uno Radicis principio in circuitu expanfum foliolis ex utraque parte geniculati culmi copiofè prodeuntibus, $8 x$ in extremitatibus velut in fpicam collectis, aliis quidem extantibus \& manifeftis, aliis ferè detritis. Helwing. Lith. P. II. p. 94. Tab. II.

79 Ignota Planta mineralis Ncurophyllon Carbonarium. Luid. TAB. n. I 84. v. TAB. IV. fig. x. Lithophyton finuatum facie A-IV. 
RUNDINEA five ftriatula Carbonaria. n. I99. Caulis cujufdam Plantx mineralis. $n$. 200. Planta mineralis Neurophyllon Carbonarium dicta. Luid. Muf. Diluv. n. 1o. Planta ftellata quxdam Diluviana cum Neurophyllo in atri coloris faxo margaceo. Muf.Dil.n. I 3. v. TAB. IV. fig. I. Striatula Carbonaria \& varia foliorum fragmenta ex Anglia. Muf. Dil. n. 20. Neurophyllon Carbonarium tum impreffum, tum integrum compreffum. $n$ 23. Neurophyllon in Lapide fiffili Oeningenfi. $n$. 41. Neurophyllon Carbonarium feu ftriatula tenuior in faxo nigro Silefiaco. $n$. 49. Neurophyllon feu ftriatula Carbonaria Anglica. n. 5 r. Neurophyllon aliud picei lavoris \& fplendoris ex Germania: $n .52$. Lapis grifeus Melanogrammos cum Neurophyllo feu ftriatula ex Anglia.n. 54. Neurophyllon feu friatula referens Gramen pictum ftriatum in Saxo Cretaceo Oeningenfr. n. 57. Caulis Plantx cujufdam in Lapide Oeningenfi. $n 6 \mathrm{I}$. ARUNDINIS aliufve Plantx caulis folidus metalliformis prope Bononiam erutus. $n .67 . v$.

TAB. TAB. III. fig. 2. conferendus cum Fœniculi caulibus lapidofis.

fig. 2. Calc. Mul. 4 I r. Striatula Carbonaria ex fodina Lithanthracum Planitzenfr. Mus. Dil.n. I r 6. Arundinis folia \& Filicula quadam ex eodem loco. n. I I9. Striatula \& caules cum foliis ftellaris cujufdam plantx ex eodem loco. n. I 2r. Neurophylla in Lapide Manebacenf margaceo. n. 246. Comparat vegerabile hocce Myl. Sax. p. 3o. Ligno Aloes \& Arundini, confidentius ego Arundini; confirmant me obfervationes in Turffifodinis Rütenfibus factx, ubi offendi talifmodi Arundinea folia adhuc mollia, quorum eminentia transverfa in fiffilibus quoque feu folfilibus obvia finis elt vaginx caulem obvolventis, \& inirium folii ipfius: Brauner. Letten aus dem Foachims Thal mit Kannenkraut. Myl. Muf. n. 801. Sebr breiter und geftreifter glatt und Scbwarzer fchilf, kommet mit feinen freiffen gleichen, oder gelenken dem ArundiniSaccharinx, Zukerrobr ziemlich bey, oder, ob es eine Arth von dem als Ebenbolz ganz Scbwarzen geftreifft and glatten Robr ift, das Jonft in der Provinz Quantung bäuffig wächft. Volkm. Silef. ror. Tab XIII. f. 7. Eine befondere Arth von einem breiten und geftreiften Robr auf grauem Schiefer in den Koblgruben zu weifflein. Id. 332. T. IV. f. 3 .

80 Arundinis vallatoriz radix. Luid. $p$. I 80.

81 Arundo Indica in Lapidem verfa Corallii fere Naturâ fimilis Calamites, à Calamo. Gefn. Fig. Lap. I I 5 . Ivobrc's ra IopḱvG. Theophr. de Lap. Ad Columellos non ineptè refert Helwing.Lith. P. II. I 4 .

TAB. I. $\quad 82$ EQUISETUMDiluvianum in faxo cinereo nigricante margaceo, 
gaceo, ex Anglia. Muf. Dil. n 22. Diluv. Ad Squamata Schemata refert Luid. $p$. I 10.

83 Equifetum adhuc tenellum in denfam foliorum fpicam congeftum, vel fica Plantre alicujus hactenus ignota ex Anglia. Muf. Dil. n. 25. Conf. A hovai Myl. Sax. p. 30. Diluv.

84. Equifetum \& Filix in Lapide Anglico. TAB. I. fg. 5. TAB. I. Mus. Dil. n. 53. Conf. Equifetum majus. Myl. Sax. p. 30. fig. 3. E5 5. ad p. I6. Diluv.

${ }_{5} 5$ Graner Kranterfchiefer mit dem Equifeto paluftri longioribus fetis. C B. Volkm. Sil. 333. T. XIV. f. 7 .

86 Equifetum paluftre brevioribus fetis polyfpermon $C B$. vel Equifetum minimum feu Cauda equina minima Myl. Sax. $p .30$. fig. 12. ad pag. 19. v. TAB. I. fig. 3. Diluv. Siebet auch der TAB. I. Spergulx Rovill. Alfines fpec. dictx majoris CB. nicht ungleich Volkm. Sil. I I 2. T.XIV. f. 7.

87 Equifetum in lapide fiffili cinereo fufco. Mufei Tigurini. TAB.II. TAB. II. fig. I. Diluv.

88 Equifetum foetidum fub Aqua repens petrificatum. Steinern Kaferfchaftheü oder Katzenwadel. Lang. Hilt. Lapid. p. 53. TAB. XIII. pertinet ad petrificata Poft-Diluviana. Conf. Mort. North. p. I 50. Plot. Staffords. 190.

89 Hippurites. Or a flone with the impreffed image or fgnatu. re of the Equifetum, or Horre-Tail: Grew. Mur. 268.

90 Herniaria cum Cauliculis, foliolis $8 \varepsilon$ vafculis feminalibus, in faxo, fingulis quafi virentibus \& eminentibus. Helwing. Lith. Ang. p. 40. Tab. I. fig. 2 r.

9 I R habarbarum lapideum hoc nomen nonnifi colóre Rhabarbari meret, \& ftructurâ plurimum à Radice illa Sinenfi differt. Besl Muf. г о 3. T. XXXVT.

92 Ganz weiffe Saamen in grauen Geftein, den Hirfekörneren nicht ungleich. Volkm. Siles. I 33. T. XXIII. f. I r. Milium vulgare, Milium album, Weiffe Hirfenkörner, aus und innwendig weifs. Id. I 34. T. XXIV. f. I6.

\section{L. A S S I S $\mathrm{XV}$ I.}

Herba \& Suffrutices, qui flovibus carent, ơ Jemine donantur.

93 M. D. n. I2. FILICIS Species in faxo fiffli margaceo nigro Manebacenfi TAB. I. fig. 8. IO. Dryopteris nigra Luid. Lith. TAB. I. p. 108. Diluv. Porofa Fronde di Felai. Imp. 577. Paproc w Kamieniu Pol. Helw. Ind. Foff. Pol. 
94 M. D. n. I5. Filix quxdam Diluviana ex Fodinis Cumbriæ. Diluv.

95 M. D. n. I6. Filicis fpecies Diluviana ex Anglia. conf. TAB. TAB. III. fig. 7 .

III. $\quad 96$ M. D. n. 44 . In eodem Lapide cinereo Silefiaco duplex Planta Diluviana, una Filix videtur, alia Filicula. TAB.I. fig.9. TAB. I. Cum priori confer 'Trichomanes minerale longifolium, f. Lithotrichomanes longioribus foliis integris donatum. Luid. n. I97.

TAB.1. 97 M. D. n. 45 . Filicis folia in Lapide Manebacenf. TAB. fig. 1о. 1. fig. го. Diluv.

98 M. D. n. 47. Filicis fpecies in faxo Faringdonenfi Anfig. 5. glix. TAB. V. fig. 5. Conf. Plukẹn. Amalth. Botan. Tab. 406. fig. 3. Dihw.

TAB. 99 M. D. n. 48. Filicis pecies pinnulis denfo ordine Cofte fig. 7. adnatis in Lapide nigro silefiaco. TAB. III. fig. 7. conf. Filix. Myl.

XIII. Sax. p. 30. fig. 6. ad. p. 19. \& Filix non ramofa major pinnulis

f. 4. longis angutis profunde dentatis, fupremâ pinnâ lorigius mucronatâ. Pluk. Amalth. p. 93. Tab. 40\%3. Dilno. Filicula petrea pinnulis longis angutis dentaris. Volkm. Silef. $\mathcal{T}$. XlII. $f \cdot 3$. roo Filix ramola mas, pinnulis obtufis mucronatis. Grofs Farrenkraut männlein mit unterkeiffien Blätteren, auf weislicbtem Sandfein. Volkm. Sil. io6. T. XI.f.2.3. no I Leberfarber fchiefer init der Silice querna CB. Eichfarren, Klein Ateinfarrenkraut weiblein Id. ro8. T. XII. f. 2.

IO2. Filicula petrxa IJ. Tab. foliis non ferratis, an dem die

Blätter ganz, und gar nicbt zerkerffet: kommet auch mit der Filice faxatili non ramola, nigris maculis punctata CB. ïber ein auf Scbwarzgrauem Schiefer, Id. I09. T. XIII. f.I. ro 3 Filicula petræa frmina. III. Tab. Id. r ro. T. XIII. f. 2. 104 Filicis Ramulus in Lapide fiffli calcario albo. Helwing. Lith. P. II. p. 94 .

ro5 M. D. n. 50. 58. Ormunda vel Filix ex North. Bierly Lancaftrenfis Agri, \& ex Fodinis Flintenfibus in Cambro BriTAB. tannia. TAB. IV. fig. 6. conf. fig. 3. TAB. cit. \& fig. 2. ac 4. IV. 3.o. Plukenet. Almag. Tab. 402. Diluv. Scbiefer mit Blätteren vorz der Filice non dentata florida. CB. Volkm. Sh. III.Tab. XIV. $f$. I. Folia Ofmund $x$ vel Filicis alius. Id. I I 2. T.XV.f. 2.

TAB.I. 106 M.D.n. 53. Equifetum \&. Filix in Lapide Anglico. TAB. fis. 5: 1. fig. s. Diluv.

TAB.I. 107 Filix mas folio dentato. CB. in Lapide fiffili, Mufei Cifo. 3. vici Tigurini. TAB. II. fig. 3. Diluv.

цo 8 Filicis fpecies foliis longis duodecies pinnatis feu conjuga- 


\section{$\begin{array}{llllllll}A & P & P & E & N & D & I & X\end{array}$}

tis impari claudente extremum fcapum. TAB. V. fig. 9. Diluv. TAB.

rog Filix quadam pinnulis valde tenuibus. Hain. fol. $26 . \mathrm{fig} 3$.

I ro Filix frmina major. Myl. Sax. p. 30. Diluv.

I I Filix. quxdam ramofa foliis denticulatis vel leguminofa. TAB. TAB. IV. fig. 5. Diluv.

I 2 Ramulus truncatus Filicis folia referens, maffx lapidex albx inclufus. Helwing. Lith. Ang. 4I. Tab. II. fig. 5 .

I 3 Lapis fciffili ferè fimiles filicem \& alias herbas petrefactas exhibens. Stein dem Scbiefer etwas äbnlich, worinnen Farnkraut, und andere kräuter, fo zu flein gezorden zufeben. Spen. Muf. 92.

i 4 Lapis partim fciffili, partim Lithomargx fimilis, Herbarum fylveftrium Filicis Polypodii \& aliarum folia petrificata exhibens. Stein zum Theil dem Sibiefer, zum theil dem Steinmarg äbnlich, worinnen petrificierte Waldkräuter, als Farrn, Engelfiifs, und dergleichen entbalten. 1.c.

I I 5 . D. n. 24. TRICHOMANES minerale ex Anglia. TAB. IV. fig. 4. Trichomanes minerale foliis integris mucrona- TAB: tis. Luid. n. 19r. Diluv. Ein Schwarz und grau, bey uns fonft zinbekantes gewäcbs. Volkm. Sil. r I2. T. XV. f. r.

I 6 M. D. n. 56. Planta epiphyllofperma Trichomani fimilis in Lapide nigro Ilmenavienfi. TAB. I. fig. 6. conf. cum Fili- TAB: ce mari non ramofo fimili pinnulis obtufius mucronatis. Luid. n. 184. \& Minera Ferri exprimente Filicem marem. Wolfart. Vale Hanov. S. Io. Diluv.

I 77. M. D. n. 66. Trichomanes feu Polytrichum officinarum C.B. \& caules Arundinis è Fodinis Faringdonenfibus Anglix. TAB. II. fig. I. Diluv.

1 18. M. D. n. I23. Trichomanes in marga fubfufca ex Commodavia Silefix. Diluv.

I I Trichomanes minus \& tenerius C B. fiebet aucb dem Adiantho albo tenui folio Rutx Murarix accedenti nicbt ungleich. Volkm. Sil. II 2, T. XV. f. I.

I 20 M. D.n. 2. $248 . b^{3}$. FILICULA fontana major , $f$. Adianthum album Filicis folio. $C B$. in marga cinerea ex Fodinis $\mathrm{Li}^{\text {- }}$ thanthracum ad pagum Altwafser, duobus à Suidnico milliaribus in Silefia. TAB.I. fig. 7. conf. non tantum Adianthum album Fi- TAB.

licis folio. IB. Sed \& Filix faxatilis caule tenui fragili. Raji. Filicula montana folio vario. Tour. feu Adianthum album tenuifolium Rutx murarix accedens. IB. Adianthum foliis minutim in oblongum fciffis pediculo viridi. CB. Confer Myl. Sax. p. 39. fig. 5. ad p. 26. Marum Majoranam \& Dictamnum Cres ticam. Memorat \& Luidius p. 108. Adianthum album, f. Ru- 
tam murariam Schifto Carbonatio impreffam. Dilur. Filicula petrea fxmina Tab: in marga cinerea colore picta nigro, von Gablau, I I $_{2}$ "meil von Landshut. Kifn. Muf. n. 8. de quo Loco natali v. Volkmann. Siles. p. so8. qui p. ro9. T. XIII. f. s. fiftit Filiculam petrxam feu faxatilem $I V$. Tab. foliis ferratis, $S E$ Filiculam fontanam folio vario. Id. p. In2. T. XIV. f. s.

I 2 I M.D. n. 3. Filicula alia Diluvialis vom Schwartzenald in Scblefen. Diluv.

I 22 M. D. n. I 17. Filicula ex Fodina Lithantracum Planitzenfi. Diluv.

I23 M. D. n. I 8. Filicula quædam \&: ftellaris cujufdam Plante folia ex eodem loco. Diluv.

I 24 M. D. n. I 3 . Filicula ex montibus Giganteis Silefix. Diluv.

I 25 M. D. n. 239. Filicula eadem cum n. 3. von Rablau in Scblefien. Diluv.

I26 M. D. n. 240 . Filicula quedam \& Neurophylla in marga fiffili Planitzenfi Silefiae. Diluv.

I27 M. D. n. 17. OSMUND $\Subset$ fpecies Diluviana ex Anglia。 XAB. TAB. TAB. X. fig. 3. Phyllitis mineralis Luidii. n. 190. Tab. V. fig. Phyllitis trifolia in Tranf. Phil. n. 337. p.95.Tab.I. Fig. 5. Diluv. I 23 M. D. n. I8. Ofmundx precedentis videtur extremitas ex Anglia. Diluv.

I 29 M. D. n. 2 I. Ofmunda alia Diluviana ex Anglia. Tab. IV. fig. 3. 4. Lithofmunda minor f. Ofmunda mineralis pinnulis brevioribus denfius difpofitis. Luid. $n$. I 89. Conf. Ofmunda Regalis, an Filix florida. Parkinf. Tour. Filix ramofa non dentata florida. CB. Filix foribus infignis IB. ut \& Pluken. Almag. Tab. 402. fig. 2.4. Dilur.

TAB. 130 M. D. n. 62. Plantx leguminofx vel Filicinx cujufdam II. frz: 2. cofta extrema foliofa in Lapide Oningenfi. TAB. II. fig. 2. Conf. Filix florida five Lithofmunda. Luid. n. 188. Diluv.

I3 I M. D. n. 46. Planta Diluviana epiphyllofpermos in faТАв. xо dimidiato convexo-plano in profunditate ingenti reperta in 1. fig. Fodinis Ferri prope Newcaltle Northumbriae. TAB. I. fig. 4. Lapis Mineræ Ferri Pilæformi fimilis in cujus meditullio unum vel plura Filicis folia reprefentantur Anglis fofforibus Catbead, Catjcamp. Thoresby in Tranfact. Phil. n. 277. p. 1071. Catsbead. Raji. Topog. obf. 3ir. Diluv.

$\mathrm{I}_{2} 2$ Epiphyllofperma mineralis fcutellata, Phyllitidis folio quatuor ad minimum nervis infignito. Luid. n. I80. Dilisv.

${ }{ }_{33} \mathrm{Li}^{-}$ 


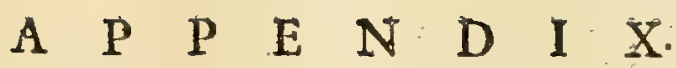

I33 Lichen petrxus latifolius petrificatus, feu Hepatica fontana. C. B. Steinenes Leberkrcut. Lang. Hift. Lap. p. 53. Tab. XIII. Poftdiluv.

134 A flone with the exatt Signature of a flem of Polypody, with the Leaves Grew. Muf. 268. Polypodium minerale Luid. Caprotka Kamienna. Helwing. Ind. Foff. Pol.

Not: Omnis generis Plantæ Lapidibus impreffx propter Filicum Frequentiam Fofforibus Carbonariis Anglis vocantur CarregRedynog. i. e. Fernftone. Luid. in Trans. Phil. n. 337. p. 94.

\section{L A S S I S X V I I.}

Herba \& Suffrutices, quarum flores \& fructus conppicui defiderantur.

I 35 M. D. n. 248. o. Tartarus lapideus ex pluribus MỨSCIS tartarum penetrantibus variegatus prope Florentiam videtur. Poftdiluv. Mufcus lapideus. Pol. Mech Kamienny. Helwing. Ind. Foff. Pol.

I36 M. D. n. 248. q. s. Lapis Calcarius Fiffilis Dendrites adinftar Mufci fquamofi ad fuperficiem infignitus prope Florentiam. Videtur Poftdiluv.

I 37 Mufcus fquamofus niger in marga cinerea von Altwafer. M. D. n. 248. a. 4. Pinus montana fylveftris. Kifn. Muf.n. 26.

I $38 \mathrm{Mu}$ cus vulgatiffimus petrificatus. Steinenes gemeines moofs. Lang. Hitt. p. 53. Tab. XIII. \& Mufcus Filicinus petrificatus. Steines Fabrnkraut moofs. Ejufd. Sunt Poftdilur.

I 39 M. D. n. 198. FUNGUS Lapideus marinus pyxidatus. Columnx de Gloffopetr. Fungites Plotii Staffordshire. Tab. XII. Fig. 3.4.v. Icon. in Querel. Pifc. p. 33. Tab. V. Tit. Caryophyllus marinus foffilis. Ex Agro Bononienfi. Diluv. Ramulus Corallii rubri cum Caryophyllo marino minore. Volkm. Sil. I 26. T.XXI. $f$. II. Columellus major turbinatus fubtiliffime in longitudinem Atriatus, \& in extremitate latius expanfa Atriatus; Caryophyllus marinus maximus. Sebr groffe graue Seemutter nägel Id. $33^{6}$. T. V. f. 10.

I40 Eine andere Arth von einem Caryophyllo marino, an denen etliche Strix bifs an das underfe Theil lauffen. Volkm. Sil. 123. Tab. XX. f, 4 .

I4I M. D. n. 199. Alius ejufdem generis Cornu adinftar recurvus. Bononienfis. Dilur.

142 M. D. n. 200 . Idem ex montibus Querfurtenfibus. Dilur,

$$
\text { K } 2 \text { I43 M.D. }
$$


I43 M. D. n. 20 r. Idem ex monte Randio lapideus. Diluv. 144 M. D. n. 202. Idem in Lapide calcario Gothlandico fluoreus. Diluv.

I45 M. D. n. 203. Idem ex fabuleto Teuttenfi Haffix exiguus. Diluv.

I46 M. D. n. 204. Idem ex Fodina Weiffenfteinenfi Haffix. Diluv.

I4 M. D. n. 205. Idem prope Maffel Silefix. Diliv.

I 48 M. D. n. 206. Idem ex Agro Bafileenfr. Dilur.

I 49 M. D. n. 209. Fungus Lapideus Silefiacus Maslenfis. Dil. The Champinion or Toadflool. Trans. Phil. n. 314. Pol. Grzybiathy Kamienn. Helwing. Ind. Foff. Polonic.

I50 Tartofale impetrite. Mofc. Muf. I75.

i 5 Fungus pileatus. Bajer. Or. 46. T. I. f. 32. Fungus lapideus. Pol.Grayb Kamienny. Helw. Ind. Foff. Pol.

I 52 M. D. n. 245. Columelli varii ftriati ex montibus arenofis Querfurtenfibus. Diluv. Columellus. Pol. Shipick. Helwing. Ind. Forf.

153 Columellus majufculus arcuatus, triuncialis longitudinis, \& craffitiei pollicaris, per fuperficiem ftriatus in bafi paulum excavatus, ftellatus frepe. Helwing. Lith. P. II. ro5.

I 4 Alcyonium majoris moduli, longitudine quinunciali inflexum; in diftantia cujufque Uncix fafciis crebris cinctum, ftriis per longitudinem (exaratum atque ita incurvatum \& intortum, ut extremitates a fe invicem vix latitudine duorum digitorum diftent, in bafi profunde excavatum. Id.. . $\varepsilon$.

I 55 Alcyonium fimbriatum in cujus bafi ftella à centro internarum partium initium fumens, ad externas partes fimbrix inftar expanditur, ut Caryophylli cujufdam fefe explicantis figuram mentiatur, cui Icon Bajeriani Alcyonii Tab. I. n. 33 . Oryct. Noric. quam proximè accedit. Helw. l. c, Tab. III. f. 4 .

I 6 Alcyonium Proliferum depreffum, vix uncialem magnitudinem xquans, obtufiori fua extremitate \& depreffa in turbinem abit, qux depreffio aretius compactas \& frequentiores in eo fafcias, \& inter fafcias, Atrias exhibere deprehenditur. Cærterum, qua parte expanfa cavitas ad modum patellæ confpicitur, in cujus fundo Pectunculus nigredine fplendefcente confpicuus immerfus hxret, in expanfione numerantur 13. alia Alcyoniola, fibi invicem in circuitu arcte ftipata, \& ita minuta, ut vix longitudine ad granum hordeaceum accedant, ex omni tamen parte perfectè ftriata, fafciata, \& in aperturis fuis pulcherrimè ftellata, tali ordine, 
ordine, ut venuftifimam rofeam Corollam effingere videantur. Id.l. c. T.III. f. . .

I 57 Alcyonii profundè ftriati fécimina plara ex uno principio. Conftat hoc ad minimum ex novenis columellis, qui extremitatibus cufpidatis ita connectuntur, ut ex uno quafi vadicationis puncto initia fumpfiffe videantur, diftinguuntur proterea profundis ftriis craffis angulis.

I $5^{8}$ Alcyonium ex uno principio pluribus ramis diftinctum. In hoc ex una quafi radice eriguntur plures excrefcentix, verùm non ftriatæ, quarum qualibet crébris ramis extuberat, $\&_{b}$ cum fuperior pars detruncata, fimulque in duriffimam materiem corallinam mutata fit, ftellifera non eft, fed ad latera circulis exornata. Halcyonio foraminofo Imp. feu 4. Diofc. haud abfimile. H. N. L. XXVIII. c. Helw. p. гоб.

159 Alcyonium columnare polygonum. Ex geniculis denfis \& craffufculis, craffitie pennx anferinx conftructum, ftellarum expers. Id. l. $c$.

I60 Columellus ftellatus Adamante gravidus. Extremitas qua bafin eft capulæ adinftar cava, ftriifque profundis fulcata Id. $p \cdot 107$.

I6I M. D. n. 248. hh. Lapis Fungo petrificato fimilis.

162 M. D. n. 248. ii. Fungiformis alius Lapis candidus pro- $\mathrm{TAB}$ pe Bononiam Diluv.

163 Fungites porofus hujus nominis Fungo fimilis. Ein in Atein verwandelte Morchel. Helwing. Lith. Ang. p. 4o. Tab. II. fig. I.

I6 Fungites Fungum Lœfelii XVII. exprimens. Germ. Rothkopf. Lapidi duriffimo, ut radici infidens. Id. Tab. II. fg. 2.

I 65 Lapis Fungum Clufii XVI. S. Augufti menfis. J. \& C. B. primo intuitu reprafentans, verum accuratius obfervatus Artocreas parvum, eine Kleine pafleten, mentiens. Id. Tab. II. fig. 3. Mycetartocreites.

166 Fungites ex Agro Eboracenfi $A$ Merret $P$ in. 215.

I 67 Fungites cinereus Humberianus gyratim fubtus undulatus, feu Porpites undulatus litoralis. Luid. n. I 57.

I 68 Fungus pileatus. Bayer. Oryct. p.46. Tab.I. fg. 32.

169 Fungitx feu Fungi petrofi. Natiurliche Steinpiltze und Schwämme. Herm. Maslof. p.219. Tab. XI. fg. I. 2. 3 4. 4. 5.6.

170 Mycetite, Fungitx. A coarse Spar in form of a Small Musbrome, refembling the Fungus Infundibuliformis of Ray. Syn. Stirp. Britt. n. 25. p. 17. A very Small Mycetites of a Conicshape, and fo friate, as the Mycetitx ufually are, viz from the 
circumference at the top, dounthe fides to the apex of this Conical littlefione, of a bluish colour \&c. Mort. North. p. 181. A motber of this figure, and thus friate; but ufyally of à Bulkier fize, confifting Wolly of spar, is the Columellus turbinatus albidus. Luid. 21. 134 . Id. 1. c.

17I Fungi Genus lapideum, intus friatum, plerumque hemifphæricum, bafi in plures circulos concentricos diftincta. M. D. n. $248 \cdot \mathrm{I}^{3}$ Lapides rotundati, hemifphrrici, faltigiati, porof, fulcati, rugofi, cavernofi, friis capillaceis prxditi, quorum bafis plana, \& in nonnullis circinis exalperata vifutur. Helwing. Lith. 72. Tab. VIII. fig. 15. 16.17.

172 Fungus marinus plicis repundis. Ein See Scbwamm mitt übergefchlagenen falten, oben mit einen grüblein, worinnen der Aiel geftanden, fiebet auch einem wejpenneft nicbt unäbnlich. Volkm. Silef. 123. Tab. XX. f. 6.

173 Fungus marinus foffilis albus orbiculatus, weiffer runder Scbwamm, rauch und fcharff als ein Bimfenften, unten bobl. Id. 124. T. XXI. f. 8.9.

174 Fungita Fungum Favaginofum cavum feu Radicem Ariftolochix rotundx exiccatx referens, Id. I37. T. XXIV. f. 24.

I7 $5-$ veluti in nodum collectus. Id. I3 8. T.XXIV. f. 25.

176. LYCOPERDITES vulgaris major. Lang. Hift.p. 52.

177 Lycoperdites rotundus orbicularis. l.c.

178 Lycoperdites minimus pediculo donatus. lic. Dubii.

I79 Apetrifyd Tuber with feveral knobs, not much unlicke that called Cervi Boletus. Grew. Muf. 274.

180 M.D. n.6. ALGA tenuifolia feu Graminis fpecies DiluTAB.v. viana. TAB. V. fig. 3 . conf. Alga tenuifolia Luid. p. Io8. Poraft w

ff. 3. Kamieniu Pol.Helw. Ind. Foff. it. Poroftowy Kamien. \& forte Phycites Plin. Lib. XXXVII. cap. ro. Sed feparandus Fucus petrificatus. Lang. Hift.p. 53. Tab. XIV.

18I M.D.n. 248.c. Dendrites Algax ramofx fimilis in Lapide viridanti.

182 M. D. n. 248. d. Alga alia latifolia ramofa in marmore viridi.

I 83 M. D.n. 248. e. Alga alia tenuifolia ex Monte Mavore in faxo cinereo.

I84 M. D. n. 248. m. Lapis Florentinis Pietra forte dictus, quafi Fucos vel arbores aphylla ad extimam partem exhibens.

- 185 Fucus folio rotundo C. B. Opuntia lapidea fimilis Opuntix marinx littorali \& faxatili. Cluf. Helw. Lith. P.II. p.96.

186.M. D. 



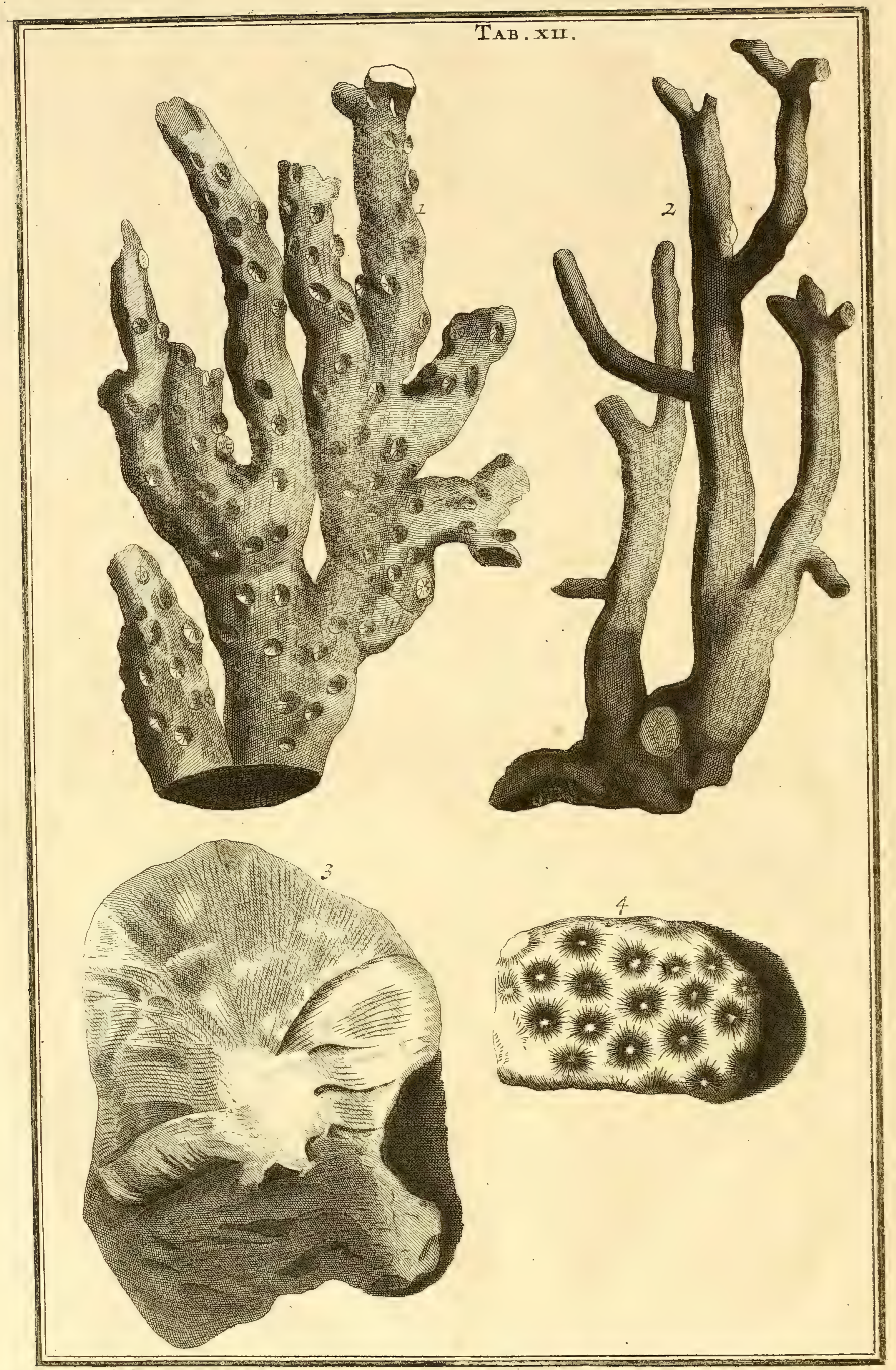

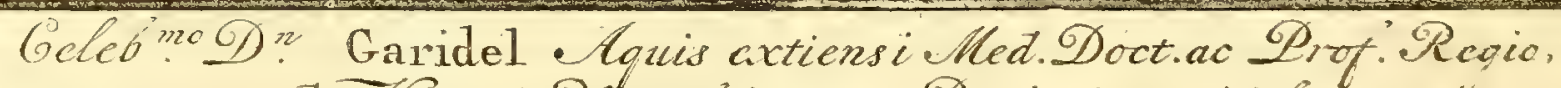
de Thistoria Waturali in primis 2 rosincico meritisfimo. 
I $86 \mathrm{M}$. D. n. II 3. Silex igniarius nigricans CORALLIIS fiftulofis, rariflimis \& Retepora Diluviana obfitus ex pago Muck prope Lipfram. $n \cdot 122$. Saxum Corallis refertum prope Lipfiam. 32. I27. Pyrites filiceus ex montibus arenofis Querfurrenfibus Corallio reticulato foffili pragnans. Corallium. Myl. $S d x . P . I I$. T. IX.f. 2. Corallium foffile. Mell. Lap. Fig. Litb. p. 2 I。 T. II. $f: 2$.

187 M. D. n. I88. Corallium foffile albidiffimum prope Lipfiam.

I 88 M. D. n. I29. Corallia varia foffilia ex montibus arenofis prope Querfurtum.

I 89 M. D. n. 4o. Corallium foffile cortice reticulato obductum. Spec. Lith. Helv. p. 14. fig. 17. Porus Gallinacex pennx minoris craffitie undequaque punctulatus. Luid. $p$. 105 . Corallites major reticulatus. Lang. Hift. p. 56. Tab. XVII. Berg-Corallen. Corallium album punctatum rugofum, aliquando lave, furcatum \& ramofum. Helwing. Lith. Ang. 49. Tab. IV. fig. x. 2. 3. conferendum cum Corallio tuberofo punctato. Worm. Muf. 233 . Mellen. Lap. Fig. Lub. p. 22.

I90 M. D. D. I45. Corallium album marinum foffile ex Gallia.

i9r M. D. n. 147. Porus Coralloides foffilis ex Sicilia. Corallites. Grew. Muf. $27 \mathrm{I}$.

192 M. D. n. 162. Corallium quoddam album ramofum in faxo arenario. De Remoulins en Languedoc.

193 M. D. n. 168 . Corallium porofum feu ftellatum cinerei coloris in faxo Querfurtenfi. Refp. Corallum album fellatum. C B. Corallium ftellatum Imp. Volkm. Siles. I $23 . T \cdot X X$. f. 9 .

I94 M. D. n. r69. Corallium albidum vel cinereum Querfurtenfe conferendum cum Hippuri faxea. Corallo articulato. Imperat. Stor. Nat. $L . X X V I I$. Scilla vana fpeculaz. difingan. p. I42. Tab. XXI. Tiene annodamenti fimili alle giunture de gli Animali - ramofo nel modo de gli altri coralli, compofto di pezzi fimili de' fincbi d'Animali Sanguigni, de' quali l'uno all' altro con profondi articoli, fi congiunge.

I95 Corallium littoreum, Hippuris marina, Hippuris faxea. Clus. feu Equifeto fimilis faxea: Columellus Coralloides craffufculus. Luid. Columellus fulcis tranfverfis exaratus. Herm. Masl. Ift ein groffes \$tuck von dem Stengel, der rund und glatt, mit gleichen oder gewerben unterfchieden, die Striat find, Zivischen den gezwerben, und oben, wo es abgebrochen, radiat, Braun oder Braungelb, oder weiss. Volk. Silefi I 19. Tab. XVII. 
f. 8. Ein fuck von einer Hippuride faxea majori ftriata, groffen feinemen Pferde Scbwanz-Katzenzagel. Id. I24. T. XXI. F. 6. Conf. n. 278. a. Pol. Strze pecza Kamienna. Helwing. Ind. Foff. Pol. Hippuris faxea littorea Rumphii craffior, \& articulis profundè ftriatis, iifque abinvicem facile feparabilibus diftincta. Helw. Lith. P. II. 95 .

I96 M. D. n. i>0. Corallii porofi Querfurtenfis fragmentum pollicaris craffitiei.

I 97 M. D. n. I7I. Silex Achatinus niger Querfurtenfis Retepora flavefcente obductus. Conf. n. $16 \mathrm{I}$.

I 98 M. D. n. I72. Corallii fofflis fragmenta parva varia ex Montibus Querfurtenfibus.

199 M. D. n. 188. Corallinorum Lapidum ftriatx matrices ex Randio.

200 The branched fort of Coralloids. Mort. North. p. 185. Tab. II. fig. I I. Forfan potius pertinet ad vermes tubulatos.

20 r Corallium foffile exalbidum minimum Luid. n. I6. $A$ branched Coralloid-bodie. Morth. North. p. 185.

202 Corallium foffile ramulofum, Coralloides fruticofa recta alba. CB. Die zu ftein gewordene Erde oder Lett, fo ficb Zwischen die Ramulos oder Virgulas geleget, ijt ockergelb, oder Pomerantzenfarb, die Virgulx weîss und glatt.Volkm. Silef. Ing. T. XVIII. $f$. r.

203 Maffa Lapidea ex ramulis Corallinis punctatis tam rectis, quam inclinatis, frepe etiam ramofis conftans, \& adinftar vermiculorum uncialis Longitudinis craffitie Lumbricis junioribus fimili fibi invicem ftipatis. Hujus Specimina nonnulla, quoniam ramulos ftellatos in extremitate oftendunt, ad Milleporam referenda reor. Helwing. Lith. p. 50, Tab. IV. fig. I4. $X I . n .5$.

204. Alia ejufdem farinx, in qua ramuli Corallini partim punctati, partim porofi, partim pectunculi adinftar ftriati, nonnulli denique depreffi apparent. Id. Tab. IV. fig. I5. Conf. Büttn. Coralliog. Tab. IV. n. I. eadem cum Campoide Helwingii , \& Ramulis feu fragmentis Corallinis triatis. Volkm. Sil. $335 . \mathcal{T}$. IT. f. 5 .

205 Fruftum Corallii dendrici, lividi \& albi coloris, fibris non rectis, fed paulum inclinatis, atque arctiffime compactis conftans, quorum denfa conftipatio in extremitate in catenulam effigiatur. Büttn. Coralliog. Tab. V. fig. I.

206 Corallii fiftulofi fpecimina, fluctuum interluentium iterata vi exefa \& ftrigis ac profundis fulcis exarata, quae expan- 
frone fua in Corallium in Büttn. Tab. Il. fig. 8. expreftum figurantur. Id. $p$. $5 \mathrm{I}$.

207 Corallium ramofum Luidii Antropodio ramofo vulgari, feu ftella foffili arborex virgulto fimile, cujus iconem vide inter Luidianas. n. I $32.1 \mathrm{l}$. Tab. XI. n. 4.

zo8 Maffa Corallina, que fparfin minutis eminentiis firtulofis turget, quas inter circelli \& ductus quidam albedine corallina confpiciuntur, totumque lapidem penetrant. Id. Tab. V. fg. 2. Fragmenta Corallii tubuloli albi cortice tenui. Volkm. Sil. 335 . T.V.f. 9 .

209 Lapis totus ex fubtilibus Tubulis fiftulofis denfiffime conftipatus, fiftulis quidem fucco petricolo farctis, quondam vero, ut conjicitur, porofis, ideoque non incongruè poris Imperati affociandus. Luid. Tab. V. fig. 3 .

210 a. Tubulariae Coralloidis ex fifulis collateralibus compofitie fpecimen. Id. Tab. V. fig. 4.

2 ro b. Lapis, in cujus fuperficie inordinati ductus albi, vermitum petrificatorum materia Corallinorum exponuntur. Id. Tab. VI. fig. 2.

2 II Corallii dendrici generis particula, ftructurx fubtilis, in extremitate faciem ftellatam exhibens. Id. Tab. V. fig. 5. Simillima eft Bürtneri Coralliog. T. I. f. i4:

2 I 2 Fruftum Corallinum, in quo varix expreffiones ductus \& fiftulæ reprefentantur, quibus catenula accuratè articulata implicatur. Helwing. T. V. fig. 6. VI. f. I.

2 3 Lapis, in quo vegetatio Corallina ex fiftulofis excrefcentiis cavis, iifque furfum prominentibus apertiffimè cognofcitur. Id. Tab. V. f. 7 .

2 I 4 Lapis Corallii nigri figuris vegetabili cuidam non diff-a milibus ex utraque parte indiftincte effigiatus. Id. T. $V . f .8$. VI. f. 3 .

2 is Corallium foffle craffius ftriatum. Id. T.V.f. i $8, p \cdot 53^{\circ}$

2 I6 Ejufdem fpecimina ovalis fere figurx. Id. T.V.f. 19.

2i Corallii fafciati, \& in fuperficie in longum ftriati fpecimina, inter Columellum \& Hippurim ambigentia, ut vult Büttn. Corall. T. II. n. IO. Id. T. V. f. $20 ; 2$ r.

2 I 8 Ramulus corallinus ftriatus, gyris nonnullis cinctus, $\mathrm{cx}^{\mathrm{m}}$ teroquin geniculatus. Id. T.VI. fig. Io.

219 Lapis albidus Catenula tam pulchrè articulata, quafi Aurifabri manu fabricata fuiffet, circumvolutus. Id. T. $V I$. f. r. $V . f .6$.

220 Matrix Corallinorum, in qua Coralline fiftule denfe L. mufci 
mufci inftar ftipatx funt, \& circumcirca eminere deprehenduntur. Id. T. VI. f. z.

2 2r Corallium externè fiftulofum, intus cancellatum. Büttn. Tab. I. n. 12. I3. falfo à nonnullis pro gyplo fpumofo venditatum. Id. T. VI. f. 4.

222 Corallii craffioris ftriati fragmentum, cujus ftrix ita manifeftr funt, ut fiftulofis Coralliis aptiffimè affimilentur. Id. T. VT. f. 5 .

223 Maffa Lapidea, in qua confractorum Coralliorum internæ partes profundius fulcatx, \& fimul transverfalibus ftriis exarata confpiciuntur. Id. p. 54. T. $V I . f .8$.

224 Corallium porolum in latum \& finuofum ambitum fungiformem expanfum. Id. T. $V I, f \cdot 9$.

225 Corallium aliud intus materia cretacea impletum, extra loco ftriarum tuberculis punctulatis fine ordine pofitis confpicuum. Id. T.VI. f. 7.

Merentur recenfionem particularem Corallia foffilia, prouti ea defcripfit $\mathrm{Cl}$. Büttnerus in Coralliograpbia fua fubterranea. nempe:

$226 \mathrm{Tab}$. I. fig. I. Tuber feu Globus corallinus fitulofus, \& quodammodo erolus \& obtufus, conferendus cum Tab.XII. n. 10. Maslog:, \& ex marinis cum Tubularia Coralloide. Tab. VIII. fig. 5. Relat. Ind.

227 - 2. Fragmentum Trunci Corallini porofi. conf. cum Corallio marino. Valentin. Muf. Muf. p. 108.

$228 \rightarrow-\ldots$ 3. Tubularia Coralloidis feu Globus corallinus.

229 - - 4. Fruftulum Corallii cujufdam nodofi ac leviter friati. Videtur Ipecies Hippuridos faxea vel Corang-Alea.

230 - - 5. Particula Corallii albi truncofi ac nodofi, caveis aftroformibus diftincti. Accedit ad fpeciem Corallii albi ac levis, Carang Bonga dictam. Volkm. Sil. I 26.

23 I - - 6. Particula Corallii punctati.

$232--7$. Globus Corallinus exhibitus quoque à Myl. Mem. Sax. P. II. Conf. cum Waffelfteine. Relat. Ind. p. $116 . \mathrm{b}$.

$233--$ 8. Furculofa punctati Corallii particula. Conf. cum Alcyonio $n$. 347 .

234 - - 9. Fragmentum maffx lapidex ramulis corallinis repletis, ftriatis, intortis, præruptis ac affabre formatis. Convenit quodammodo cum Carang-Goyla Afiatico.

$235 \div$ 10. Fragmentum Corallii. Conf. cum $A$ carba- 
carbabar Speciei ruber, vel Datu Szangi Relat. Ind. p. r r 4 b. Placenta corallina tubulofa ramulis tenerioribus, Corallen klump, mit vielen kleinen Pfeifien, dicht aneinander ßebend. Volkn. Sil. T. XXI. f. I.

236 Tab. I. Fig. I 1 . Corallium globolum \& quodammodo preffum, ductibus erroneis gyratis \& contortis. Idem cum Maffa Corallina Indis dicta Patu Parudan.

$237-1$ - 12. I. Fragmentum Corallii fiftulofi externè, intus cancellati: adjudicanda maffre eidem $P$ atu $P a-$ mudan.

238 - - 14. Particula Corallii placentiformis, Atructurx fubtiliffimx generis lignei.

239 - Is. Corallion ejufdem fpeciei ac Indolis. $\mathrm{Co}_{-}$ rallium placentiforme ftellatum; Aftroites ftellulis clegantiffimis exornatus. Volkm. Sil. $335 . T_{\text {. }} V . f .6$.

240 - - I6. Particula Corallii e genere lignofo porofi magis quam ftellati.

$24 \mathrm{I}$ - - 17. Particula ejufdem indolis denfror prexcedente. An Efchara marina rimis feu poris longiufculis. Volkm. Siles. $123 \cdot T \cdot X X, f .7$.

$242 \div-18$. Foffle, quod proxime accedit ad $C_{y-}$ lindriten geniculatum fubcoruleum. Herm. Maslog. p. 22 I. Tab. XI. n. 36 .

243 - - 19. Fruftulum Corallii albi Dendrici generis, fed indurati.

244 Tab. II. fig. I. 2. Corallinum foffile ramis collateralibus nodofis, Zonulis elegantioribus inftructis ac leviter friatis.

245 - - 3. 4. Truncus Corallinus albida ac punctata cortice obductus. Conf. cum Maslog. T.XI. f. 62. Luid. Lith. $f .176$. item Corallio albo pelagio. Relat. Ind. T. VIII. f. 4. 7. Volkm. Sil. $335 . T_{0}$. i. f. 7 .

246 - 5. Pars Corallii lignei ac Atellati generis. conf. cum Tab. I. fig. 14. 15 .

247 - 6. 7. Maffula Corallina globulum porofum una cum ramis incurvatis ac punctatis continens.

$248--$ 8. 9. Corallium fiftulofum ac lúridum.

$249-$ 10. II. Fragmentum rami Corallini denfioris, nodofi, ftriati ac gyrati. Medium tenet inter Columnellum \& Hippurim faxeam. videtur Carang Alea. Relat. Ind. p, 116. 250. - - 12. 13. Corallium album marinum valgare. Conf. Maslog. T. XI. f. $5 \%$.

$251-14$. Extremitas cujusdam Corallii lignei.

$$
\text { L } 2 \quad 252 \mathrm{Tab}_{1}
$$


$25^{2}$ Tab.II. fig. I5. \& 16 . Superior \& inferior pars Placentic Corallinx. Huic amulum Corallium, in cujus una parte ramuli trbulofi tenues, ut culmuli arcte coherentes \&c. Helw. Lith. P. II. 126 .

$253---17$. Particula Hippuridis, ut videtur, incurvata, gyrata, perdura, pernigra.

$254 \div-18$. Maffa faxea, lurida, coralliis Candidis fiftulofis, leviter gyratis, fed diffitis confpicua. conf. cum Millepora Imperat. delineata in Relat. Ind. T. IIII. f. ro. Corallia candida Zonis feu gyris circumfcripta. Volkm. Sil. I24. $T$. XXI. f. 2 .

255 - - 19. Columnellus conf. cum Polonglant, $\mathrm{Co}-$ rallio marino Afiatico, \& Caryopbyllo marino. Querel. Pifc. p. 33. Caryophyllus marinus ftellis majoribus. Groffe Seemutter Nelke. Volkm. Sil. I2 2. T. XX. f. I.

256 - 20. Mafla calcaria, qua captivi tenentur articuli ftellarum marinarum, cum duobus caryophyllis marinis preffis.

$257-2$ - 2 . Coryophyllus minor, feu Columnellus albidus, conf. cum Tfrenielant Malabarum. Seenagelein.

258 ' $\Gamma$ ab. III. fig. 2. Id. $\operatorname{cum} n$. 192 .

$259-3$ - Corallion, Lithoftrotion ac Bafaltes Luidio, \& Hermanno dictum, inftructum majoribus ftellis ex Maslog. T. XII. n. 20. mutuatum. Corallium foffile Madrepora. Imp. Volkm. Sil. I т. T. XVT. f. I.

260 - - 4. Fragmentum Corallii, idem cum i. s92. ex Spec. Lith. Helv. f. 50 .

$261--5$. videtur Fungi marini pars.

$262--7$. Idem videtur $\operatorname{cum} n_{0} 334 \cdot 8 c$.

$263--1$. videtur Corallion generis lignei placentiformis.

$264-$ - - Foffile cortice nigro \& Caftaneo ad $\mathrm{Co}-$ rallina referendum.

265 - - Io. I I. I2. Vegetabile quoddam marinum. 266 Tab. IV. fig. i. Corallia fubriliffima (flores CoralliXI. fgi:z. nos dixerim) in maffa lapidea.

$267-2-2$. Ramulus Microfcopii ope major jufto delineatus.

268 - - 3. Reticulum Corallinum cavum \& porofum, itidem Microfcopio fubjectum.

269 - - 4. Ramuli Corallini, porofi, punctati, exColuti è Lapide corneo.

$270 \mathrm{Tab}$. 


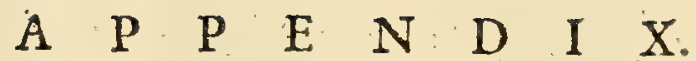

270 Tab. IV.fig. 9. Truncus lapidis cornei ramulis preruptis ac concavis, in cavitate albicantibus.

271 - - 6. Fragmentum lapidis cornei ramis fubnigris $\&$ punctatis.

272 - - 7. Truncus ex utraque parte preruptus; ftriis eminentioribus: luridus \& cretacea circumdatus vefte.

273 - - 3. Lapis cornets ramulis ac globulis fibi invicem adunatis.

274 - - 9 .

teporầ \& Efcharâ obductus.

275 - - 20. Corallium latiforme, friatum, puncta tum, nodofum, fufcidum.

276 Tab. V. fig. 8. IO. I r. Ramuli Corallini in lapide corneo.

277 - - 9. Ramulus prxcifus prediati lapidis cornei partim ftriatus, partim punctatus.

278 - I2. 13. I4. I 5. Ramuli Corallini poris in modum gyri ac Zonulx inftructis.

279 - - 16. 17. Reticula marina in lapide corneo. Hucufque Bittnerus.

\section{Ex Volkmanni Silefía.}

280 Corallium foffile ramofum feu furcatum, In einèm lie chts gelben Sandlein. p. I 17. T. XVI. f. 2.

28 I Corallium tuberculofum, Fungum Coralloid, Corallen Schwamm, fiebet auch einem Alcyonio nicht ungleich, 沙 weiss, wie mit vielen Hoggern, bat die geftallt eines Gebirns. Id. Fig. 3.

282 Fragmenta Corallii albi, Corallii albi fortè geniculati. Chabr: weiffe Corallen Röbrlein, oder abgebrochene röbrichte Zincken, bin und her zerftreuet auf weifem Stein. Id. T. XVII. f. r.

283 Madrepora, oder Corallium rotulis feu Circulis punctulatis albis, in braungelben Geftein. Id. 118. fig. 2.

284 Corallium Madrepora dictum albidum, foraminofum, Lapis Corallinus albus eleganter ftellatus, Aftroites Maris Orientalis, nonnullis. Ift löchericht, wie ein Scbwamm, oder ein Os fpongiofum, doch fteinhart, die Tubuli bobl und oben geftirnt. Id. f. 3 .

285. Corallium foffile verrucofum, \& cancellatim Atriatum. Corallium album verrucofum Boetii de Boot. An potius Pfendo Corallium foffile pufillum ramulorum loco tuberculis compofitum. Luid. Anfswendig grau und gëfreifft, bin wnd wieder böckericht und mit kleinen verrucis oder Wäralein befeat, welche poros, wind um den rand weiss find. Id. I18. T. XVII. f. 5.

286 Corallina cortice reticulato; planta marina retiformis.

$$
\text { I } 3 \quad \text { Cluf: }
$$


Clur. Tebet wie ein geftriktes weiffes, und über einen Stein gezogenes Netze aus, das von dem Geftein etwas erboben. Id. f.6. Corallina reticulata. Id. T. $X X I$. $f .5$.

287 Corallium catenulatum, weil es wie eine gliederketse gefrallt, die Catenulx find weifs, der Stein Ockergeel, kommet mit dem Antopodio ramofo vulgari, feu Stellx foffilis arborex Virgulto, Luid. in etwas iberein, Id. f. 7. Corallium catenulatum ductibus erroneis, gyratis, \& catenulatis notatum, die Catenulx find kleiner, mebr erboben mit weiffen rändlein. Id. T. XX. f. 3 .

288 Aftroites littoralis punctatus, das Geftein if braunroth, and glatt, dhe puneta fleischfarb, zurveilen if das Gefein gran, oder Afchfarb, die puncta weifs. Id i ig. Tab. XVII. F. Io.

289 Ein Ziegeilfarbener Stein mit dunkelrothen Ringlein, welche vor das obere theil eines Corallii tubulofi, Alcyonii rubri fortè, können angefeben werden. Id: T. XVII. fig. II.

290 Eine Species Corallii fofflis, Aftroites dictus, circellis albis radiatis paffim notatus. Der Stein if dinkelgrat, die Circelli oder Afterifci radiati weiss.ld. T. XVIII. f. 3 .

291 Corallium Arachnion, Aftroites Arachnoides, feu telis quafi araneis obtextus, pentagonus, Aftroites vorticalis, weil ermeinem weiffen ftein, der mit den allerfubtilften und meift fiunfeckicbten Spinnenweben ïber zogen wäre, oder die vortices Cartefii artlich reprefentiert, äbnlich febet. Id. r 20. T. XVII. f. 5.

292 Alcyonium fpongiofum, feu porofum, afchgrau um und um als wie mit einer nadel getiipft. Id. T. XVIII. f. 6 .

293 Scheinet das obere theil von einer Urtica marina, und zwar von der vierten fpecie Bouffueti de Nat. Aq. Oben if es grau, glatt und rugos, unten da es zufammen gepreff, um und um mit vielen brannen und fubtilen bäbrlein als ftacblen befezt. Id. T. XVIII. f. 7.

${ }_{294}$ Corallium ftriatum feu Columnellus ftriatus glandiformis, frebet wie eine Eichel, die noch am Calyce oder Köpflein fizt, grau, nach der Länge von unten bis oben aus geftreifft, wie ein Lapis Judaicus. Id. T. XVIII. f. ro.

295 Aftroites afterifcis magnis feu radiis folaribus notatus, Sonnenflein, ift grau, rauch, und von einer Kifelbärte. Id. I II. T. XVIII. $\mathrm{f} . \mathrm{I} 2$.

296 Corallium non ramofum Madreporx fecunda fpecies Chabr. in grauem kieficbten Stein: die Tubuli find gran, mit einem breiten rand bobl, und bis in die tieffe geftreifft. Id. T. XIX. f。 2 。 


\section{\begin{tabular}{lllllllll} 
A & $\mathrm{P}$ & $\mathrm{P}$ & $\mathrm{E}$ & $\mathrm{N}$ & $\mathrm{D}$ & $\mathrm{I}$ & $\mathrm{X}$ & \\
\hline
\end{tabular}}

297 Sebr curieufes und groffes Corallium, fo eine fpecies $\mathrm{Ma}$ dreporx.Die tubuli nebft dem Geftein, find roth, von unterfchiedenerGröffe, dicht aneinander gefezt, eines guten mefferrukens dick, auch dicker, geben durch und durch; die innere fubftanz if fchwammicht, einem Off Spongiofo gleich. Id. I22. T. XIX. f. 5 .

298 Eine befondere arth Aftroiten, brain, durch und durch geflirnt. Id. I 33. T. XX. f. 2 .

299 Eine Placenta Corallinoides, und eine fpecies reticuli marini, oben punctulat, unten rugos, oder undulat, grau. Id. T. XX. f. 5 .

300 Scheinet ein fragmentum $P$ alme feu manus marine. Gefn. $\mathrm{CB}$. braun, oder rufsfarb, risntzelicbt, löchericht, und bin und wieder gekrimmet, auch oben wieder in zwey oder drey kleine finger zertheilt. Id. I23. 'T. XX. f. Iо.

30 I Corallium cortice reticulato \& tubulis repleto, weiss und gegittert, oder wie mit einem fubtilen nez überzogen. Id. T. XX. f. Ir.

302 Ein vegetabile marinum, deffen untere theil kommet dem Fungo marino, oder Meerschwamm, Buttn. T. III. fig.- 5. nicbt ungleich, das obere aber if obne falten, mebr convex und punctulat. Id. T. XX. f. I r.

303. Aftroites, deffen durch und durch geftirnte fubftanz wie Röfslein ausfiebet, Rhodites. Id. 124. T. XX. f. I 3 .

$304 \mathrm{Maffa}$ Corallina porofa, Aftroites cellulis quafi depictus. Herm. Masl. T. XI. n. 29. Corallen klumpen, mit runden klumpen, wie zellchen for. Id. I 24. T.XXI. f. I.

305 Corallia fiftulofa. Corallenpfeiffen, welche tieff im Geftein feken. Id. T.XXI. f. 3 .

306 Ein ftuk oder Schale einer Urticx marinx parvx Bouffueti de Nat. Aquat. oder eines Malo Granati. Id. I 25. Tab. XXI. f. 9 .

307 Corallina alba Tab. Corallina tenuifolia. Velfch. Flores Corallini, weiffe Corallen bliumlein, Mufcus marinus Coralloides in einem gelben Lapide corneo feu Silice. Flores Corallini auf einem mit gelbem Lette überzogenem dunkelgrauen Hornftein. Die Flores find theils punctulat, theils obne punctis, und fiftulos, Corallina minima fiftulofa genannt. Id. I 26. T. XXI. f. 10

308 Corallium nigrum foraminofum feu porofam, das sim und um mit runden locblein, und oben won dem inneren Circul an bis au derPeripherie geftreifft oder geftirnt iff.Id.334. T.V.f. 4. 
309 Fin dicker $A R$, von einem Corallio punculato, der oben und unten mit den allerjubtilften friis von dem inneren Circul an bis zu der peripherie gefirnt, als wenn fie mit einer nadel binein geftocben wären. Id. 335 . T. V. F. 8.

Ex Helwingio.

3 ro Corallium ramulis punctatis maffx lapidex immerfis, magnitudine \& crallitie fua notabili, Corallia punctata ramofa, hucufque à Lithographis propofica fuperans. Helwing. Lith. P.II. I 26. T. VI. n. I.

3 I M. D. n. I35. MADREPOR E ftella in marmore EyAtettenfi.

3 I 2 M. D. n. I 36 . Aftroires pyxidatus feu faraginofus $\mathrm{Sa}-$ buletorum. Luid. Lith. $n$. 167. ex Sabuletis Oxonienfibus. Altroites cellulis quafi depictus, Bienenzellchen, Bienen maf. Herm. Masl. p. 22 I. fig. 29. Fabago feu Favago lapidea. Helw. Lith. P.II. I 24 .

313 M. D. n. I37. Aftroites ex Danubio.

3 I M. D. n. I38. Afroites in Marmore grifei coloris Salisburgenfi

3 I5 M. D. n. I4I. Aftroites Tyrolenfis crudus n. I 42, politus. Starryfone, Starred-frone. Angl. Grew. Muf. 305 .

3 r6 M. D. n. I 46. Madrepora Rellata foffilis. De Cbaumont en France.

3r7 M.D. n. 148 . Conf. n. 259. Aftroites majoribus ftellis ex Birfa. Spec. Lith. Helv. p. 36. fig. 49. 50. Pierre etoilée TAB. avec les Etoiles amples. Pierre etoilée marquée de grands pores fir. 4. raifonés. Coralloides. Boccon. Rech. Nat. p. I I 9. Porpitz aliquatenus affinis Radiatula. Luid. n. is 8. Lithoftrotion feu Bafaltes minimus ftriatus \& ftellatus. Id. p. 122. Tab. XXIIT. Lapidis Aftroitidis f. Aellaris primum genus B. de Boot. L. II. c. 146. Cat. p.2. Trans. Phil. n. 252. Pietra Stellaria di Gregorio. Tranfter. Lapillus in India è capite Draconis erutus. Mars. Ficin. de Vita Colit. compar. L. III. c. I5. Lapis ftellaris. Card. Rer. variet. L. VII. Draconites five Dracontias. Agric. Nat. Foff. L. VI. Aftroites difinctiffimè ftellas æmulans. Muf. Swammerd. p. 6. Afroites Gefn. Fig. Lap. 35. Stellatus Lapis Aldrovand. Mul. Met. p. 872. fig. p. 877. 878. 879. Afroites or Stary Stones Plot Oxfordshir. p. 87. Tab. II. fig. 6. 7. 8. \&. p. I30. Tab. VIII. fig. 2. Millepora Imperat p. \%20. Aftroites ligneus elegantior ftellulis totam maflam permeantibus. Luid. $p \cdot 9 \cdot n \cdot 160$. Tab.II. An Aftroitx congener Radularia cretacea. Ejufd. p.10.n.176. Tab.II? \& Tab.III.n. 98. 


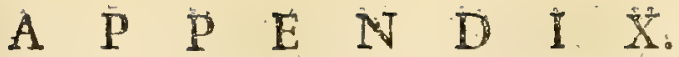

Afterias Cardioides nojor. Velich. Hecat. p. 6o. Afterias fellis majusculis. Afterias ftellis minoribus. Cometites an Rhodites? an Afteria confufé ftellas reprefentans. Ejusd. 1. c. Starftone. Aftroites in Anglia repertus, atque ita immutatus, ut in Achateam vel filiceam duritient \& diaphaneitatem converfus fit. Sloane Nat. Hifl. of Gamaica. Tab. XXI. fig. 10. i I A Atroites Mort. Nat. Hift. of Northampt. p. 18 3. 184. Tab. II. fig. 9. Io. Aftroites vulgaris cineretis. Lang. Hif $\mu_{0}$ p. 59. Tab. XVII. Aftroites Stellis maximis, Geftirnftein mit den gröftenSternen. Id. Tab. XX. Aftroites tubularis candidus. Ein Röbrigeftim Stein. Id. T. XVII. Aftrochites. The flars are round. The Jpaces between the feveral ftars and Rays of a dark blakish colour. They rays or Aars themfelves are pale. And alfo firrounded with a tootbed Circle: fo as not unaptliy to reprefent the wheel of a watch, from whence i bave nam'dit. Grew. Muf. 305 . Aftroites ftellis prominentibus, foraminibus apertis. Helwing. Lith. Ang. p. $3 \mathrm{r}$. Tab. I. fig. 2. 3. Millepora Imperati feu Corallium foffile tubulis Lumbricorum ad inftar craffis, ramofis, \& tam in fuperiore, quam inferiore parte prominentibus, extremitatibus itellatis $8 x$ fucco petrificante impragnatis \& claufis. Id. $p .49$. Tab. IV . $f: 7$. Corallium albidum fuperficie figuris atriformibus. Id. $T$. $V . f$. 22. quod Echinometrx meo Spec. Lith. fig. 8 s. minus rectè comparat. Lapis Jaspideus cinereo-rubefcens \& $\mathrm{x}$. Hort. Cath. Lege. Lapis marmor è rubro pallens, ftellis multo majoribus, Petra ftelIaria marmoria. Sic Cup. Hort. Cath. Suppl. att. 48. Idem Jaspidea fubftantia \&c. Hort Cath. lege. Lapis Marmor è rubro pallidus, folari.fpecie figillatus, Petra ftellaria Marmoria, $c t$ fiddi grandi comefuli. 1. c. Lapis ftellatus vel ftellaris, aut Aftroites marmoreus candidus. Petra Stellaria marmoria uranea. Sic. Id. $p$. 49. Idem cinereus. Petra ftellaria Chiummina. l. c. Lapis ftellatus major arenofus. Porofus ftellatus major Imp. Petra Atellaria duci ordinaria. 1.c. A fort of Marble, wich when polishd reprefents a number of fmall Oranges cut acrofs; the reafon whereof is an infinite quantity of Porus or Alcyonium, ftulck throug the ftone. Luid. in Tranfact. Philof. n. 337. p. 275. Porofa ftellata maggiore è minore. Imp. 577. Aftroites, Sternftein theils mit groffen braunenSternen auf weiffen boden, theils mit bellbraunen Sternen auf dunckelen Boden. Brack. Muf. 8. Aftroites mit 5. groffen, tieffen, runden löcheren, in welchen Sternen von vielen Radiis zufeben. loc. Rarer Aftroites mit groffen Sternen, ijt bart wie ein Marmor, und gläntzet, wie ein Glafs. Id. 9. AAtroites mit ganz verflofenen und confufen löcheren. 1. c. Aftroi- 
tes Indicus, Sernftein aus India. Besl. Muf. roo. Tab. XXXV. hic non eft fofilis. Altroites undulatus \& ftellatus. $l$. $c$. Huc quoque pertinere mihi videtui Lapis catenulâ albâ obduotus. Helì. Linb. Ang. p. 53. ni 40. M. D. n. 248. f. ". Aftroites minoribus Rellis marmoreus. Bajer. Or. 42. T. I. f. 17. Myl. Sax.P.II.T. IX.f. 4. Aftroites Mercat. Met. 235: Corallium album Madrepora dicum, in braunem eifenhaltigem. Tofo. Volkm. rilee. I 17. Tab. XVI. f. 4. Madrepora foraminofa minor, Pfeudo-Corallium album, if fchwammicht, die Tubuli geftreifft, bobl, und in der böbe gefurnt. Id. I 8 . Tab. XVII. f. 4. Antoices radiis folaribus undulatis. Diefer bat feine fchlangenformicbte Strablen nicbtinner, oder zwifcben, fonder anffer den Circulis, die in einem grangelben und platten Stein um etwas erböbet. Id. I 19. T. XVIII. f. 4. Afroites, der mit feinen geftirnten tubulis Comeien vorftellet, Cometites; ift leicht, poros, tubilos, durch und durch geftrmi. Id. I 20. T. XVIII. f. I. . Litholtrotion feu Bafaltes albus, ftriatus, \& Atellatus afper, der oben und unten von dem Centro an bis ïber die Circul oder Tubulos geftreiffi ift. Die Afterifci fezen durch und durch. Id. I 2 I. T. XIX.f. I. Aftroites tubularis. Id. I 23. T. $X X . f .8$. Aftroites fafciatus folaris, Sternftein, Sonnenftein, weiss und glatt, mit eiwas diukleren fafciis oder Zonis ungeben, auf welchem 3. kleine fchwarze Afterfci, wie Sonnen zifeben. Id. 334. T. V. f. 2. Rhodites oder A= Rroites, der bin und wieder auf der glatten und convexen Jeiten mit artigen dunkelgrauen. Rö/schen, und zwischen denselben mit mit fchwäralichten puncten befezet ift, won Mafsel. Id T. V.f. 3. Rhodites Pol.Rozany kamien. Helw. Ind. Foff.Pol.Afroites 凡ellulis plurimis radiis circinata rotunditare in Lapide coralloide digitalis craffitiei, ex utraque parte confpicuus Id. Lith P.II. I 4 . T ab.V. fig.2. Aftroites fubftantix Corallinx partim ftellulis in globulos elevatis, partim profundius immerfis. Id. l. c. Aftroites magnis ftellis in filice vulgari radiancibus. Id. l. c. Aftroites Madreporæ ftellas in Lapide albo, fufco \& grifeo exhibens. Id. l.c. T.V.f. I. 2. Aftroites tubularis ex Littore Niendorpienfi. Mell. Lap. fig. Lub. T. I.f. 5.

318 M. D. n. 149. Aftroites minoribus ftellis. Spec. Lith. Helv. p. 39. fig. 52. Ex Birfa. Afroites luteus ftellulis minoribus elegantiffimis, totam fuperficiem permeantibus, notatus. iiber und iiber lauter walgebildete und ordentlicb locierte Sterne. Herm. Maslog. 22 r. fig. 32.

319 M. D. n 50 . Aftroites minimis Atellis. Spec, Lith. Helv. p. 39. fig. 53 .

$320 \mathrm{M}$. D. n. I 5 r. Aftroites Bafilienfis ftellulis in globulos clevatis. Ex Birfa. 
32I M. D. n. I52. Madreporæ vel Corallii in longum ftriaii frufta tum fimplicia tum bifurcata. Ex Birfa. Spec. Lith. Helv. p. 43. fig. 58. Branchiali congener Columellus ftriatus feu Bryonix Radix lapidea Plotii. Luid. $n$. I 20. conf. Madrepora verrucofo punctata. Tour. Corallium album verrucofum pun. ctatum. CB. The Schaffi. Tranf. Phil. n. 3 14. p. 78.

322 M. D. D. I53.Cometites Spec. Lith. Helv. p. 39. fg. 54. exBirfa.

323 M. D. n. 154. Madrepora lapidea Bafileenfis in longum ftriata, Ficui vel Caricx fimilis. Ex Birfa, forfan huc pertinet Lycoperdites vulgaris major. Lang. Hifl.p. 52.T.XII.

324 M. D. n. I 6 . Aftroites fcolopendrites Bafileenfis. Ex Birfa. Lapidis Aftroitidis, $\int$ ftellaris tertium genus. B. de Boot. XAB. L. Il. c. I 46. Fig. B. Cat.p. 2. Aftroites undulâtus. Muf. Swamff.3. merdam.p. 6. Aftroites undulatus major concavus, capitium reprafentans, duorum pedum circumferentiam habens. Ejusd. An Hydatites f. Cymatites. Velfch. Hecat. p. 6o. T. XXI. Fungus lapideus major undulatus. Sloane $N$. H. of Famaica. p. 54 . Ejusd. p. 56: Tab. XVIII. fig. 5. Scolopendrites Gefn. Fig: Lap. I69.Scolopendrites magnitudine nondum æqualis ovo Gallinaceo. Naffel oder Obratzelftein. Spen. Muf. r 2: Scolopendrites. Lætii. L. II.c. 28. p. 176 . Adde M.D.n. 248.K. Aftroites ftellis fcolopendreformibus grifei coloris ex Agro Placentino \& 2.248. cc. Aftroites undulatus major totus faxeus, cujus nonnifi Cavitates in extima fuperficie, exque non ftriatx fuperfunt. Ex Territorio Raperfuilano. Comatiformes Atrix à Lapidis medio verfus peripheriam expanfe fcoparum in modum. Spec. Lith. Helv. p. 38. fig. 5 I. $M$. D. n. I 59. Lapis Agarico ftriato fermè fimilis. Ex Birfa. The wared tone. Grew. Muf. 305. Erotylos, f. Ampbicome. Merc. Met. 3 I 4 it. Lapis lumbricatus. Pol. Stonogowiek. Helwing. Ind. Foff. Pol. Undulago. Id. Lith. P. II. 126.

325 M. D. n. 157 . Aftroites tubularis maximus \& elegantiffimus Bafileenfis. 2uerel. Pifc. $p .3$ r. Tab. V. Idem cum n. I 48.

326 M. D. n. I58. Aftroites majoribus ftellis in faxo porofiori ex Birfa.

327 M. D. n. 560 . Aftroites elegantiffimis ftellulis in faxo grifeo flavefcente. De Chatelaut Burgundix. Congruere hic videtur cum Lepidote Plinii, qui fquamas Pifcium variis coloribus imitatur, juxta interpretationem nempe Mercati. Met. 3 I 5 . Ubi ita defcribitur: Materia lenior marmore duritiem babet mediocrem, albidus color alteri, in alio rubidus; momentis coloris fufci; partion Squamas, partim cutem pifcis referentibus, binc undulatim confipatis, inde in gyros converfis. $\quad$ M. 2.328 
328 a. M. D. n. I6r. Aftroites Maslenfis Silefiæ.

328 b. M. D. n. 163 . Aftroites cinerei coloris lapideus ex Montibus Querfurtenfibus.

329 M. D. n. I64. Aftroites fluoreus flavefcenti colore tinctus Querfurtenfis, frellulis in globulos elevatis. furtenfis.

330 M. D. n. I67. Aftroites flavefcens fpongiofus levis Quer $\rightarrow$

33 I M. D. n. I68. Aftroites albus fpongiofus Querfurtenfis.

332 M. D. n. I96. Millepora Imperati ex Infula Gothlandix Carlsöhe. Pertinet potius ad vermes tubulatos.

333 M. D. n. I97. Madrepora lapidea ex Bognolo Ditionis Veronenfis.

334 Madreporæ Imperati fimilis. Helwing. Lith.T.IV. fig. Ir. P. 50.

335 Madrepora compreffa punctata foffilis. Id. T.IV. fig. I 2.

336 Madrepora placentiformis. Büttn. T. II. n. 9. fiftulis tenuiffimis fucco petricofo impletis. Id. T.IV. fig. I 3 .

337 LITHOPHYTA in fenfu Tournefortiano Diluviana nulla novi, fed plurima in fenfu Luidiano, quo infignit omnes Claffis inprimis XV. Plantas.

338 M. D. n. I65. I94. TUBULARIA lapidea Querfurtenfis. Refpondet namque Tubularia purpurea Imperati. Stor. Nat.p. 63r. Tubularia Coralloides, Corallenfchwamm, weifs grau, ockergeel. Volkm. Sil. I 20. T XVIII. f. 9.

339 M. D. n. 145. Tubularix fragmina maffe faxex fine ordine immerfa.

340 Tubularia hexagonis plerumque tubulis frequentibus in terfepimentis difinctis petrefacta. Helwing. Lith. Ang. 49. T.IV. f. .. M. D. n. $248 . k^{3}$.

$34 \mathrm{I}$ Tubularia pentagona, in qua renuiffimi tubuli fepimentis albidis fegregantur. Id. T.IV.f. 6. M. D. n. 248. $l^{3}$. Myl. Sax. P. II. T. IX.f. 5 .

342 Tubularia Coralloidea tubulis minoribus, tribus ordinibus fiftulofis diftincta, cujus fiftulx omnes \& fingulæ fucco petricolo ita farctx funt, ut in fuperficie quali protuberare videantur. ad Büttn. Corall.T.I.n.3. delineatum quam proxime accedens. Id. T. IV. fig. 9.

343 Tubulariæ Coralloidex purpurex Imp. feu Halcyonio Milefio licet non colore, tamen effigie fimili. Id. T.IV. fig. Io.

344 Tubularia folfilis porofa, lavis, Angerburgica. $M . D$. 22. $248 \cdot p^{3}$.

345 Tubularia alba, in einem grauen geftein, an der die Tus 
buli bobl. Volkm. Sil. I I9. T. XVII f. 9. Eine Species Tubularix, in einem grauen geftein, die dem Alcyonio rubro CB. nit ungleich feebet. Id. I I 9. T. XVIII. f. 2.

346 M. D. n. 173. 174. ALCYONII bifurcati fragmentum. Ex monte Legerio \& Randio. Spec. Lith. Helv. p. 15 . fg. I 8. conf. Madreporæ cujusdam fofflis fragmentum. Luid. n. 107. Alcyonium foraminofun vel quartum. Diofc. Imp.p. 641. Corallium foffile furcatum \& ramofum. Helw. Lith. p. 49. T.IV. f. 2. M. D. n. 248. $0^{3}$.

347. M. D. n. 175. Alcyonium foffile Atuppofum Imp. 1. quartum Diofc. Spec. Lith. Helv. p. i s. fig. I9. Ex Randio \& Legerio. Fungus lapideus Wagneri. Hift. Nat. 309. Fungites maximus pileolo lato. Lang. Hift. p. 52. Tab. XII. Fungites major orbicularis. Id. $p .52 . T$. XI. Fungites major oris intus reflexis. Id. l. c. Fungites fungos referens Infundibuliformes. Melle. Lap. fig. p. 34.

348 M. D. n. 176 . Alcyonium tuberofum formâ fructus alicujus, Ficus, vel Alcyonium quintum Diofc. Imper. $p .64 \mathrm{r}$. Spec. Lith. Helv. p. 17. fig. 20. 24. Ex Randio \& Legerio. Ficoides, Caricoides, Feigenftein. Wagner. An Tubera lapidea. Calceol. Mus. p. 4o. Huc quoque pertinent Branchiali congener columellus ftriatus, five Bryonix radix lapidea Plotii.Luid. n. I 20. Spec, Lith. fig. 58. p. 43. Ficoides Bajeri N. 46. f. 30. 31. Kommet den kleinen frucbten der Ficoid. African. Herm. Hottentots feigen amäbnlichften.Volkm. Sil. I 2 I. Tab. IX. f. 3. a \& b. Columellus major Ficoides Atriatus, Ficoides, feu Caricoides, geftreiffter FeigenAtein. Id. 336. T. V. f. I 1. Pol. Figownik. Helw. Ind. foff. Pol. apud Langium proftant fpecies fequentes. p. 72.

349. Alcyonium tuberofum majus cinereum in bafi cavitate donatum. Tab. XIX.fig. I.

350. Alcyonium majus cinereum oblongum \& acuminatum, punctis quadratis Corallitx reticulati inftar infignitum, \& in bafi tuberofa cavitate donatum. T. $X I X$ fig. 2.

3 I Alcyonium cinereum bifurcatum punctis quadratis Corallitz inftar reticulati infignitum, \& in bafi tuberofa cavitate donatum. T. XIX. fig 3 .

$35^{2}$ Alcyonium minus cinereum pediculo infidens, \& in bafi tuberofa ac ftriata cavitate donatum. T. $X I X$. fg. 4 .

353 M. D. n. 177. Alcyonium non friatum, fed teigmatibus veluti acu factis punctulatum. Spec. Lith. p. 17. fig. 21。 ex Randio.

354 M. D. n. 178 . Idem tuberofus. Tuber lapideum ex Randio. Spec.Lith.p.17.f.220 $\mathbf{M}_{3}=355$ 
355 M. D. n. I79. Idem fulcis profundis excavatum. 16id. Alcyonium Bajer. Or. 46. T. I. $f .33$.

356 M. D. n. 180 . Alcyonium vel Fungus ftriatus compreffior. Spec. Litth. p. 17. f. 22.

357 M. D. n. 182 . Alcyonium formx Radicis nodofx. Ibid.

358 M. D. n. I 84 . Alcyonium pennx anferinx craffitie longum ex Legerio. Spec. Lith. p. I8.

359 M.D. n. 186 . Alcyonium ftriis veluti annularibus transverfis præditum. Ex Randio.

360 M. D. n. 189 . Alcyoniis accedens Fafciculus Luidii. 2. ro5. Ex Cumbriâ. Aliis junciformis Lapis. Attentius confideranti hoc foffile videtur referendum potius ad vermes tubulatos.

36I M. D. n. 190. Fafciculus aliis conftans tubulis intus fluoreis \& Alavefcentibus in marmoreo faxo nigro. Ejufdem videtur cum precedenti Profapix. Icon ipforum vermium tubulatorum marinorum videri poteft in Mem. de l'Acad. Royal. 171I. $p$. I 28.

362 M. D. n. I9r. Fafciculus è columnulis polygonis conflatus. Ex monte Tigurino.

$3^{6}{ }_{3}$ M. D. n. I92. Saxum cinerei fere coloris fpongiofum leve. Cylindris Atriatis coralliformibus refertum. Waxenvein from Arkendale in Torkshire. Milleporo petrificato. Scilla van Specul. P. I33. T. XVII.

364 M. D. n. 193. Saxum ejuldem generis candidum Querfurtenfe.

365 M. D. n. 208. SPONGIA marina foffilis Bononienfis: funt hæc recenfita omnia Diluviana, fed ut quidem exiftimo, durante jpfo Diluvio pleraque ex prxcipitata materia nata. Spongoetes, feu Lapis Spongiam marinam referens, Scbwammftein, um und um fpongios und löchericht. Volkm. Sil. 62. Tab. IV. f, 2. 366 Retepora feu ESCHARA marina foffilis. Lang. Hif. p. 57. Tab. XVII. Retepora feu Efchara marina Imperati lapidea. Spec. Lith. Helv. p. 1 3. f. 16. Retepore feu Efcharx marinæ fimilis. Helwing. Lith. Ang. 49. Tab. IV. fig. 4, Exchara marina, an der die puncta, wie mit einer Nadel geftochen. Volkm. Sil. 121. T. XIX. f. 4. Siatkowy Kamien. Pol. Helw. Ind. Foff. Pol.

$3^{67}$ Corallinum, ut videtur, foffle, perrarum ex multis veluti laminis Atriatis, Alveolorum \& Infundibulorum forma invicem infertis conftans. Angerburgo Pruffix. M. D. n. 248. $q^{3}$. conf. $c_{0} n_{0} 195$. 


\section{$\begin{array}{llllllll}A & P & P & E & N & D & I & X\end{array}$

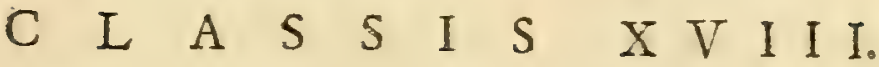 \\ Arbores of Frutices floribus Apetalis.}

368 FRAXINEA folia. Luid. p. Io8. Pol. Ge fronowe lifcie w Kamienizu. Helw. Ind. Foff. Pol.

369 Efchenes Holz, fo zu feimi worden. Volkm. Sil. p. ro4. 370 BUXUS. Myl. Sax. T. XXX. fig. 1o. Buxus Germanicus, Buxus vulgaris, feu humilis. Dod. Volkm. Sil. I Io. Tab.XIII. fig. 4 .

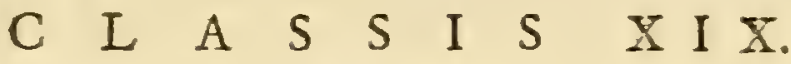

Arbores \& Frutices floribus apetalis Amentaceis.

37 I M. D. n. 43. Folium NUCIS JUGLANDIS, fo Regixtab. vulgaris in Lapide fiffili Oeningenfr. TAB. IV. fg. Io. Diluz. IV.

$3>2$ M.D. n. 73. AVELLANE \& farmenta CORYLACEA putrefcentia ex Vecti Infula n. 91. Avellanx ad ro. pedum profunditatem repertx in Turffa Rütenfi. Diluv. Conf. Mort. Northampt. 88. 256 .

373 Nix Avellana petrificata. Helwing. Lith. Ang. 38. Avellana Lapidea. Bauh. Font. Boll. 30 . Lapillus nucleum Avellanæ referens. Id. 36. Silex cinereus Avellanx domefticx fimilis. Id. $3^{6 .}$

374 M. D. n. 59. CARPINI aliaque folia in lapide Oenin-TAB. genfi. TAB. IV. fig. 9.

375 Oftryx lignum impetritum. Helwing. Lith. Ang. 4I. Lignum Orneum petrificatum. Ein futck Hagenbucben Holz I 5 . zoll lang, if von ungläublicher Härte, glanzt und klenget wie ein Thon. Brack. Muf, i6. Ligni Ormi particula alia. Ein ander fucklein Hagenbucben Holz, mit feinen adern und rinden in ftein verwandlet. 1. c. Oftryx Lignum in duriffimam, filiceamque cotem mutatum. Gefn. Fig. Lap. 130. b. Pol, Grabina Kamienne, Helw. Ind. Foff Pol.

376 M. D. n. 28. Lignum foffile videtur QUERCINUM, ex ftrato lignorum foffilium fupra Thunum. Diluv. A piece of oak barque, coverd with a frony critf. Grew. Mur. 270 . Lignum Quercinum petrefactum. M. D. 1. 248. fi. Eichenes Hola, welches durch und durch sarcafiert --- Dryites, fchwarz-eichens, fo vitriol und filber bält. Volkm. Sil. 104. Drzawnick, Dembownick. Pol. Helw. Ind. Forf. Pol. Quercina Ligna lapidea. Helw. Lith. P. II. 202.

377 Ramus quernus una cum Cochlea adhrente petrificatus. Lang. Hift. p. 54. Tab. XV. Dub. 
378 Cortex ejufdem Arboris petrificatus. 1. c. Dub. Pol. Kora Dambowa Kamienna. Helw. Ind. Foff. Pol.

379 Folia Quercus petrificata. Id. p. 54. Tab. XVI. PofsDiluo. Folium Quercinum petrificatum. Eichenlaub, fo zu Stein worden. Brack. Muf. I6.

380 Calyx Glandis Quercinx una cum pediculo petrificatus. Id. p. 55. Tab. XIX. Dub. GLANDITES. verfteinerte Eichel. Helw. Lith. P. II. p. 99. Tab. $X$

38 I Balanites major cinereus verrucofus. Lang. Hif. $p \cdot 4^{8}$

382 Tubulites Balanorum Calicem referens lxvis mediocris, fubcinereus, ore latiore. Lang. Hift. I6r.T.L.f. I.— idem ore magno, quadrato, tuberofus. Id. T.L.f.z.— idem ore angulto. Id. $T$. L. . . 3 .

$3^{8}{ }_{3}$ Gallites puniceus conglomeratus. Lang. Hift.p. 48. Tab. $X$. Ex Monte Legerio ut \& pireced. Dub.

$38{ }_{4}$ Fragmenta Gallarum angulofarum.Stucke voneckicbten Galläpflen, und der Gallx Indicx.n. 3. Chabr. am abnlichfien. In des mitte fiebet man nocb die Griiblein, in welchem im Frïbjabr fich eine Made generirt, liegen in einem rotben mit einem Cryftallfuss vermifcbten Tofo. Volkm. Sil. I 30 . T. XXIII. f. 4.

$3^{8} 5$ Ein ausgebrochener Galläpfel. Galla angulofa. CB. Id. I 34" T. XXIV. fig. 5 .

386. Die belfte eines petrificirten Galläpfels; Gallx minoris rotundæ lævis. Id. I 3 I. T. XXIII. $f$. 5 .

387 Quernum Lignum colore nigro in lapidem induratum. Helwing. Lith. Ang. 42.

388 M. D. n. 212. CASTANEA atri fplendentis coloris è Montibus Querfurtenfibus. v. Büttn. Rud. Diluv. T. XVIII. n. I. Diluv. Caltanites. Steinerne Caftanien. Valent. Muf. P. II. I 9. ex Aldrov. Forfan huc pertinet Lapillus Caftaneam fimulans corticibus exutam, colore paleari, expreffis ftriis. Mercat. Met.283.

389 M.D. n. 27. Folia bina, unum videtur Salicis, alterum ABIETIS albre in marga albicante prope Pagum Erla Ditionis Bernenfis. Diluv. Cum học Abietis albx congruit, Lapis fiffilis impreffionibus frugum elegantiffimè notatus. Scbieferftein mit frucbtäbren. Wolf. Hift. Nat. Haff. T. VI. n. 4.

390 Abietis cujufdam ramuli Cortex. Luid.p. 109.

39I M. D. n. 29. "PINI videtur ramus valde compreffus," Cortice fuo adhuc veftitus. Ex ftrato prope Strättlingen fupra Thunum. Diluv. Ficbtenes Holz. Volkm. Sil. p. 104. Pini Lignum petrificatum. Helw. Lith. P. II. 20I. 


\section{$\begin{array}{lllllllll}\text { A } & \mathbf{P} & \mathrm{P} & \mathrm{E} & \mathrm{N} & \mathrm{D} & \mathrm{I} & \mathrm{X}\end{array}$}

392 M. D. n. 30. Pini videtur Lignum foffile, Ex eodem Strato. Diluv. Pinea Ligna vel Abiegna fubterranea. Firrood Anglis dicta inftar Ebeni, nigra multa \& grandia.v. in Trans. Pbil.n. 228. 277. p. 1073 .

393 Conus Picea lapidea frobilitis, feu Pineum fructum $x-$ mulans Lapis. Besl. Muf. 9r. To XXXI. Aldrov. Muf. Met. p. 829 .

394 Fructus Pinex lapidei. Besl. 102. Tab. XXXVI.

395 Nucleus Pinix (lege Pini) lapideus. Steinen Pinien Niiplein (lege Niifslein) Id. 104. Tab. $X X X V I I$. referendus ad Judaicos lapides inter Crultacea Diluviana.

396 Abiegnum lignum petrefactum. Angefturgo Pruffix. $M$. D. n. $248 \cdot b^{3}$.

397 Zweige von dem Pinu fylv. Mugo dicta. Tab. Pinu montana altera. CB. auf.dunkelgrauem fcbiefer. Volkm. Sil. ı09. T. XII. f。 6 .

398 Afte von dem Pinu Sylv. montana. Tab. Pinu montana minore. Gerh. cum Julo. Id. I I r. T. XIV.f. 4.

399. Eindruck eines Coni pinaftri alpini repentis, Pinus humidx alpinx. Scbwenck. Sýlv. repentis. Matth. Zapfen eines kleinen Alpenkiefers, in gelbem Sandftein; die veltigia der Scbuppen find gell, wie der Sandflein, das ubrige des Eindruckes fchwarz. Id. I29. Tab. XXII. f. 3 .

400 Sebr netter Eindruck eines Coni Laricis, Zapfens vosm Lerchenbaum, von farben braunroth, in gelberm Sandlein. Id. 129. Tab. XXII. f. 4 .

401 Gross und kleine Pineoli, Pinolen, Pinnlein. Id. I34. T. XXIV. f. 9 .

402 Elatites feu fruftum ligni Abiegni iconi Gefnerianx $p$. I 25. delineatx xquale. Helwing. Lith. Ang. 4r. T.II.f. 6. Elatites mit Vitriol und Scbwefel impregniert. Volkm. Sil. s04. Pol. Krwarwick fedlinowy Kamien. Helw. Ind. Foff. Pol.

403 M. D. n. 70 . Conus Abietis fæminæ ex cefpitibus bituminofis Agri Ceftrienfis. $n$. 238. Pinei Coni ex cefpitibus bituminofis Rutenfibus Ditionis Tigurin. Diluv.

404 Fructus TAXI petrificatus. Lang. Hiff. p. 56. Tab. XIX.

n. 3. Ex monte Legerio. Dub.

$405 A$ flone, which in colour and texture feems to refemble a piece of Yew-Tree. Grew. Muf. 269.

406 M.D. n. 32. Folia varia ALNI, Salicis in marga albicante, prope pagum Erla Ditionis Bernenfis. Dilur.

407 M. D. n. 34. Folia Alni unum vel Fagi alterum, tri- 
nervium in faxo arenario flavefcente duriori. Ex Abbatiscellano Territorio. Dub.

408 Folia Alni petrificata. Steinene Erlenblätter. Folia item FAGl petrificata, Steinene Bucbblätter. Lang. Hift. P. 54 T.XVI. Fagi folia in Tofo Stallikonenfi Ditionis. Tigurinæ. $M \cdot D \cdot n \cdot 215$. Tofus candidus Mifenus, in quo Folia Quercus \& Alni funt impreffa. Kentm. Foof. 38. Tofus, cui Figura Frondium Arborum à natura impreffa. Wagn. Hilt. 323. Pietra Tartara figurata di TAB.X.foglie è Rami di Rovo. Imperat. Stor. Nat. 58 5.v. TAB. X. fig. 4. fg. 40 Sarnius Lapis. Merc. Met. 328. Append. T. XIV.f: 22.

409 Ligni Alnei petrificati fruftum. Ein Stuck petrificiert bolz, von einer Erlen, welche Sebr tieff unter der Erden, mit äfen, und wurzlen gefunden worden. Brack. Mur. I7. Cletbrites, feu Alneum lignum petrificatum. Helw: Lith. P.II. 20 I. 4.10 SALICIS angufifolix folium in Lapide fiffili Oeningenfr. TAR. TAB. IV. fig. 8. Diluv. Krauterfchieffer mit einem weidenen Blatt. Myl. Muf. n. 790.

4I I Ein aufgedrucktes Blatt von einer Weiden, die Salix faxatilis. Scwenckf. Salix pumila alp. Cluf. beifft. Volkm. Sil. I I r. Tab. XIV.f. 3 .

$4 \mathrm{I} 2$ Folia falicis petrificata. Steinene Weidenblätter. Lang. Hift. p. 5.4. Tab. XVI. Poftditur.

4I 3 Salicites ejusdem $p .69$. ad Vegetabilia prorfus non pertinet. TAB.II. 4IA M. D. n. 60. POPULI nigre folium in Lapide Oeninfor.4. genfi. TAB. II. fig. 4. Diluv.

TAв. 4 II Dendrites folium Populi albæ reprafentans. Lang. Hift. X.8. fr.p. 40. TAB. VIII. fig. 3. Dendrites folium Populi albre magis elongatum reprefentans. Ejusd. fig. 4. Dilur. In Lapide fiffiliOeningenfr. Krauterfchiefer mit einem Blatt von einer Pappel. Myl. Muf. n. 798.

4r6 A flone, which looks like a piece of Becbwood. Grew. Muf. 269.

4I7 Fagus ferrificata. Liebknecht. Diluv, 290.

$4 \mathrm{r} 8$ Cletrites Lapis ab Alni fimilitudine. Boot. 529.

4 I9 Betulatum Lignum petrificatum. Ein Auck Bürkenbolz mit. Seiner Rinde, fo zuStein worden. Brack. Muf. 17. Birkenbolz zu Beblendorff bey Lübeck. Volkm. Sil. 87.

420. Lignum Fagi lapideum. Oxytites Besl. Muf. 92. Tab. XXI. Phegites è Fago. Buchen in Stein verwandlet. Kentm. Foff. 39. Pol. Bukowy Kamien. Helw. Ind. Foff. Pol. 


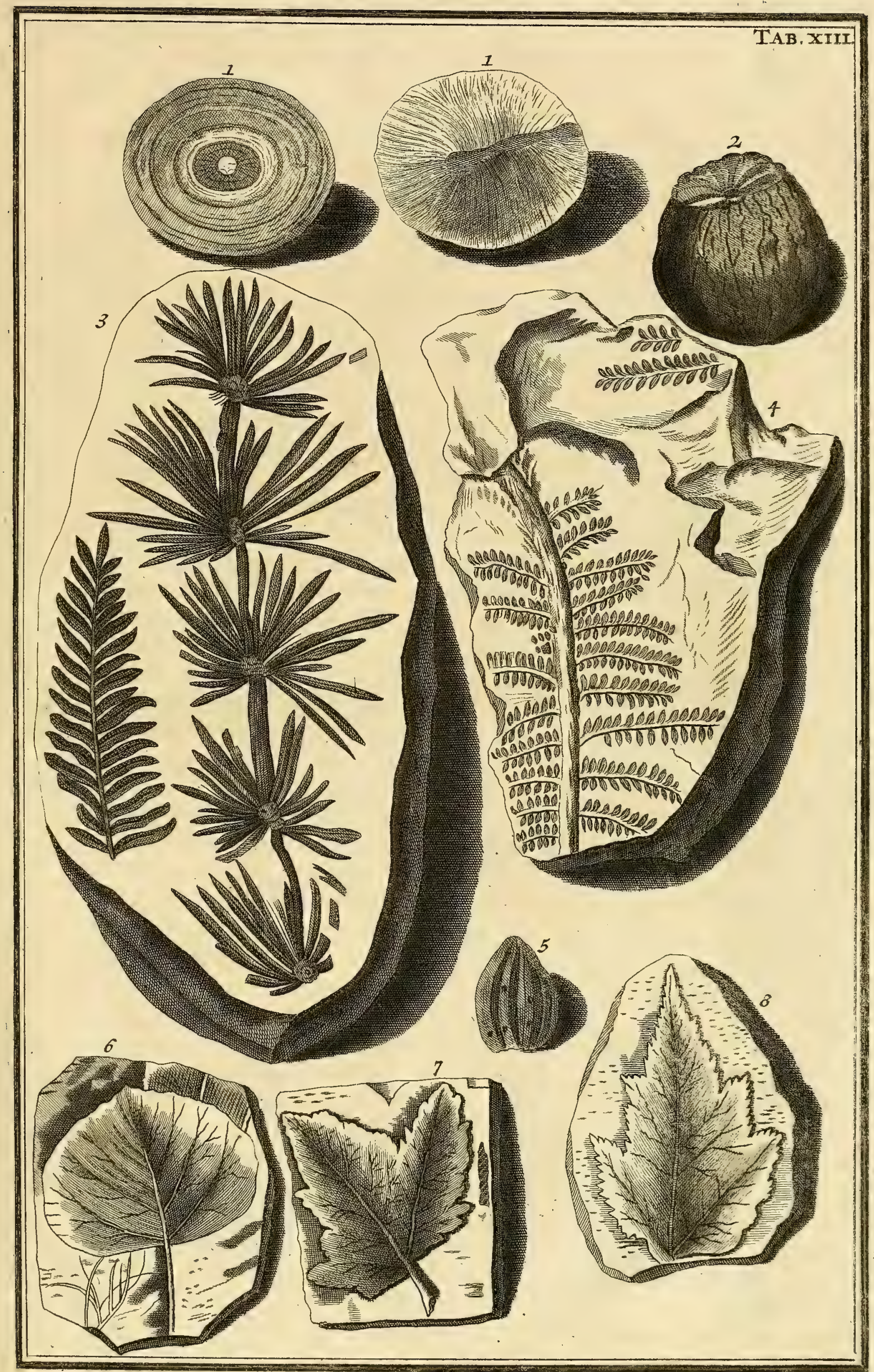

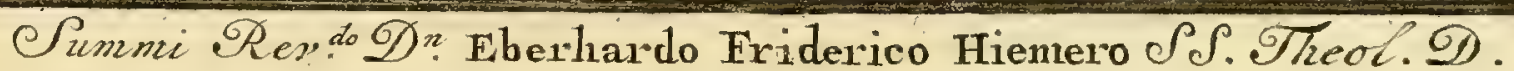
Per.mo Whirtenbernensi Duci à Goncionibus ct Consilius anlicis. 



\section{$\begin{array}{llllllll}A & P & P & E & N & D & I & X\end{array}$ \\ C $\mathrm{L}$ A $S$. S I $S$ X X. Arbores \& Frutices floribus Monopetalis.}

42 I MYRTILLITES major cinereus umbilico magis excarato. Lang. Hif. p. 56.Tab. XlX. fig. I. Similis fructui Vitis Idex foliis oblongis, crenatis, fructu nigricante. CB.

422 Myrtillites major cinereus umbilico minore. Id. fig. 2. Similis fructui Vitis Idex foliis oblongis albicantibus. CB. uterque Dubius valdè.

423 Ulmi affulx in nigrum lapidem mutatæ. Helw. Lith. P. II. 202 .

\section{L A S S I S $\mathrm{X} \times \mathrm{I}$. Arbores \& Frutices foliis Rofaceis.}

424 M. D. n. I68. TILI Æ folium in lapide fiffili Oeningen-TAB. fi. TAB. Ill. fig. 8. Dendrites folium Tilix cum gramine re- $8 \times$ TAB prafentans. Lang. Hift. p. 40. Tab. VIII. fig. 2. Diluv.

425 Fruftum Ligni Tilix petrificatum. Steinenes Lindenbolz. Lang. Hift. p. 54. Tab. XV. Dub.

426 Ciffites in candido collucet EDER $\mathbb{E}$ foliis, qux totam tenent. Narciffites venis etiam Eder $x$ difinctx. Plin. $L . X X X V I I$. c. Io Quid fit, non conftat, videtur Naturæ lufus, in Achate. Hedera in Tofo Rorbacenfi eft Poffdilive. Pro Narciffites Inocif fites viri docti reftituendum judicant. Nihil enim huic Gemmx cum Narciffo convenit. At pofterius nomen ex argumento natur $x$ -

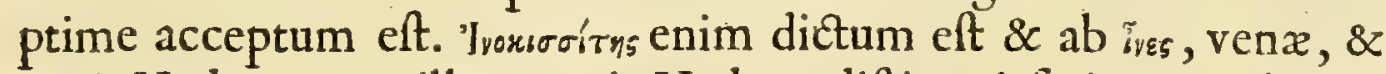
zı $\sigma$ 's Hedera, cum illam venis Hederæ diftingui fcriptum reliquerit Plinius. Affalt. Not. ad Mercat. 276.

427 M. D. n. 55. VITIS, ut videtur, Folium Lapidi fiffili TAB. I. Oeningenfi impreffum, eique melano grammo. TAB. I. fig. 2. Dilurv.

428 M. D. n. 5. Pruni folium, ut videtur, in Lapide fiffili Oeningenfi. Tab. IV. fig. 7. Diluv.

429 Aftone like a petrify'd damafcene plum. Agread petrify'd flone of an exotick Plum-A blackfone figur'd like the tione of ( $a$ Praecock-Plum ) an Aprecock. Grew. Muf. 266. Prunellarium, f. Lapis pruneoli officulum referens majus. Luid. n.233. Prunellarium minimum longiufculum. Id. n. 234. Cocco Meloite, feu Lapides prunum referentes, Pflaum/leine, wie Planmen gefaltet, braun oder Oliven farb, glatt. Volkm. Sil. 62.T.IV.f. 3 der wie ein Prunum magnum rotundum rubrum $\mathrm{CB}$, oder das. Prunum lbericum Tragi, als wie blane Marunken geftallt. fig. 4. Einbraun $\mathrm{N}_{2}$ gelber. 
gelber, der dem Pruno dulci amygdalino feu - xreo noftrati, Germ. Spillerchen gleicbet. Id fig. 5. Ein ganz fchwarzer, der wie das Prunum Hungaricum, Prunam magnum dulce atrocaruleum $\mathrm{CB}$ ausfiebet.

$43^{\circ}$ Siehet wie ein Myrobalatius Bellirica, oder auch, wie Nux infana oder Prunulum infanum Chabr. aus, von farbe brainroth. Id. I $34 . T$. XXIV, f. 10.

4.3 M. D. n. II 4. AMYGDALITES vel Amygdaloides. Lapis Planitzenfis ex Agro Zuiccavienfi. Myl. Sax. p. 35. Dub. Amygdaloides conftans ex materia filiadofa cruftâ exteriore gypfeâ. Helwing. Lith. Ang. 3.8. Steinerne Mandeln. Valentin. Mur. P. II. 19. Lapis Fructui Amygdaî faccharo incruftato fimilis. Gefn. Fig. Lap. r 26.6. Lapides, qui Amygdalam faccharo incruftatam tam probè referunt, ut fimpliciores facile fit iis fallere. Continent autem intus filiculum Amygdaliformem, crufta

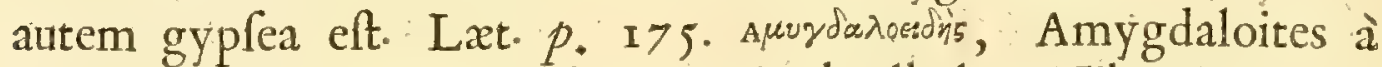

- forma Amygdalorum ita dicti, uti ad Albulam Tiburtinam inveniuntur. Kirch. Mund. Subt. L.VIII. p. 82. Hi frpe funt factitii. Aliquando Lapides, non folum Amygdali nucleum, fed \& os ambiens referunt. Huc pertinet Lapis Amygdali offi perfimilis. Gefn. Fig. 1. c. A tone being very agreable to the Amygdaloides of Aldrovand. Muf. Metall. L.IV. c. x. Plott. Oxfordsh, p. 195. Amygdaḷ in Lapidem converfa. Besl. Muf. ro3. Tab. $X X X V T$. Amygdalam referens Lapis. Bajer. Or. 45. T. I. f.2 3 . Siliculi Amygdaliformes. Lapides Amygdalis perfimiles. Mandelfein. Steine wie Mandeln formirt. Volkm. Sil. 62. Eine Mandel, wie fie noch in der aufferlichen grauen Schale, liegt. Id. I 34. T. XXIV. f. 6. Kamien Migdalowy. Pol. Helw. Ind. Foff. Pol. 432 M. D. n. 244* Amygdaloides Echterdingenfis. Dub.

433 Amygdaloides fubluteus major \& minor. Mandelfein. Lang. Hift. T. XIX. P. 56. videtur Silex Mandole impetrite. Mofcard. Muf. i 75 .

434 M. D. n. 24r. ff. Lapides fufci Amygdalas, Nucleos prunorum, Ceraforum, aliosque fructus referentes : Ex lutifodina Altdorffina. NodiSoapballs. Beaumepotts dicti. Lift. Cocblit. Angl.p. 2 I3. Naturie lufus.

435 Stein, der if wie ein Malas Perfica, Pferfing, anf der einten Seithen grau, anf der anderenbraunroth; etwas gepletfcht. Volkm. Sil. I3 3. Tab. XXIV. fo 3 .

436 Silex cinereus Piftacif fructum exprimens, Bacch. Font. Boll. 36. Eine Piflacien, mit der' gelben barten Scbalen. Volkm. Sil. I 34. T. XXIV. f. 7. der länglichte Kern oder Nïsslein auffert der Scljale. Id. fig. 8. 
437 M. D. n. 9. PYRI folium in lapide Oeningenfi. Diluv. TAB: Brauner Letten bey Foactirns Thal mit einem Bimbaum blatt. IV. for Myl. Muf. n. 787.

438 M. D. n. 36. Folium Pyri, aliudye in faxo cretaceo fiffili Oeningenfi. Dendrites folium Pyri repræentans. Lang. Hilt. Lap. p. 4o. Tab. VIII fig . Dilur.

439 M. D. n. 22. Pyri petrefactx \& maledictx Norimbergenfis fruita. Poft-Diluv.

440 Lapillus pyriformis. Lang. Hift.p. $5^{6} \cdot \mathcal{T} \cdot X I X . n .2$. Dub. A petrifyd Katberine Pear Grew. Muf. 265. Pyra Mofchatellina. Steinerne Zuckerbirn Bajer. Oryct. 46. Valentin. Muf. P. II. p. r 9. Pyrum Mofchatellinum, aut aliud exiguum, aliudve Pyrum grandius. Bajer. Or. 46. T. I. f. 26. 28 Eine Frucht, wie eine Birn, oder die Orientaliche Frucht Sambos. Volkm. Sil. 1 33. T. XXIV. f. I. Eine andere gleich einer Birn. frebet auch der krummen Frucht des Solani pomiferi 5. CB nicht ungleich; Id. f. 2.

44I M. D. n. I I. Saxum arenarium durius, cinereo flavefcens, in quo folia SORBI alpinx I. B. Ex Cantone Abbatiscel-TAB.Ií
lano. TAB. II. fig. 8 .

442 Steinerne Pomerantze: die conlewr, glätte, ind tiuplein an der Schalen ift den natirlichen und frifchen Pomeranzen ganz gleich, worann auch oben das griblein, darinnen der Stiebl geftanden, zujeben, hat eine kiefelbärte. Volkm.Sil. r 30.T.XXIII. f. I.

443 M. D. n. 64. Folium MESPILI A pii Folio fylveftris fpinofx five Oxyacanthx CB, in Lapide Öningenfi TAB. HI. fg. TAB. 6. Diluv.

\section{I $\quad A \quad S \quad S \quad I \quad S \quad X \quad X \quad I \quad$.}

444 Zwey Scbooten auf einem grauen Scbiefer, die obere fcbinet eine Siliqua Arboris Judx (Siliquantum Tour.) oder auch Vicia dumetorum maximx CB. die untere eine Siliqua Afclepiadis Tab. Fuchs, Volkm. Sil. I 29. T. XXII. f. I.

445 Ficui haud abfimilis Lapis ex Mufeo Valkeneriano, cui illatus ex Suitenfium montibus prope Artam. Eine kleine Feige, Ficus communis CB. Auswendig, wie bey den meiften feigen bran oder dunkelroth, inwwendig rötblicht oder rofenfarb, wie das fleifch einer Feige, mitten eine fchwarze Erden oder Moler mi vielen verweften dunnen capillamentis oder Fäferlein, welche etliche Botanici, vor die Blüth der Feigen balten, nebf einem Cryftall flufs. Volkm. Sil. Izo. Tab. XXIII. f. 3 . 


\section{Ad nullam certam Claffem redigenda.}

446 M. D. n. 7. Folium Plantæ in oblongâ figurâ rotundaT. fa. ${ }_{\text {V. }}$ tum in faxo fiffili candido ex Bolga Valle Agri Veronenfis. TAB, V. fig. 8. Diluv.

447 M. D. n. I 3. Planta ftellata quxdam Diluviana cum NeuIV.ffg.r. rophyllo in atri coloris faxo margaceo, ex Fodinis Cumbrix. TAB. IV. fig. I. Diluv.

448 M. D. n. I4. Alia Planta Diluviana ex eodem loco.

449 M. D. n. 19. Lapis margaceus melanogrammos cineTA. f. r. reus quaf, ftipulisve combultis confperfus ex Anglia. TAB. IV. fig. 2. Diluv.

450 M. D. n. 26. Plantula videtur fpinofa ex Anglia. Diluv.

45 I M. D. n. 3 I. Congeries varia Lignorum \& Corticum foffilium, ex ftrato fupra Thunum. Diluv.

452 M.D. n. 33. Folium quoddam majus \& latius in Lapide fiffili Oeningenfi. Diluv.

453 M. D. n. 35 . Folium trinervium flavefcens in faxo cretaceo fiffili Oeningenfi. Diluv.

454 M. D. n. 37. Folia alia in Saxo Oeningenfr. Dilur.

455 M. D. n. 38. Terra foliata Siculx frmilis mollior in lapicidina Oeningenfi.

456 M.D.n. 39. Lapis fiffilis Terræ foliatx Siculx haud abfimilis durior, ex eadem Lapicidina. Terra foliata bituminofa mineralis foffilis ex Italia. Bocc. Muf. di Piante rare. 157.

457 M. D. n. 63. Folia Arborum diverfarum in faxo cinereo flavefcente Territorii Abbatiscellani. Dub.

458 M. D. n. 7 I. maffa quadam leviffima ex materia vegetabili in Terris fepulta, omnino conftans, ex Agro Ceftrienfi Anglix n. 88. Cefpes bituminofus leviffumi generis prorfus ex vegetabili materia conftans. Ex Weftmorlandia Anglix. Diluv.

459 M. D. n. 72. LITHOXYLON ex Infula Antego. Diluv. \& omnia pene fequentia. Lignum foffile. Pol. Drzewo Kamienne. Helwing. Ind. Foff. Pol.

460 M. D. n. 74. Lignum foffile ex Fodinis aluminofis Dubenfibus Saxonix.

461 M. D n. 75. Lignum bituminofum foffile, quod paulo infra Terram bituminofam Mufcovienfem invenitur.

462 M.D. n. 76. Lithoxylon Bononienfe ex Argilla erutum. 

feld.

463 M. D. n. 77 . Lignum petrificatum ex oppido Bitter-

464 M. D. n. 78. Terra affulofa vel Ampelitis pyrite ærofo copiofiffime imprægnata, ex valle Grundfpurgenfi Agri Altorffini, Territorii Norimbergenfis. Libav. Sing. P. III. L. VIII.c.8. p. 1034. Bajer. Oryitog. Norica.p. 8 I.

465 M. D. n. 79. Lithoxylon nigricans in faxo arenario duriori ex Agro Altorffino.

466 M. D. n. 8o. Lithoxylum nigrum Prufficum.

467 M. D. n. 8 r. Lignum foffile Luneburgicum ex Fodinis Argillaceis.

468 M. D. n. 82. Lithoxylon ex Hifpania.

469 M. D. n. 83 . Lithoxylon foffile bituminofum, Lithantraces etiam reprefentans. Ex Crypta Diaboli, \& prope Grundspurg (Griunperg) Agri Altorffini.

470 M. D. n. 84 . Lignum foffile ex prato Kellen im Waltikumerriedt, milliari ferè à Tiguro.

47. M. D. n. 84. Lithoxylon argentiferum Franckenbergenfe Chryfocolla adfperfum.

472 M. D. n. 85. Lignum foffile, vulgo Steinkoblen von dert Habicbtwald bey Caffel.

473 M. D. n. 86. Lignum in venam Ferri converfum Laubacenfe. Liebknecht Difcurfo de Diluv. Gieff. \&. Francof. 1714. 8. 474 M. D. n. 89. Lithoxylon ex Fodina Vallis Joachimicx. 475 M. D. n. 90. Lignum foffile Pyrite vitriolico foetum ex montibus Prufficis, in quibus fuccinum effoditur.

476. M. D. 0. 93. Lignum prorfus petrefactum ex Fodinis fuccini Pruffici.

477 M. D. n. 95. Lithoxyla Altdorffina.

478 M. D. n. 125. Lignum foffile Dübenfe ad Muldam 3. Leucis à Lipfia.

479 M. D.n. I26. Lignum petrificatum ex montibus arenofis Querfurtenfibus.

480 M. D. n. I $3^{\circ}$. Lignum foffile ftrato petrofo fubftratum Querfurtenfe.

48 I M. D. n. I32. Lignum foffile ex ftratis Lithanthracum Dübenfium.

482 M. D. n. 217 . Lignum foffile ex Sylvâ fubmerfầ 4 horis à Querfurto, I. à Sangerhufầ verfus NW. Büttn. Dil. Teft. p. 303 .

483 M. D. n. 2 I8. Lignum foffile ex altiffmo jugo Thutingix, Finne dicto. 
484 M. D. n. 2 I9. Lignum foffile ex montibus arenofis Querfurtenfibus.

485 M. D. n. 220. Lignum foffile nigrum Bononienfe.

486 M. D. n. 22 I. Lignum ex montibus arenofis Querfurtenfibus candidum, Faginum videtur. Büttn. Dil.Teft.p. 189 .

487 M. D. n. 222. Lignum foffile Pyrite impragnatum, cui oftreum lapideum adhæreficit. D'Tves aupres de Cant fur le bort de la mer en Normandie.

488 M. D. n. 223. Lignum foffile fufci coloris Querfurtenfe.

489 M. D. n. 224. Lignum Laubacenfe ferrificatum, cui vena Ferri adhæret.

490 M. D. n. 225. Lignum ferrificatum Laubacenfe è nucleo Trunci, ut videtur, defumptum.

491 M. D. n. 226. Idem minus ex majori frufto decerptum. 492 M. D. n. 230. Lignum foffile metallifatum, quod in valle Bufeccenfi I. horâ à Gieffa diftante intra Terram ad $\mathbf{I}$. orgyas lutofam repertum eft.

493 M. D. n. 23 I. Lignum foffile petrificatum ad Thermas Wisbacenfes repertum.

494 M. D. n. 234. Carbones bituminofi Haffiaci.

495 M. D. n. 235 . Lignum foffle, quod in Terra Gieffen fi præfertim ad Flumen Lanum in maxima copia reperitur.Liebknecht. de Diliv. p. 49.

496 M. D. n. 247. Lithoxylon videtur impreffum lapidi fiffili Glaronenfi.

497 M. D. n. 248. Lignum anthracini coloris Pyrite vitriolico prxgnans, forfan ad Lithanthraces referendum. Ex Lapicidina Megenweilenfi in liberis Provinciis, ubi \& offa foffilia \& Gloffopetrix reperiuntur.

498 M. D. n. 248.a. Lignum foffile conferendum cum Carbone foffili Xylode Libavii. Vom Heiligenberg im Furftenbergin fchen.

499 M. D. n. 248. z. Lignum foffile prope Lubecam ad pagum Beblendorff 3. milliaribus a Lubeca.

soo M. D. n. 248. bb. Lignum foffile ex Italia.

50 I Lithoxylon fciffile five tegulatum ex albo \& caftaneo verficolor, ftalagmite refertum. Ex arenofis Afplejanis in Agro Bedfordienfi. Luid. $n$. 2 I r.

502 Lithoxylon tabulatum rubiginofum. Id. $n .2$ I 2 .

503 - confragofum Faringdonenfe rubigine infectum. Id. n. 213 .

504 - luteum fordidum five Ochram referens Cirenceftrenfe. Id.n.2I4. 


\section{$\begin{array}{llllllll}A & P & P & E & N & D & I & \ddot{X}_{0}\end{array}$}

505 Lithoxylon ftriatum atrorubens. Id. 2.2 I 5 .

506 album, fufcitabuli five Ligni incendiarii æmulum.

Ex arenofis Marchamix lapicidinis. Id. $n .216$.

507 - cryftallinum, five ex Fluore Belemnitx ad inftar

ftriato conflatum exterius rubiginofum. Ib. Id. $n .217$.

508 - atrorubens nitidum Antimonii ad inftar ftriatum.

lb. Id. $n .2$ I 8 .

509 - teres, fufcum, five paxillare inter Ligna \& offa foffilia ambiguum Marchamix. Id. n. 220.

5 10 - rubiginofum venis nigris diftinctum. E Lapicidinis Byfeldianis apud Northamptonienfes. Id. $n .22 \mathrm{I}$.'

$5 \mathrm{I1}-$ fufcum pulverulentum è Fodina Ashleana in eodem Comitatu. Id. $n .222$.

$5 I_{2}-$ fufcum fluoribus minimis refertum. Id. n. 225.

SI 3 - fufcum Sabrinianum Selenite faturatum. Ex Litto-

re Sabriniano ad pagum Frethern in Comitatu Gloceftrix.

$514-$ exiguum ferrugineum cuneolum referens. Witnejx.

Id. $n .227$.

I5 - Sabrinianum ligno Quercino xmulum ex æetuario Sabriniano ad Trajectum Pyrtonenfe. Id. n. 228.

5 I 6 - anthracinum vitriolatum. Ex Lapicidina Kidlingtonenfi prope Oxonium. Id. n. 229.

Id. $n .230$.

5 I7 - Gagati æmulum littorale. Ex Agro Lincolnienfi. 5 I 8 - textile f. reticulatum capillare fabuletorum. Ex fabuleto Framptonienfr. Id. $n .23$ r

5 I9 - ftupofum f. punicea raritate leviffimum. Id.n. 232 . 520 Loughneagftone in Hybernia pro Lithoxylo habet Molyneux in Transact. Phil. n. I 58.

52 I M. D. n. 87. Carbones ex Cefpitibus bituminofis Agri Ceftrienfis.

522 Great numbers of Trees, particularly. Oaks and Firs in the Peath-Earth of Northolm. \&c. Morton. Nat. Hift. of Northampt. p. 253. 255.263 . Mosswood. Raji Topographical. Obf. 7. Plot. Staffordsh. 217 . Transact. Phil. n. 275 . Sorturbrandur. Worm. Muí. I69.

523 A large piece of petrify'd wood. Grew. Mul 269.

- 524 A globular flone wich loocks, as if it had been a piece of Abswood Tourned in a Lathe in to that figure. Grew. 1. c.

525 A piece of incombutible wood, as it were balf petrify. Forbeing Held into Fire, it bekomes red like à Coal. Grew. l.c.

$5.26 \mathrm{~A}$ very odd piece of the branch of a Tree as Thik as a $\mathrm{Ca}$ - 
ble rope, whereof the barque, is turned into perfect Iron, or at leaft a very rich Ironore and the wood intoltone. Grew. 1. c.

527 The petrify'd barque of a Tree. Tis thin and Rowiled up as Cinamom but rather of the colour of that called winterane's. Grew. 270.

528 Lignum nigrum foffile. Blackoack Scotis. Sibb. Prodr. Hift. Nat. Scot. p. 44 .

Occafione Lignorum fofflium monendim, non Quercina duntaxat Ligna, fed \& alia plurima, ubivis fere 'Terrarum mutationem fuiffe paffa ratione coloris, \& nigrum quidem induiffe multis in locis tantum non carbonificata; \& ibi quidem, ubi vel Pyritx adfunt vitriolici, ipfis Lignis fre adhuc adhærentes, vel venæ Ferri \& fulphuris. Non mirum hoc videbitur iis, qui norunt ex mittura Limaturx Ferri, Sulphuris \& Aqua excitari non duntaxàt ingentem Fermentationem, \& xftum, fed etiam Flammam quæ in Terre vifceribus ftatim à Diluvio Ligna demerfa facile mutare poterant in Carbones, vel iis faltem nigrum colorem inducere.

529 M. D. n. 1 24 . Arborum folia in Tofo duriori ex Saxonia. $P$ oft-Diluv. Arborum folia in Tophaceis Lapidibus. Helwing. Lith. Ang. 4I. Tab. II. fig. 4 .

530 M. D. n. 143. Surculus lapideus Adarce vel Tartaro in. cruftatus. Spec. Lith. Helv. p. 20. fig. 25. Montis Legerii. Diluv.

53 I M. D. n. r44. Glomellaria fpongiofa. Luid, n. r ro, Ex Monte Legerio.

532 M. D. n. 155. Lapis hand abfimilis trunco abfciffo Arboris, in quo Circuli annui confpiciuntur. Ex Birfa. Diluv.

533 M.D. n. I8 r. 187. Patella lapidea. Spec. Lith. Helv. p. 19. fig. 24. Wagner. Helv. Curios. p. 3 18. Ex Randio \& Legerio forfan ad Fungos referenda. Dihur.

534 M. D. n $20 \%$. Nux Vomica lapidea. Spec. Lith. p. 44. fig. 60. Lapis Nuci vomicx fimilis, Stein den Krayenaüglein gantz'gleich. Brackenhof. Mus p. . . . Conf. bafis Urticx marinx. Mem. de locad Roy. 17 10. p. 475. fig. 24 Diluv. Apetrify'd Nux Vomica. Grew. Muf. 266. Caftanites. Aldrov. Muf. Met. Pol. Wronowe oko Kamienne. Helw. Ind. Foff Pol. tum definens mucronem, nervo per medium decurrente in marga cinerea. Ex monte Blancano prope Mavore in ditione Bononienfr. Dilur.

536 M.D. n. 2 i3. Palmæ corymbiferx farmenta, ut videtur, Monfpelii foffilia. Dil. 


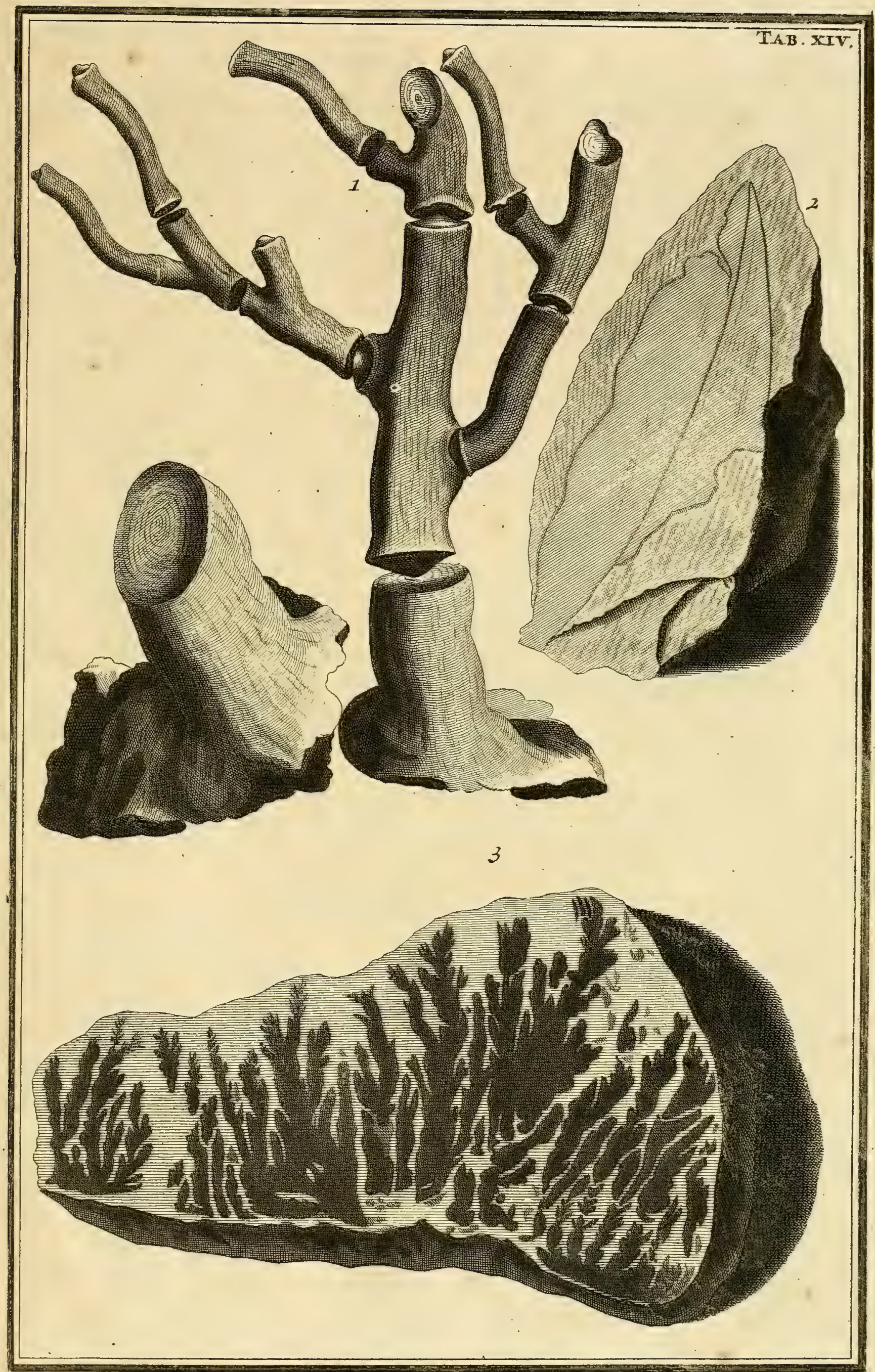

Tll. Dn Samueli Kölesero de Keres-eer, Cecretario Guberniali Gasareo-Regio Drincipatus Transylorance. 



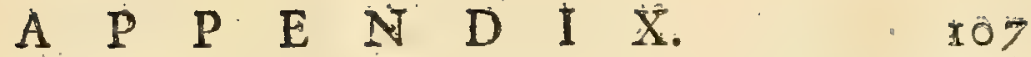

537 M. D. n. 214. Cefpes bituminofus Kreyfingenfis Thus ringix. Diluv.

$53^{8}$ M. D. n. 243. Semen Plantx cujusdam umbelliferx lapideum. Echterdingx in Ducatu Wirtembergico. Dil.

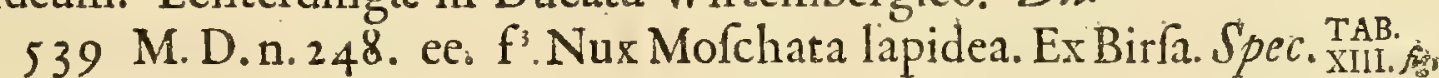
Lith. Helv. p. 42. f. 57. Helwing. Lith. Ang. 37. Nux myrifi-2. ca lapidea cinerea. Bauh. Font. Boll. 35 . Stein, fo eine Mufcatnuss praeentirt. Myl. Sax. P. II. p. 74, fig. Mufatnuls, Nux Mofchata frictu rotundo CB. die ibre couleur fo wol aus als inwendig bebalten. Auf der barten braunen fibalen fiebet man a. dein eindruck, oder Adern, da die bliuthe gelegen, und als man fie zerfuffet, die brounen Atrix, fo von der peripherie des Kernes bis an das Centrum lauffen. Volkm. Sil. I 29. T. XXII. f. 6. Siebet aus, wie die griune Mufcaten $N u / s$, von farb, braunroth. Id. I33. T. XXIV. fig. 4. Pol. Mufcatowa galka Kamienna. Helw. Ind. Foff. Pol. Nux Mofchata lapidea tota filicix fubftantix, referens ex affe Nucem Mofchatam fructu oblongo. CB. Helw. Lith.P. II. p. 97. Tab. III. $n^{\circ}$. 3. qui Nuces Mofchatas lapidéas hactenus cognitas refert ad Tubera quxdam marina, quondam vel faxis adnata, vel fub Mufco marino progenita.

$54^{\circ}$ Foliorum quorundam mineralium pediculi compreffi. Luid. $n .185$.

54I Lithophyllon gelafinis quibusdam Salebrofum Malleatula dictum. Id. n. 204.

542 Planta incognita ex minera Ferri. Wolfart $V$ ale Hanov. \$. 10. fig. 6. conf. Tab. VIIl. fig. 5 .

543 Capilli Veneris in Lapide fiffili Manebacenfi. Myl. Sax. p. 30. fig. 2. ad.p. 19.

544 Conferva Plinii. Luid. p. xо8. Pol. Gaebka w Kamieniu. Helw. Ind. Foff. Pol.

545 Arbufcula vel Planta in Lapide fifflil. Myl. Sax. p. 28.v. TAB TAB. VIII. fig. 5. Dub. 5.

546 Fructum quendam exprimens Lapis Metallicus. Spec. Lith. TAB. Helv. 67. fig. 89. conf. Sceleton Echini marini intra Teftam re- ${ }_{5 .}$. periundi.

547 Virgulta petrificata. Steinenes geftaìd. Lang. Hift. p. 53. Tab. XIV. Poft-Dilur.

548 Radix petrificata. Steinene Wurz. Lang. Hift. p. 54. Tab. XIV. Dub.

549 Fructus Arboris AHOVAI Indicus. Myl. $S_{a x} p$. 30. TAB.Is. TAB. II. fig. 6. Diluv. Ejus nucleus. Volkm. Sil. I34. T. $X X I V . f .18$.

O 2 
550 Folia quxdam (an Leguminofa?) rotunda in lapide fifili. Ex Mufco Vallisneriano.

5) I Stelecbites effigie ftipitis truncati, cum rudimentis ramorum, in lapide albo \& cinereo quandoque nigricante, per longitudinem friato. Alii radici Raphani rufticanæ æmuli. Helwing. Lith. Ang. 42. Tab. II. fig. 7. 8. M. D. n. $248 . \mathrm{t}^{3}$.

$552 T^{3}$ wo frait slender ftones refembling the Columns eredted in the middle of Some Flowers, one convex of the top, and almoftflat. The other fphericalles Triangular, fomewbat like the feedcafe of a Tulip. Grew. Muf. 267.

553. Two other joynted ftones, looking as if they were pieces of the geniculated falk, of fome Plant. Id. l. c.

554 Lapis divaricationes ramofas vegetabilis cujusdam oftendens, colore albo. Helwing. Lith. p. 53. T. VI. fig. 3. conf Tab.V.fig. 8.

555 Hexapetalon Carbonarium Luid. in Tranfact. Pbil.n. 33 I. p. 95. Tab. I. fig. 3 .

$55^{6}$ Abietis an potius Lycopodii cujusdam ramulus? Id. l.c.f. 6.

557 Lignum Molavin petrefactum Paracalenfe, exalbidum corticem verfus fubfufcum, fubluftre \& Pyrite compar foliditate. Camell. in Tranfact. Pbil. n. 3II. P. 2405. Aliud coloris fubglauci.

$55^{8}$ Ligni aliud frufum Palicpicanum, vertim non videtur ef fe Ligni Molavin, fed potius Ligni Guixo. Coloris æruginof, corticem verfus luteo \& rubente \& fufco varium, pectinibus minus rectis quafi interruptis. Id. l. c. p. 2406.

559 Baobab lapideus, Fructus illius fimilitudinem gerit, quo ad extinguendam fitim Ethiopes utuntur, de quo Profper Alpinus Plant. Esypt. \& C. Cluf. L. II. c. r. Exotic. quemve à nautis, qui ex Ethiopia redierunt, redemptum Londino miferat. Jac. Garetus. Calc. Mis. 4 I4.

560 Ebenum foffle. Hildesheimii reperitur in Commiffuris intra Terram aluminofam - Stips nigra foliis \& fructu carens, cornu politi modo fplendida, folida, levis, omnino afpectu $\mathrm{f}^{2}-$ milis Gagati Lapidi, fed naturâ diverfâ. Nam Ebenum, ignem non fentir, Gagates accenfus ardet \& igne perit. Agric. Nat. Foff. L. III. c. 22. Pol. Heban.

$56 \mathrm{x}$ Ebenum folfile in Islandia laminatim eruitur, colore nigerrimo, quandoque fubfufco, ponderofum, fragile, exiccatum ubi fuerie, Faber Ligniarius in lignis judicandis peritus juglandis Arboris radicem longâ, annorum ferie nigredine tanta infeftam effe putabat. Sed iis locis nunquam hx Arbores confpecte 


\section{A P P E N D I X.}

funt; Polituram non facile admittit -... Hoc Lignum vulgo Sorturbrandur vocant, \& latere ajunt in monte adeo prarupto \& alto, ut eo nullus nifi andaciffimus penetrare valeat. Worm. $M u$ s。 169.

562 Lignum foffile Umbrie, quod reperitur in Umbria in Territorio Todi. Inveniuntur particulæ ex parte cretofx, ex parte lignex, ex parte Carbonis inftar adufte. Siquidem de minerali ac vegetabili participare videtur, Metallopbitum feu Minerephitum appellari poffe videtur, fimile Cedro Montis Atlantis in Mauritania. Colore eft Leonino obfcuro, venis inordinatis, obfcurioribus aliquanto reliqua fubftantia. Id. l.c.

563 Lignum Carbonis modo nigram, aridum, ac leve, effoditur in montibus vallis D. Joachimi 40 . Orgyiarum profunditate. Cord. Obf. 2 I8.

564 Petrificirtes Flojsholz, Lignum petrefactum, aus der Saal. Myl. Muf n. 64 r。

565 - Eichentiolz, Quercinum, Id. n. 642 .

566 - Holz, von Giebichenftein bey Hall. Id. n. 643 . 655. - aus Moscaut. n. 644. aus Thuringen, balt der C. I Gold. n. 645. aus dem. Teufelstimpel zu Merleburg. n. 647. vom $P$ faffendorffichen acker. n. 649. von Görlitz. n. 65 I. von Altorff. n. 65 2. von Merjeburg. n. 653. aus Siam. n. 654. von Halle. n. 66r. von Querfurth. n. 670.673 . 567. Hols so petrificirt, vitriol baltend von Querfurth. Id. n. 646. vitriolifch gegraben Holz. n. 656. Lignum petrefactum $\mathrm{Vi}=$ triolicum.

568 Lithoxylon Ligno Abiegno albo xmulum zon Abrecbtsdorff im Neumarkifchen. Id. n. 649.

569 Lignum foffle Bituminofum von Querfurth. Id. n. 6 ; o.è vena quadam fuccini Boruffica. Id. n. 662.

570 Lithoxylon feu Lignum foffile ftriatum in fua matrice, aus dem Kirchberge bey Landsbut. Id. n. 658.

571 Ligni fruftum, hujus generis Arbores vaftx effodiuntur cum Cefpitibus bituminofis in Agro Weftmorlandix. Id. $n .659$.

572 Lignum foffle Goldbergenfe. Id. n. 665 .

573 - daran die Refina zueeben. Id. n.666.

574 Zu eifen gewordenes Holz, in ferrum mutatum, aus Engelland. Id. n. 668. Zu ftein \&c. Id. n. 667. Zu Marcafit. Id. n. 669. 575 Ein fiuckgen brett brauner Farb vom Ligno foffli, , fo bey Caffel gegraben wird. Id. n. 676 .

576 Truncus Ligni è Valle Joachimica in Lapidem converfus. Besl, Muf.p. 9 I. T. XXXI.ubilegitur Infcriptio. A. MDLXXVII. 
DISER BAUM IST MIT S. BARBARA PRULNSTOLN ANTROFFEN VOM MUNTLOCH MM, UND VOM TAGSAIGER CL. LACHTER DEN XVII. FEBRUARI IM JOACHIMSTHAL.

577. Myrobalanus lapideus. Id. 104. T XXXVII. Myrobalanus nigra feu Indica. Volkm. Sil. I35: T. XXIV.f. 20.

578 Piper longum lapideum. 1. c.

579 Lignum foffile Bituminofum feu Matrix fuccini Hartmarini, fine \& cum Vitriolo. Ex Littore Maris Balthici. M. D. ns 2.48. $g^{3}$.

580 Lapis metallaris fcifflis cinereus, variorum feminum fis gnaturis copiofè exornatus, ut Melonum Anifi, Foniculi, fortè Lapis frumentarius. Wolfart. Hift. Nat. Haff: 34. T. V. f. 4. Ein Erafchieffer aus denen Franckenbergifchen Bergwerken, auf welchem bulfen von mancherley faamen ligen. Dubito ego valdè, an fit Lapis ita dictus Frumentarius.

58I Radix lignofa dentibus obfita ex fovea profunda propè Tennebergam Thuringix arcem cruta. Mercat. Met. App. $p .3^{6}$.

582 Lithoxylon Ligno Quercino æmulum, an dem die Rinden, wie an den alten Eichen grau, runzlicht und geriffen. Volkm. Sil. 93. T. VII. f. I.

$5^{8} 3$ - Atriis feu lineis rectis, \& transverfis cancellatum, ein ftuck fleinernes bolz, nach der länge, und quer geftreiff, braun gelb. Id. f. 2.

$584-$ complanatius, latè ftriatum, \& quafi reticulatum; ein fuck mit weit von einander flebenden frreiffen, und uber denfels ben gleichsam, wie ein netze gegittert. Id. t. 3 .

$585-$ Atriis rectis, rarioribus, magisque depreflis exaratum, mit feicht und weit von einander flehenden frichen, braunrotb. Id fig. 4.

586 - feu fulcis altioribus cancellatum \& alveolatum, mit erbobenen frichen gegittert, braunroth und mit vielen grus bert. Id. f. 5.

587 - Atriatum \& nodofum, ligno Quercus petrx feu Roboris æmulum, nach der längen und quer mit gleichen linien geAreift, rund und mit vielen knoten und knorren um und um befeat. Id. f. 6.

588 - altius ftriatum, \& geniculatiom, braun mit erbobenen und breiten ftreiffen, und mit vielen knotichten gleichen oder gewerben unterfcbieden, wie der Calamus Aromaticus, oder das robr. Id f. 7.

s89 cancellatum, \& quafi articulatum, atque comprefo 


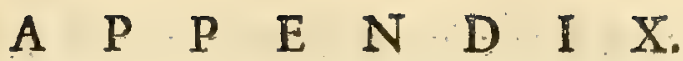

fum, caftanienbrann, nach der länge breit geftreifft, und awischen den Articulis, mit fubtilen querlinien gegittert, hin und wieder eingedrukt, und gequetscbt. Id. Tab. VIII. f. I.

590 Lithoxylon frriatum, compreffum, cortice adufto, Scbwarzbraun, unter der noch klebenden fcbruarzgebranten Rinden geftreiff. Id. f. 2.

$59 \mathrm{I}-$ arenofum leviter ftriatum, \& arcuatum, ein fuck von einem krumgebogenen Afl, rusffarb, von der bin und wieder gebranten Rinden gefcbreärzt, und ungleich geftreifft. Id. f. 3 .

592 Lithoryza ftriata \& nodofa, fiebet mebr einer wurzel, als einembolz äbnlich, braun, glatt, etwas geplätfcht, nach der länge geftreifft, um und um mit ftriis oder fafciis Catenulatis, und mit vielen knoten befezt. Id. fig. 4 .

593 Lithoxylum paxillare afperum, ocker oder Leimgetb mit vielen Rumalen, riffen und Spälten, wie die Rinde an einem Lerchenbaum. Id. f. 5 .

$594-$ denfius \& fubtilius ftriatum \& articulatum, ein nach der länge febr eng und fubtil geftreifftes, verfteinertes fuck braunes bolz, mit krummen querftrichen oder gelenken. Id. fig. 6 .

595 Ein fuck von einer $Z$ wiesel, fiebet dem Eichenbola nicht ungleich, die Rinde ift allentbalben buckelicbt oder Tuberculos. Id. $\mathrm{f} .8$.

597 Ein nodus, oder ausgefprungener knorre braunroth, wie an dem Eichenbolz. Id. f. 9.

598 Lithoxylon fquanofum, Leimfarb, mit groffen breiten and fumpffen Scbuppen gleich denen fifchschuppen befezt. Id. fig. ro.

$599-$ - fquamis longioribus \& cufpidatis. Auf der Rinde des Pinus fylv. Mugo dictx Tab. gleich, klebet bin und wieder ein fchwarz gebrantes Harz, wie ein Pech. Id. f. I r.

600 - — \& majoribus minus cufpidatis, mit langen Schmalen, ftumpf und dicht über einander ftehenden grauen fcbuppen befezt, der Schuppichten Rinden des Pinus maritinx III. Tab. nicht ungleich. Id. f. I 2 .

601 - colorisferruginofi arenâ \& ochrâ infarctum. Braungelbes oder rothfarbenes ftuck mit langen, fobmalen, erböbeten, und etwas zugefpizten fchuppen, wie an dem Pinu fylv. valgari feu Tæda. Id. f. I 3 .

$602-1$ margaceum; Grau, mit vielen langen, sebr Spitzigen fchuppen, wie an dem Pinaftro Auftriaco majori, mit einem grau und barten feinmark gefullet. Id. f. I 4 .

603 - fquamis anguftioribus \& obtufioribus à fe invi- 
invicem disjunctis, mit langen und ftumpen fchuppen, welche weit von einander gefezt. Id. f. I 5 .

604 Lithoxylon fquamofum fquamis minimis cufpidatis, fehet wie eine Zwiefel von einen kleinen Aft, des Pinus Italicx aus, mit kleinen Jpitzigen Scbuppen, braunroth. Id. f. 16.

605 Ein Stuck von einem kleinen Afl, fchwarabraun, mit kleinen runden Scbuppen. Id. f. I7.

606. Zwey Stuk mit langen und Schmalen Schuppen braun oder. infsfarb, mit etwas grau untermifcht. Id. T. IX. f. I.

607 Lithoxylon Atriatum lxve, geftreifftes braun und glattes bolz. Id. fig. 2.

608 - denfius ftriatum ex cinereo coruleum. Ein blaulichtes Stuk mit dichteren freiffen. Id. f. 3 .

609 Ein rares Stuk mit runden und bolen tuberculis reibenweise befezt, die fich gar leicht in 4 . theile von einander theilen laffen, den diken fchuppen, aus welchen die Coni an dem Pinu Italica zufammen gepakt, oder aucb den tuberculis der Indianifsben. Ananaffen frucht nicht gar wäbnlich, grau und platt. \&c. Id. f. 4.

6 ro Ein bräuner fchuppichter. Aft, mit einer Zwiefel von einer rothen Tanne. Id. f. s.

6 I I Ein geftreiffes Stuk, bin and wieder gekrïnt, eingebogen, und gefalten. Id. fig. 6 .

6 I 2 Eine Zwiefel von einem ftarken Aft, grau, auf der Rinde punctulat, oder mit kleinen puncten, die mit kurzen ftris durchzogen. Id. f. 7.

6 r 3 Lithoxylon verrucufum, braunes Stuk von einem diken Af, snit runden pucklen oder knoten befezt. Id. f. 8.

6r 4 - fquamis rotundioribus luteum, ein gelbes Stuk mit runden fchuppen, fo fich getheilet und gefpalten. Id. fig. 9. 10. das Marck fig. I I.

6 I5 - arenofum nodofum. - Ligno alno æmulum læve albidum, dem weifs buchenen Holz nicht ingleich. - rotundum læve fpadiceum. Id. p. 97.

6 I6 Cortices Arborum lutofi \& arenofi, déren etliche tuberculos, etliche fquamos oder Jchuppicht find. Id. p. 98.

6 I 7 Ein Stuk einer dicken und krummen wurzel nicht ungleich, musfarb, geffreiff, und mit gleichen. Lithoriza ftriata, \& quafi geniculata; Cornu Animalis cujusdam referens. Id. p. I00. T. IX. f. I 2 .

618 Lithoxylon fquamis cancellatim dispofitis afperum, ein ftarker Aft, an dem die fchuppen, um und um gegitteret ftehen. Id. f. 13 . 


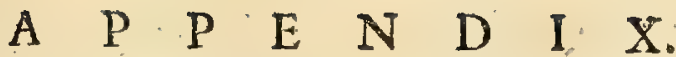

619 Lithoxylon ftriis hamulatis. Braunes und Reinernes bols, bin and wieder mit kurzen ftris, oder frichen, fo wie boklein, formirt. Id. f. 14.

620 - luteum denfe nodofum, das uber und uber flatt der Jchuppen mit lauter buckeln dicbte befezt. Id p. 101 . f. 15.

621 Scheinet ein kleiner Aft eines Pinaftri fultriaci tenuifolii. Cluf. oder einer Weistanine. Id. p. 102 . fig. 16.

622 Lithoxylum fquamofum cortice nigro, die fchuppen find breit und fumpf. Id. p. 102 .

ftriatum. Id. $1 \mathrm{c}$.

$62_{3}$ - nigrum oculatum - alveolatum, articulatum \&

624 Geftreifftes und fandicbtes Lithoxylon, das in etwas geplät fcht, und unter der Jchwaragebranten Rinden geftreift. Id. fig. 17.

625 Ein groffer Stam im Burgberg. Id. Tab. X.

626 Lignum foffile atro purpureum, woraus eine fchwarze Refina dringet. Id. p. 104.

627 Ein unbekantes vegetabile. Die Rinde if fchwarzgran sind gefchuppt. Die zierlich ubereinander flebende fchuppen schwarz und glatt, welche den fchuppen des Palmbaums nicht ungleich. Id. $113 . \mathrm{T}$. XV. fig. 4 .

628 Ein unbekante gefchupte frucbt oder Conus, deren scbuppen gegittert fteben auf dunkelgrauem Jcbiefer. Die auf beiden feiten daran febende Blätter fehen wie fcbilfblätter aus, und find wie die Frucht, fchwarz und glatt. Id. I29. T. XXII. f. 2.

629 Frucbte fo dem Piperi nigro, fchwarzen Pfeffer oder auch den Cübeben gleich, auswendig fchwarz, inwendig griingelb oder grau. Id. 134. T. XXIV. f. 15.

630 Kommet mit der frembden frucbt Tab. II. fructu fubrotundo cineraceo duplici angulo. CB. ïberein. Id. I34. T.XXIV.f. 19 .

$6_{3}$. Fructus Indicus Juglandi fimilis. Chabr. Fruetus rotundus flavus tuberculis obfitus. CB. Id. 137. T. XXIV. 22 .

632 Lithoxylum albidum, tuberculis circum circa notatum; verfteintes bolz, aus dem Kircbberg vor Landsbut, aufswendig glatt mit ovalen warzen oder knoten. Id. 33 I. T. III. f. I.

$6_{33}$ - tuberculis quafi cancellatum, fcheinet ein Cortex tuberculofus zufein, an dem die mebr vierekicht, als runde $\mathrm{Tu}$ bercula an und ubereinander gegittert fteben. Id. T. III. f. 2.

634 Abdruk eines Vegetabilis mit leiften oder faltzen, zwifchen welchen viel unten und oben zugespizte, und eingedrukte Scbuppen oder Flämmchen zufeben fein. Id. T. III. f. 3.

635 Ein abdruk in grauem Sandfein, vermutblich von einem vegetabili, allenthalben mit narben befezt, als wan man mit ei- 
nem meffer binein gefuchen oder gefcbnitten. Id. 332. T. III. f. 4 .

636 Eindruck in grauem Sandfein, von einem vegetabili, mit pinnis in forma quincuncis, die wie ein Lateinifch V. ausmachen. Id. T. II. f. 5 .

637 Villeicht ein abdruck von einem vegetabili anf der einen reiten allentbalben mit runden löcblein oder grüblein geaieret, oben fiebt man etwas, wie eine Quafte oder Blubme mit einem gefchupten Kropff, wie bey den Cyanis und Jaceis. Id. T. III. fig. 6 .

638 Lithoxylum nigrum articulatum, friisque undulatis notatum, verfteintes fchwarzgranes bolz mit vielen gleichen oder gelenken, und zwifchen difen oben mit ein wenig, unten aber mebr ausswarts gebogenen und tieffen freiffen aus einer Koblgrube zu Schönbutt. Id. T. IV. f. r.

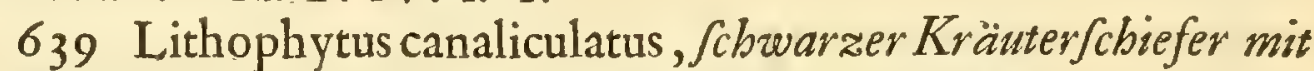
Hoblkäblen, aus gleichem Kobljchacht. Id. T. IV. f. 2.

640 Eine glatte, glänzichte und fchwarze rinde, die wie das innere theil von einer gefchuppten Rinde ausfiebet, dann die fchuppen alle vertiefft in grau und Leberfarbenem fchiefer von Liebersdorff bey Gablau. Id. 333. T. IV. f. 4 .

$64 \mathrm{I}$ Gefchupter grauer Scbiefer an dem die fchuppen kleiner, erböbet, oben rund, und unten etwas zugefpizt. Id. T. IV. f. 5 .

642 Grauer gefchupter Kräuterfchiefer auf beiden feiten mit erbobenen groffen fchuppen befezt, derer die meiften oben fumpf, unten alle jpitzig zugeben, und darauff gewurflet fieben. Dife Steine werden Lepidotx, Scbuppenfteine genennet. Id.T.IV. f. 6.

643 Anthracodendrum oculatum, fcheinet, wie eine ganz ausgekoblte Rinde eines Baums, aus einem Kobllchacht zu Rudolfsdorff. Id. T. IV. f. 9. Die au/swendige Seite ift mit runden tuberculis befezt, in geftalt der augen, in zelchen die Pupillie ein wenig erböbet, glatt, und gläntzicht, wie eine Steinkoble.

644 Scbeinet eine auslandifche Frucht zusein, nnd zwaren eine Art eines Kerns einer Nuculx oder Avellanx Indicx, anf der einen feiten a flach, doch ein wenig eingebogen, auf der andern b convex, mit einem erbabenen freiffen, der mitten um den weifsen Kern laufft. Id. 336. T. V. f. I 2.

\section{P S E U D O P H Y T A,}

Lapides, qui Plantarum figuras mentiuntur.

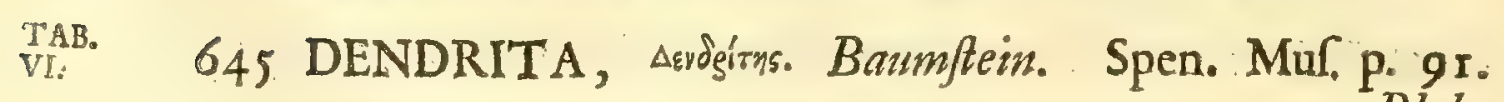


Blubmen, Fofforibus Suhlenfibus. Wafferfein circa Wurzburgum. Dendrites Plin. L. XXXVII. c. I I. Dendrachates, velut Arbu-

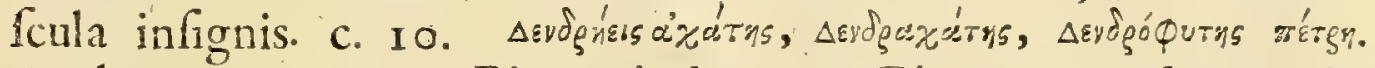
Orph. Lap. p. 203. Pietra imbofcata. Pietra naturalmente delineata in figura de' bofchi. Pietra di Sinai. Imperat. Stor. Nat. L. XXIV. p. 578 . Pietra del monte Sinai. Mofc. Mul. 47. Achates in cujus Planitie 7. arbores delineata confpiciebantur, Camill. Pifaurenf. apud Dalech. Boomfreentje, Boomtje Achate. Rumpf. Amboinfch. Rariteitk. p. 287. Lapides qui Ericeta repræéntant. B, de Boot. L. Il. $c .285$. Lapis artificiofa cælaturâ in figuram Abrotani plantæe effictus. Lapis Naturx vi affabrè efformatus in figuram \& typum nemoris. Calc. Mre. Ject. III. p. 419.420. Lapis fiffilis, per quem difcurrentes venx ex argilla cinerea delicatius lapidefcente arborem Corallii inftar pazulam in ramos hinc inde diffufos reprefentant. Bauh. Hift. Font. Boll. de Lapidib. $p .4$. Icones varias Dendritarum vide Herb. Diluv. TAB. VII. Ð VIII. Dendrita Saxonicus, Sylvas \& Dumeta pulcherrime repræfentans. M. D. n.96. Dendrita elegantiffimus in lapide fiffili marmoreo candido. Ex Lapicidina pagi Solnhof Comitatus Pappenheimenfis. 2 . 97. TAB. VII. fig. 8. Dendriticum VAB. Marmor Florentinum. n. 98. Dendrites Suhlenfis niger in mar-8. more carneo. n. 99. Myl. Sax. Relat. VIII. n. 100. Dendrites Suhlenfis fubtiliffimus in marmore flavefcente. $n$. гоo. Myl. l. $c$. Marmor album Dendritis nigricantibus in ipfo corpore hinc inde delitefcentibus perfufum ex Valle Raurica prope Terznach. n. Iо I. Dendrita Glacenfis ex Bohemia in lapide fiffili rubente. $n$. I02. Dendritæe prope pagum Popperg Ducatus Solisbacenfis. $n$. 103. Dendrita fruticeti furgentis effigie ex Lapicidina prope Solnhof. $n$. so4. Dendrita Haffiacus in marmore fiffli flavefente. $n$. 105. Dendrita vel ftigmita in Marmore feu faxo candido Scaphufienfi. n. 106. Dendritx \& Atigmitx in Badenfis Comitatus Ferrifodinis prope Cappel in marmore flavo albefcente. $n$. 167 . Dendritx parvi ex Agro Bafilienfi. $n$. 108. Dendritx \& ftigmitx in faxo ffffiliöningenfi. $n$. I 09. TAB. VIII. fig. 6. Dendrites Algx VIII. fs. fere figura. Ex Agris Altenburgenfibus Mifnix n. I ı. Saxum Montis Legerii Ditionis Tigurinæ, in quo obfcura Dendritarum \& Aftroitarum indicia. $n$. I I r. Dendrita fucum ferè referens in faxo carnei coloris ex collibus Euganeis. n. 112. Dendrites Eyftettenfis elegantiflimus nigro-flavus. $n$. I33. Eyftettenfis martialis Tincturx arbufculis craffioribus. $n$. I 34. Dendritx obfcura veftigia in marga fiffili candida ex Gallia. $n .241$. Stellaformes figurx Aftroitis fimiles in marmore fubflavo ex montibus Bononienfibus. 
n. 248. f. Stellulx nigrx in filice marmoreo coloris rubrofufici ex montibus iifdem. $n .248 . \mathrm{g}$. Silex marmoreus pallidi coloris Rellulis nigris confperfus ex montibus iifdem. $n .248$. b. Silex marmoreus albidus Atellulis nigricantibus confperfus. ibid. $n .248 . i$ Lapis calcarius fifilis Dendrites Mufci fquamofi inftar in fuperficie pictus. Prope Campiliam Hetrurix. n. 248: $n$. Lapis calcarius dendrites grifeus, quafi mufcos albidos marinos reprefentans. Ex Agro Florentino. n. 248. p. Lapis Florentinis Pietra forte dictus ramulis quafi cupreffinis dimidiatz eminentix \& opere crultaceo perbellè à Natura depictus. Conferendus cum Lapide marmoreo Rhombi fere figura, altero latere protuberantibus quafi graminulis albis obducto. Spen. Mus. gJ. Prope Florentiam. n. 248.x. Lapis Calcarius Florentinus, ex tribus varietatibus Alberini del Ponte à Rignano al Fiume d'Arno. n. 248. y. Cryftallus in cujus finu confpicitur flavefcentis \& nigroviridantis coloris arbufcularum feries inter Dendritas rariffimos jure referenda. Mus. Mincral. n. 553. Dendrites major Triangularis per integram circumferentiam frutices reprafentans. Lang. Hift. $p$. 39. Tab. IX. f. I. Dendrites major rofeus in extremitate ramiTAB. ficationum Tinctura fublutea ornatus. TAB. IX. fig. 2. DendriIX. fig.2. tes fylvulam reprefentans, in principio ramificationum. TinctuTAB, ra nigricante ornatus. TAB. VII. fig. 3. Dendrites. Grew. Muf. 3. 268. A nother reprefenting a plein Field, inclofed with a bedge. of Trees - Dendropotamites. A Kind of Alabafler baving a mixture of browne, tawny with and green, and not unaptly re. fembling a couple of Rivers. Id. 1. c. Busby Marble Angl. Sibb. Prodr. de Foffil. p. 46. Lapis Sinai feu montis Hyerufalem aut nemoratus $1 \mathrm{mp}$. Lapis fubluride cinerafeens, maculis nigris arbores exprimentibus lamnulatus. Petra Scagbiola o Ciappeddi, Gappeddi virdozza annirizza, pinta nuura d'Arvnli. Sic. Cup. Hort. Cath. Suppl. alt. 52. Marmor Dendrites integram quaft fylvam arbuftorum égregie repræfentans, Baumftein, fo gleichfam einen ganzez Waldvon Baumen artig prefentirt. Spen. Muf.9 I. Simile collem exhibens dumetis coopertam. Dito, fo einen $H_{i i-}$ gel mit Dornbecken umgeben vorftellet. 1. c. Marmor Dendrites cinereum opacum. Dunkelgraner Baumftein. 1. c. Marmor Dendrites. Baum Marmor. Brack. Muf. 78. Marmor cum fruticibus, Herbulis \& aranea. Besl. Muf. 96. T. XXIV. घendgó фopos, Dendrophorus, Dendropbytos triplex. r. Gypfo paululum durior mediam continet coagmentationem filicum coloris fufci, ordinatis circumquaque arbufculis, \& fruticibus, herbis enafcentibus, flofculis dejectis, interea colore croceo afperfus. Gafidanes Plinii 


\section{A $\quad P \quad P \quad E \quad N \quad D \quad I \quad X$.}

eft \&rc. 2. Sinaites eft, proveniens in Melane monte Arabix, quem Sinai vocamus. Turla Mauri. Difinguitur duritie amplioris ffgurx. Plantas edit, raris maculis \& Aavis magis, quam croceis. 3. Brixianus fimilis fecundo, extra quod pumilas plantas \& frequentiores abfque ordine figuret. Mercat. Met. 272. Lapidis cujudam fritis \& mollioris Tabulx, aut crufx Montium, \& in illis A rborum tenuillmarum figuris difindx. Id. App. p. 37. Ein gelblicbter minder flein auf welchem fich bin und wieder fibwarze baümlein, wie ein Mufcus faxatilis repens minimus, klein kriecbendes fein moofs prefentirt. Volkm. Sil. p. 58. T. II. fig I. Ein andere von gleicher couleur mit der abbildung des Mufci cupreffiformis feu foliis Abrotani fominx. Tab. repentis ramofr, kriechendes wid äfiges Cupreffen moofs. Id. fig. 2. ein graner Stein, worauff ein in der fchönften miniatur arbeit gefchildertes Baitmlein zufeben. Id. fig. 3. ein weiffer, auf dem das fchwarze Bä̈mlein einem Mufco Corallino, fet Corallinx mont. Tab. nicbt unäbnlich. Id. fig. 4. Ein gelber, auf dem die Baïmlein unten mit farken äften und famm, oben mit den allerfubtilften ramufculis, wie die allerfeinfe miniatur arbeit fteben. Id. fig. 5. Ein grofer Dendrites von Cuntzendorff, an dem die Farbe weifs, mit gelben Fleken, und einem fchwiarzen gröffern Baimlein, fo mit dem Mufco Coralloide lato folio. CB. oderauch Candido Betulino faft uber ein komt. Id. Tab. III. fig. I. Ein weiffer Kiefs von Gottesberg, in welchem ein angeflogenes fchwarzes Baimlein, an deme die Blätthein tieff zerkerffi, etwas breit, und oben rund und fumpf, wie an den blätteren des Chelidonii querni. Id. T. II. n. 6. Ein weiffer Kies, auf deme fich prafentirt, eine aus kleinen geburgen, und einem boben and fpitzigen felfen beftebende Landfchaft, mit febr zarten Baümlein. Id. T. III. fig. 2. 3. Ein graugelber Kalchftein von Lemberg im Faurifchen, mit febwarzen und fubtilen Baümlein. Id. 324. T.I. f. 2. Lapis corneus, Fewerftein, von Maffel, mit bleyfarb gebildeten Baismlein, nebft einem gelben Belemniten. Id. f. 3. Gielbicbter Kies won Hermsdorff mit fchwarzen Baïmlein, die der Erica vulg. Heide, äbnlich feben. Id. 329. f. 4. Glatte weiffe Stein oder Kiefel von Reichenbach, nit fchwarzen und fubtilen Baümlein. 1. c. Pol. Kamien Drzewny. Galezify. Helw. Ind. Foff. Pol. Dendrites vel $\Delta \varepsilon v \delta$ gendn's potius Angerburgicus. 1d. Lith. P. Il. 85. Tab. I. n. I. Dendrites calcarius Angerburgenfis ad Littora Kehlenfia obvius, qui ramos per totum lapidem frondofos nigrore notabili confpicuos exhibet. Id. $p \cdot 93 . T . I . n .2$. Dendrites calcarius Infterburgenfis, per totam fuperficiem figuras quafi ftellatas exhibens. Id. T. I. n. 3 . 
Lapillus totus quantus arbuftis ac virgultis obfitus. Melle Lap. fig. Lubec.p. 23 . Tab.II. fig. 3.a.

646 M. D. n. 4. Lapis fiffilis cinereus ornamentis foliaceis viridibus \& corulefcentibus pulchre notatus Franckenbergenfis xrifer. Fliegenfittich, quia veluti mufcarum alis eft confperfus. Lapis metallaris, combuftis quafi ftipulis confperfus. Ein Erzscbieffer, fo gleichfam verbrennten Stoplen äbnliche Flecken bat, deswegen von dem gemeinen mann Fliegenfittich genennet wird. Wolf. H. Nat. Haff. p. 30. T. III. f. 6. Winckelmann. Chronol. Haff. P. I. p. 37.

647 M. D. n. 65. Lapis fifflis cinereus melanoftichos \& meTAB. lanogrammos Öningenfis. TAB. IV. fig. 2.

648 . Figure in congelata Aqua Borraginis deftillata confpeTAB. ctx. TAB. VII. fig. I. Icones Filicis vel 'Trichomanis xmulx in

1.2.3. Aqua Nitri Antimoniati conglaciata. TAB. VII. fig. 2. 3. FiTAB. guræ Plantarum in fpecie Mufci clavellati $x$ mulx in Glacie fenevilI. fig. fris adhærente. TAB. VIII. fig. I.

649 Concretiones Plantarum xmulx in Aqua Camphorata confpicux. Icones Arbufcularum vitro adhrrentes, cui infufum TAB fuit Errhinum ex Manna foluta in Aqua Rofarum, Liliorum ConVII.fg.5. vallium. TAB. VII. fig. 5 .

TAB. 650 Sal volatile Serici. TAB. VII. fig. 6.

TAB. 6 s 1 Argentum purum Arbufculi forma. TAB. VIII. fig 2. 2. fil. Argentum crifpatum Abrotani fruticem ferme xmulans denfe fipatis ramufculis. Worm. Mus.p. I r6. Argentum purum fruticefcens egregium undequaque ramulis abietinis, vel pennis $\mathrm{fl}_{1}$ mile. Ein fuffen gewachsen Silber durch und durch gleich fichtenen Aeften oder Federen. Spen. Mul p. I 34. Argentum purum virgularum fpeciem pre fe ferens, wie Zweiglen oder Reislein von den Baimen. Encel. de Re Metall.L.I. c. 5. Argentum, quod Natura format in figuras Virgularum. Agric Nat. Fo/fl. VIII. p. 334. Argentum purum fruticefcens figura Abietis. Gewachfen Silber in geftalt einer Fiecbten. Spen. MuI. 1. c. Argentum purum arborefcens undequaque quafi ramunculis prxditum. Ein fuffe wie ein baum gewach fen mit Aeften, ift durchaus gediegen Silber. Id. 1. c. Argentum arborefcens in figuram Abietis elatum album. Gewachfen Silber in geftalt einer Fiechten Jehr weich. Id. p. 137. Argentum ftatim fuum in figuram Arbufti concretum. Ein ftiiffli gediegen Silber anf Ficbtenart gewach/en. 1. c. Argentum purum Arborefcens. Gediegen Har Silber auf Fichtenart gewachjen. Id. p. $13^{8}$.

$6 g_{2}$ Figurx Plantarum xmulx in Regulo Antimonii ftellato. VAB fig. TAB. VIl. fig. 7 . 
653 Flores Antimonii fublimati nigri. TAB. VIII. fig. 3. TAB. 654 Fluor Cryltallinus Ericæformis. TAB. VII. fig. 4 .

655 A fort of Alabaftrites, reprefenting a transverfe jection of $f_{\mathrm{V} U \mathrm{~B}}^{\mathrm{T}}$. the Trunck of a Tree. Grew. Mur. 268.

656 A flone exprefing part of a transverse fection of Olive-wood. Id. 269 .

657 Anotber fort of Fasper, reprefenting a piece of wood. One would take it for a fort of Lignum vitx. 1d. 1. c.

658 A flone figur'd like a piece of. Angelica Root. Id. 274.

659 Two flones, one refermbling the Root of Cichory, the other of Tormentile. 1. c.

660 A flone fomewhat flat like the Root of Iris. 1. c.

66 I Aftone as it were bared of the Rind, and baving one End with a Kind of button, on which the rayswind toward the center, as the lines of a rbumb upon a map or the fuites of the attire of any corymbiferous Flower. 1. c.

\section{FIGURAE IN PLANTIS VEL LIGNIS}

\section{Naturâ, vel Arte elaborate.}

662 Virunculi effigies in Ligno Fagino. TAB. X. fig. 2. TAB.X. $66_{3}$ Virunculus in Ligno nodofo ac tortuofo confpicuus. TiB. TAB. X. fig. 2.

664 Crux in Ligno Fagino confpicua. In Biblioth. , Bernenf.

665 Corona Regia in apice gladii ex fcypho furgentis, cum infra fcriptis numeris 167. qui indicant Fago incifam effe hanc figuram anno quodam poft feptuagefimum feculi prateriti. Refecta hæc Arbor A. I 7 I 7 .

666 Crux cum lit. H. \& infra tribus clavis in Ligno Fagino. Valentin. Mus. P. II. p. 76. Ex Mifc. Nat. Curiof.

667 Crux cum informi icone \& corona in Ligno. Valentin.

1. c. Ex Mifc. Cur. An. VIII. E๑ IX. Dec. III. p. I9 r.

668 Crux triplex in Ligno Fagino. Valentin. 1.c. ex An.IX. छ X. Dec. III. Mijc. Cur.p. 187.

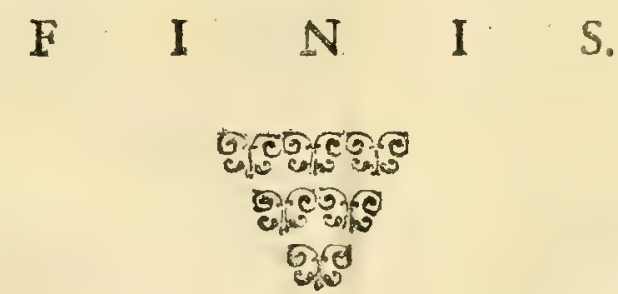




\section{A P P E N D I C E M.}

A.

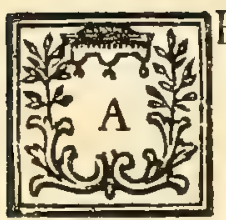

Bies, num. 389.390 .556 Abrotanum. 645 . Acarbahar Jpeciei robbea. 235. Achates. 645.

Adianthum. 120 .

A hovai. 83. 549 .

Alberini. $6+5$.

Alcyonium. 154. \&c. 346 \& c.

Alga. 73.74. $180 . \&$ c.

Alnus. 406. \&c.

Alfine. 12.13.

Ampelites. 464 .

Amphicome. 324 .

Amygdalites. 43 .

Amygdaloides, $43 \mathrm{I}$.

'A eu y da doerdy's. $43 \mathrm{I}$.

Amygdalus $43 \mathrm{I}$.

Anthracodendrum. 643.

Antimonii flores. 653 .

Aparine. 1. Regulus fellatus. 652.

Apium. 15.

Arbor Judæ. 444.

Argentum Arbufculi figura. $65 \mathrm{I}$. A rquatula. 49.

Artocreas. 165.

Arundo. 79. \&c.

Afclepias. 444.

After. 65.66.

Afteria. 317.

Aftrochites. $31 \%$.

Aftroites. 290. \&C. 3II. \& c.

Avellana. 644.

Aurantium, 442 .

B.

RAlanites. 38r.

Balfamina. 59

Baobab. 559.

Bafaltes. 259.

Baum Marmor. 645.

Baumftein. 645.
Beaumepotts. 434.

Bechwood. 416 .

Betula 4ig.

Bienenruft. 312.

Bienen Zellchen. 3 T2.

Blackoack. 528.

Blumen. 645 .

Boomftentje. 645 .

Boomtje Achate. 645 .

Bryoniæ Radix. 321.346.

Bukowy Kamien. 420.

Busby Marble. $6+5$.

Buxus. 370.

C.

CAlamites. 8I. Kárapes 'ivdixos. 8I.

Campoides. 204.

Capillus Veneris. 543.

Caprotka Kamienna. I 34.

Carang Bonga. 230.

Carang Goila. 234.

Caricoides. 348.

Carpinus. 374 .

Carreg-Redynog. 134. Not.

Caryophyllus marinus. I 39.255 . 257.

Caftanea. 388.

Caltanites. 534.

Catbead. I $3 \mathbf{I}$.

Catscamp. I3I.

Catshead. I 3 I.

Centaurium majus. 68

Champinion. I 49.

Chryfanthemum. 63.

Ciappeddi. 645.

Ciflites. 426.

Cletrites. 409.418.

Cocco Meloites. 429.

Columellus. I 39. I $52.8 \mathrm{c}$. 170.255 . 348.

Cometites. 317.322

Conferva Plinii. 544 .

Corallites. 189. I91.

Corallium. 1 86. \&c. 


\section{N D E X I N A P P E N D I C E M.}

Corallium Marinum Afraticum.227. Corang Alea. 229.249.

Corona Regia. 665.

Corylus. 372 .

Crux in Ligno Fagino. 664. \&c.

Cryltallinus Fluor Ericaformis. 654.

Cryftallus Dendrites. 645.

Cubebx. 629.

Cyclamen. 6.

Cylindrites. 242.

Cymatites. 324.

D.

Fmbownik. 376.

Datu Swangi. 235.

Dendrachates. 645 .

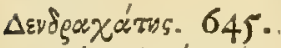

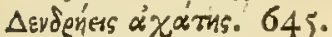

Dendrita. 645.

$\triangle$ svdeitus. 645 .

Dendrophorus. 645 .

Dendropotamites. 645 .

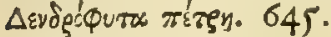

Dendrophytos, 645 .

Draconites. 317.

Dryites. 376 .

Dryopteris. 93 .

Kamien Drzewny. 645.

Drzernik: 376.

Drzewo Kamienne. 459.

E:

7 Benum folfile. 560 .

1 Echini marini Sceleton. 546.

Lichinometra. 317.

Elatites. 402.

Equifetum. 82 .

Ericeta repræfentans Lapis. 645 .

Erotylos, 324.

Efchara. $36 \%$.

Pierre Etoilée. $31 \%$

$$
\mathrm{F} \text {. }
$$

TAba. 55. \&c.

Fabago. 3 I2.

Fagus. 417 .

Fagino Ligno imprefe varie figura. 662. \&c.

Fafciculus. 360 .

Favago. 312 .

Feigenftein. 348.

Fernftone. 134. Not.

Ficoides. 348.445 .

Ficus. 445 .

Figowrik. 348.
Filicula. 102.\&c. 120. \&c.

Filix: 93. \&c.

Firwood. 392.

Fliegenfittich. 646.

Florentinum Marmor. 645 .

Foniculum. 16.

Fœniculi Caules. 79.

Pietra forte. $18+645$.

Fragaria. 9.

Fraxinus. 368 .

Fructus figura Lapis. 546.

Frumenti Culmus. 70.

Fumaria. 58.

Fungites. 139.346.

Fungus. 139.344 .346$.

$$
\text { G. }
$$

Aabka w Kamieniu. 544. Galezifty. 645.

Gallites. 383 . \&c.

Gallium. 2. 4 .

Gafidanes. 645 .

Geftirnftein. 317.

Glandites. 380.

Glomellaria. 531 .

Grabina Kamienna. 375.

Gramen. 72. 73. \&c.

Grzyb Kamienuy. I 5 I.

Grzybiafti Kamien. I49.

Gypfum fpumofum. $22 I$.

T TEban. 560.

H.

1 Hedera. 426 .

Herniaria. 90.

Hexapetalon. 555 .

Hippuris faxea. 229.

Hippurites. 89.

Hordeum. 67. \&c.

Hydatites. 324 .

TAcea. 60.61.

I.

Fedlinowy Kamien. 402.

Fefronowe lifciers Kamieniu. 368.

Pietra Imbofcata. 645.

Inociffites. 4,26 .

Juglans. 371 .

Junciformis Lapis. 360 .

$\mathrm{K}$

T Atberine-Pear. 440.

Klos Zytny w Kamieniu. 60.

Kora Dembowa Kamienna. 378.

Korfen Iamarifskowy Kamienny. 321.

Koto 


\section{I $\mathrm{N} \quad \mathrm{D} \quad \mathrm{E} \quad \mathrm{X}$}

Kotzia rutka w Kamieniut. 17. Krwatweric. 402.

Arix. 400

1 Leberkraut. I 33.

Lepidotes. 6 \&2.

Lichen petra14s. 133.

Lignum faffile. $459.8 \mathrm{c}$.

Limaculum. 52 .

Limularia. 44 .

Lithophyllon. 54I.

Lithophyton. 337.

Lithopteris. 58.

Lithosmunda. r29. \&c.

Lithoftrotion. 259.

Litho Tricbomanes. 96.

Lithoxylon. 459. \&c.

Lougbneagflone. 520.

Lumbricatus Lapis. 324.

Lupinatum. 37.

Lupini fliqua. 25.38 .

l.y coperdites. 176.323.

Lycopodium. 556 .

$$
\text { M. }
$$

Adrepora. 3 II. \&c.

A/ Malleatula. 541 .

Mandale. 431.432 .

Mandelftein. 43I. $43^{2}$.

Manus marina. 300.

Mech Kamienny. 135.

Mclpilus. 443 .

Metallophytum. 562 .

Kanien Migdowy. 43 I.

Milium. 92 .

Millefolium. I 6 .

Millepora. $254 \cdot 332.363$.

Minerephitum. 562 .

Molavin. $557^{\circ}$

Momordica. 59.

Morchel. I63.

Mofchata Nux. 539.

Mo/swood. 522 .

Mu/skatowa galka Kamienna. 539.

Mufcus. 135.645 .

Mycetartocreites. 165 .

Mycetites. 170.

Myriftica Nux. 539.

Myrobalanus. 430.577.

Myrrhis. I4.

Myrtillices. $42 \mathrm{I}$.

N.

TArciffites. 426.

D Neurophyllon. 79.

Nigeila. I I.

O.

Hratzelfein. 324

Onobrychis. 17.

Upuntia. 10.185.

Osmunda. 105.\&c 127.\&c.

Oltryx Lignum. 375.

Oxytites. 420 .

\section{P.}

DAlma Corymbifera. 536 .

1 - marina. 300.

Paprocw Kamieniu. 93.

Patella lapidea. 533.

Patu parudan. 236.

Perfica. 435.

Yfiaumftein. 429.

Phafeolithus. 20. \&c.

Phafeolus. 20. \&c.

Phægites. 420.

Phycites. 180.

Phyllites. 127.

Pietra forte. 184.

Pinei Coni. 393. \&c.

Pinus. 137. 391 .

Piper. 578.

Pifa. 18.

Piftacii Fructus. 436 .

Plantago. 5.

Polonglant. 255.

Polypodium. 98.

Populus alba. 415 .

Populus nigra. 4 I 4 .

Porafte Kamieniu. 180.

Porofa ftellata. 312.

- Fronde di Felai. 93.

Poroftowy Kamien. I 80.

Porpites. 326.

Portellaria. 43.

Porus. 189.

Prunellarium. 429.

Prunus. 28.

Punctularia: 29.

Pufchfeits. 645 .

Pyriformis Lapis. 440.

Pyrus. 437. \&c.

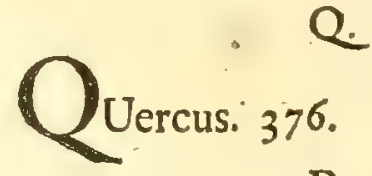

R.

Ddiatula. 64.

Radius nedofus. $53^{\circ}$ 


\section{$\begin{array}{llllllllllll}I & N & A & P & P & E & N & D & I & C & E & M\end{array}$}

Radix petrificata. $54^{8}$.

Radularia. 317.

Rapa. 8. $\begin{aligned} & \text { Stonogowiek. } 324 \\ & \text { Storyftone } 315 .\end{aligned}$

Retepora. 366.

Reticula. 279.

Sirak bobozey Kamiemy. 56.

Rhibarbarum. 9I.

Rhodites. 303 .

Striatiula. 79.

Rozany Kamiett. 317.

Ricinus. 27.

Rubeola. I.

\section{S.}

SAlicites. 413.

Salix. 410 .

Sarnius Lapis. 408.

Scaghiola. 645 .

The Schafft. 321.

Scbuppenftein. 642.

Scolopendrites. 324 .

Scorpioides. I 9.

Secalina Jpica. 69.

Securidaca. 54

Seenägelein. $257^{\circ}$

Serpillum. 7.

Siatskowy Kamien. 366.

Siliquaftrum. 24. \&c. 444.

Silo. 24.

Pietra di Sinai. 645.

Shupik. I 52 .

Soapballs. 433.

Sonnenftein. 295.317.

Sorbus Alpina. 44I.

Sorturbrandur. 522.561 ;

Spongia. 365.

Spongodes. 365 .

Starredfone. 315 .

Staryftones. 315 .

Stelechites. 55 I.

Stellaria Pietra. 317.

Stellaris Lapis. 317.

Stellatus Lapis. 317.

Stigmita. 655 .

Strza peczka Kamienna. 195.

surculus Lapideuss. 530 .

$T$.

7 Artofale. I 50.

1 Taxi fructus. 40.4.

Terra foliata Sicula. 456.

'Thymus.' 7 .

Tilia. $424 \cdot 425$.

Tithymalus. 3 .

Toadftone. 149.

Tofus cum foliis. 408 .

Trawne Lijcie w kamienach Wy. rafone. 75.

Trichomanes. 115 - \&c.

Trifolium. 9.

Tritici fpica. 71 .

Tfiencelint. 257.

Tubera Lapidea. 348.

Tubularia. 226. 338 . \& c

Tubulites. 382. Tuffilago. 62 .

TIcia. 444. $\mathrm{V}$.

$\checkmark$ Virgulta petrificata. 547.

Virunculus.662.663. Vitis. 427

Vitis Idea. 42I. 422 .

Ulmus. 423 .

Umbriæ Lignum foffile. 562 .

Undulago. 324 .

Vomica Nux. 534.

IV Affelfein. 232

Taflerftein. 645 .

Warvedfone. 324.

Waxenvein. 363.

Wronowe Oko Kamienne. 534.

F I N I S.

$\begin{array}{lllllllll}E & M & E & N & D & A & N & D & A .\end{array}$

Pag. 79. in marg. ad num. 194. ponendum erat: TAB. XII. fg. r. 2. \& TAB. XIV. fg. I.

A D MONITIO A D B I L IOPEGUM, 2uò Figura inferenda.

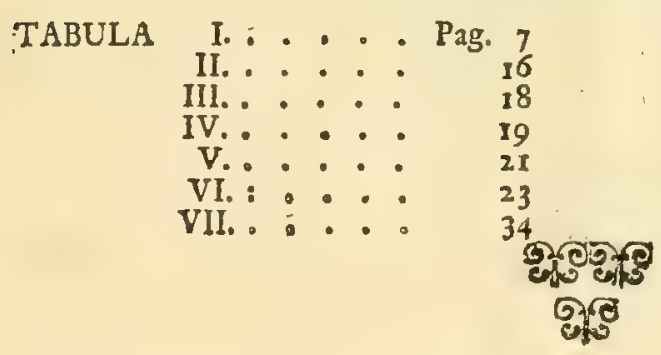

TABULA VIII. . . . Pag. 40

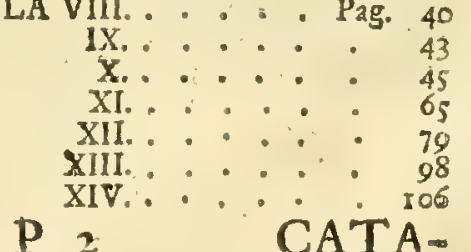




\section{CATALOGUS LIBRORUM,}

Qui novifime apud PLTRUM VANDER Aa prodierunt.

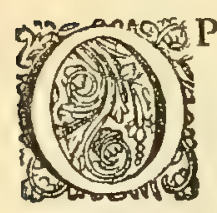

culum Anatomicum de fabrica Glandularum in corpore humano, continens binas Epiftolas: quarum prior eft Hermanni Boerhave, fuper hac re, ad Fredericum Ruyfchium; alcera F. Ruyfchii ad H. Boerhaave, qua priori refpondetur, $4^{\circ}$. cum figuris.

Hermanni Boerhaave Index alter Plantarum qua in Horto Academico Lugduno-Batavo aluntur, $4^{\circ} .2$ voll. cum figuris. Iicis, $4^{\circ}$

de comparando certo in Phy-

-

gante, $4^{\circ}$

de Chemia fuos errores expurde Vita \& Obitu Viri Clariflmi Bernhardi Albini, $4^{\circ}$.

Guiljelmi Jacobi 's Gravefande Phyfices Elementa Mathematica, Experimentis confirmata, five Introductio ad Philofophiam Newtonianam, $4^{\circ}$ cum figuris, 2 voll.

- Infticutiones Philofophix Nev. ronianx, in ufus Academicos, $12^{\circ}$. cum figuris.

Thefaurus Antiquitatum \& Hiftoriarum Italix, Neapolis, Sicilix, Sardirije \&rc. ex Confilio \& cum Prafationibus Petri Burmanni, Tomus IVus Vos VIus VII"ss VIIIus \& IXus infolio, 2i voll. cum figuris. Tomus $X^{\text {us }}$ Siciliam, Sardiniam \&c.complectens, brevi prodibit.

Johannis Jacobi Scheuchzeri Herbarium Diluvianum, Editio Novifima, duplo auctior, in folio, cum figuris.

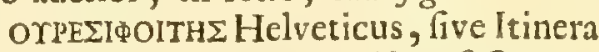
per Helvetix Alpinas Regiones facta Annis MDCCII. MDCCI II. MDCIV. MDCCV. MDCcVI. MDccVII. MDCCs. MDccx. Plurimis Tabulis Eneis illuftrata à Jolanne Jacobo Scheuchzero, Tigurino, Med. D. Math. Prof. Acad. Leopoldino-Carolina \& Socc. Regg. Anglicx ac Pruflica Membro, $4^{\circ} .4$ voll. cum figuris.

Thefaurus Imaginum Pifcium Tefta.* ccorum; quales funt Cancri, Echini, Echinometra, Stella Marinæ, \&c. Ut $\&$ Cochlearum; inter quas numerantur Lunares, Laciniata; 'Trochii, Valva. tre, five Semilunares; Valvatz Striaזx; Caffides tuberofa, verrucofx, laves \& Murices; Globofx; Buccinx;
Strombi: Voluta; Alare; Porcellanze majores $\&$ minores; Cylindri, \&c. quibus accedunt Conchylia, ut Nautilus, Cornu Ammonis, Sc. Conclix Univalvia $\&$ Bivalvia ; quarum fpecies 1 inge Solenos Univalvii, Chama afpera, Chama laves, Pectines, Pectunculi, Tellinæ, Solenes, Bivalvii, Mufculi, Pinnæ, Ottrea, \&c. Denique Minewajis Uti Metalla, Lapides \& Argillx, varis in locis reperta. Quorum omnium m2ximam partem Georgius Everbardur Ruasteploius M.D. Et Academice Cefare Natsre Curioforum Collega, diEus Plinius Indicus, collegit, jam vero Nature Ams tor \& Curiolus quidam in hunc ordiners digeflit, \& nitidiflimè zeri incidi curavit. In folio.

Vaillant Sermo de Structura Florum, horum differentia; ufuque partium cos conftituentium, habicus in ip fis aufpiciis Demonftrationis publica Srirpium in Horto Regio Parifino 10. Junii 1717. \& Conftitutio Trium novorum generum Plantarum; Aralialtri, Scherardix, Bocrhavix. Cum defcriptione duarum Plantarum nowarum genere pofremo Infcriptarum. $4^{\circ}$.

Wilfon Principia Trigonometrix. fuccincte demonfrata, $8^{\circ}$.

Mariotte Oenores, divifées en deun Tiomes, comprenant tures les Traite $\mathrm{d}$ de cot $M \mathrm{M}$ teur, tant ceux qui avoient déja paru feparement, que ceux qui n'avoicnt pas excore été publiez; Imprimées fur les Exerz. plaires les plus exalts. ET les plas complets: revuës E corrigées de nouveau. $4^{\circ} .2$ voll.

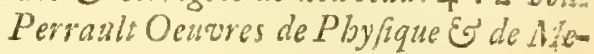
chanique, $4^{\circ} .2$ voll. avec Figures.

La plus nouvelle Academie Univer Jelle dex Jeux, contenant les Regles des Jeu de Cartes permis; des Lcbecs, du Tribrat Erc. Avec des In/tructions faciles pour op pientre à les bien joüuer. Derniere Edition. revu, corrigé, angmenté EF cnrichi des Figures en Taille-douce, 2 Tomes, $12^{\circ}$.

Vojages tres curieux d'Olearius, fol. 2 roll. - remarquables de Mandelfo, fol. 2 voll Plaute par Gueudeville, $12^{\circ} .10$. voll. Colloques d'Eralme, $12^{\circ}$. 6. voll.

Gronovii Marmorea Bafis, $8^{\circ}$.

Maimonides de Siclis, $4^{\circ}$.

Marckii Differt. Philol. in V.Teftam. $4^{\circ}$.

Magnol Hortus Regius Boranicue Monfpelienfis, $8^{\circ}$.

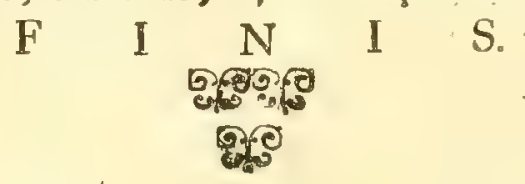








32476

8

ज्ञ 


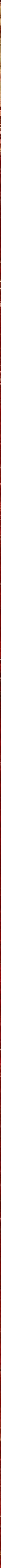

